\title{
WestVirginiaUniversity
}

THE RESEARCH REPOSITORY @ WVU

Graduate Theses, Dissertations, and Problem Reports

2017

\section{The Costume Design Process for "Courtship" and "Valentine's Day"}

Lauren E. Brennan

Follow this and additional works at: https://researchrepository.wvu.edu/etd

\section{Recommended Citation}

Brennan, Lauren E., "The Costume Design Process for "Courtship" and "Valentine's Day"'" (2017). Graduate Theses, Dissertations, and Problem Reports. 5258.

https://researchrepository.wvu.edu/etd/5258

This Thesis is protected by copyright and/or related rights. It has been brought to you by the The Research Repository @ WVU with permission from the rights-holder(s). You are free to use this Thesis in any way that is permitted by the copyright and related rights legislation that applies to your use. For other uses you must obtain permission from the rights-holder(s) directly, unless additional rights are indicated by a Creative Commons license in the record and/ or on the work itself. This Thesis has been accepted for inclusion in WVU Graduate Theses, Dissertations, and Problem Reports collection by an authorized administrator of The Research Repository @ WVU. For more information, please contact researchrepository@mail.wvu.edu. 


\author{
Lauren E. Brennan \\ Thesis submitted \\ to the College of Creative Arts \\ at West Virginia University \\ in partial fulfillment of the requirements for the degree of \\ Master of Fine Arts in \\ Design and Technical Theatre: Costume Design and Technology
}

Mary McClung, M.F.A., Chair

Gerald McGonigle, M.F.A.

Alan McEwen, M.F.A.

Steven Neuenschwander, M.F.A.

WVU School of Theatre \& Dance

\author{
Morgantown, West Virginia \\ 2016
}

Keywords: Costume Design, Theatre, Drama, Turn of the century, Texas, Horton Foote Copyright 2016 Lauren E. Brennan 


\section{ABSTRACT \\ The Costume Design Process for Courtship and Valentine's Day}

\section{Lauren E. Brennan}

Courtship and Valentine's Day are the last two installments in a trilogy of one act plays by Horton Foote. The plays depict the everyday life of a family between the years of 1915 and 1917 in Harrison, Texas. Both Courtship and Valentine's Day are examples of "slice of life" realism. However, this slice of life is from a vantage point, as Horton Foote "wrote about [the] period, but not from [the] period" (McGonigle, Initial Design Meeting).

Above all else, the Director stressed that the purpose of both plays should be to support the journey towards finding and defining home. In an era where clothing had the potential to be visually stunning, the costumes needed to portray reality without overpowering the meaning behind the shows. Finding a visual balance between high-class and down to earth was an important consideration in the design process. Family portraits and yearbook photos constituted the bulk of my research within the period. Mug shots were also an excellent resource for lower class characters as they show people for who they really are, caught in a moment in their life that they were not expecting to be documented.

With research and final designs approved, my responsibilities moved to the build in the costume shop where I created a budget, organizational paperwork, coordinated fittings, and took charge of pulling and purchasing. The costume shop pushed through the production's build in an organized and efficient manner, leading to the technical rehearsals and performances where adjustments were made as needed.

An important lesson that I have taken from this process is the importance of pushing to see the details of built garments in mockup fittings before moving into real fabrics, as well as the importance of asserting yourself as a designer, and communicating clearly with your costume shop. I am grateful to have had the opportunity to learn and grow with a piece which pushed me outside of my comfort zone. 


\section{ACKNOWLEDGEMENTS}

Thank you to my family. Mom, Dad, and Zach: your belief in me and your unending support has carried me through my graduate career. Thank you for believing in me, and for teaching me that I can do anything that I set my mind to. I love you all!

To my Borg. Thank you for all of your hard work, your love, your support, and most of all: for being an extension of my brain. I could not have hoped to work with a better group of friends.

To my thesis committee and to my production team, thank you for your contributions to my work, and your encouragement throughout this process. Thank you, Mary, in particular, for guiding me through these three years of constant learning - from my first day at WVU to the last (the fun is not yet over!)

And finally, thank you to Nicole, and to Suncrest Yoga, for keeping me centered, sane, and engaged. Thank you for constantly reminding me that sometimes the best way to deal with our stresses is to simply stop for an hour and take the time to breathe. 


\section{TABLE OF CONTENTS}

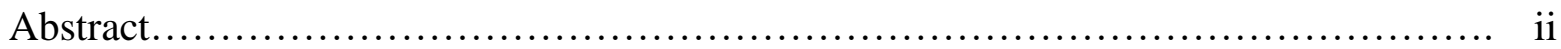

Acknowledgements...................................................... iii

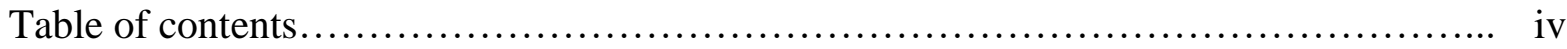

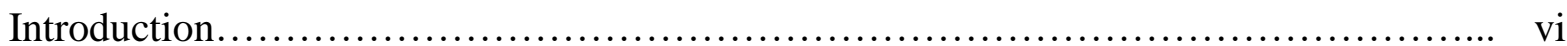

Plot..................................................................... 1

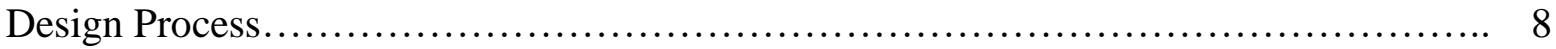

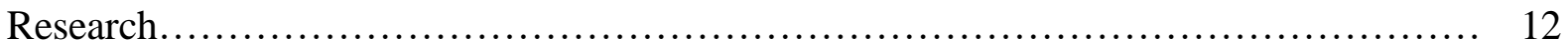

Menswear in the Early $20^{\text {th }}$ Century................................. 14

Women's Fashion in the Early $20^{\text {th }}$ Century........................... 16

Common Fabrics and Color Choices.................................... 19

Character Breakdown...................................................... 20

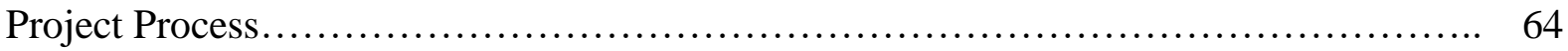

Casting Issues and Ongoing Design Challenges.......................... 64

Costume Shop Organization....................................... 68

Costume Shop Build ........................................... 70

Rental Process..................................................... 75

Execution of Performance.................................................... 76

Technical Rehearsals................................................ 76

Hair, Wigs \& Makeup............................................... 81

Paid Performances.................................................. 85

Conclusion................................................................... 88

Positive Learning Outcomes....................................... 88

Considerations for the Future ........................................ 89

Appendices......................................................... 91

Appendix I: Research Image Plates \& Fabric Swatches................... 91

Appendix II: Image Sources for Research Plates........................ 102

Appendix III: Production Photos and Costume Renderings.................. 106

Appendix IV: Working Drawings for Build Items..................... 166

Appendix V: Wig and Prosthetic Makeup Design....................... 173 
Appendix VI: Production Calendar................................... 176

Appendix VII: Build Lists......................................... 178

Appendix VIII: Sample of Costume Plot List.......................... 180

Appendix XIX: Sample of Costume Piece List........................ 183

Appendix X: Character Plot.......................................... 185

Appendix XI: Budget Spreadsheet................................... 186

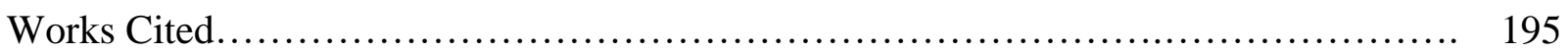

Images Sources.................................................... 196 


\section{INTRODUCTION}

The plays Courtship and Valentine's Day, by Horton Foote were produced in the Gladys G. Davis Theatre at West Virginia University's College of Creative Arts as a part of WVU's School of Theatre \& Dance spring 2016 season. The production was directed by Professor Gerald McGonigle, with Scenic Design by Professor Jacob Bigelow, and Lighting and Sound Design by Professor Alan McEwen. Professor Steven Neuenschwander served as both Production Manager and Technical Director, with undergraduate student Emily Stafford as Stage Manager. In the costume shop, graduate student Cecelia A. Hill served as Cutter Draper.

Courtship and Valentine's Day are the last two installments in The Story of a Marriage trilogy, by Horton Foote. Both plays depict the everyday life of a family between the years of 1915 and 1917 in Harrison, Texas. The Widow Claire, the first play of the trilogy, which West Virginia University did not produce, recounts the fruitless search for love that precedes Horace Robedaux's budding relationship with Elizabeth Vaughn in Courtship. In addition, The Widow Claire, Courtship, and Valentine's Day fall in the center section of a nine-play series by Foote dubbed: The Orphans' Home Cycle. This series is divided into three units, made up of the trilogies: The Story of a Childhood, The Story of a Marriage, and The Story of a Family.

While the individual plays in each section can be enjoyed on their own, the plays are meant to be produced in a cycle all together, much like a modern day television mini-series. West Virginia University's decision to produce only the last two pieces of The Story of a Marriage - due to limited space in the three show season-leaves the audience with a hole in their understanding of the characters' trajectory in life. This understanding would have been quite different had the audience been able to experience the entirety of the trilogy, or better still, the cycle as a whole. Though the character development in each of the plays is strong enough to paint a fairly complete image, the audience misses out on a depiction of Horace Robedaux's upbringing in The Story of a Childhood, and on the trials and tribulations of Horace and Elizabeth Robedaux's family life in The Story of a Family. Additionally, the absence of the third play in The Story of a Marriage trilogy leaves the audience without the full picture of this portion of the Robedaux family's lives. The plays, as a whole, are meant to cultivate an understanding of what it is to be a human, to search for a place to call home, to make a home 
there, and then to maintain that home. In essence, the audience's understanding of these characters and of Foote's message about the human life cycle is severely narrowed through lack of access to the fully developed story.

Conversely, producing these two plays on their own offers a detailed perspective on the trajectory of the lives of two young lovers and their families without the bias of previous knowledge. Due to the fact that WVU's production was not billed as an installment in a series, but rather as something that stands alone, the audience is able to focus solely on the two stories presented. The individual audience members' knowledge of the place of the plays within the Orphan's Home Cycle can greatly affect their perception of the story. For most of WVU's audience members, the beginning of Courtship is the beginning of the story, and the end of Valentine's Day is all that we are meant to see of these characters' lives. Although the production's program note offered up information about the trilogies, in general, the audience did not come to the theatre to see another part of a series, but rather to experience the intimacy and immediacy of the stories, complete as they were presented.

Realistic theatre is, by its very name, imitation of "real life." In other words, the aim to create theatre that is accurate to the time period in which a play is set, and which expresses the circumstances of the play in as true a manner as possible. There should be nothing in the production which might detract from the true to life nature of the theatregoer's experience. Both Courtship and Valentine's Day can be considered a form of "slice of life" realism, wherein a play endeavors to show a snippet of real life without the usual introduction, flow of action to a climax, or conclusion. In essence, this means that no extraordinarily significant action takes place within the plays. There are no monumental turning points. There is just observation of life, as it naturally flows. While "slice of life" implies an attempt at creating a true-to-life viewing experience, it is important to note that theatre can never fully convey reality. There will always remain an abstract quality to hand selected moments from the human life cycle submitted for examination by a large group of people. The voyeuristic nature of theatre, and especially of this particular genre of theatre, lends to an impressionistic view on life, regardless of how much effort we put into recreating a realistic viewpoint.

In the span of his or her career, a designer will inevitably run into a play, or other type of theatrical performance, that is not to his or her personal taste. This clash of duty and distaste is a 
challenge to overcome, but can also be an excellent learning experience. The best solution to this challenge is to find something within the play that speaks to the designer. Though realism is a genre that I struggle to enjoy, in the case of Courtship and Valentine's Day, I was able to allow the beauty of the time period - the years following the turn of the $20^{\text {th }}$ century - to enrapture me. I was able to delve into the way of life in the early $20^{\text {th }}$ century and immerse myself in the psychology of the characters based on the society in which they lived. Although it ultimately had little bearing on my overall design concept, my strong interest in the history of the feminist movement fueled my research and helped me to find a connection with this play, as I was interested in observing and analyzing how the role of women in society was changing both at this time in history as well as over the 100 years since the period of this play. Noticing the development of women's clothing, as well as the development of behavioral patterns and societal norms was extremely intriguing, and was much of what kept me engaged throughout the design and production processes. Naturally, the desire to put forth a good product was also a driving force, as well as to challenge myself and delve into a genre of theatre with which I am not used to working. 


\section{PLOT}

\section{Courtship}

The play opens in Harrison, Texas, on the gallery off of the front porch of the Vaughn family home. It is a summer evening in 1915. Elizabeth Vaughn and her younger sister Laura Vaughn finally have the chance to converse away from the rest of the family. They discuss Laura's schooling, how Elizabeth is enjoying giving piano lessons, as well as reminisce about a few family members and times past. As the sisters catch up, their mother, Mrs. Mary Vaughn enters from the front door requesting that the girls come inside in a little while to visit with their Aunts Lucy and Sarah, and to perhaps play a few songs for their enjoyment on the piano.

As Mrs. Vaughn returns inside, the girls begin to talk about the beautiful dresses that they have seen other girls wear to the dances in town. Elizabeth reveals that she has been asked to this evening's dance by Horace Robedaux, and that she has learned to dance in secret despite the fact that both girls have been expressly forbidden to dance by their father. As the girls discuss the merits and caveats of dancing, love, and marriage, the discussion turns to town gossip, which leads Elizabeth to confess that a few nights ago she slipped out with her friend Rita and a few boys to go buggy riding. Before Laura has the chance to respond to this news, Mrs. Vaughn calls the girls inside to play music for their Aunts Lucy and Sarah.

The girls head in to the music room, where their father, Mr. Henry Vaughn, along with Mrs. Vaughn and Aunts Lucy and Sarah are already seated and waiting for the girls to play. Aunt Sarah requests that Laura sing "Nellie Grey." Laura begins to sing while Elizabeth plays piano, but Laura becomes emotionally affected and begins to cry mid-song. Elizabeth begins to play a new song on the piano when there is a knock at the front door. Mr. Vaughn gets up to answer, and finds Horace Robedaux standing at the door in a tuxedo. Horace asks for Elizabeth, and Mr. Vaughn calls her in, returning to the music room. With disdain in his voice, he expresses his dislike of Horace Robedaux. Mr. Vaughn expresses the fact that he does not want anyone at all to call on his girls, as he believes that he can give them all that they need, even after he has passed on, with the money he will leave for them.

Meanwhile, on the front porch, Elizabeth greets Horace and asks why he has left the dance. He says he would rather spend time with Elizabeth, then asks her if she can take a walk with him uptown. Elizabeth returns inside to check with her father, who will not allow it, as 
much as Elizabeth pleads. Defeated, Elizabeth returns to the gallery to tell Horace that she cannot go. Horace tells her that he will be leaving for a travelling sales job in two days. He asks to see her both days before he leaves. Elizabeth agrees to see him. Hearing the orchestra music in the distance, Horace asks Elizabeth to dance. She politely refuses, giving her father's views on dancing as an excuse. The pair begin to talk about Sybil Thomas and Leo Theil, who have decided to have a wedding after becoming pregnant. At this moment, Mr. Vaughn returns to the door and asks Elizabeth to come inside. Elizabeth asks to visit a few moments longer, and Mr. Vaughn acquiesces, on the terms that he does not have to ask her to come in a second time. Horace asks Elizabeth for a date every night that he is in town over Christmas, when he will have returned from work, and asks her to make sure to write to him every day. Elizabeth says that she will write, but reminds Horace not to write her every day so as not to provoke her father's anger. She then shows him that she has been wearing the ring that he gave her on a chain beneath her blouse. Horace mentions that he would someday like to stop travelling and settle as a merchant and perhaps owner of his own store. As they converse, the porch light turns on, and Mr. Vaughn is seen in the doorway. Elizabeth quickly finishes the conversation and says goodnight.

As Horace leaves, Mr. Vaughn steps out onto the porch and warns Elizabeth against the perils of Horace Robedaux. He implores Elizabeth not to rush into marriage, and reminds her that she has an education, which means that she can support herself, and asks her to live a little more before settling into the idea of marriage. He believes that Horace would not be capable of providing for a family, and wants Elizabeth to find a husband who is more grounded. Mr. Vaughn then points out that he was older when he married, and had also lived in poverty as a young man. Mr. Vaughn reminds Elizabeth that she does not truly understand what it is like to do without the luxuries that she has been afforded by her family.

While father and daughter talk, Mrs. Vaughn comes out onto the porch to report that Sybil Thomas had gone into premature labor and that the baby has died. Laura promptly comes outside to tell the family that they received another call reporting that Sybil had passed away along with her baby. Surprised by this news, Mrs. Vaughn decides that she must confirm the news, and rushes inside to make a phone call. Mr. Vaughn tells the girls that they should both head to bed, then heads inside himself. The girls remain on the porch, and Laura blurts out to Elizabeth that she too, has learned how to dance in secret. She admits that she, along with her friend Annie Gayle, had snuck out to take a walk with two boys from town the night before. As 
Laura admits this, Mrs. Vaughn returns to the porch to report that Sybil's alleged death was misinformation. Mrs. Vaughn brings up Elizabeth's buggy ride with Rita and the boys, and asks her if this rumor is true. Elizabeth admits to the buggy ride, and Laura then blurts out her own story, crying with the burden of the guilt. As Mrs. Vaughn scolds her daughters, Mr. Vaughn walks out to report that he has just received a call that Sybil did, indeed pass away with her baby, and so Mr. and Mrs. Vaughn prepare to walk over to the Thomas' house to offer their condolences. They direct the girls to remain at home while they are gone.

As Mr. and Mrs. Vaughn head over to the Thomas' house, the girls are left on the gallery to talk woefully about the tragedy. Laura brings up Horace and inquires about Elizabeth's true feelings for him. Elizabeth tells Laura that both she and Horace have agreed not to see other people, and then shows Laura the ring that Horace gave to her that she wears on a chain hidden beneath her blouse. Laura exclaims that she hates all the sneaking around that they have to do, and wishes that they could receive gentlemen at the house like other girls their age. Laura despairs that she may end up like Aunt Sarah, an old maid, or like Sybil Thomas, pregnant before marriage.

Horace and Steve Tyler walk by the Vaughn house on the way to pay their respects to the Thomas family. The boys pause to see if the girls wish to accompany them, Laura and Elizabeth politely refuse, explaining that they have been asked to stay at home. Mr. and Mrs. Vaughn return from the Thomas' home, and Elizabeth asks if the boys may escort herself and Laura to pay their respects to the family. Mr. Vaughn replies firmly that they may not, and the boys head on their way. Elizabeth, upset with her father for being so rude, begins to rant about his strictness, and in the fury of words, the chain holding her ring from Horace breaks, causing the ring to fall to the ground. Mr. Vaughn is disturbed by his daughter's deceit, and demands that Elizabeth return the ring to Horace. Mr. Vaughn exits, followed quickly by Mrs. Vaughn. Laura asks Elizabeth if she really will return the ring, Elizabeth replies that she will not, but that she will tell her parents that she has. Mr. Vaughn returns to the gallery, and both parents reiterate that they only want the best for their daughters, which is why they worry so much about them. Mr. Vaughn suggests throwing a party a week or so after Sybil's funeral in order to lighten the mood. Mr. and Mrs. Vaughn head inside, and as they do, with Laura still there to witness it, Elizabeth proclaims to herself, “I’m marrying Horace Robedaux...If he asks me” (Foote, Courtship, 49). 


\section{Valentine's Day}

\section{Scene 1}

It is the afternoon of Christmas Eve, 1917. Elizabeth and Horace have made a temporary home in a rented room at the Pate house; Elizabeth is five months pregnant. She is home alone when Bessie Stillman, a young girl in the neighborhood, knocks on the door and brings in a present for her and the unborn baby. Elizabeth offers Bessie a gift from under the tree, just as Mr. George Tyler knocks at the door looking for Horace. Upon hearing that he is not home, Mr. Tyler wishes them a Merry Christmas and leaves. Bessie and Elizabeth discuss Mr. Tyler's addled mental state, noting that Horace is related to Mr. Tyler by marriage. Elizabeth then tells Bessie the story of how she defied her parents by eloping with Horace, and how unhappy it had made her family. Bobby Pate, the landlord's son, knocks on the door. Bobby is drunk, and looking around for his mother. Elizabeth reminds him that she has gone to Bay City to be with Bobby's brother on Christmas. Bobby is confused, and babbles about the year, his ex-wife, and Elizabeth's family, while Bessie chatters about the guinea pigs that she wants, but knows that she will not get for Christmas.

Horace returns home from work with Miss Ruth Amos, another tenant, in tow. She brings in a gift for Horace and Elizabeth, and Elizabeth offers Miss Ruth a gift as well. They reminisce about old times, as George Tyler knocks at the door again. Horace answers, but Mr. Tyler is confused, and wishes them all a Merry Christmas as he walks away. Peering out the window, Horace sees Steve Tyler, George's son, leading him away. Bobby continues to drunkenly babble away as Steve Tyler knocks at the door. Steve asks Horace to come over to the house later that night, as his father has something life or death to discuss with him. Horace agrees to go, and Steve leaves. Those remaining in the room express their worry about Mr. George Tyler's current mental state, and Steve quickly reappears to say that Mr. Tyler has decided that his talk with Horace can wait until after the holiday, and wishes them all a Merry Christmas.

\section{Scene 2}

The scene begins in Horace and Elizabeth's room on Christmas morning. The phone rings, and Horace goes to answer it. Horace returns, saying that he believes that it is Elizabeth's mother on the phone. Elizabeth drops what she is doing and hurries off to pick up the call. Elizabeth reenters the room telling Horace that the call was, indeed, from her mother asking if 
she and her father and brother could stop by for a few minutes to bring over some presents. She pleads with Horace to find a way to pick up some gifts for her family, as she does not want to be empty handed when they come. Horace, having closed Mr. Dickerson's shop the night before, takes the keys to the store, dresses quickly, and exits.

Elizabeth begins to straighten up the room and get dressed. As she is dressing, Bessie comes by to call. She has been gifted the guinea pigs that she wanted after all, and excitedly shows them to Elizabeth, who is still bustling around trying to get the apartment ready. Miss Ruth knocks on the door looking for Horace in hopes that he will look in on Bobby Pate, who Miss Ruth reports to be sick. As they are discussing Bobby’s well-being, Mr. George Tyler knocks on the door, also asking for Horace. He says that he has a small Christmas gift for him. As Mr. Tyler is leaving, Horace returns with the presents for Elizabeth's family, and they wish each other a Merry Christmas in passing. Horace lays out the gifts for approval, and Elizabeth begins to wrap and place them under the tree. Horace finally takes a moment to open George Tyler's gift and is shocked to find that there are 10 one hundred dollar bills in the small box. As the two marvel at such an oddly generous gift, there is a knock on the door. The Vaughn family has arrived.

Mr., Mrs., and Brother Vaughn enter, greeting the happy couple and offering gifts for Horace, Elizabeth, and the baby. The family catches up, and Brother inadvertently reveals that he has placed a small bet on the outcome of a murder trial. This news infuriates Mr. Vaughn, who has seen Brother spiral out of control with gambling and drinking before. This ordeal sets off an argument within the family, which is set aside with the entrance of Miss Ruth, who asks if Horace and Brother could help hold Bobby down while the doctor gives him an injection. Bobby stumbles in, drunk, followed soon by Dr. Goodhue, who tries to get Bobby to calm down and go with him to receive treatment. Bobby, however, is not easily convinced, so Brother grabs his arms while Horace picks him up by the legs, and the two men and Dr. Goodhue drag him out. In the small room, the conversation turns towards Horace's relationship with his family. They discuss Horace's dislike of his stepfather, and the fact that Horace has never truly had a home. Horace returns, exhausted, and says that Brother is still helping Miss Ruth to locate Mr. Bobby's stash of whisky so that there is nothing for him to drink once he sobers up. Brother then calls Horace to the phone. Horace returns from his phone call to announce that Steve Tyler would be stopping by shortly. 
The Vaughn family decides that it is time to leave; Mrs. Vaughn promises to call. After they have left, Elizabeth professes how happy she is that her family has been able to reconcile. Horace is happy for it as well, but admits that he is a little jealous of Elizabeth's family, their affluence, and having grown up with a home and with a father who could provide luxuries to his children. He says that he considers himself an orphan, and that the only place that he feels that he belongs is with Elizabeth. There is a knock on the door, and Steve enters. Steve kindly asks that the couple return Mr. George Tyler's gift, explaining that his father had gone to the bank and taken out \$15,000 and was handing it out to friends and family as Christmas gifts. Horace returns the money without a word, and Steve thanks him and heads off to see if he can discover the other recipients of his father's generosity.

\section{Scene 3}

It is now an afternoon in January, a few weeks after Christmas. Elizabeth is alone in her rented room when Bessie knocks on the door to frantically inform her that Mr. George Tyler is loose with a gun, and that he is now running around the river bottoms. Elizabeth shows Bessie the plans for a new house along with a letter from her father and mother telling her that they want to give the couple a house. She worries that Horace will have trouble accepting the gift, as much as they both want a house together. Horace walks in to report that Mr. Tyler has been cornered by the authorities. Elizabeth shows Horace the letter from her parents about the new house that they want to buy for them and the baby. Horace says that he will only accept the gift if the house is put into Elizabeth's name, as he does not wish for anyone to think that he married Elizabeth for the house, or for money. Elizabeth thinks that he is being overly sensitive, but before they can continue the conversation, Mr. George Tyler enters, extremely disoriented. Mr. Tyler says he wants Horace to tell his family that he needs help, and that if they can't get him help, he wants them to kill him. Horace goes out with him, and Elizabeth is left with Bessie to worry.

Mr. Vaughn enters, and Bessie excuses herself. Elizabeth expresses her sadness for Mr. Tyler to her father, and Mr. Vaughn comforts her. Mr. Vaughn sees the plans for the house on the bed and asks to take them to look over. He also asks how Horace is feeling about the whole idea, and he also admits to Elizabeth that he does like Horace after all, it will just take some time to adjust. Horace reenters, and says that he only got to walk Mr. Tyler halfway home before 
Steve Tyler and the sheriff drove up to them and took over. Mr. Vaughn tells Horace that he has the plans and will look them over, but that he also wants to show them both the property in the next few days. Mr. Vaughn then heads out.

Bessie reenters to report that Mr. Tyler had escaped from Steve and the sheriff when they got back to the jailhouse, and that he has stabbed himself to death. Horace leaves quickly to go see if there is anything that he can do for the Tyler family. Elizabeth is upset, but Bessie stays and chatters away, which distracts her. Mr. Bobby stumbles in, drunk, just as Horace reenters the room. Bessie leaves for home at her mother's request. Horace says that the sheriff caught him before he made it to the Tyler's house, and told him there was nothing that he could do. Mr. Vaughn enters asking if they have heard about Mr. Tyler's death, and bearing some books that had once belonged to Horace's father, which he promptly gives to Horace. Mr. Vaughn then tells Horace directly that he both likes and respects him.

Bobby and Miss Ruth enter the room, and there is talk of Horace and Elizabeth's new home. The group fondly reminisces about Elizabeth and Horace's wedding last Valentine's Day. The play closes with Miss Ruth singing "Oh Promise Me," the song that Horace and Elizabeth were married to. Elizabeth joins in and the lights fade. 


\section{DESIGN APPROACH}

As the initial design meeting for the production commenced the Director, Professor Gerald McGonigle, began by asking each of the designers to briefly describe their thoughts on the plays' meaning and focus. Scenic Designer, Professor Jacob Bigelow, opened the discussion by noting that the plays are "very human, very delicate, subtle piece[s]." The plays are about the relationships between the characters, and how those relationships develop through time (Bigelow, Initial Design Meeting). Jumping in, I made the point that Courtship and Valentine's Day provide an in depth view of the characters as people, and therefore are not necessarily centered around events, as are many other plays. Lighting and Sound Designer, Professor Alan McEwen, added that while the shows are "rooted in their time," the plays are not specifically about the time period (McEwen, Initial Design Meeting). For these reasons, the show is decidedly character driven. In regard to costumes, this means that the clothing must be the truest expression of the character in order to aid in the audience's understanding of the plays.

When prompted to discuss the central theme of the two plays, Professor McGonigle described "the pursuit of home," and "what that means on a physical level, on a heart level, on a practical level" (McGonigle, Initial Design Meeting). In order to focus the design team's understanding of the plays Professor McGonigle pinpointed one of Horace's lines in Valentine's Day, which he felt fully embodied this search for home:

"I am no orphan, but I see myself as an orphan, belonging to no one but you. I intend to have everything I didn't have before. A house of my own, some land, a yard, and in that yard I will plant growing things, fruitful things, fig trees, pecan trees, pear trees, peach trees... and I will have a garden and chickens. (Pause.) And I do believe I might now have these things, because you married me. I said to myself before our marriage, 'She'll never marry you, no matter how much she says she loves you, because her father will stop it. He's a powerful man, and he will prevail as he does in all ways.' But he didn't stop us; you did marry me, and I tell you I've begun to know happiness for the first time in my life. I adore you. I worship you... and I thank you for marrying me." (Foote, Valentine's Day, 83) 
Both Courtship and Valentine's Day are examples of slice of life realism. However, Professor McGonigle pointed out that Horton Foote "wrote about [the] period, but not from [the] period" (McGonigle, Initial Design Meeting). In this sense, the plays can be considered slice of life realism from a vantage point. The author's choice to set the plays anywhere other than the present day (for Foote, this would have been 1987) slightly alienates the audience, and removes a level of certainty on the authenticity of the lives portrayed in the stories. Foote made a choice to return to this particular time in this small, fictional town in order to examine the idea of finding home at a time that was simpler than modern day. According to McGonigle there is a simplicity and a purity about the time. It was a time when love meant love, not sex, and when family was an important part of the meaning of home. "There is something transparent and mystical about it" (McGonigle, Initial Design Meeting). With this in mind, Professor McGonigle allowed that the design of the set could deviate from staunch realism in favor of a more minimalistic approach. In order to ground the actors in their somewhat abstracted space and time period, however, the costumes needed to remain true to history.

In Courtship, the front porch plays a significant role in the show's action, as well as in the design. The Vaughn family interacts with each other, as well as with their neighbors on the front porch, making it a place where the personal and private worlds intersect. The music room in Courtship serves as a glimpse into the purely private world of the Vaughn family, while the front porch leads to the yard, which leads into the community. The same concept can be applied to the costumes, in that anything that is worn in the out-of-doors is meant to be seen. Articles of clothing that are expressly meant to be seen by the public communicate specific information about a character's mood, job, or financial status. There is a large contrast between clothing worn in the public eye and clothing which is only meant for use in private. Using garments meant only for the privacy of the home out of their normal context can completely change the tone of a scene. For example, the scene in Valentine's Day when Elizabeth changes from her nightgown and robe into her day clothing is an extremely intimate scene. The way that she behaves during this scene can be partially attributed to the manner in which she is dressed. In our production of the play, Elizabeth is half dressed while frantically preparing for her parents' arrival and reluctantly entertaining guests. Trying to get dressed in proper clothing while other characters continuously interrupt her progress prompts a rushed, panicky mood within the dialogue and the overall atmosphere of that particular scene. Once she is fully dressed, however, and prepared to 
have the outside world look at and interact with her, Elizabeth's demeanor becomes much more composed. While her new, more communal style of living conditions do alter the way that Elizabeth interacts with others around her, there is a sense of formality that Elizabeth knows her family will expect when they arrive. Elizabeth wants to match the formality of her family when they arrive bearing gifts, in order to show that she is doing well despite having disobeyed her parents' orders by eloping with Horace. This apprehension of how she and Horace will be perceived by her parents prompts Elizabeth to dress herself in an outfit that is perhaps nicer than she might normally wear in order to nonverbally communicate her well-being and happiness to her family.

Above all else, Professor McGonigle stressed that the purpose of both plays should be to support the journey towards finding and defining home. Therefore, the total production value should not overshadow this overarching theme. In an era where clothing had the potential to be visually stunning, the costumes needed to portray reality without overpowering the meaning behind the shows. The members of the Vaughn family are upper class citizens living in Harrison, Texas. Although they are wealthy, the fact that the Vaughns live in a small town far from the eastern coast of the United States, where the newest waves of fashion tend to first take root means that they are not necessarily in touch with the latest fashion trends. This, along with the conservative nature of the family means that they are less likely to project an extravagant lifestyle through their choices in clothing. Therefore, finding a visual balance between high-class and down-to-earth was an important consideration in the design process.

When determining the clothing for the Vaughn family, especially Mr. and Mrs. Vaughn, I avoided the use of flashy colors and fabrics with too much sheen, frivolous detail, or flowing movement. Given the circumstantial elements of the plays and specific character traits, I crafted a somewhat stiff, conservative, yet elegant look for the Vaughn family which showed their apparent wealth along with their restrained personalities and conservative moral values. This overall look served as a visual portrayal of what "home" means to Elizabeth Vaughn in Courtship, which would later be viewed in contrast with the clothing choices for Valentine's Day, where "home" is viewed from a much more simplistic point of view. The different atmospheres, and the different characters in each play show the audience that the word "home" can have many definitions. For Horace and Elizabeth, the purest form of home is the feeling of love and belonging together, regardless of where they are, what they wear, and what they own. 
The design team continued to have informal meetings where we showed research and sketches. Using the idea of "home" and things that were lived-in and well worn, I delved into research of silhouette and style. Once we determined that the shape and class level of each character was correct, I moved into colors and fabrics. Due to the nature of the show and of its characters, I utilized bold colors sparingly, and limited my color palette to mainly neutral colors, with the occasional deep blue, deep red, or ochre. Any color outside of a neutral palette that was used was muted - except in the case of the dancers in Courtship. The dancers are the most whimsical element to Courtship, and their role in the play was a topic of discussion which remained unresolved throughout the initial design process. Ultimately, the dancers were cut from WVU's production (see: Casting Issues and Ongoing Design Challenges), therefore the overall color palette steered away from any amount of brighter tones. When first researching fabric options, I was careful to look exclusively into natural fibers which would show wear and tear, or wrinkles easily. The idea that the costumes show a "lived in" quality was important to maintaining the accuracy of the time period, but even more important because this lived-in quality embodies the theme "home." 


\section{RESEARCH}

My primary research sources came from yearbook photographs, family portraits, mugshots, and fashion catalogues of the era. In order to supplement this visual information, I read the "New Century" chapter of Lucy Barton's Historic Costume for the Stage, which includes simplistic, but informational line drawings of various silhouettes for men and women of the period. The book also provides supplemental information on how clothing was layered for both men and women, as well as which materials, colors, and accessories were most prominent. In addition, Barton's book takes a look at the political atmosphere of the era which can have a definite influence on fashion trends. For example, the early 1900s launched an era of ready-towear clothing, wherein garments began to be produced in mass quantities in factories. Due to this shift in production, clothing became simpler, and more uniform than in years past. This new method of garment production and sales greatly influenced the way that people dressed, as factory-made garments presented a major change from a time period when almost all clothing was custom made for the individual.

In my visual research, I kept to photography over paintings and other drawn art forms for two reasons: first, because photography was the more readily available primary art source, and second, because I wanted to base my designs on real people, rather than on society's ideal or abstracted versions of people. In order to preserve a strong sense of reality in the costumes, my final renderings closely replicated the styles found in my photographic research. Within that research, I searched for "characters" which matched my interpretation of the personalities of each of the characters in both plays. Steve Tyler's Christmas Day look in Valentine's Day, for instance, was modeled almost exactly after a yearbook photo from a 1915 Texas school as seen in Figures 1 and 2 (See Image Sources for citation information for all figures). 


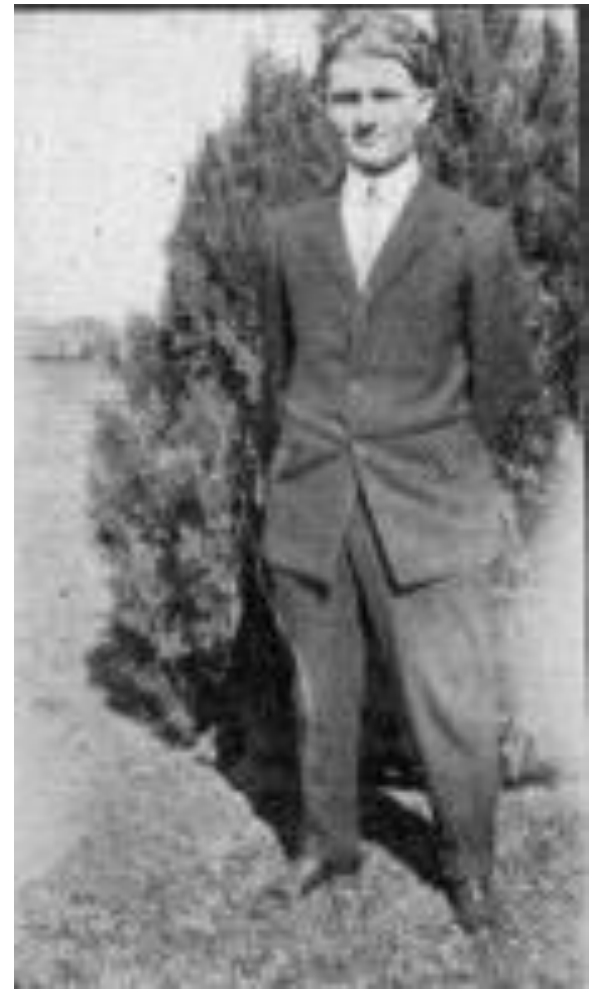

Figure 1: Research image for Steve Tyler.

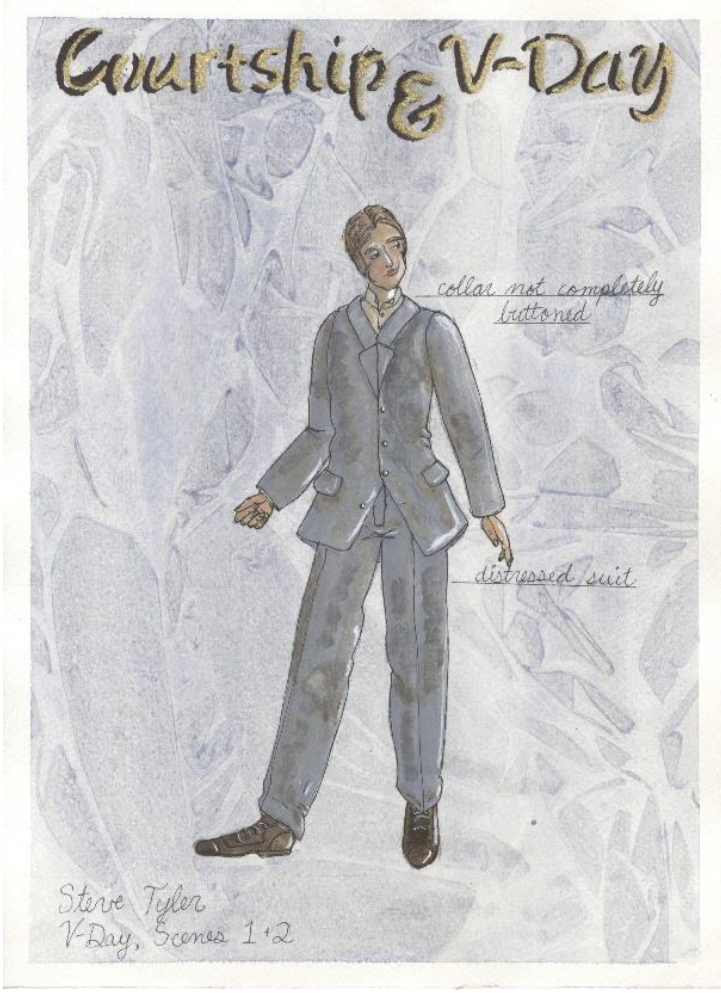

Figure 2: Final rendering for Steve Tyler in Valentine's Day.

Since the invention of photography in 1839 , the growing art form had become more accessible to the public by the turn of the $20^{\text {th }}$ century. Photography became the new norm for portraiture. In terms of historical accuracy, it is important to note that photographs quite often only show a portion of the historical whole. Around the turn of the $20^{\text {th }}$ century, the act of taking a photograph became a much quicker process than in previous years. Given the ever evolving techniques in the field, photographs were still very often staged for specific purposes, such as family portraits. This points to the fact that, while photographs are an excellent resource for learning about the history of clothing, the circumstantial information behind a photograph must always be taken into account. The clothing worn in early 1900s photographs cannot necessarily be considered the clothing of everyday life. People would commonly dress in their best outfits for a family portrait, which creates a more formal look than perhaps was truly common on a daily basis. Consequently, family portraits are excellent resources for researching the clothing of wealthier characters. Yearbook photos, while sometimes on the formal side, tend to be a little more down-to-earth in terms of style. Much of what is seen in yearbooks from around the year 1915 includes close up shots of the head and face, which are extremely useful for researching 
hairstyles as well as makeup usage of the era (see Figure 3). Some yearbooks also boast the occasional section of full body photographs which have a more lived-in, candid feel, than a family portrait. In these photographs, the viewer can often see the lived-in features of the clothing, such as wrinkles and wear and tear. Naturally, yearbooks provide imagery from a limited sample of people, namely young adults. Mug shots and the occasional candid photograph can also be used to supplement the lack of age and class diversity in yearbooks and family portraits. Mug shots are excellent research for lower class characters as, aside from candid photographs, they are the best collection of images that show people for who they really are, caught in a moment in their life that they were not expecting to have documented for all to see.

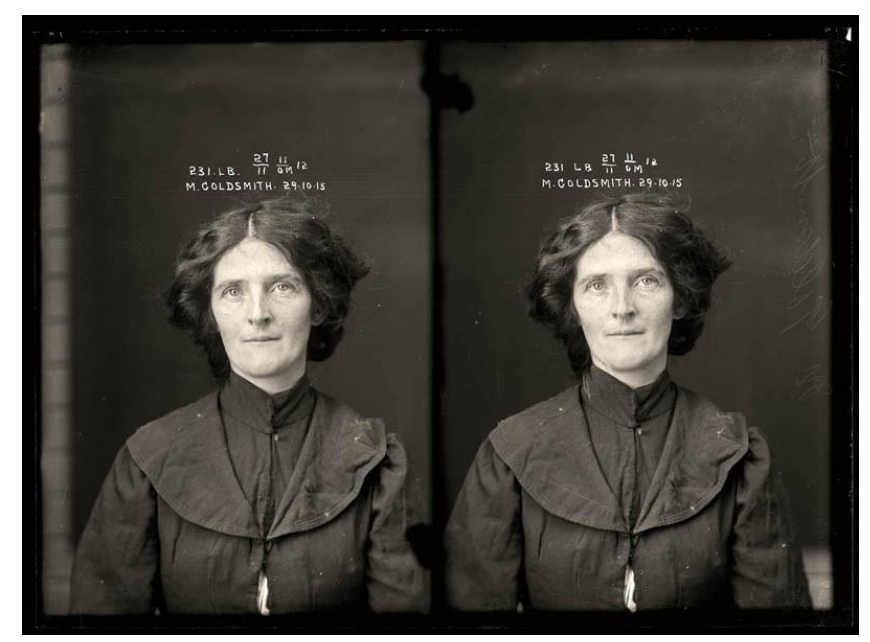

Figure 3: Research image for Aunt Lucy's hairstyle.

\section{Menswear in the early $20^{\text {th }}$ century}

One of the most defining characteristics of menswear in the early 1900s is most certainly the stiff, tall, detachable collar (Figures $4 \& 5$ ). One could equate these detachable collars to a men's version of a corset, but in this case, meant to keep the neck tall, and the chin up. The look was severe and extremely uncomfortable, both in look and in practice. Wing tipped collars were popular at the time because, although still tall, they were slightly more open at the center front. This made wing tipped collars less bulky, and therefore less restrictive than most other styles of collar with a turn over. Men's suits were now most commonly sack suits. These suits had extremely square shoulders, were loosely fitted, and were cut to be long-waisted. Lapels on suit jackets were high, pants hems were short, with no break, and while trousers generally matched the jacket of the suit, there was occasion for the pants to be lighter in color, especially in the 
summer months. Frock coats, usually with satin-faced lapels, were still common among older, more distinguished men, while cutaway coats became more popular with the younger crowd. Tuxedos were becoming more and more common in this period. They were often worn for small dinner parties and informal dances. High laced shoes became popular, but if oxfords were worn they were often black. Toothpick shoes went out of style in favor of a much rounder toe. Socks, unless offering a pop of color, were general black when visible.

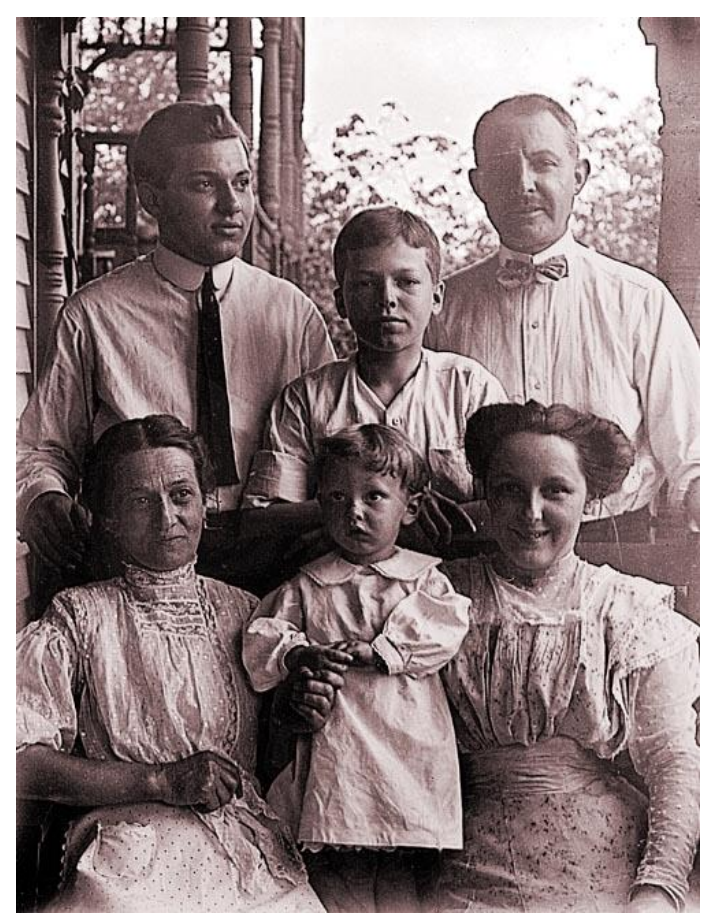

Figure 4: Men and Women in high collars. Note the lack of high-necked collars on the children.

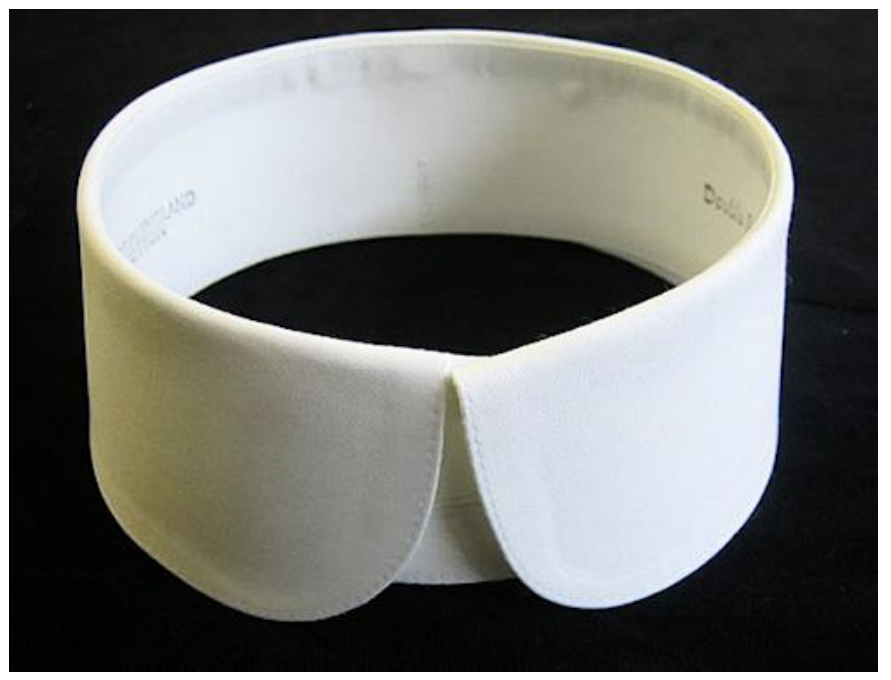

Figure 5: Example of a detachable linen collar.

In terms of men's hairstyles, middle parts became obsolete for the younger crowd after 1910. This means that older men, or those who were out of touch with fashion trends, might have a middle part, but younger men would most likely avoid this hairstyle choice in favor of a side part (Figure 6). Hair was generally short and neat with more length on top of the head so that the hair could be slicked into place. In terms of facial hair, men were most often clean shaven. Mustaches were occasionally seen, but not as often. Mustaches were usually straight clipped, clean, and straight across, though the walrus mustache (Figure 7) was still common among older gentleman. A man who was truly out of fashion might still wear mutton chops. 


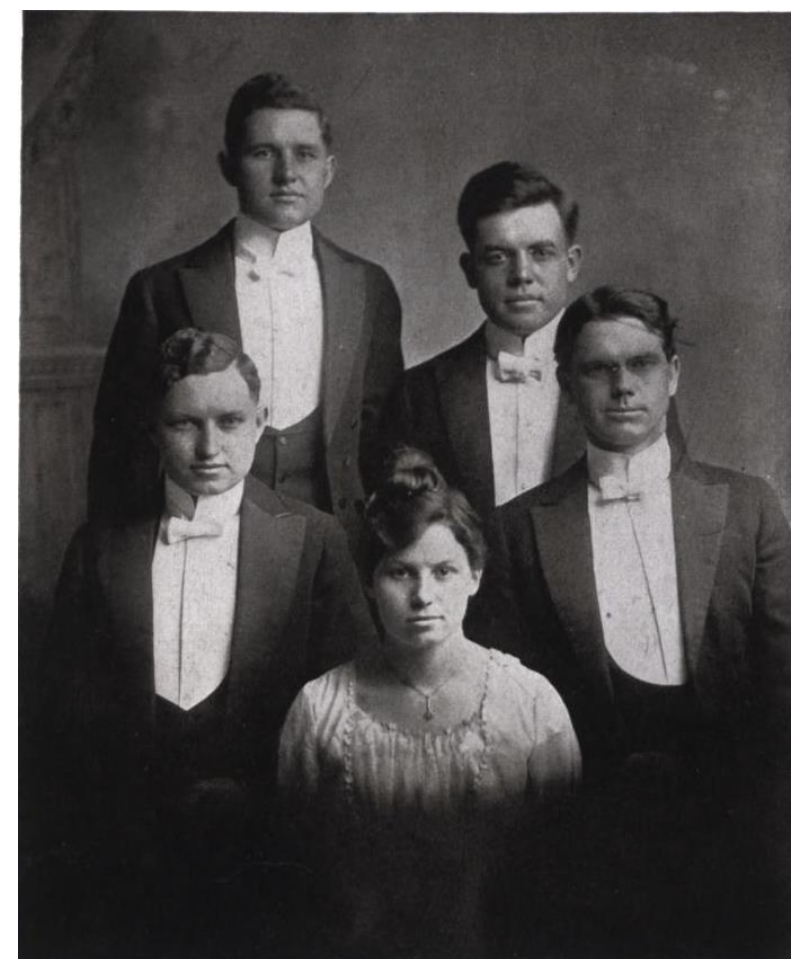

Figure 6: Young men sporting side parts for school photos in 1917.

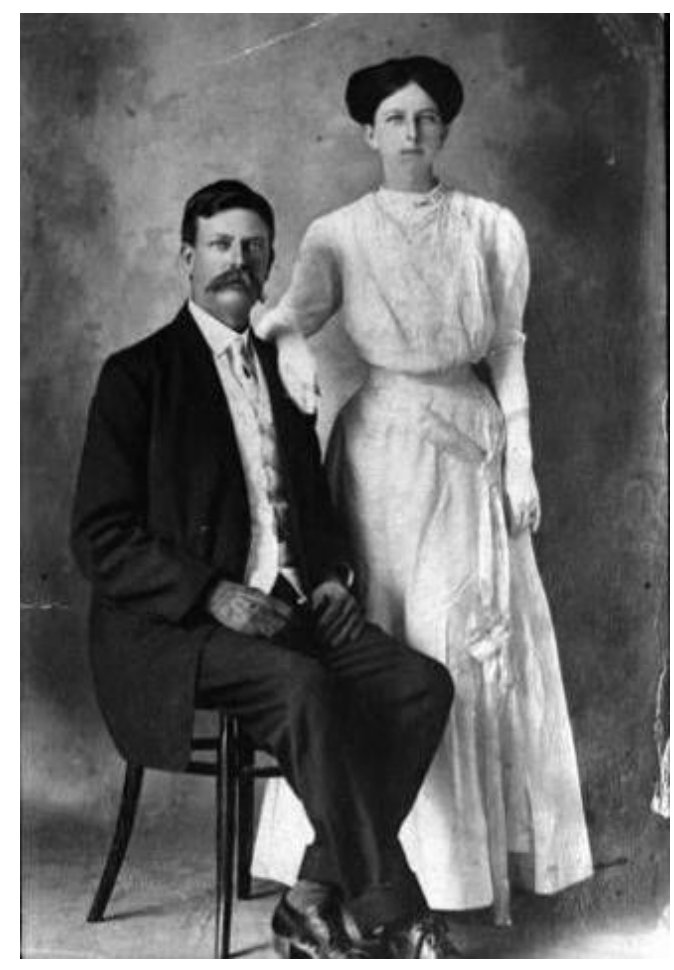

Figure 7: Man with a walrus mustache and woman wearing shirtwaist dress circa 1915.

\section{Women's fashion in the early $20^{\text {th }}$ century}

Mimicking the style of menswear, collars tended to be stiff and high, especially when it came to everyday wear (Figure 4). It became increasingly common for women's clothing to come as separates. Shirtwaist blouses paired with a skirt (two-piece ensembles) held the overwhelming majority in terms of women's fashion trends in the early 1900s. Shirtwaist dresses (one-piece ensembles) were equally as common, though were considered the more formal of the two options. These blouses and dresses were most often bloused above the waist (Figure 7) before cinching in to be belted. Sleeve styles could range from fairly fitted with a stiff cuff (Figure 8) to bloused at the cap with a fitted sleeve from elbow to cuff (Figure 9). The blousy bishop sleeve came back into style briefly before fashion reverted to the fitted sleeve which fit neatly under jackets. 


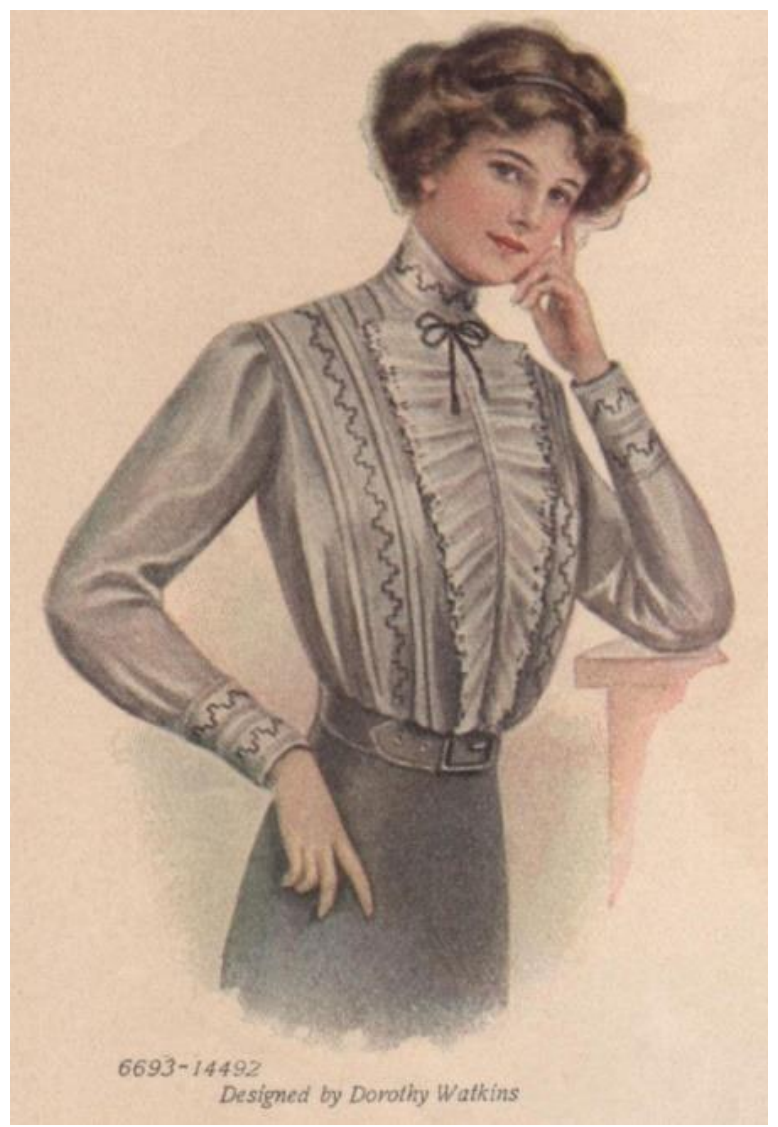

Figure 8: Shirtwaist Blouse with fitted sleeve.

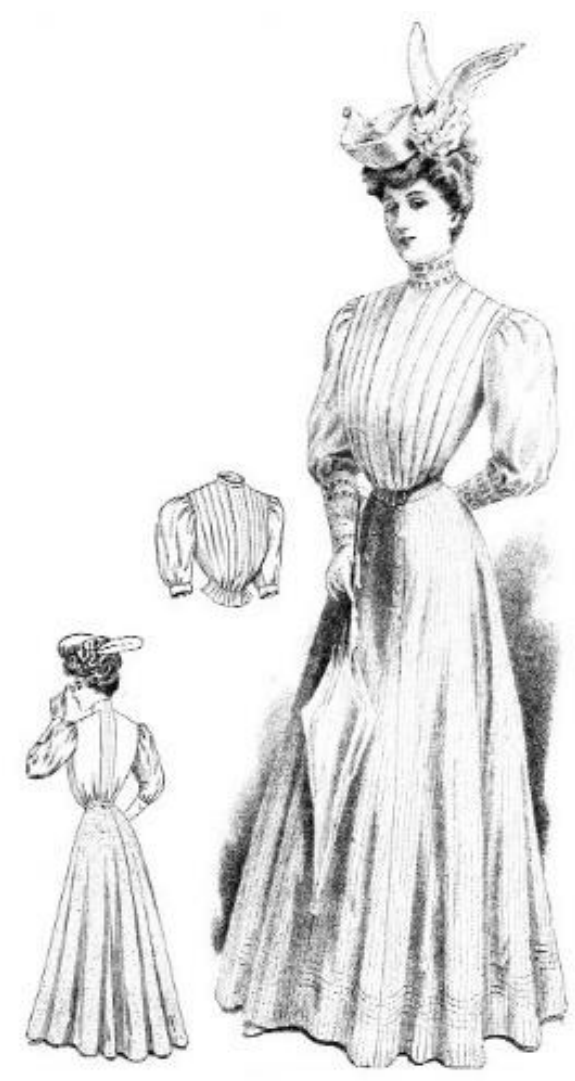

Figure 9: Sleeve bloused at the cap and fitted at the forearm to the wrist. 1906.

Unlike men's suit jackets, women's jackets were severely tailored (Figure 10). The length of jackets generally hit past the hip, and sometimes might be longer in back than in the front. In 1914 a new style of jacket was introduced which flared out slightly below the hips. Corsets were still worn, but developing towards a straight front look in lieu of previous popular styles which created a wasp-shaped waist. These straight front corsets were longer than previous styles of corsets, covering the hips and making sitting extremely difficult until the length of the corset was reduced in around 1910. 


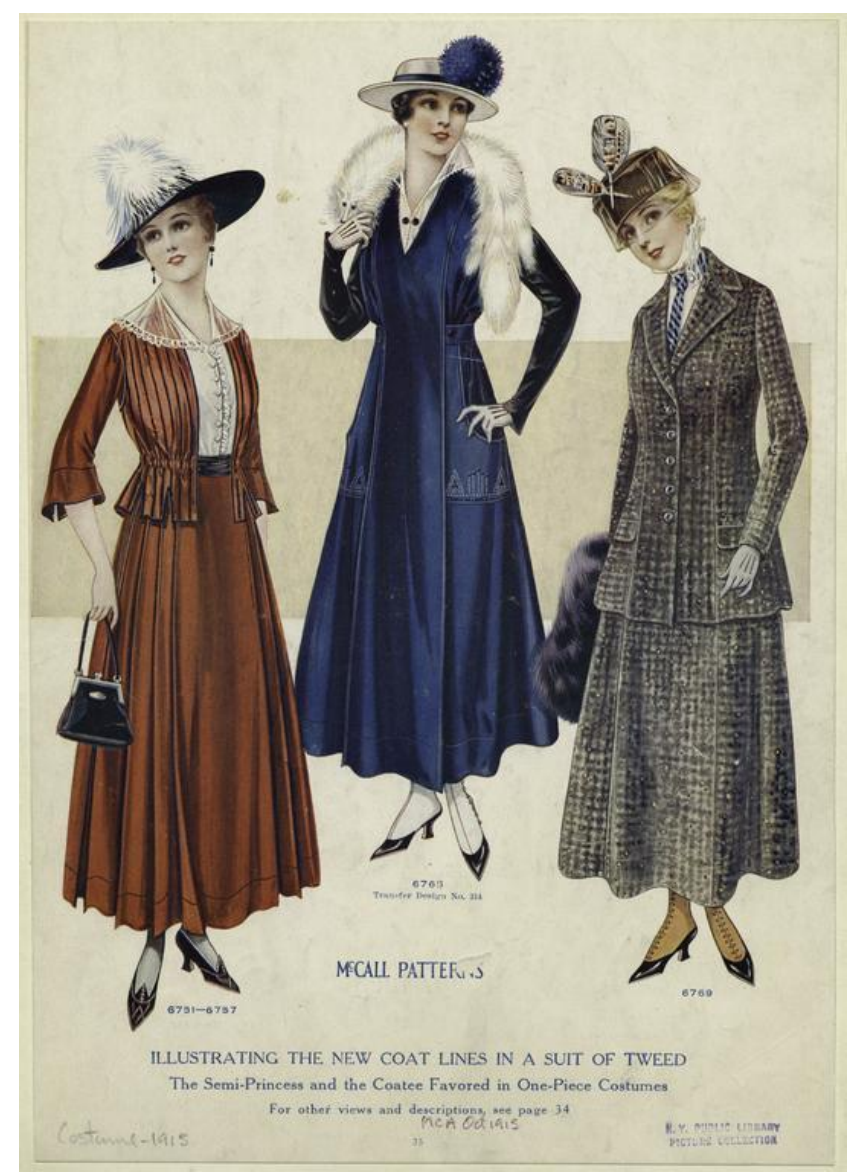

Figure 10: On the right, an example of a woman's suit from 1915. Note the shorter hems and the spats over pumps.

Through 1910 petticoats were worn without exception under all skirts to give them body and movement at the bottom. The petticoats had ruffles at the bottom which kicked the skirt outwards at the hem. Skirts were generally fitted at the waist and over the hips, then flared below the hips (Figure 9). Skirts were sometimes gored to exemplify the narrow fit to the hips or gathered so that the fullness fell to the back of the skirt. Skirt hems either touched the ground or fell an inch or two off of the ground unless for sport or for rainy days (Figures $9 \& 10$ ). These types of skirts were hemmed to the ankle. In 1910 skirts began to narrow. 1910 and 1911 saw the hobble skirt come into fashion, which was so fitted around the lower legs that it made walking quite difficult, and in some cases dangerous. In 1912 skirts stayed narrow, but the sides were slashed to allow for more natural movement. This made petticoats almost impossible, especially 
if one did not have the means for an underskirt of quality fabric, and so began the phasing out of this particular item from the world of fashion.

High shoes were most appropriate in the street in the winter, while low shoes were worn at home and in the summer. Light colored spats were commonly worn over pumps or oxfords. Even slippers were often made to match the outfit, and were often decorated with bows and other trims.

Hairstyles for women varied, though controlled waves were substituted for the tight ringlet curls of previous periods. Between the years of 1900 and 1908, virtually every woman wore a pompadour hairstyle, which included building the hair out with puffs as well as letting the hair develop frizz and wispy tendrils through natural wear and tear of the style. Top knots, psyche knots, and French twists were common. Around 1914 hairstyles began to shrink from the voluminous pompadour to hair parted at center and brushed behind the ears into a low chignon. Hair ornaments were common when paired with fancier clothing.

\section{Common fabric and color choices}

Men's suits were most commonly made of cotton broadcloth. Woolen tweeds were extremely common for sporting. In the summertime suits were also occasionally made of "Panama cloth" linen, alpaca wool, and cotton seersucker. Button up shirts were linen or cotton. Men's clothing had a very limited color palette during this time period. Black and white were the only colors acceptable for formalwear. However, some color and pattern was possible in everyday wear of the era. While the base colors of suits were neutral or muted hues such as black, white, brown, warm and cool greys, navy blue, or dark green, there was also some opportunity to break up the monotony of a suit with colorful accents which could be added into the weaving process of fabrics for suits, button up shirts, and socks. In the summertime, lighter colors such as ecru and silvery grey were especially common.

Women had many options for materials based on their social class. Middle and lower class women most often wore cottons, linens, and wools in varying weights. Some examples include: cotton lawn, dimity, handkerchief linen, and Swiss dot. Wealthier women might be able to afford fabrics such as satin, china silk, taffeta, crepe silk, velvet, and brocade. The more money a person had, the more details a garment could afford to have, including lace trims and overlays, which were popular at the time. Suiting material for women was very similar to that of 
men, though women's suits were occasionally more colorful. Subdued colors were fashionable between 1900 and 1910; it was not until around 1912 that the color palette for clothing began to expand once again. In the most affluent parts of the country colors such as pink, orange, jade, cerise, and bright blue came into fashion. This was notable in ballrooms, and especially with Ragtime dancing. Billowy, lightweight silks such as chiffon became extremely fashionable to complement this change towards a more fun and carefree palette of colors.

\section{Character Breakdown:}

The dialogue in both Courtship and Valentine's Day is meticulously crafted. Horton Foote tailors each individual detail in the script to create and support the world that he hopes to convey. The specificity of Foote's wording means that the observations made by the characters about themselves and about others within these plays are written in a way that cannot be ignored by the designer. A large portion of my design process for any show includes searching the text and pinpointing every observation made about each individual character. Once I have this information, I consolidate these details into a few paragraphs. For these particular shows, the character information that I gathered heavily influenced the direction of my research for each character. While Foote does not provide the reader with every single piece of the puzzle, his words are precise enough to guide the designer's work in a predefined direction. Developing a character takes analytical ability and inference, but the power of textual observation and adherence to those observations is unparalleled. For this reason, I begin the research process for each character in the following breakdown with information pulled directly from the script. These short synopses frame the character's development, and help to focus on where changes might need to happen, as well as on which details are most important to the visual essence of each character.

\section{Elizabeth Vaughn}

\section{Courtship}

\section{Character Information:}

Elizabeth is 23 years old, and has graduated from a 2 year college. She teaches piano to make money, though her family is wealthy. Her father is very strict, and because of this Elizabeth has never been allowed to go to a dance, although she longs to join in the festivities. 
Elizabeth learned to dance without her parents' knowledge or permission, though she does not show off her abilities anywhere where she might be caught. Her dating past is not extensive, but she has been in love before, and becomes adamant about her feelings even with her father's disapproval. Upon learning of her affection for Horace Robedaux, Elizabeth's mother tells her that it seems she is only attracted to wild men, but Elizabeth does not quite believe this.

Elizabeth says that she views herself as unconfident and timid, though she admits to sneaking out of her friend Rita's parents' home late at night to go riding in a buggy with some boys (including Horace Robedaux). Horace has given Elizabeth a ring, which she considers a promise to marriage. She wears the ring on a chain around her neck in order to hide it from her parents, though this chain eventually breaks, exposing the ring to her family. When her parents learn of the ring, they demand that Elizabeth return it, Elizabeth promises to do so, but soon after reveals to her sister that she has lied. Elizabeth claims that she does not always think, but rather lets her feelings guide her.

\section{Research:}

In order to portray a young woman struggling with the burden of a forbidden true love, due to an overbearing father, I created a costume that is generally conservative and sweet. If the audience looks closely enough, however, they will notice a spark of danger and adventurousness in the details of the costume. In contrast to her sister, Laura, who is much more nervous about breaking the rules, Elizabeth's clothing is far more playful. Her blouse, inspired by the dress pictured in Figure 4, has a lace-backed yoke which gives the illusion that a little bit of bare skin is being shown between the lines of trim on the blouse. The neckline of Elizabeth's blouse sits purposefully lower than the necklines of the rest of the women in her family in order to subtly suggest Elizabeth's sense of adventure. While Elizabeth could never wear bold colors due to her father's conservatism. I chose a warm brown color for her skirt with a slightly red hue. 


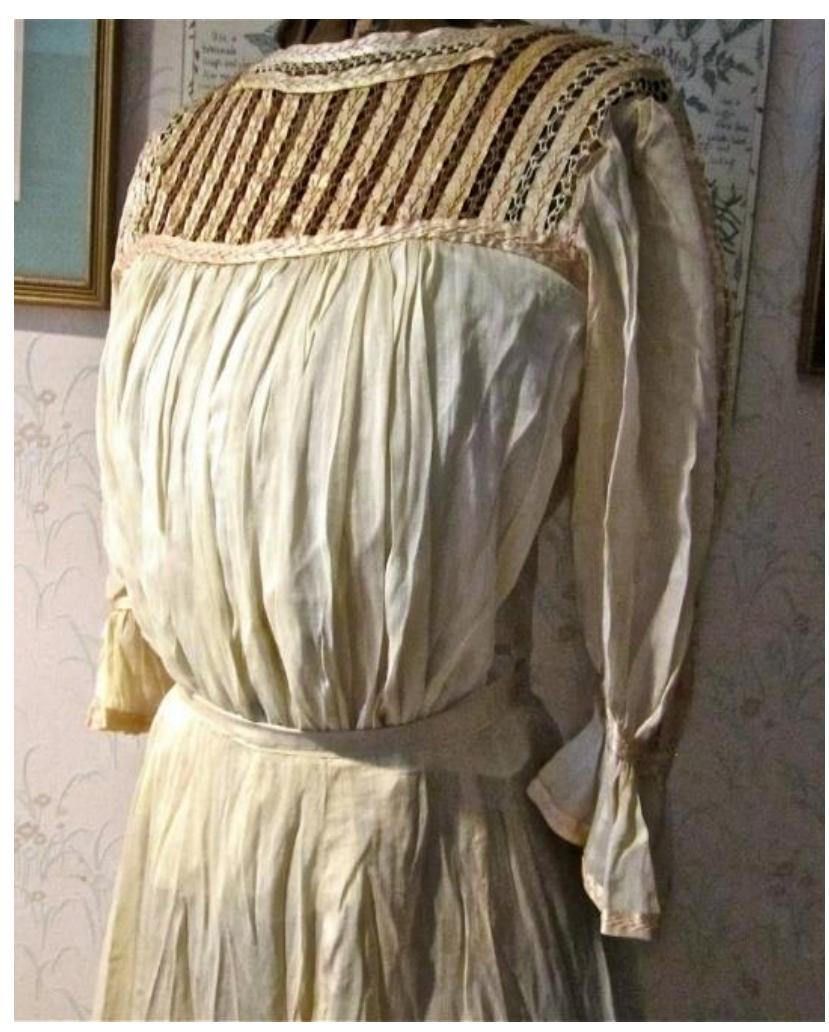

Figure 11: Research image for Elizabeth's blouse in Courtship.

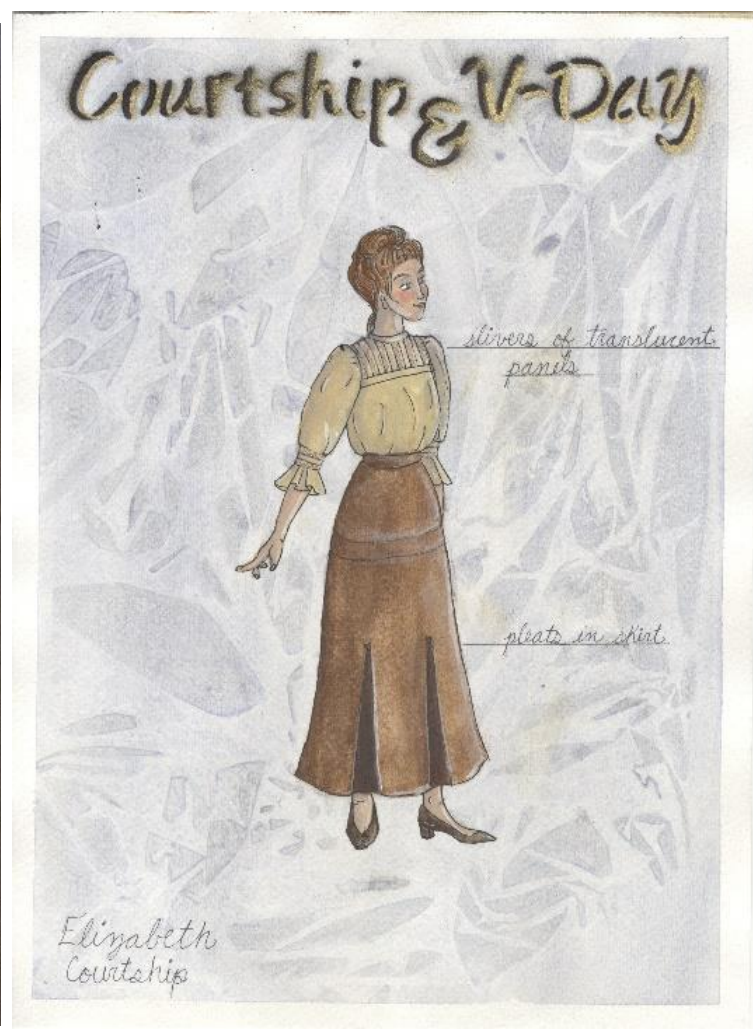

Figure 12: Final rendering for Elizabeth in Courtship.

This hint at a daring color adds a little bit of spark to Elizabeth's visual personality, coinciding with the spark that is evident through her dialogue with others in the play. The overall look is meant to portray Elizabeth as a generally obedient child, with a wild streak, waiting to escape from her father's watchful eye.

In terms of fabric choices, I was diligent in maintaining a selection of fabrics which was exclusively natural. I chose a medium weight linen for her skirt, which allowed the skirt to hang heavily, and draped alluringly over the curve of her hips. The heaviness in the hem swished and bounced delightfully while the actress, Ms. Margaret Dransfield, moved about the front porch, adding a youthful spring to Elizabeth's step. For her blouse, a very lightweight cotton lawn was chosen as the base fabric, and a light weight lace was placed underneath of the trim on the yoke of the blouse. Cotton lawn is smooth and simple, but gathers neatly, without much bulk at the waist. The lawn was able to simultaneously hold the desired shape of the blouse without appearing too stiff. 


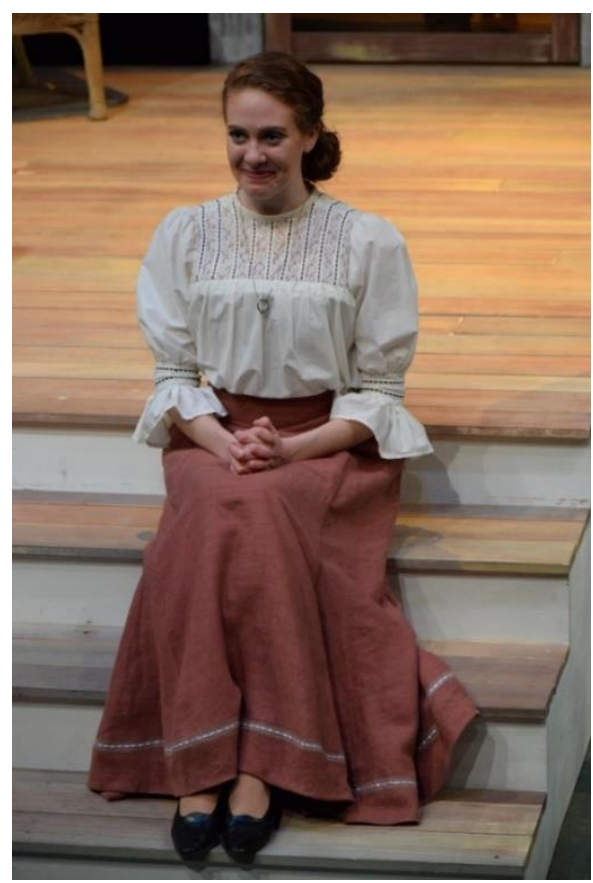

Figure 13: Elizabeth Vaugh (Margaret Dransfield) in Courtship; front view.

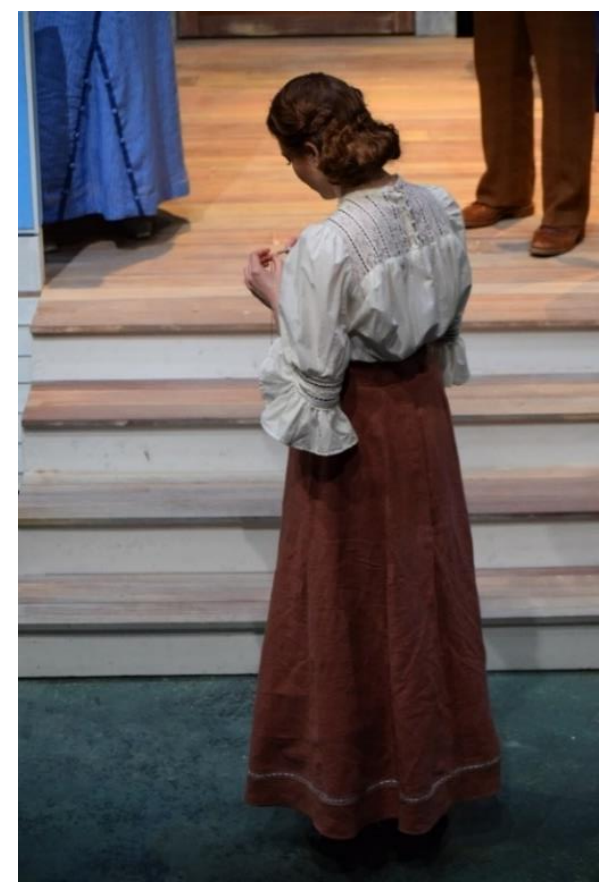

Figure 14: Elizabeth Vaughn (Margaret) Dransfield in Courtship; back view.

\section{Valentine's Day}

\section{Character Information:}

At the opening of the second play, it is now Christmas time in 1917. Elizabeth is five months pregnant. She and Horace have been married for almost a year, but their marriage was not approved by Elizabeth's father. The loving couple had to elope in order to get married. Elizabeth's relationship with her family has been nonexistent ever since.

\section{Research:}

In terms of written information and analysis, clothing related to pregnancy before the turn of the century is well documented. In contrast, there is very little written on the development of maternity wear and trends in the early 1900s. There is a veritable gap in available information, and although I did come across a few fashion catalogues which contained ads for maternity clothing and maternity corsets, the information on those ads does not necessarily detail what type of woman purchased those garments. I discovered a master's thesis by Fashion Institute of Technology alumna Marianne Brown which acknowledged the lack of information available to an interested reader and which went into as much detail as possible on the subject. It is through 
this thesis that I was able to determine that, although many women in Elizabeth's parents' social class might own maternity clothing and maternity corsets, Elizabeth was no longer a part of that social class, and so would have had to repurpose some of her preexisting wardrobe to fit her in her pregnancy. Though pregnancy corsets were considered healthy for a pregnant woman at the time-doctors recommended them, in fact! - such a corset would have been prohibitively expensive, and therefore unattainable for Elizabeth and Horace in their present financial situation.

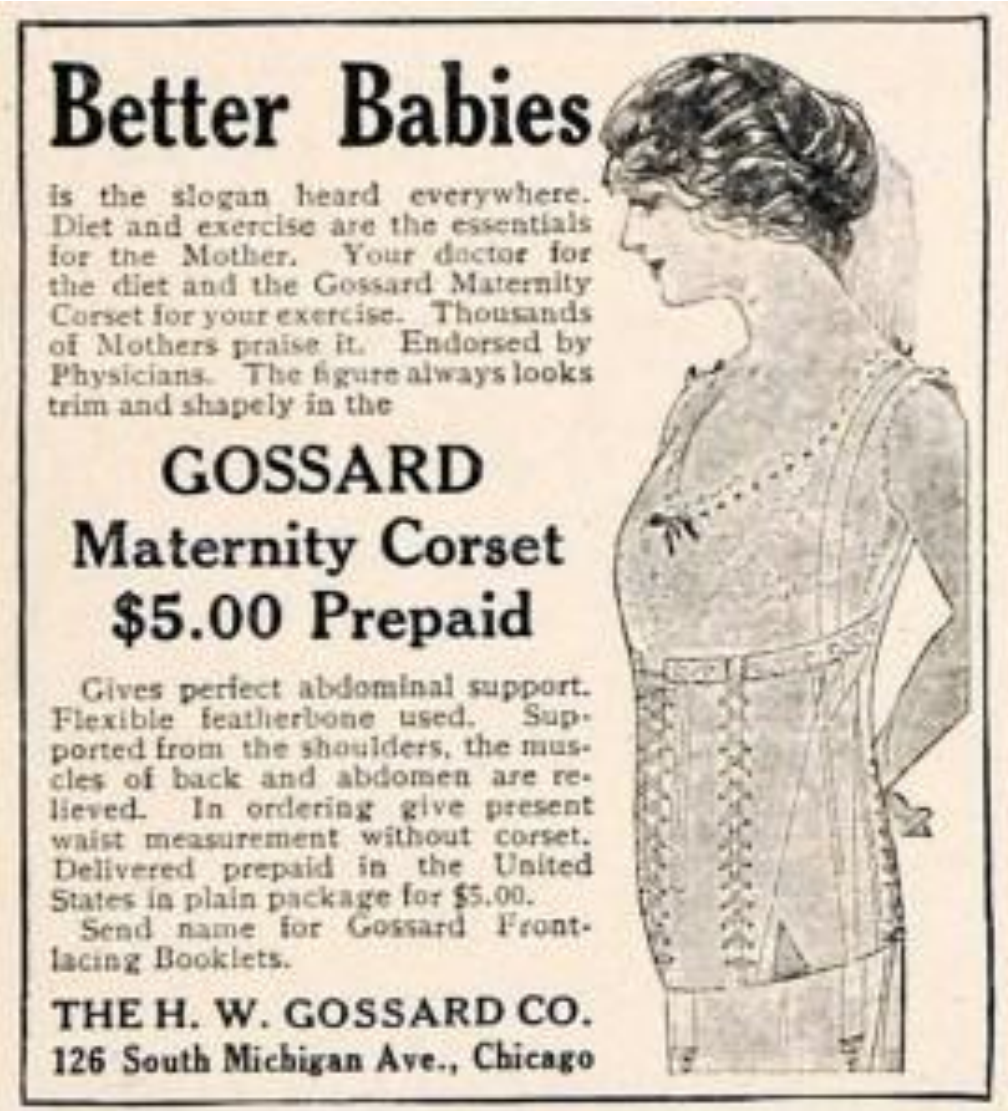

Figure 15: Advertisement for pregnancy corsets.

As far as outer garments are concerned, there were looser fitting styles of clothing in this era which, at first, piqued my interest, given that Elizabeth would want to dress as formally as possible in order to impress her parents when they visit on Christmas. These styles, however, were absolutely too new for Elizabeth to own. The more I looked into the character, the more I realized that what Elizabeth really wants is to project to her family that she is perfectly content with the meager life that she leads. Being seen in this state is ultimately the most important factor 
her family's decision to forgive her for her hasty marriage, so it was imperative that Elizabeth's costume for scene 2 of Valentine's Day be simple, sweet, and modest.

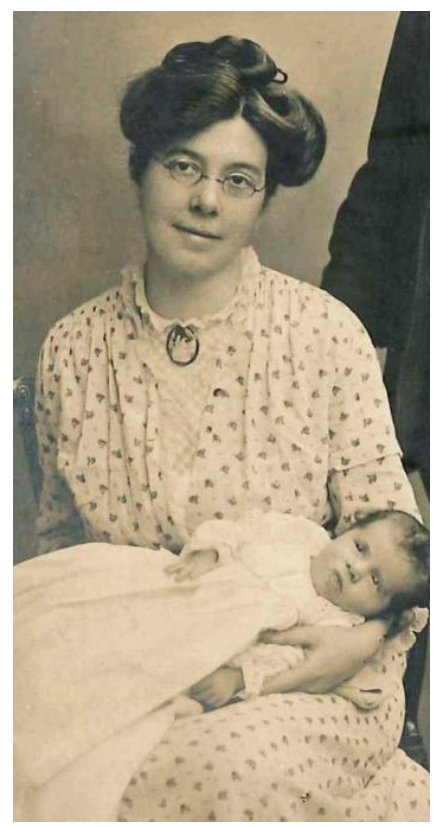

Figure 16: Research image for Elizabeth's Christmas day blouse in Valentine's Day, scene 2.

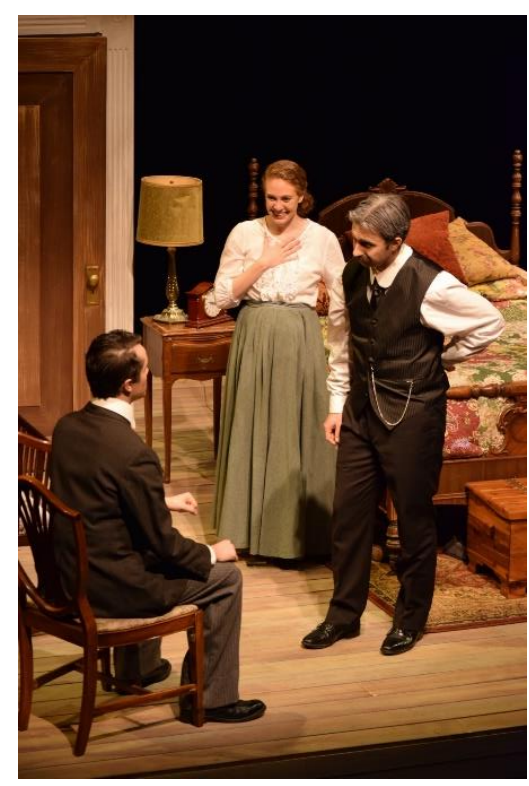

Figure 18: Horace (Isaac Snyder), Elizabeth (Margaret Dransfield), and Mr. Vaughn (Joseph Bussey) in Valentine's Day, scene 3.

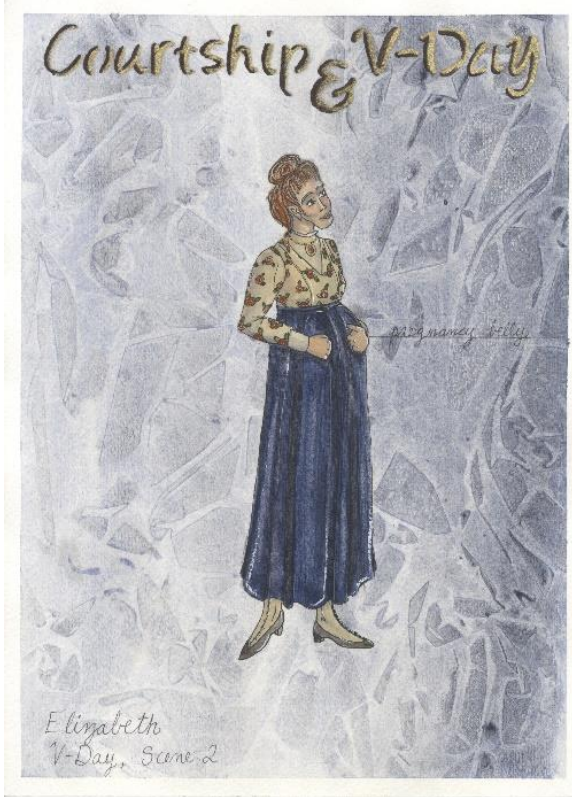

Figure 17: Final rendering for Elizabeth in Valentine's Day, scene 2.

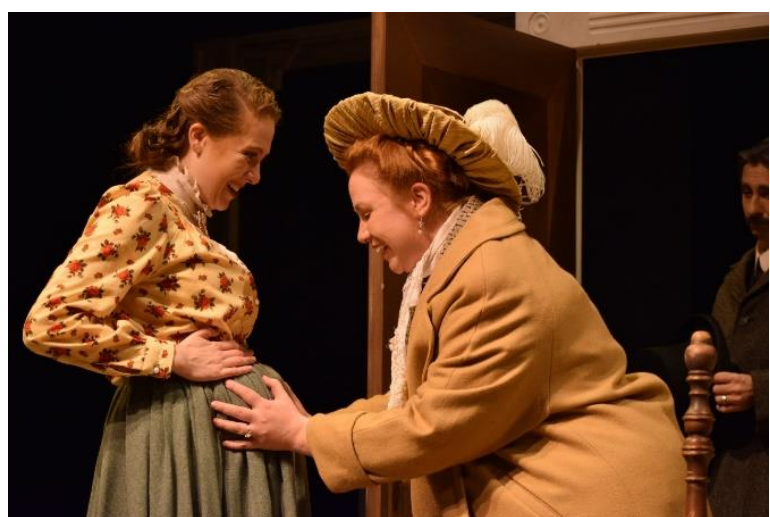

Figure 19: Elizabeth (Margaret Dransfield) and Mrs. Vaughn (Madeline Hintz) in Valentine's Day, scene 2. 


\section{$\underline{\text { Laura Vaughn }}$}

\section{Courtship}

\section{Character Information:}

Laura is currently enrolled in a two year college, although her father hopes to transfer her to a school in Virginia. Her mother thinks that she would be well suited to teach a kindergarten class in the sun room after she graduates. According to her mother, Laura is tender-hearted. This fact is highlighted when Laura begins to sob in the midst of singing "Nellie Grey" for the family's entertainment. Her parents are very strict, and Laura is generally careful to follow their orders and bend to their desires. Because of her strict parents, she has never been to a dance, but she longs to go as she learned to dance at school and wishes very much to try it. Like her sister, Laura admits to slipping out to spend time walking with her friend Annie and a group of boys late one evening. When she was two years old, Laura drank carbolic acid, which very nearly killed her, and caused a scar on her neck. Laura is self-conscious about this scar, although Elizabeth tells her that it is barely noticeable.

\section{Research:}

It is clear from her interactions with her mother and sister in the script that Laura is a much more delicate creature than Elizabeth. Laura is a self-conscious young woman. She is stuck between her extreme naivety and her desire to follow in the footsteps of her older sister, whom she adores and admires. While Laura has a desire to break the mold, she is not quite daring enough to show this side of her in the way that she dresses. I chose a high-necked dress with opaque lace accents to both make the actress appear young and naïve, and to help Laura hide her insecurities about the scar on her neck. 


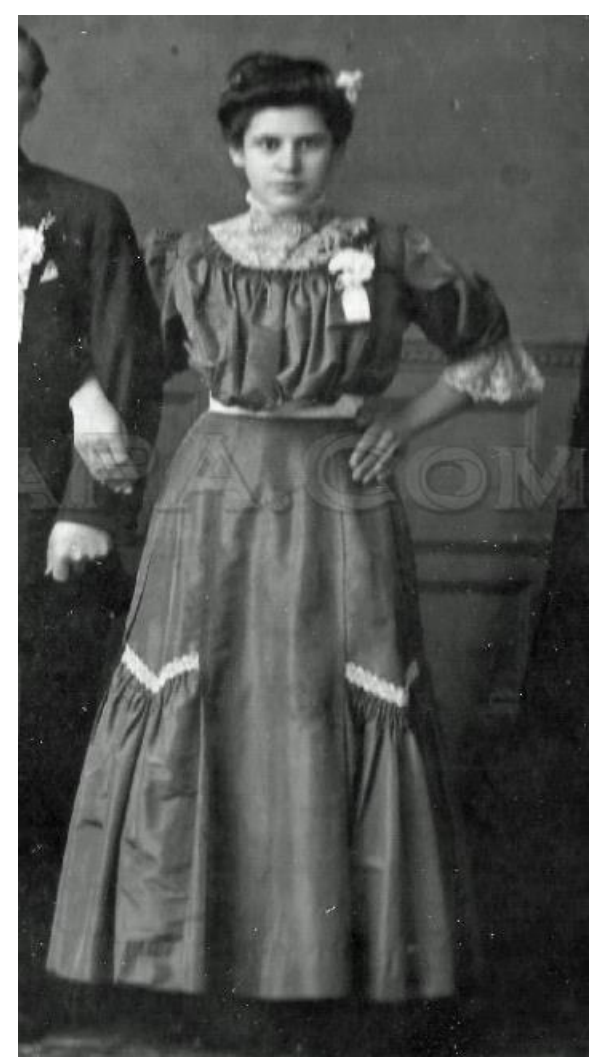

Figure 20: Research image for Laura's dress in Courtship.

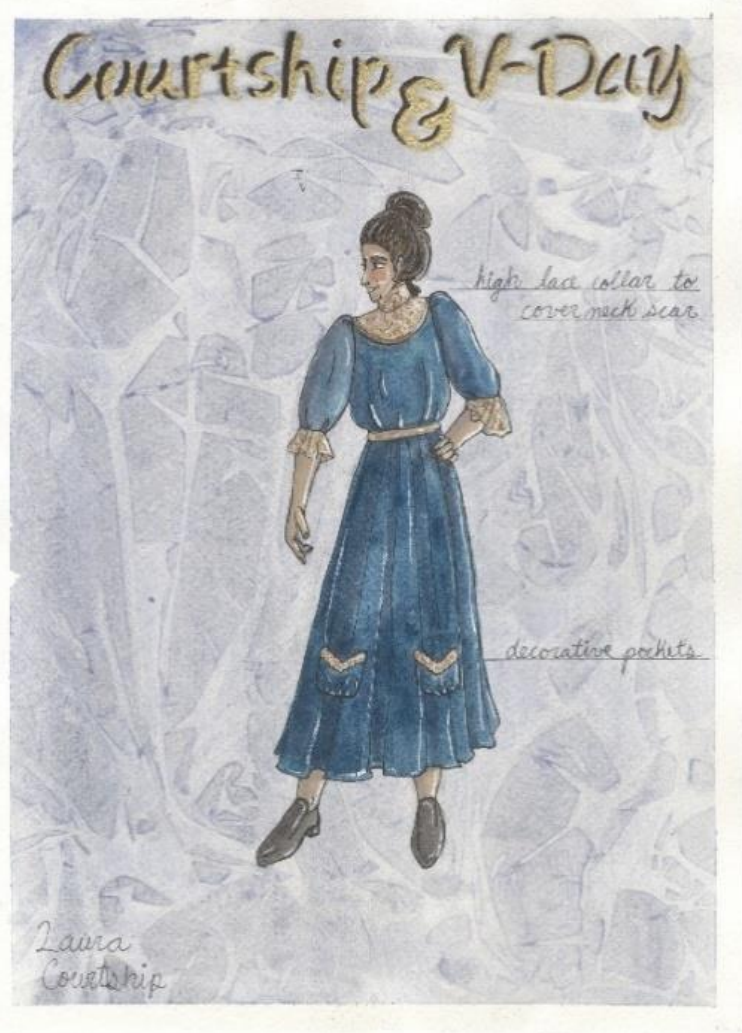

Figure 21: Final rendering for Laura in Courtship.

The back of the dress has many buttons, which, while an accurate closure for the period, is also representative of the painstaking dedication it takes to put on and take off such an outfit each day and night. This dedication speaks to Laura's obedient personality.

Laura struggles with her emotions given her age and her home life situation, so I chose a subdued dark blue color for her dress in hopes of personifying her youthful, yet obedient nature. Though Laura has a streak of adventurousness in her, she is not always the adventurous girl that her stories paint her to be. For this reason, the blue of her dress helps to ground her into the set, which also contains elements of blue. This connection to the set fades Laura into the scenery, making her a permanent part of the Vaughn family home, just as her father desires her to be. There is nothing bold about Laura's costume. She merely hides beneath ruffles, gathering, loose folds and girlish lace details. 


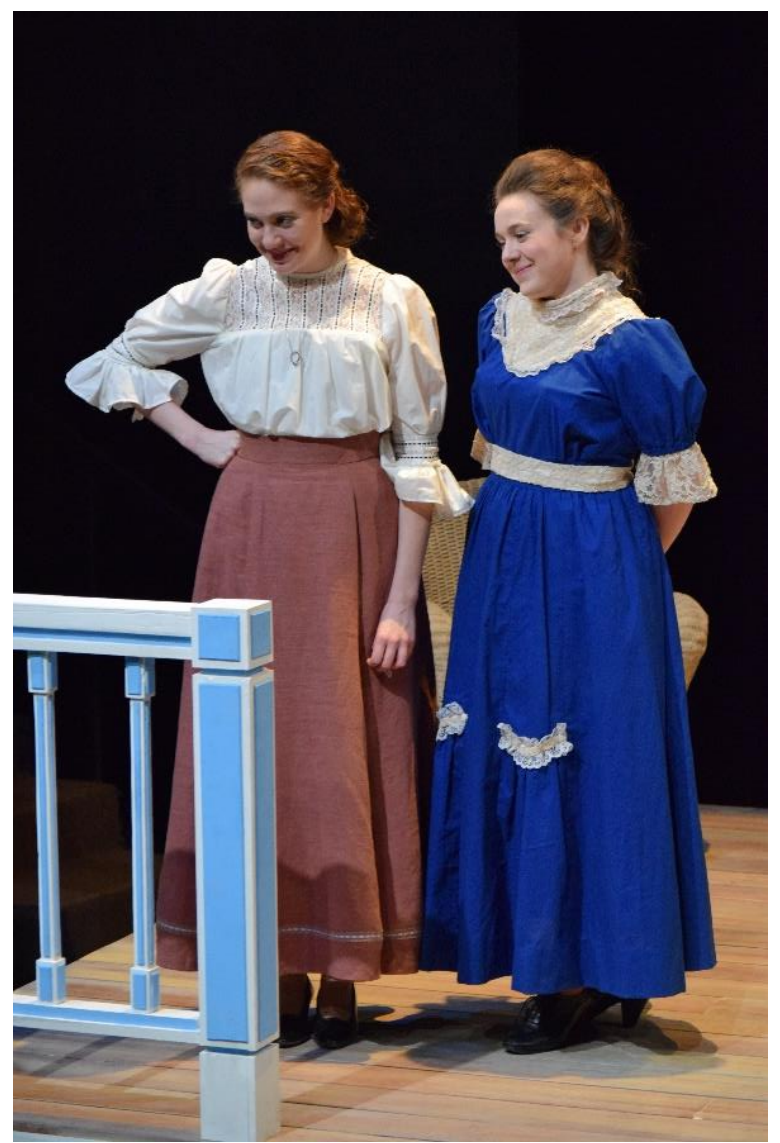

Figure 22: Elizabeth (Margaret Dransfield) and Laura (Mallory Robson) in Courtship.

$\underline{\text { Mr. Vaughn }}$

\section{Courtship}

\section{Character Information:}

Mr. Henry Vaughn is viewed by his daughters, and most everyone around him as a strict parent. He does not deny this fact, but rather embraces it in hopes of maintaining control over the quality of life of his children and family. Most others consider him successful and affluent. His intentions are good, but he is not always viewed in a good light by other characters. Mr. Vaughn grew up poor in Brazoria County. His father passed away when he was 12, leaving young Henry Vaughn to be passed from uncaring relative to uncaring relative until he took his first job which allowed him to start providing for himself. From this moment on, Mr. Vaughn worked hard, put himself through college, and built himself into a very wealthy man who has the means to leave his daughters with enough money to take care of themselves for the rest of their lives, even if they never marry. Mr. Vaughn was engaged to a girl in East Columbia before he met Mrs. 
Vaughn, but she was unfaithful to him. This soured young Henry on relationships, until he met the woman who would be his wife, Mary. The two met while Henry was working as County Treasurer, and married at a later age than was common for couples in the time period. Despite all this, the two have been happy in their marriage ever since. This fact feeds into Mr. Vaughn's hesitance to allow any man into his daughters' lives, as he views them as too young to truly understand love and marriage.

\section{Research:}

Mr. Vaughn's austere personality was the driving force for my design of his costume. I felt that in contrast to the second play, which shows Mr. Vaughn in a much more formal situation, that Courtship should showcase Mr. Vaughn at his most relaxed. For Mr. Vaughn, this still means that his dress is fairly proper. His look is neat, his clothes are well-fitted, and it is clear by his accessories, such as his pocket watch and shiny pink tie that he is wealthy. I chose a mismatched color combination for this look in hopes of showing the side of Mr. Vaughn that is only seen at home. So while he is still very much put together, and poised for action at any moment, he is at home and relaxed.

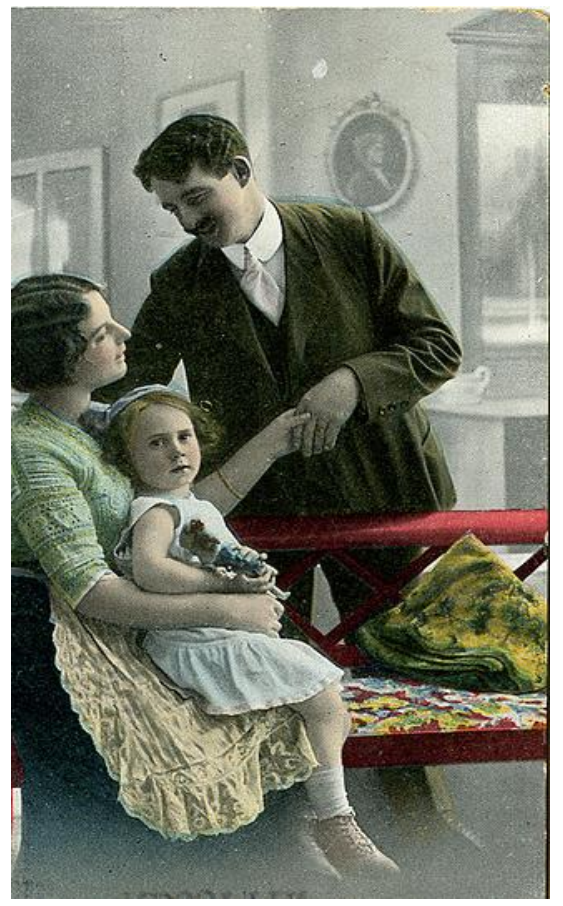

Figure 23: Research image for Mr. Vaughn's suit in Courtship.

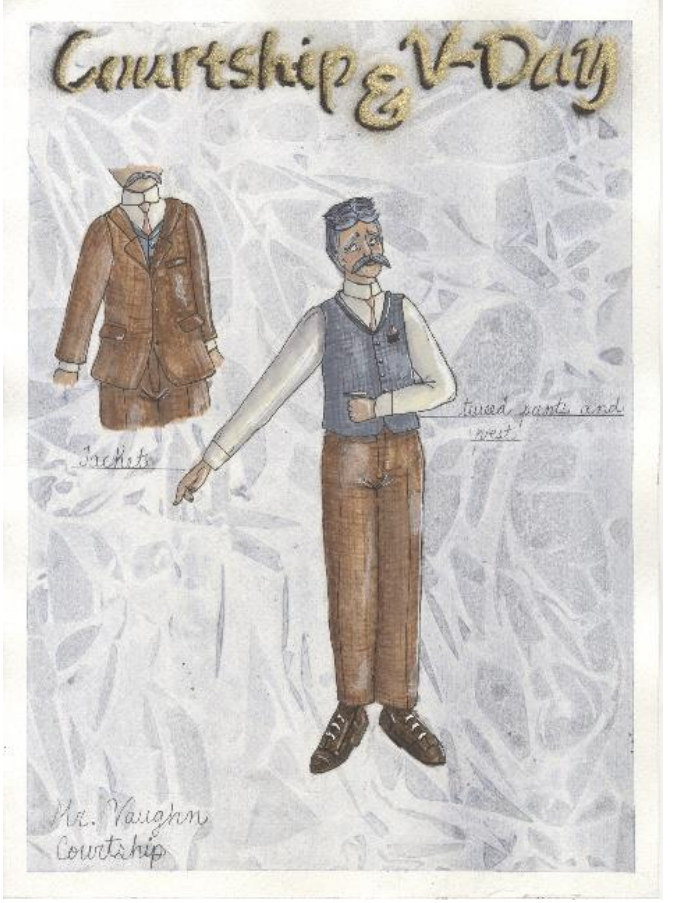

Figure 24: Final rendering for Mr. Vaughn in Courtship. 


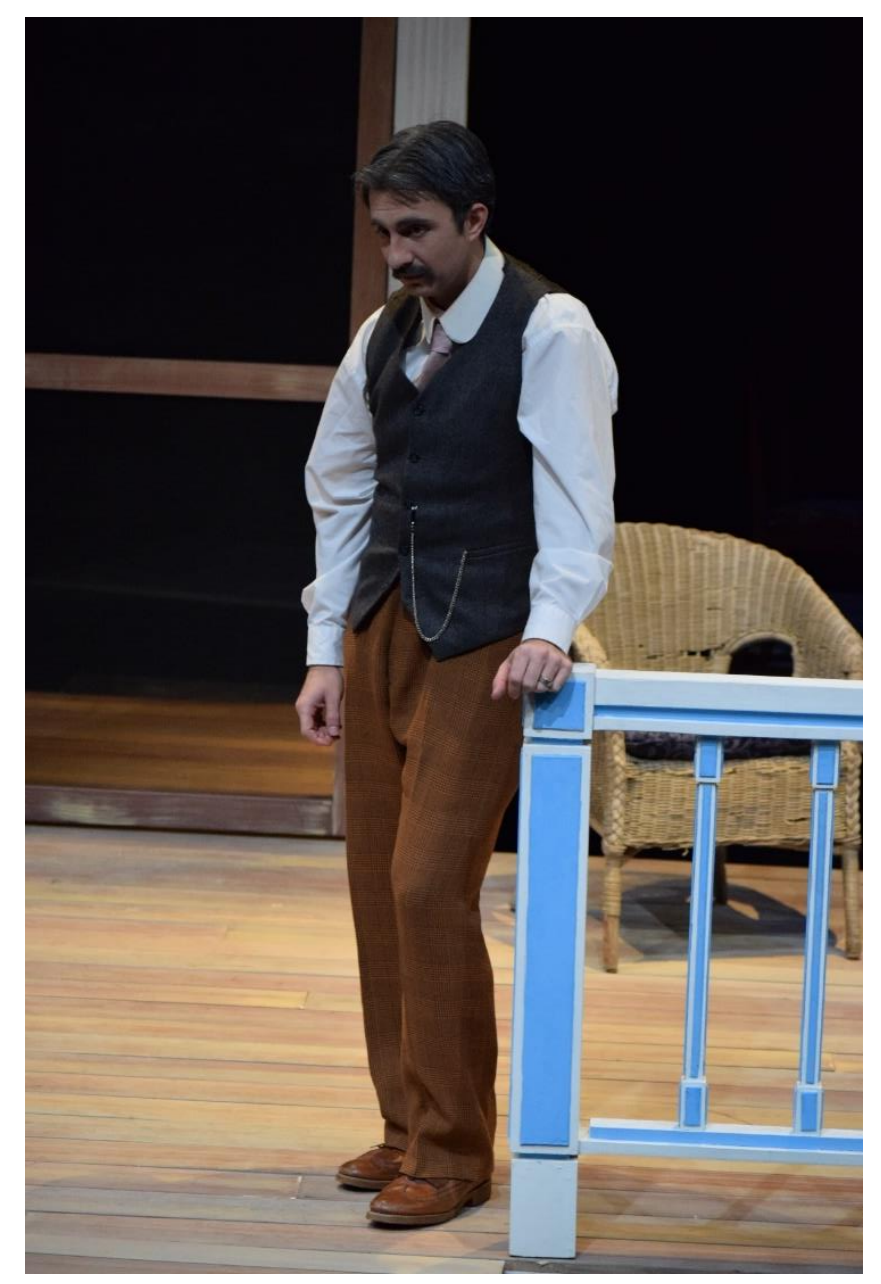

Figure 25: Mr. Vaughn (Joseph Bussey) in Courtship.

\section{Valentine's Day}

\section{Character Information:}

Now that Elizabeth and Horace have eloped, Mr. Vaughn must get used to the idea of their loving marriage. He progressively warms up to Horace as the show moves forward, and attempts to demonstrate his acceptance by offering to help Horace monetarily. Mr. Vaughn, at one point in his life, invested $\$ 50,000$ to save a bank, and so he makes it clear he has the means to help out the new and struggling family. It is also revealed that Mr. and Mrs. Vaughn had a few other children, Jenny and Daisy, who were too frail to make it into adulthood. These losses have sculpted the way that Mr. Vaughn views the world, perhaps adding a touch of cynicism to his demeanor, as he is already very pragmatic, and a realist. 


\section{Research:}

The events which unfold in Valentine's Day mark a transitional time in Mr. Vaughn's life. As a man who was surprised to have lost his daughter to marriage in the past year, Mr. Vaughn has had to wrestle with his own thoughts and emotions over the fact that his daughter made a choice that he did not agree with. At first, this manifests in Mr. Vaughn's portrayal of himself as overly formal and cold when he finally visits Elizabeth and Horace's new home on Christmas day. At this point, it is evident that it was not Mr. Vaughn's idea to call on the happy new couple, but rather the idea of Mrs. Vaughn. The truly visible transition comes becomes appaarent in the final scene of the play, when Mr. Vaughn finally starts to come around to the idea of Horace and Elizabeth having a good, strong, happy marriage like his own. The shift in costume is subtle. His suit is the same one that he wore on Christmas day, this time without all its pieces. This marks a lack of formality, which, in turn, marks Mr. Vaughn's realization that he was incorrect about the fate of his daughter's relationship. I originally designed Mr. Vaughn's scene 3 look to be collarless and without his vest, thinking that this would appear relaxed and informal. However, in practice this look was too extreme of a change, so I decided to swap out my original idea and place Mr. Vaughn in just his vest and tie to give a nod towards the idea that Mr. Vaughn is relaxed in the home of his daughter, just like he was relaxed in his own home. 


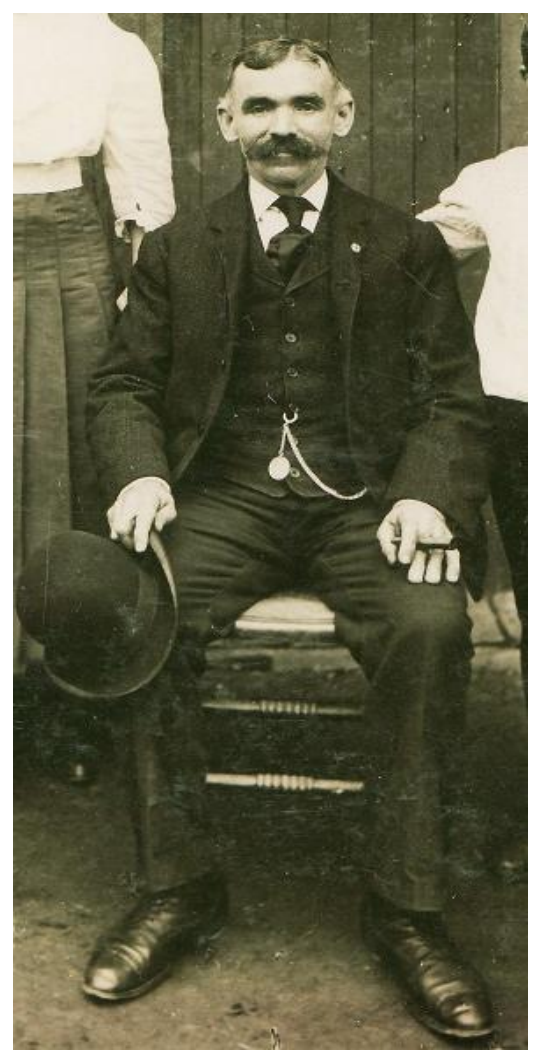

Figure 26: Research image for Mr. Vaughn's suit in Valentine's Day.

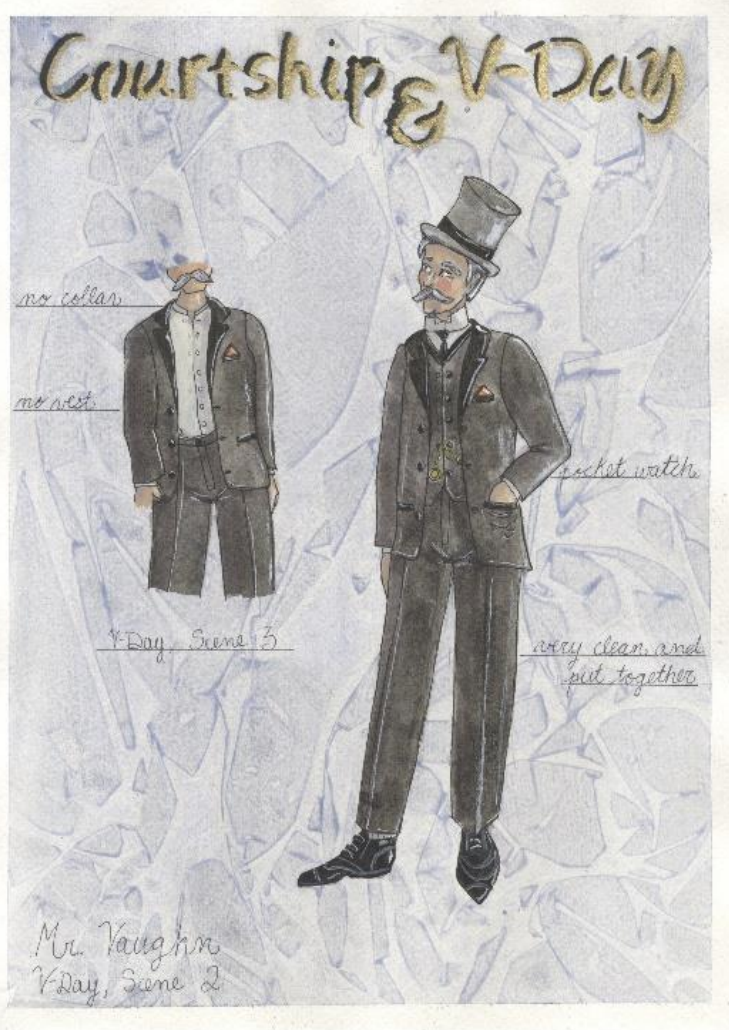

Figure 27: Final rendering for Mr. Vaughn in Valentine's Day.

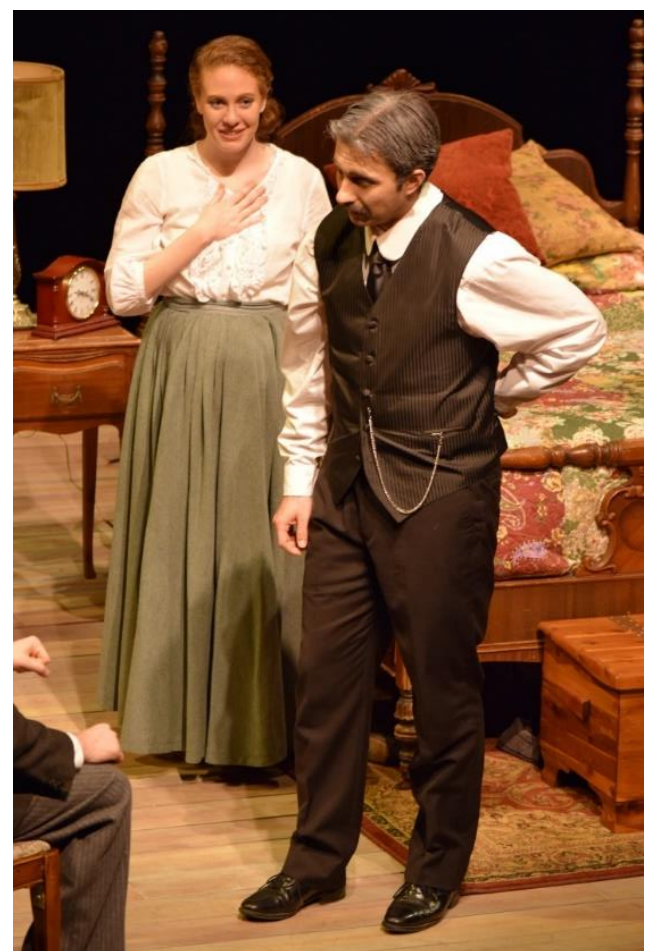

Figure 28: Elizabeth (Margaret Dransfield) and Mr. Vaughn (Joseph Bussey) in Valentine's Day, scene 3. 
$\underline{\text { Mrs. Vaughn }}$

\section{Courtship}

\section{Character Information:}

Mrs. Mary Vaughn was born in Brazoria County on a plantation in Oyster Creek. Her father was a planter, but he was never prosperous. When she was younger, Mary had to work for a living. She served as a governess on a plantation, and later, a secretary in a court house. Mary met Henry Vaughn while working at the court house, and they married at 26 years old. Though she used to dance, Mary stopped dancing once she married Henry Vaughn. She has been happily married, but suffered some times of despair and unhappiness when she lost two of her children. Her daughters Daisy and Jenny both passed away at a young age, and she nearly lost Laura as well at the age of two. Mrs. Vaughn stayed by Laura's bedside at all hours to nurse her when she was ill. By no small miracle, Mrs. Vaughn was able to bring Laura back to full strength and good health. This fear of loss is perhaps what prompts Mrs. Vaughn to be as overprotective with her daughters as she proves herself to be.

\section{Research:}

The styles that I chose for Mrs. Vaughn were meant to simultaneously signify that she is motherly, but not necessarily a whole-hearted nurturer. The line of the blouse and the skirt that I chose for her is sharp and severe, much like the style of discipline that Mr. and Mrs. Vaughn employ with their children. The colors and patterns chosen for Mrs. Vaughn's ensemble in Courtship are soft and country inspired, which leads them in a gentler direction. The juxtaposition of the harsh decorative lines found in Mrs. Vaughn's look in combination with the softness of the patterns and colors which meld into the rest of the set, make Mrs. Vaughn a part of the home, in much the same way as her daughter, Laura. Country elegance was the aim when choosing costume pieces for Mrs. Vaughn, and the skirt and blouse combination in lieu of a one piece dress was a way to dress the character down while still maintaining her social class. 


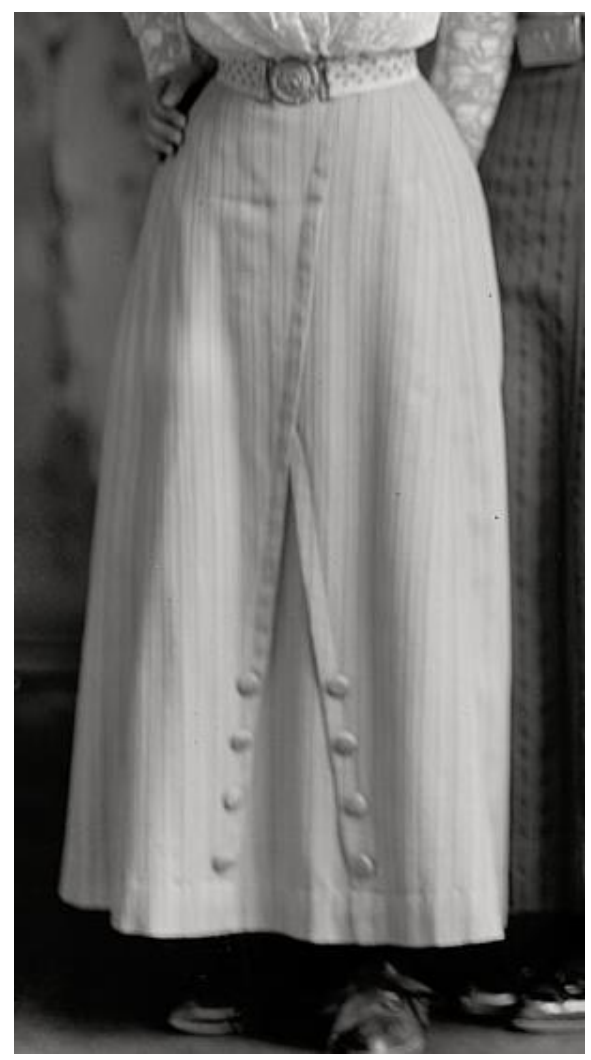

Figure 29: Research image for Mrs. Vaughn's blouse in Courtship.

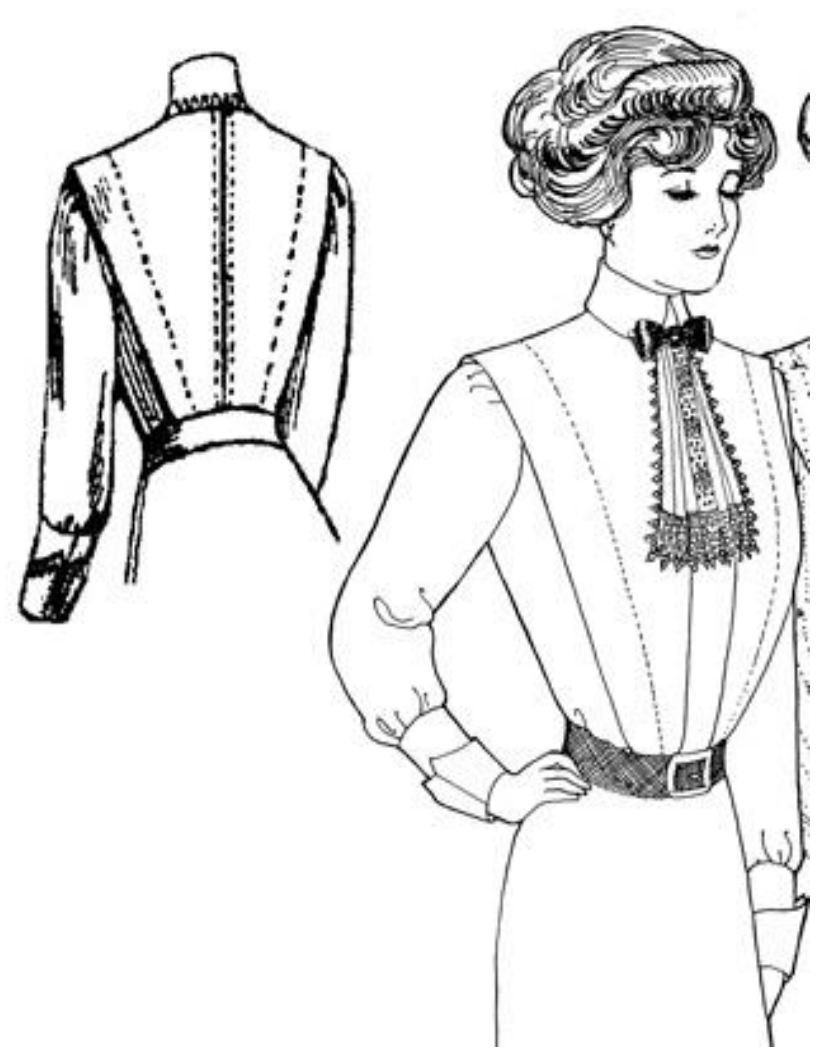

Figure 30: Research image for Mrs. Vaughn's skirt in Courtship.

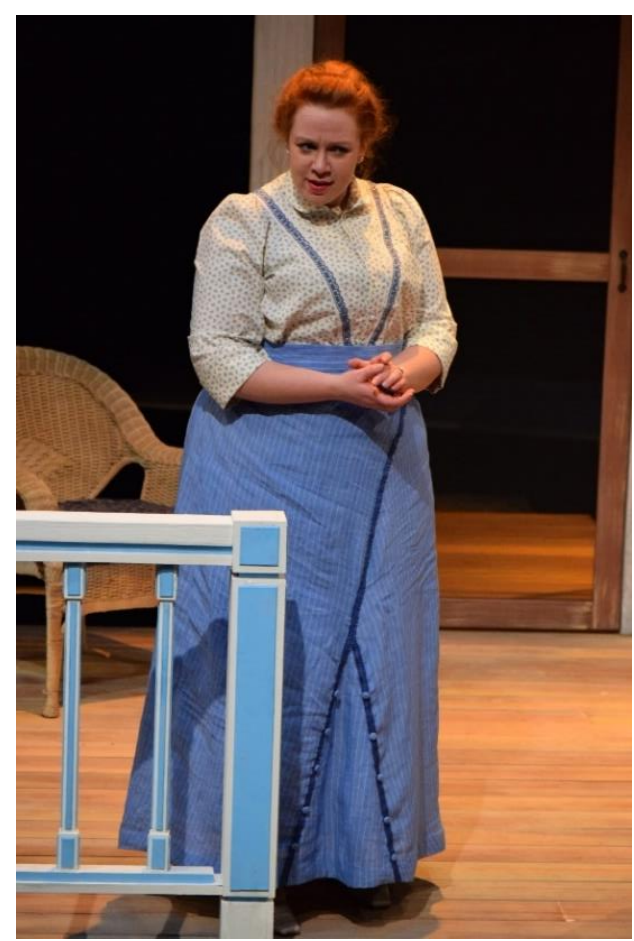

Figure 31: Mrs. Vaughn (Madeline Hintz) in Courtship. 


\section{Valentine's Day}

\section{Character Information:}

It is Mrs. Vaughn who calls Elizabeth in hopes of reconciling after her marriage to Horace. She makes a point to bring gifts for Elizabeth and Horace as well as for her unborn grandchild in hopes of reconciliation. During her visit, Mrs. Vaughn shows off her new, expensive pin that was her Christmas gift, and there is mention of Jenny and Daisy. Mrs. Vaughn planted roses by both girls' graves in tribute to them. The fact that she planted something by their graves is symbolic of the pain that she must always carry with her as a mother who has lost children before their time. This also speaks to the reason that she has decided to reach out to her estranged daughter, Elizabeth. The pain of losing another daughter outweighs the pain of the disappointment that Elizabeth brought to her family by eloping with Horace.

\section{Research:}

Mrs. Vaughn's Christmas day look in Valentine's Day is much more elegant than her outfit in Courtship. The choice to visit her estranged daughter on Christmas is most certainly spawned from her motherly instinct to make things right with her child. While the focus of scene 2 is on the mending of a shattered relationship, Mrs. Vaughn's costume must still ensure that her higher social status is known. Therefore, I placed Mrs. Vaughn in a velvet-trimmed, tailored suit. This style of outfit was meant to showcase her wealth while simultaneously maintaining a simplicity that lends itself to the country elegance seen in her costume for Courtship. When I first laid eyes on the research image (Figure 32) which inspired the final rendering (Figure 33), I was immediately drawn to the silhouette as well as the striped fabric. I felt a connection between the stiff elegant air of the woman posing in a ridicuous feathered hat and Mrs. Vaughn's bottled up personality. Though I chose to tone down the size of the hat and the feather in my design, the look itself maintains a similar air to the research image. There is something beautiful, mature, and strong about a skirt suit which far outweights any other style of dress as an option. 


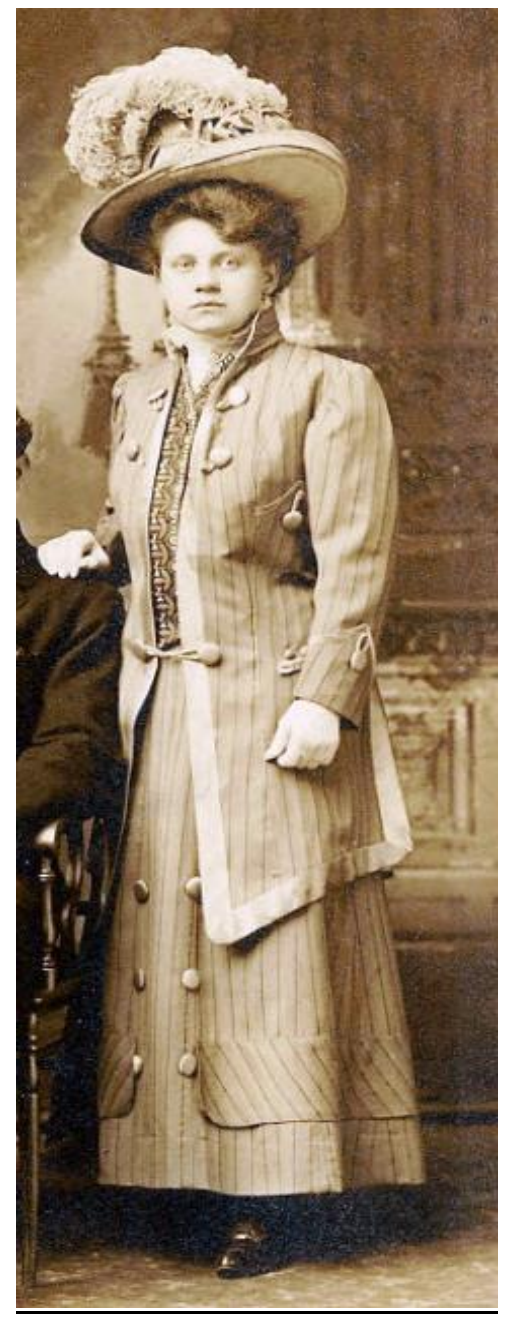

Figure 32: Research image for Mrs. Vaughn's Christmas suit, as originally designed.

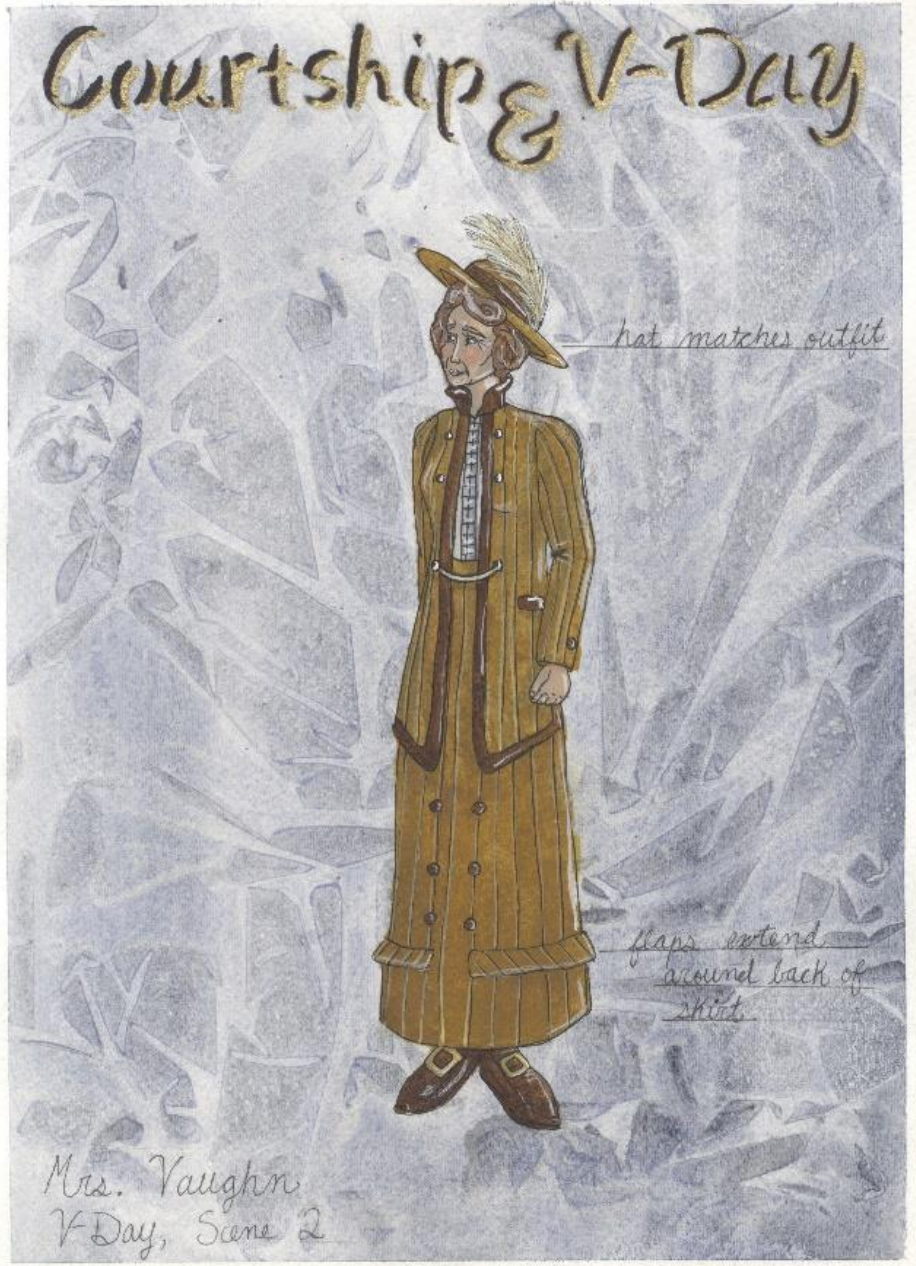

Figure 33: Original design for Mrs. Vaughn's Christmas suit in Valentine's Day, scene 2.

The linear quality of both looks for Mrs. Vaughn was a conscious decision, as I felt that incorporating strong lines into both of her costumes would reflect the rigid conservatism in her personality. In terms of material, I struggled to find a fabric which would yield a similar look to the striped jacquard suit in my research image. My search mostly yielded polyester fabrics with stripes that were far too wide. Finding the correct golden ochre color was also a challenge. When I ordered the final fabric, I expected a deep golden color and a much more supple hand than I received, and was disappointed with the stiff quality and lemon-yellow color of the fabric. The polyester did not suit the costume as well as I had imagined, but due to time restraints, I decided to modify the fabric as best as possible and push forward with the fabric in hand. Though the 
look was eventually cut from the production (see Costume Shop Build), I felt that the look was an adequate representation of the rendering following the modification of the fabric.

When the original design was found to be unsatisfactory, I searched for items within a similar, yet slightly darker color palette which offered a feel akin to the originally designed Christmas suit. I kept to skirt and blouse combinations and looked for a non-matching jacket to tailor to fit the actress, Ms. Madeline Hintz. As my hope was to maintain the feel of the original design in the new look, I pulled as many details as possible fom the original research image (Figure 32), such as the soft chain link closure and a small wale courduroy skirt to subtly maintain the linear quality of the costume. This look was ultimately more successful than the original design due to the stronger variation in color and texture in the final garment.

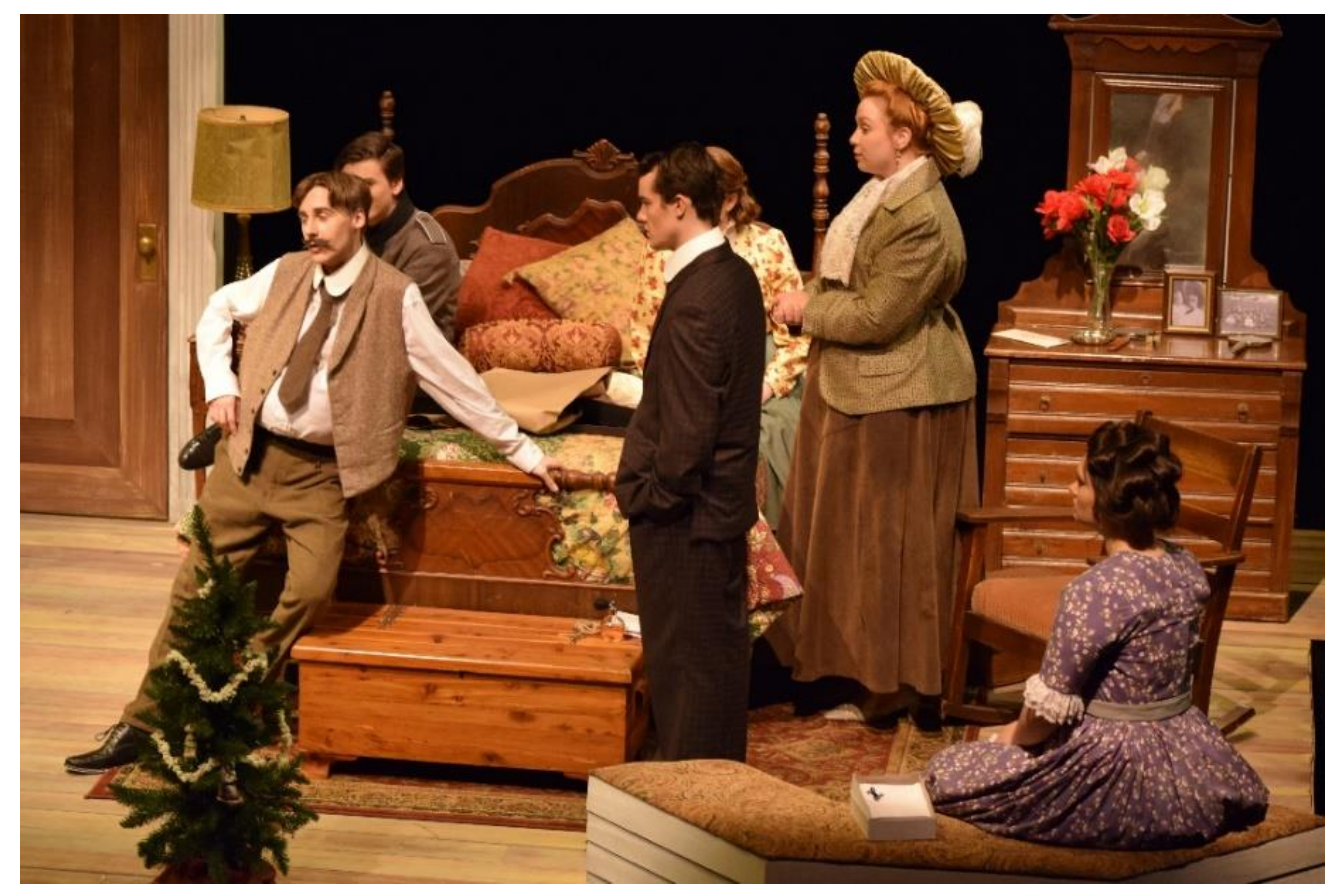

Figure 34: Bobby Pate (Zachary Powers), Brother Vaughn (Woody Pond), Horace Robedaux (Isaac Snyder), Mrs. Vaughn (Madeline Hintz), Elizabeth Vaughn (Margaret Dransfield), and Miss Ruth Amos (Brianna Bowers) in Valentine's Day, scene 2.

Aunts Lucy \& Sarah

Courtship

\section{Character Information:}

Lucy and Sarah are the sisters of Mrs. Vaughn. Lucy was widowed at 32, and was left with four children to take care of on her own. Her late husband was 20 years her senior. He was 
also a captain in the confederate army. It is rumored that Lucy has always been in love with her first cousin, Irvin Murray. Since their love was forbidden, nothing ever came of it, and although she most likely still loves him, they have been separated from one another for quite some time. Sarah is very much a gossip, and likes going to the graveyards to see what is written on the tombstones. She never married, but does not seem bothered by this fact.

\section{Research:}

With the idea in mind that Aunts Lucy and Sarah are much older than any of the other characters in Courtship, I pulled images that were dated somewhat earlier than the rest of my research. I wanted the Aunts to look out of touch with current fashion trends, but in slightly different ways. As the overall female silhouette had not changed too drastically in the 25 years prior to 1915, the easiest way to create a dated look for the Aunts was to adjust the shape of the sleeves on their dresses. Aunt Sarah, as a spinster, has had more time to herself in which to update her look, but has not always been the most stylish or alluring, try as she might. Therefore, I designed Sarah's costume with a type of sleeve which was popular for only a very brief time in 1902 (Figure 26). For Aunt Lucy, who was widowed and left with four children, I designed her look with a sleeve that might have hearkened back to the 1890s, to truly set her back from the fashion trends of the moment. Given that she had to take care of her children without a husband to help, it was clear that Aunt Lucy would not have had time, nor would she have cared much to keep her style as up to date as possible. 


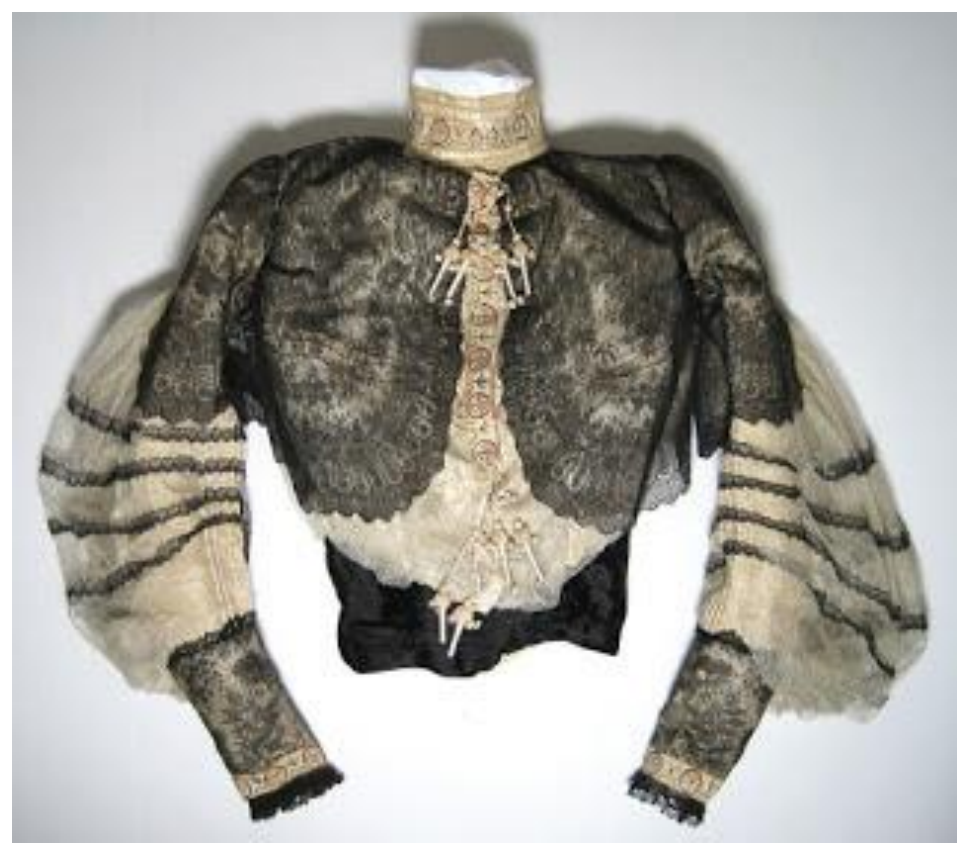

Figure 35: Style of sleeve which was popular in 1902 .

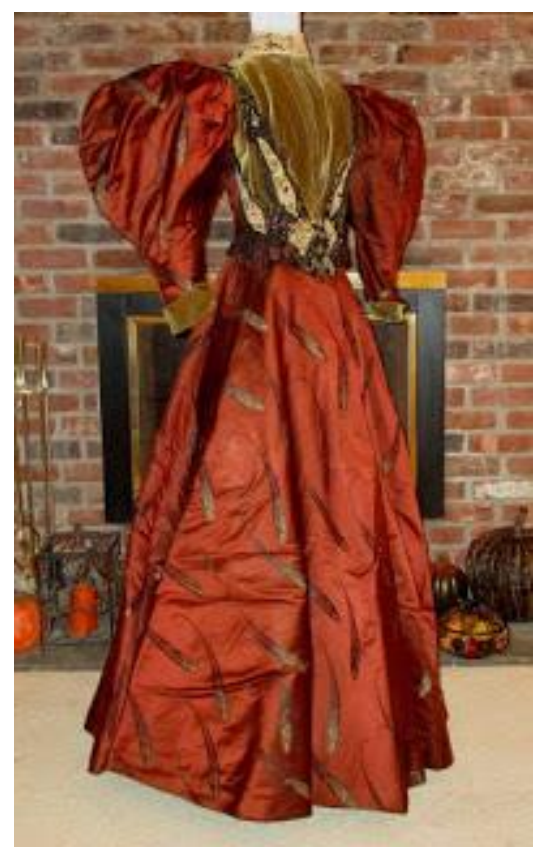

Figure 36: 1890s style dress, with gigot sleeves.

Outside of sleeves, and for general silhouette, I looked into severe styles of clothing that would appear stiff and mature. I carefully selected elements of the clothing of the two older women pictured in Figures 37 and 38 to incorporate into the styles of the two Aunts. In Figure 38, the pointed neck detail of the dress was my main interest, as I found the sharp angles with curved lines severe, and intimidating. For Aunt Sarah, I pulled the overly tight bodice, pictured in Figure 28, into her costume. With something so fitted, Aunt Sarah's figure could be emphasized along with her poor posture, brought on by age. 


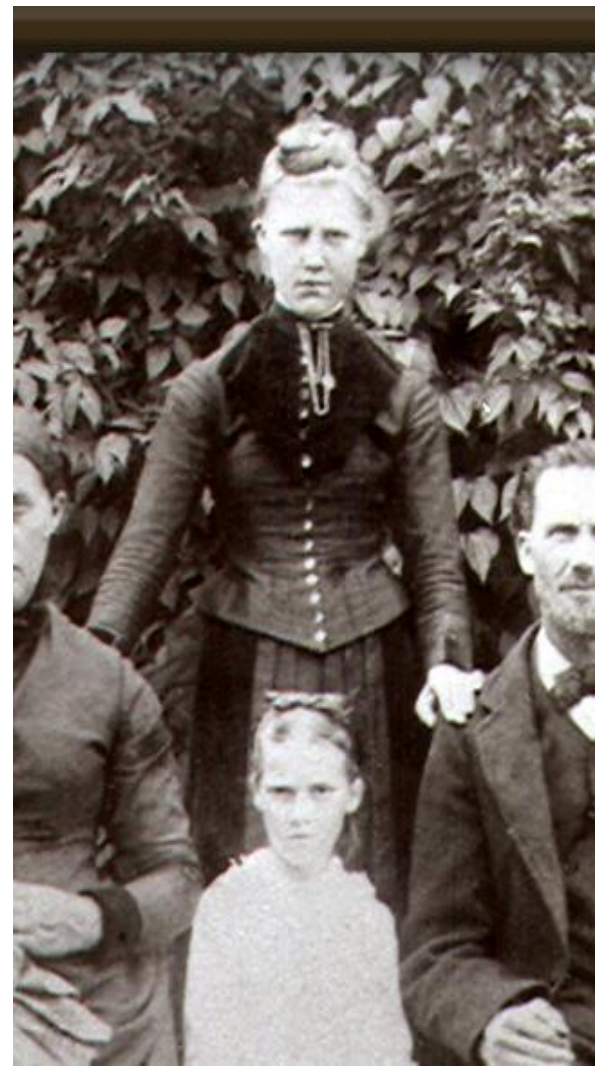

Figure 37: Research image for Aunt Sarah in Courtship.

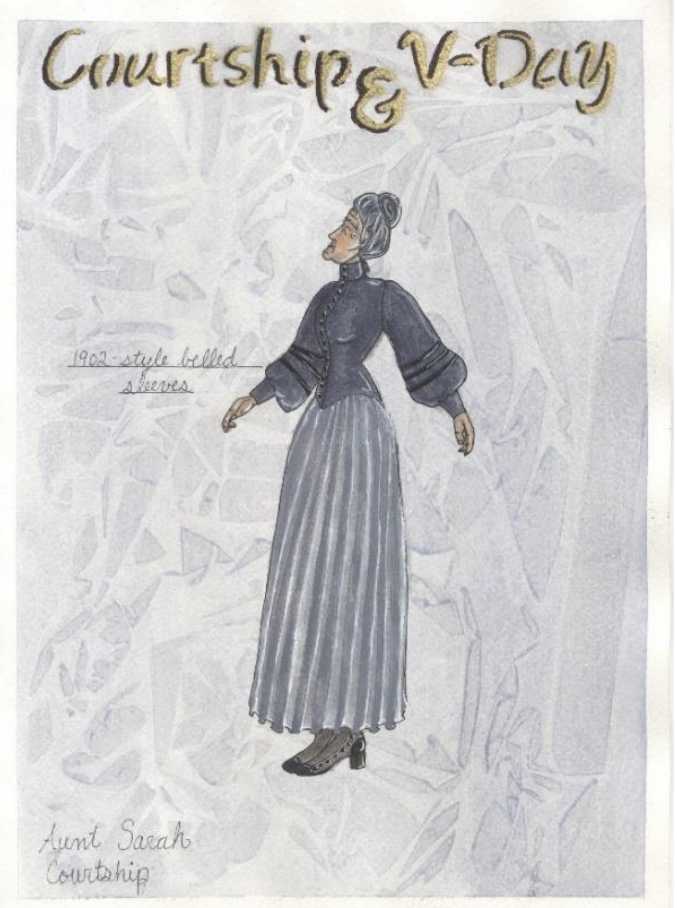

Figure 39: Final rendering for Aunt Sarah.

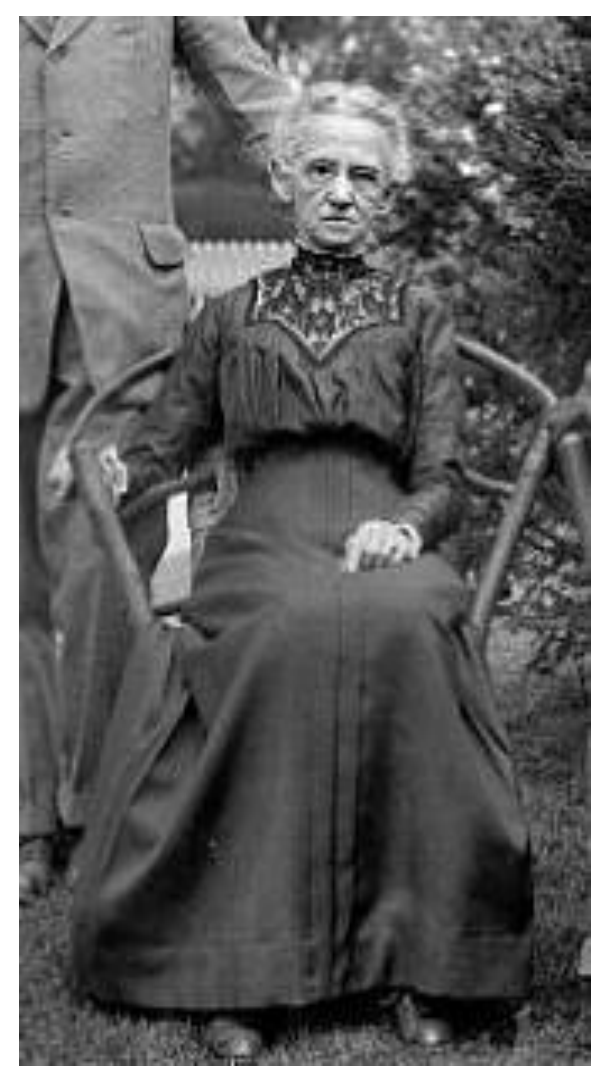

Figure 38: Research image for Aunt Lucy in Courtship.

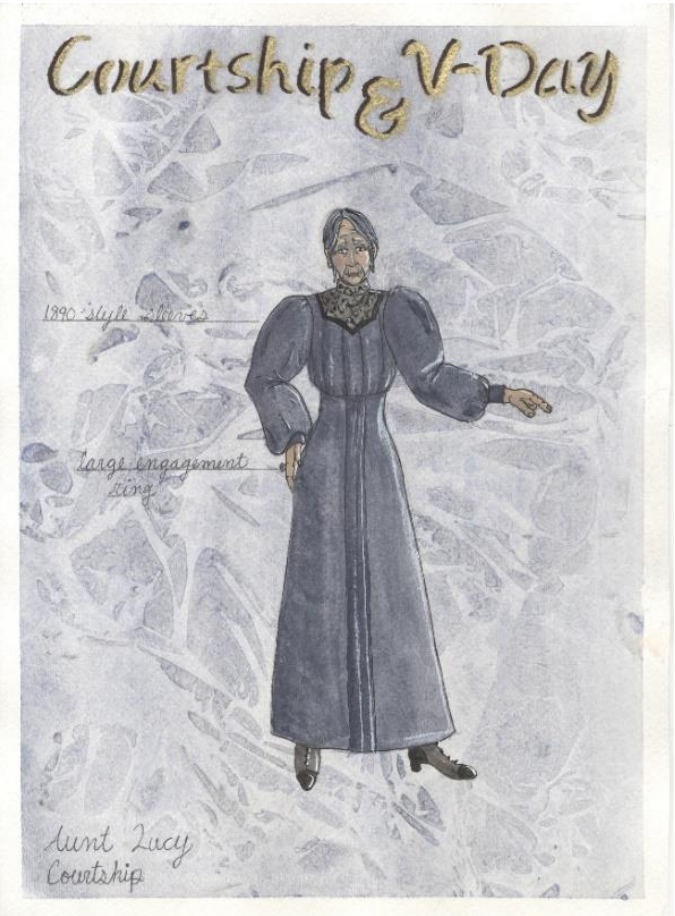

Figure 40: Final Rendering for Aunt Lucy. 


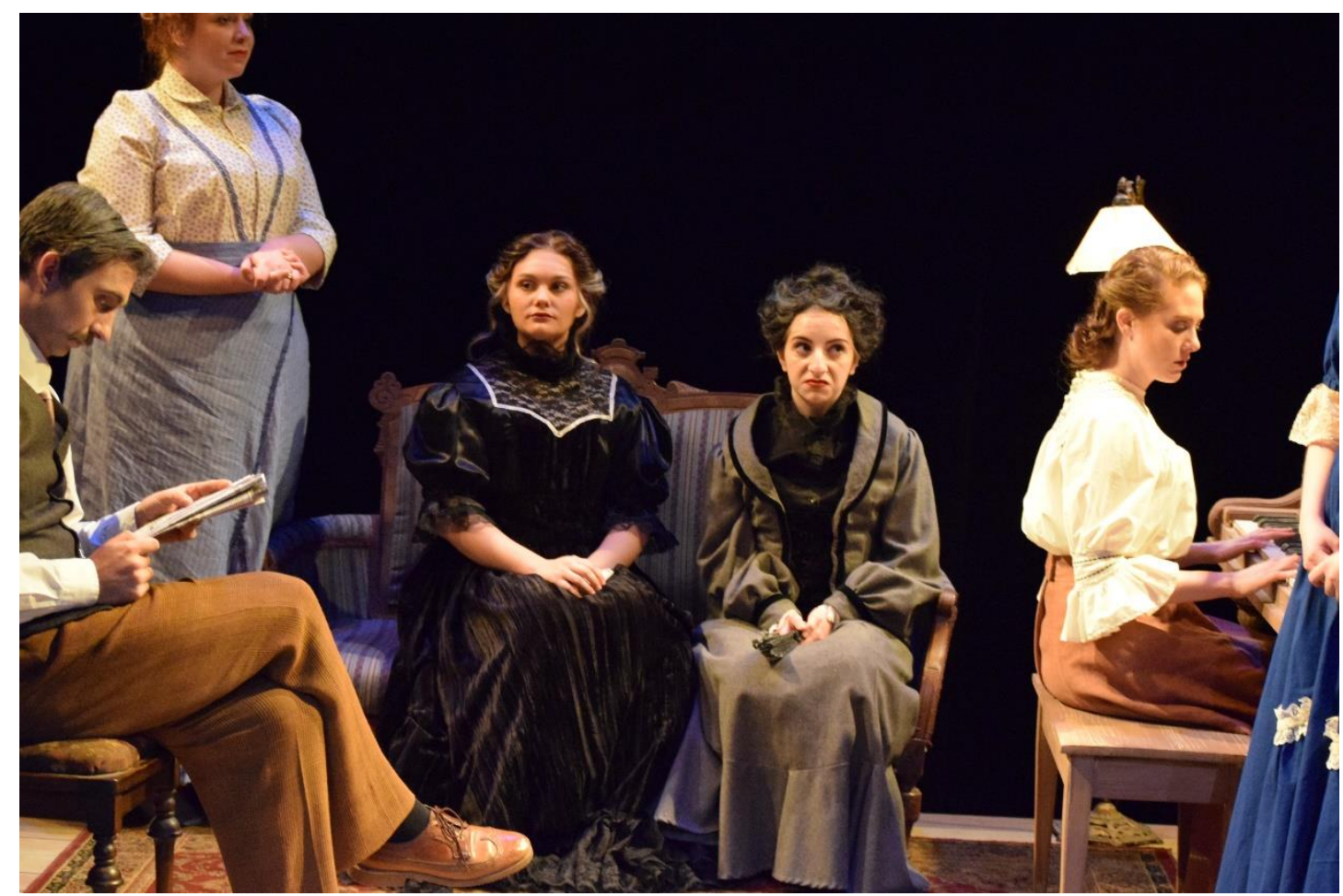

Figure 41: Aunt Lucy (Brianna Bowers) and Aunt Sarah (Katie Boothby) in Courtship.

\section{Horace Robedaux}

\section{Courtship}

\section{Character Information:}

Horace Robedaux is 26 years old, and when he shows up at the Vaughn household, he has just come from a dance. Horace often attends dances, just as his whole family always has, and this time it is mentioned that he is still wearing his tuxedo. Horace is in love with Elizabeth, but since he hangs with the "wild boys" he has a bad reputation in the eyes of some. Horace does not consider himself all that wild. He is a traveling salesman, and enjoys his job, but admits that he does wish to settle down someday as a merchant of dry goods and to, perhaps, have his own store. Horace was raised an Episcopalian, but he does not attend church often. Horace's mother was 18 when she had him, and Horace was 12 when his father passed away. He has been working, starting off as a clerk in stores since his father passed. Horace's mother now lives in Houston, and she is remarried. According to Mr. Vaughn, Horace never had authority in his life, which explains why he turned out the way he did. 


\section{Research:}

Tuxedos, and all suits, have the potential for so much minute detail, from pants hem length to pocket squares. For some, specific combinations of these minute details mimic a desired period style, or can give a suit some personal flair. In the case of Horace, all of his costumes were meant to be a little bit different. Each suit had slightly different hem lengths, style lines, and accessories which showed that his wardrobe consisted, perhaps, of many second hand items given his social status in the lower middle class. If Horace were a part of the upper middle class, there might be less variation in the fit of his clothing, as he would have newer suits which were all tailored in the way that was fashionable at the time.

While the research image in Figure 42 is very polished and distinguished, this was merely used as a starting point for the style of Horace's tuxedo. I knew that the tails on the tuxedo jacket would be too much for Horace, as he is simple, and not necessarily wealthy. A tailcoat would be too rich for him, so a straight cut jacket was chosen instead. I liked the shape of the lapels and the low riding tuxedo vest, however, and pulled those details into his costume design for Courtship. While Horace is drawn wearing a top hat in the final rendering (Figure 43), this does not necessarily mean that he is meant to wear the top hat the entire time that he is onstage. The top hat was an element of the costume that I hoped the actor could fidget with to keep his hands busy in moments of stillness or awkwardness between himself and Elizabeth or himself and Mr. Vaughn. The fabric of the tuxedo was a matte, textured wool with lapels which had a slight sheen to them. Because Horace does not have the means to own a tuxedo of the highest quality, the tuxedo was distressed using baby powder to look as if it had been worn many times, through many dances. 


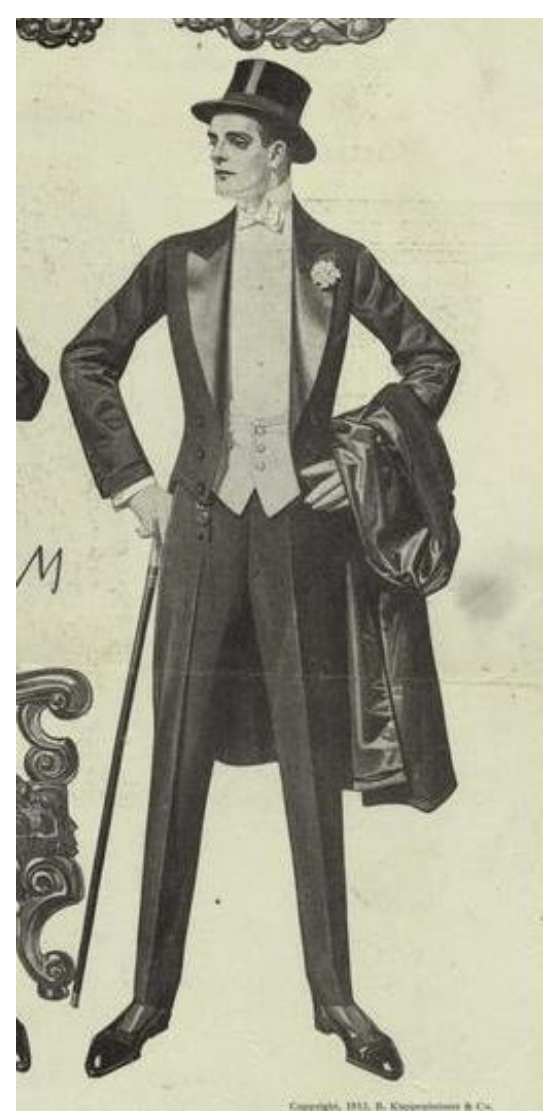

Figure 42: Research image for Horace's tuxedo in Courtship.

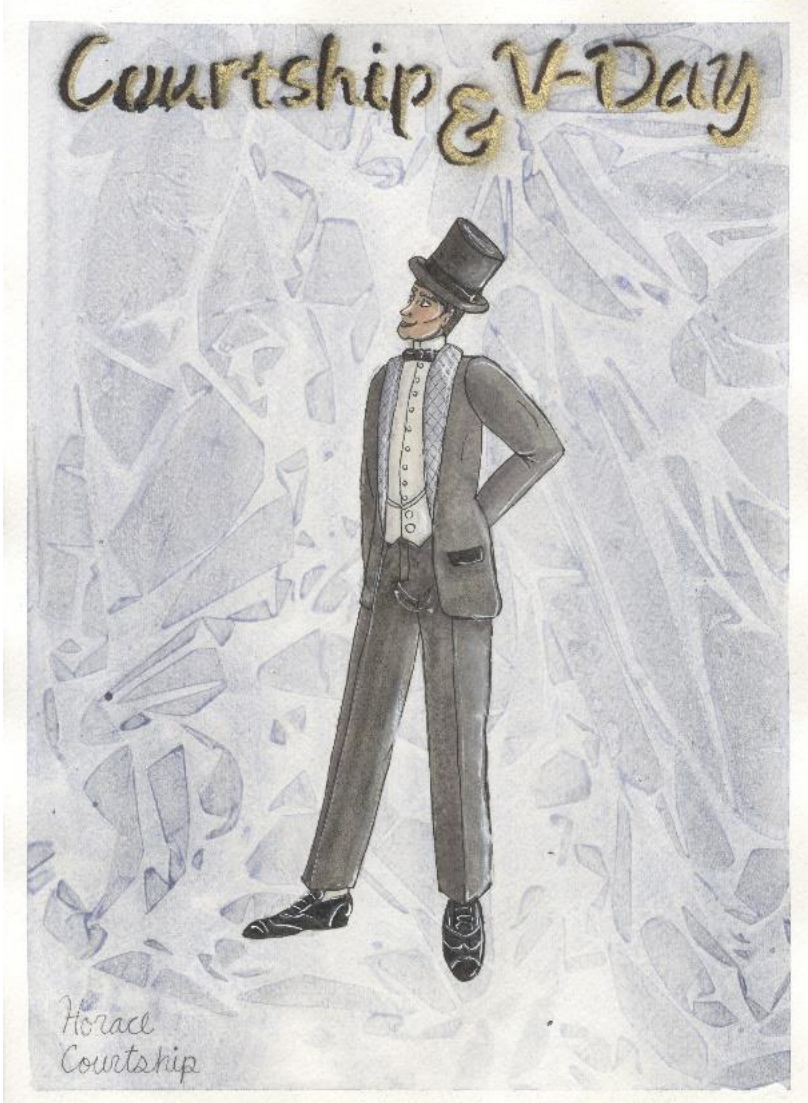

Figure 43: Final rendering for Horace in Courtship.

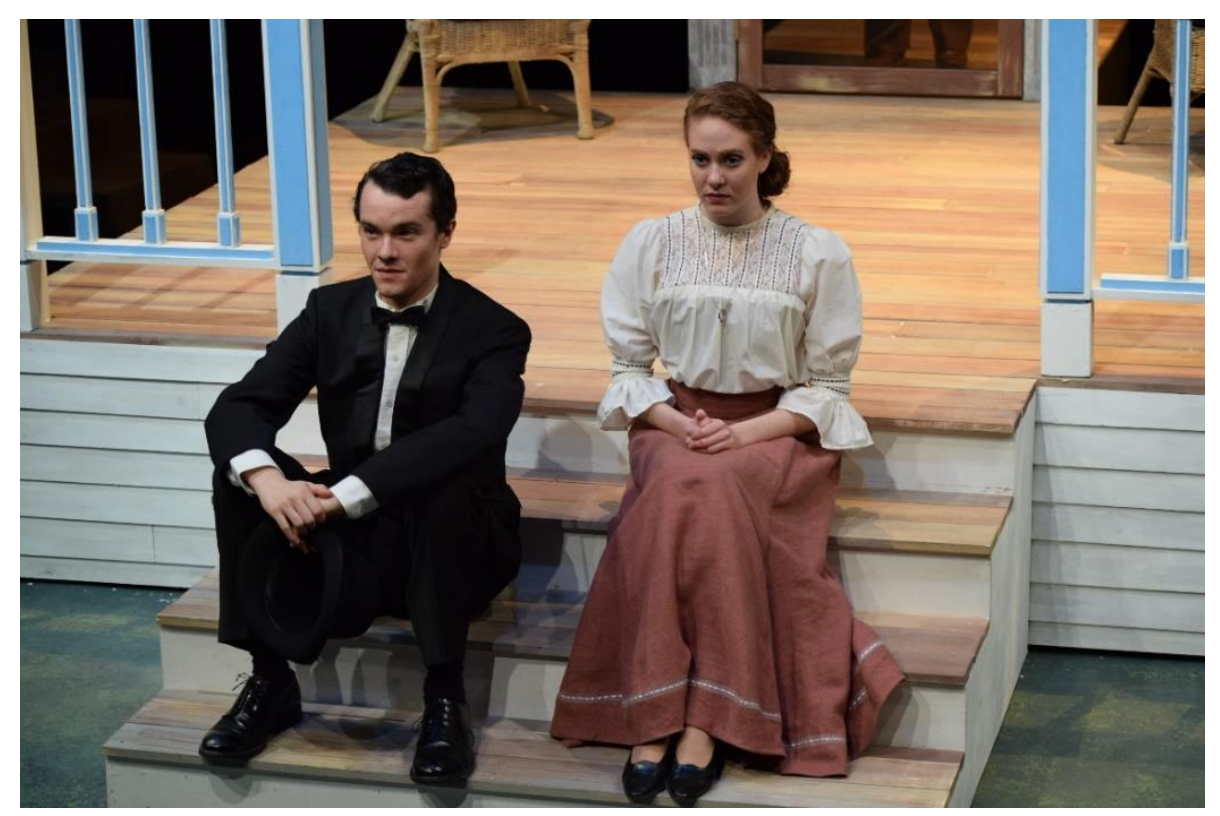

Figure 44: Horace (Isaac Snyder) and Elizabeth (Margaret Dransfield) in Courtship. 


\section{Valentine's Day}

\section{Character Information:}

Now 28 years old, Horace has eloped with Elizabeth and is working all the time in hopes of impressing Mr. Vaughn. Horace never exchanges gifts with his family, but was hopeful for a change in that tradition this particular Christmas because he and Elizabeth are expecting a baby. Horace does not care for his stepfather. Since her remarriage, Horace's mother and stepfather have not come near him, and this fact hurts him. Horace tells Elizabeth a story about how his mother killed his pet chickens when he was young because they needed food. He talks of how this event scarred him deeply, as he loved his pet chickens very much. Horace feels that he is an orphan, even though he is not technically parentless. He feels that he has truly found himself a home with Elizabeth, after almost a full year of marriage coming up in one month, on Valentine's Day.

\section{Research:}

Because Horace and Elizabeth eloped without the blessing of her father, and due to Horace's lack of parental presence in his life, the newlywed couple does not have much money to spend on luxuries. For this reason, I designed a worn union suit for Horace's pajamas (Figure 32), and a three-piece sack suit for Horace's every day wear. The costume shop was able to take on the build for the vest and pants portion of this suit, but was not able to build a matching suit coat. With this in mind, I realized that the use of a mismatched suit coat would be even more appropriate for Horace than my original design. A mismatched suit would point to the fact that Horace might not always have the money to buy a whole suit, and so has had to work with the bits and pieces that he has managed to accumulate throughout his life. Because the costume shop was set to build the pants and vest for this suit, I was able to be more specific about the fabric, cut, and fit of this particular costume. Knowing that a heavier weight wool would give the look a lived-in and comfortable feel, I opted for a loosely woven pinstripe wool over other lighter weight suiting options. Because this particular suit was meant to be worn in stages, it was important that all pieces hit at the correct place for the period. For the pants, this meant that they should sit on the natural waist, much higher than modern suit pants. The length of the vest was cut to sit just below the natural waist to complement the height of the pants. The light grey color was chosen because it felt much more informal than the black of the tuxedo or the deep grey 
houndstooth of Horace's Christmas suit. I thought it was important to show a large juxtaposition between the everyday Horace and the Horace who is trying to impress his parents-in-law.

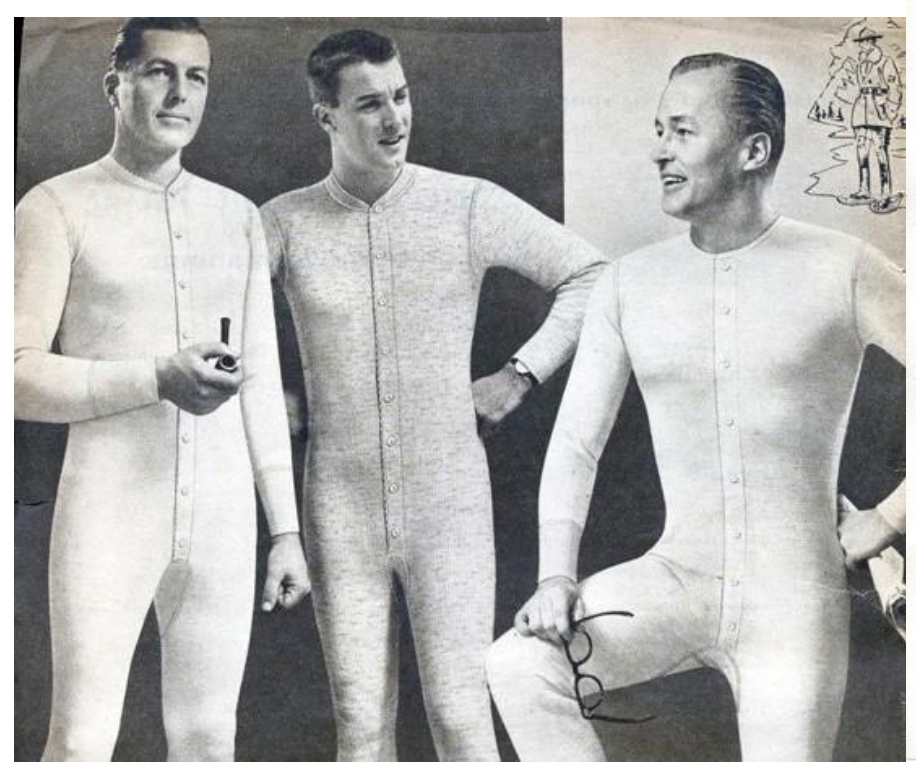

Figure 45: Research image for Horace's union suit which was worn as pajamas in Valentine's Day, scene 1.

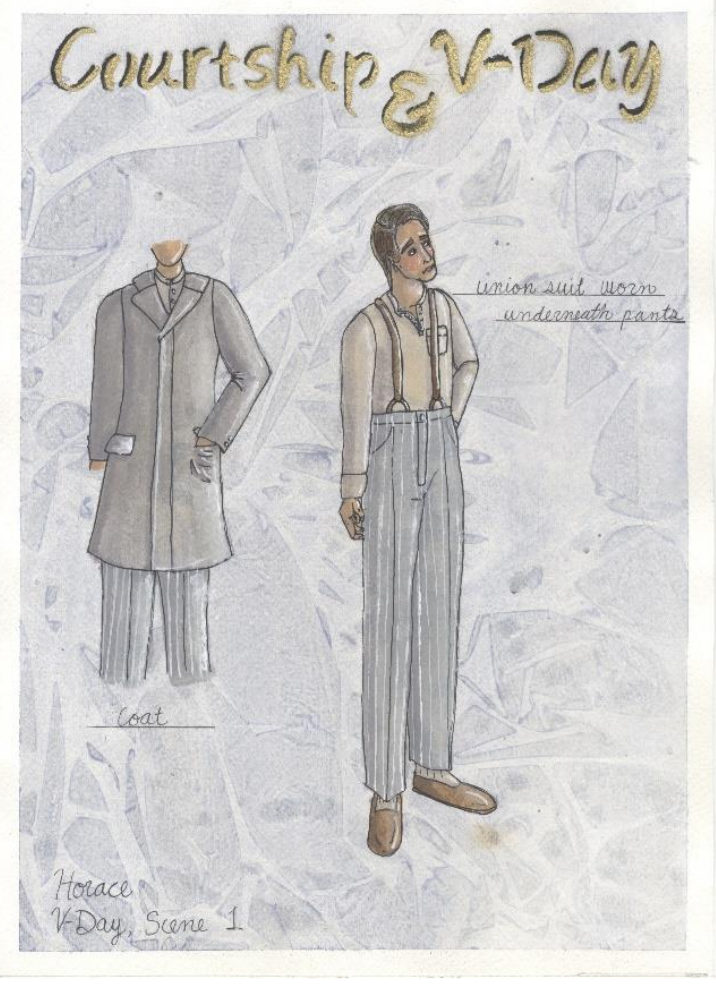

Figure 46: Final Rendering for Horace in Valentine's Day, scene 1.

It is appropriate to assume that Horace would have at least one good, crisp, clean suit set aside for special occasions such as Christmas. It was imperative that this be a three-piece matching suit which was well tailored to his body. This would be seen in contrast with his everyday wear, which is not fully matched. For Christmas and the impending visit of his wife's family, Horace dons a very nice pocket watch and tries to make himself as presentable as possible in hopes of finally being accepted by the Vaughn family. The pattern of his suit is a subtle, yet dignified houndstooth, which gives Horace a sense of classiness while still showcasing his individuality. I had originally considered making Horace's Christmas suit plain black, similar to the research image in Figure 47, but I wanted to make sure that he stood out from Mr. Vaughn in both look and personality. Mr. Vaughn would most certainly dress himself in black for a formal occasion, which prompted me to choose a dark grey patterned suit for 
Horace. Black can read as austere, and by keeping Horace in grey I hoped to both soften his rough edges as well as create a visual contrast with Mr. Vaughn.

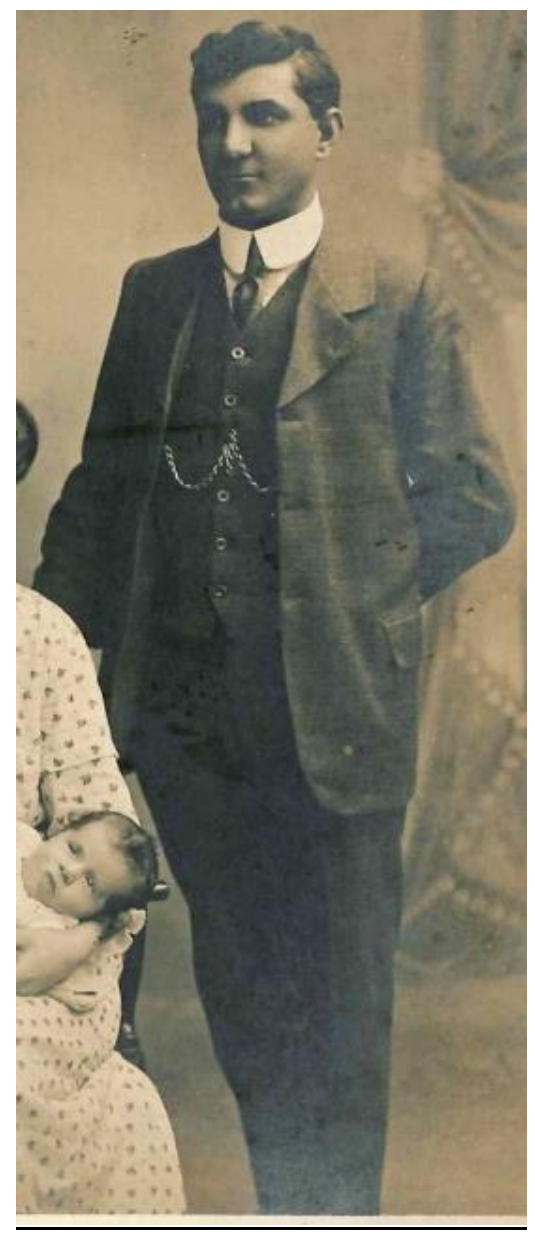

Figure 47: Research image for Horace's Christmas suit in Valentine's Day, scene 2.

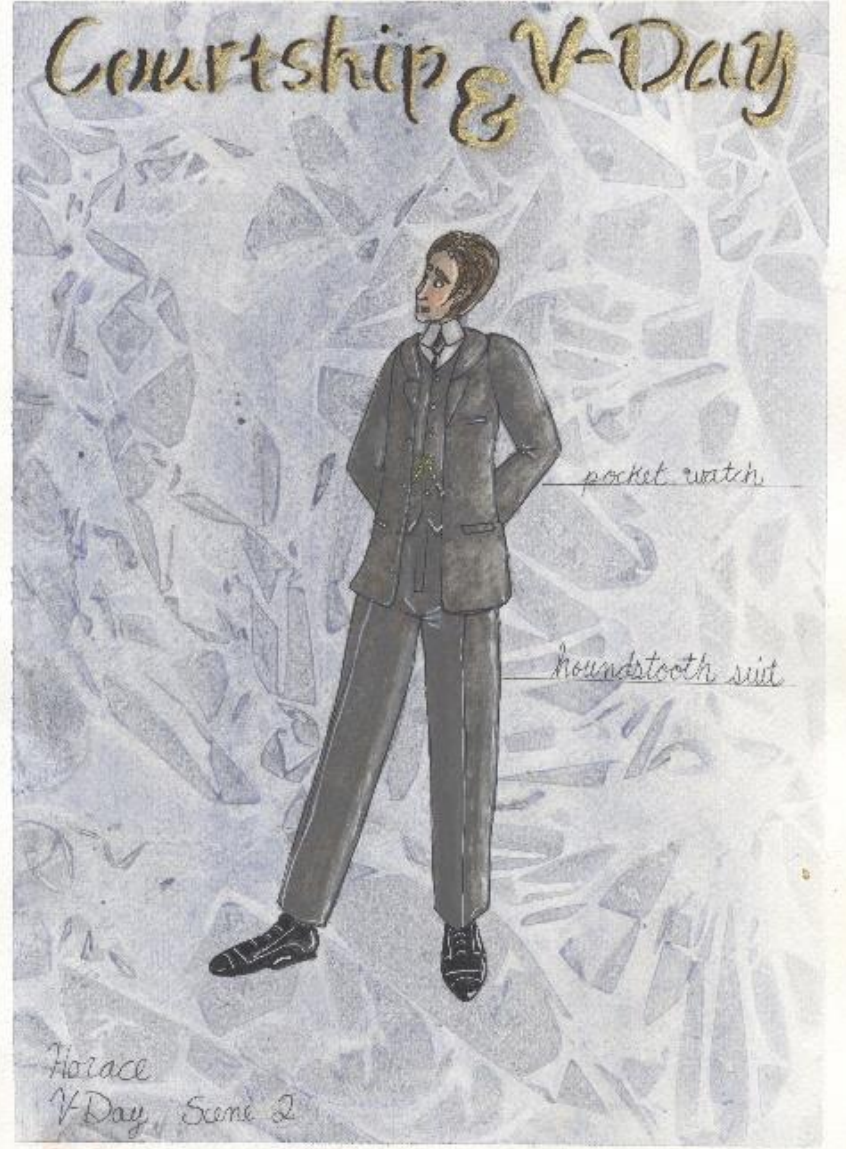

Figure 48: Final rendering for Horace in Valentine's Day, scene 2. 


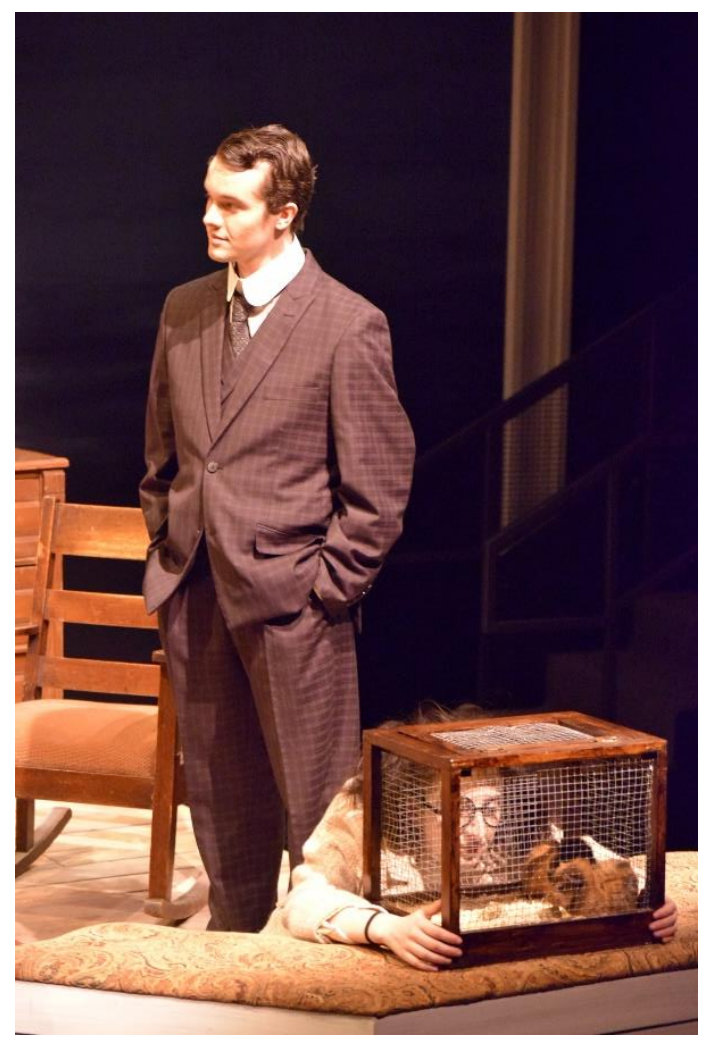

Figure 49: Horace (Isaac Snyder) and Bessie (Katie Boothby) in Valentine's Day, scene 2.

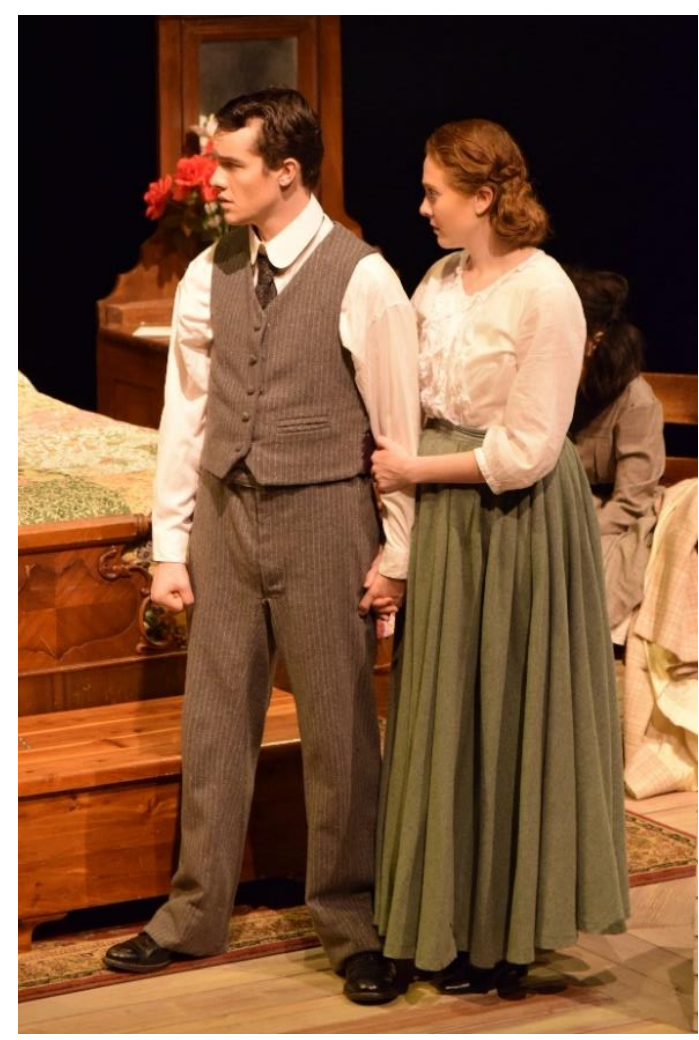

Figure 50: Horace (Isaac Snyder) and Elizabeth (Margaret Dransfield) in Valentine's Day, scene 3.

Steve Tyler

\section{Courtship}

Steve Tyler is the son of George Tyler. He is kin to Horace through marriage. According to Horace, Steve has a big mouth, and according to everyone else in town, Steve is considered a wild boy. Steve accompanies Horace on his way over to pay his respects to the Thomas family. Both are still dressed in their tuxedos. As neither Steve nor Horace are very rich, it seemed appropriate that the style of their tuxedos would not necessarily be similar. Steve's tuxedo would be an older style, well-worn suit, as Steve has frequented the town's dances for quite a few years. Figure 51 is a variation on a tuxedo from the period which caught my attention due to the width of the lapels. I thought that the wider lapels embodied the breadth of Steve's personality, which is rather boisterous. The energy and humor that Steve brings to the table is reflected by the boxy shape of the coat as well as the casual manner in which he wears it. The relaxed nature of Steve Tyler's personality allows for a good deal of play within the costume. This tones down the 
formality of the tuxedo, as Steve may be likely to play with his hat, carry his jacket on his arm, or perhaps even loosen his tie.

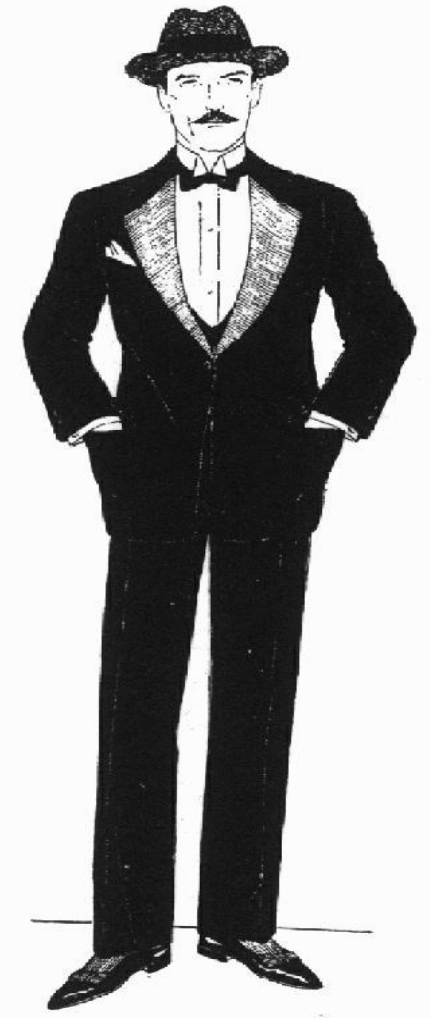

Figure 51: Research image for Steve Tyler's tuxedo in Courtship.

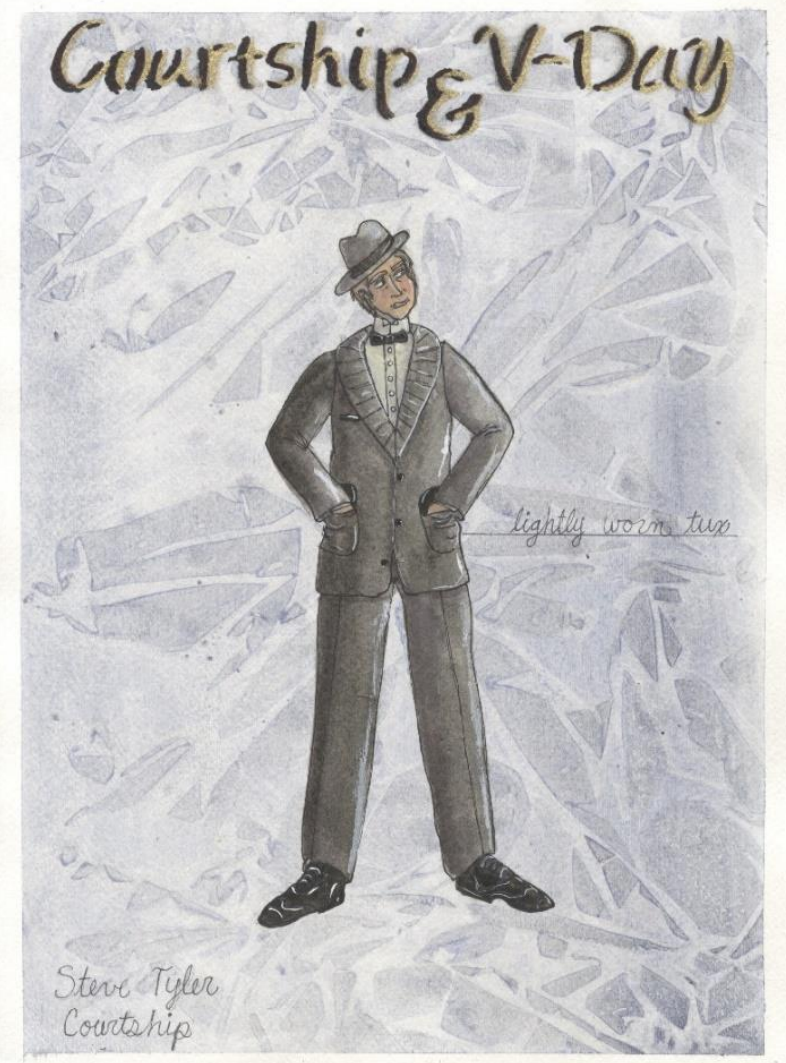

Figure 52: Final rendering for Steve Tyler in Courtship.

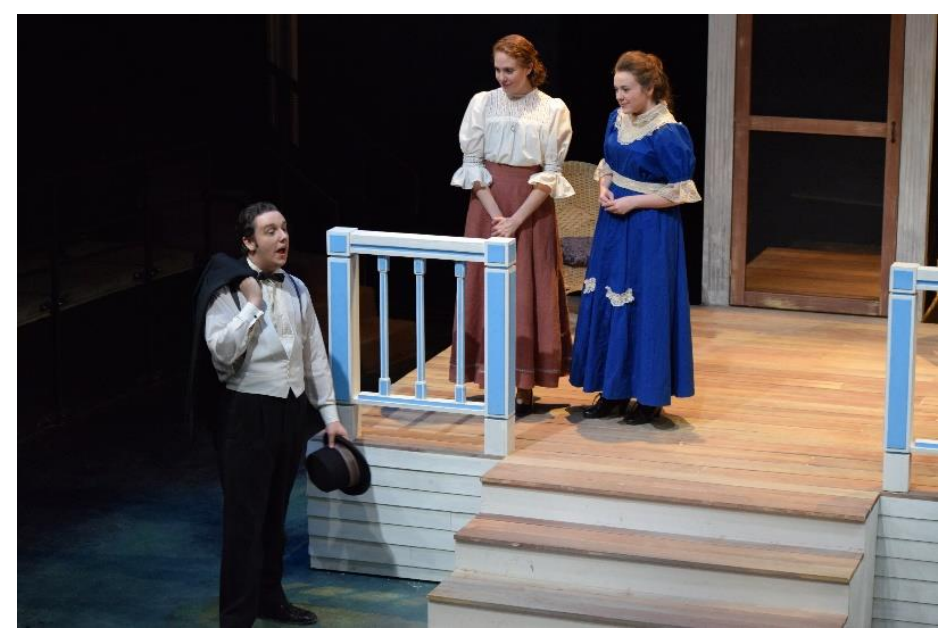

Figure 53: Steve Tyler (Joshua Clevenger), Elizabeth Vaughn (Margaret Dransfield), and Laura Vaughn (Mallory Robson) in Courtship. 


\section{Valentine's Day}

Steve spends much of his time taking care of his father, and spends his Christmas frantically searching for all of the people to whom his father might have gifted his family's savings in hopes of getting the money back. For this venture, I imagined Steve to be dressed in an everyday suit that is perhaps wrinkled because it has been hastily thrown on. As Steve's father, Mr. George Tyler, is on the loose with a good deal of money, Steve is in a frantic mode, and has not given much thought to what he might be wearing. Figure 1 (pg. 16), which was used as inspiration for Steve Tyler's costume in Valentine's Day (Figure 2, pg. 16) shows a young man in a yearbook photo. The stance and attitude of this young man, along with the manner in which he uses his suit's pockets reminded me very much of Steve. For this reason, I transposed this style onto the character in hopes that it would help inspire the actor to bring out the slouchy, kind hearted-ness that I saw within this character.

\section{$\underline{\text { Bessie Stillman }}$}

\section{Valentine's Day}

Bessie is a young girl from the neighborhood; her family has lived in town for 10 years. Bessie is very naïve and self-absorbed. She cannot remember Elizabeth's name correctly, and many times refers to her by her mother's name: Mary. Because Bessie is a young child, her dresses are shorter than her adult female counterparts, as was the tradition for children of the period. The young girl in the pleated dress in Figure 53 shows a very juvenile style of clothing. Since I was charged with making a 21 year old actress look like a 12 year old child, the boxy nature of the pleated dress helped to mask the actress's curves and create a younger overall look for the character. At Bessie's age, she might have already been training for corset wearing, but the decision was made for this particular character that she would be without a corset to allow her the ability to run, jump, and flop around the stage as she pleased. Because Bessie is still quite immature, her hair and costume needed to be messy, worn, and dirty to show that she still likes to play outside. Bessie's hair was put into messy, greasy, uneven pigtails to show her carefree and childish spirit. Her clothing was, likewise, distressed with general wear as well as dirt in order to make her clothing seem as if it might be second hand. Even Bessie's dress for Christmas day, while nicer than her every day look had some wear to it to show that Bessie was not necessarily the first owner of this dress. Each of Bessie's costume pieces were made or chosen so 
that they did not fit her perfectly. Children often wear clothing which is either slightly too large or slightly too small for them, as they are constantly going through growth spurts. Bessie's coat was designed to be old and ratty as well as too tight in the shoulders, while her dresses were designed to be slightly baggy and otherwise ill fitted. The choice to put Bessie in a plaid print was made to mirror Bessie's eclectic and busy personality. The oversized glasses that she wore were supposed to look as if they could have been handed down to Bessie by an uncle. Although the final pair used in the show had tortoise shell frames, which is not a historically accurate choice, the thick-framed glasses evoked the gawkiness of a young child wearing an adult's glasses better than the wire framed glasses of the period.

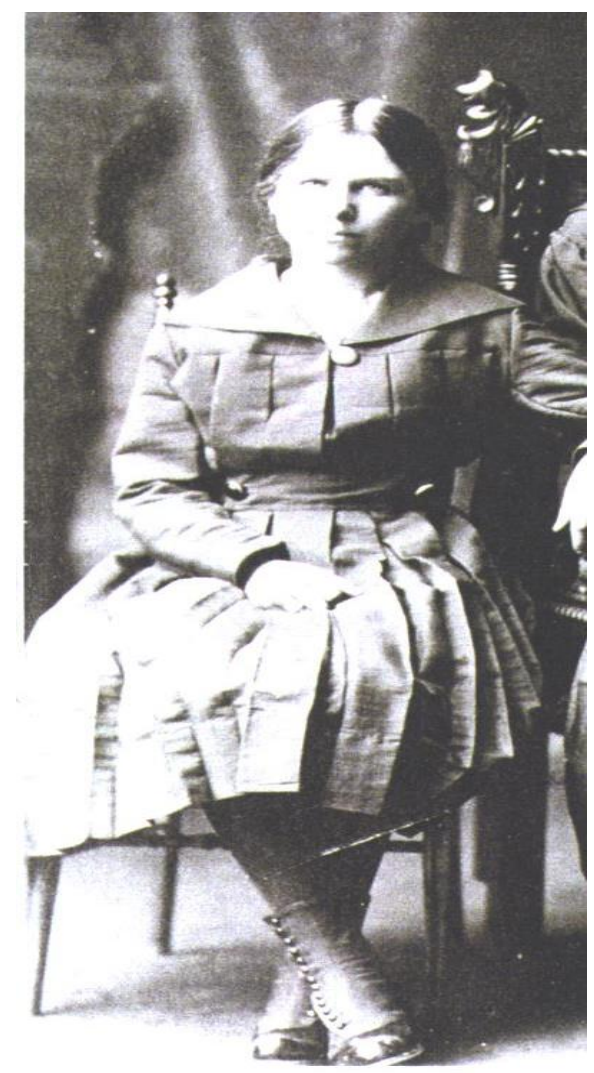

Figure 54: Research image for Bessie's dress in Valentine's Day, scenes 1 and 2 (originally designed for scene 2).

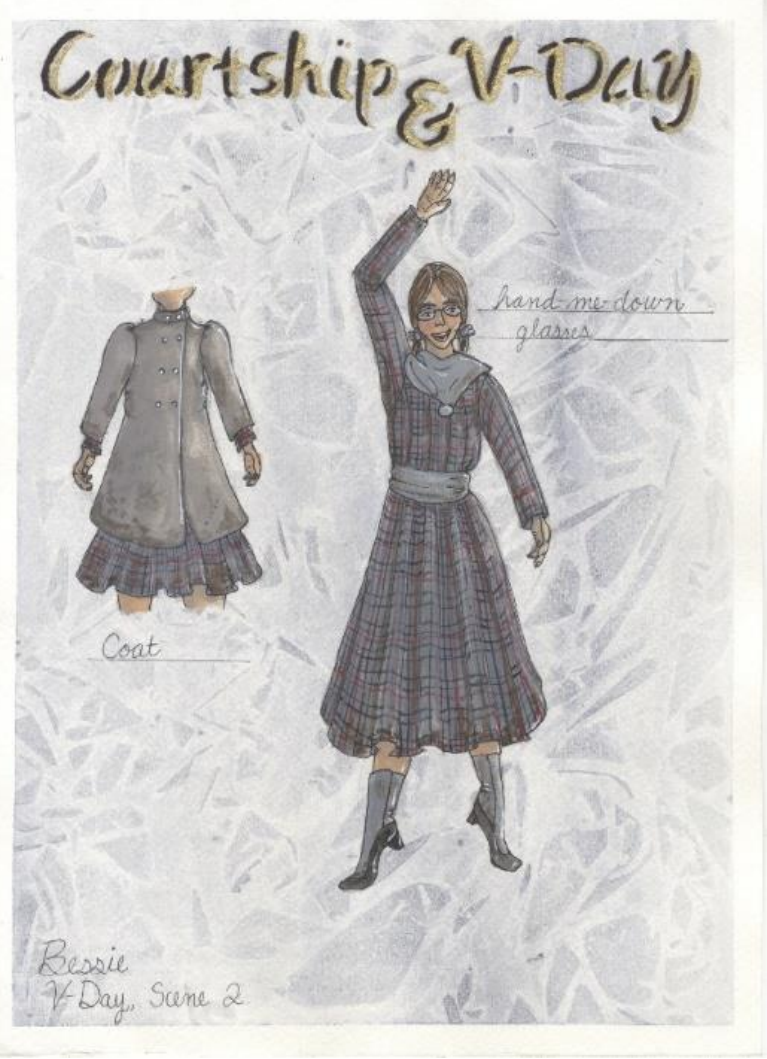

Figure 55: Final rendering for Bessie in Valentine's Day, scenes 1 and 3 (originally designed for scene 2). 


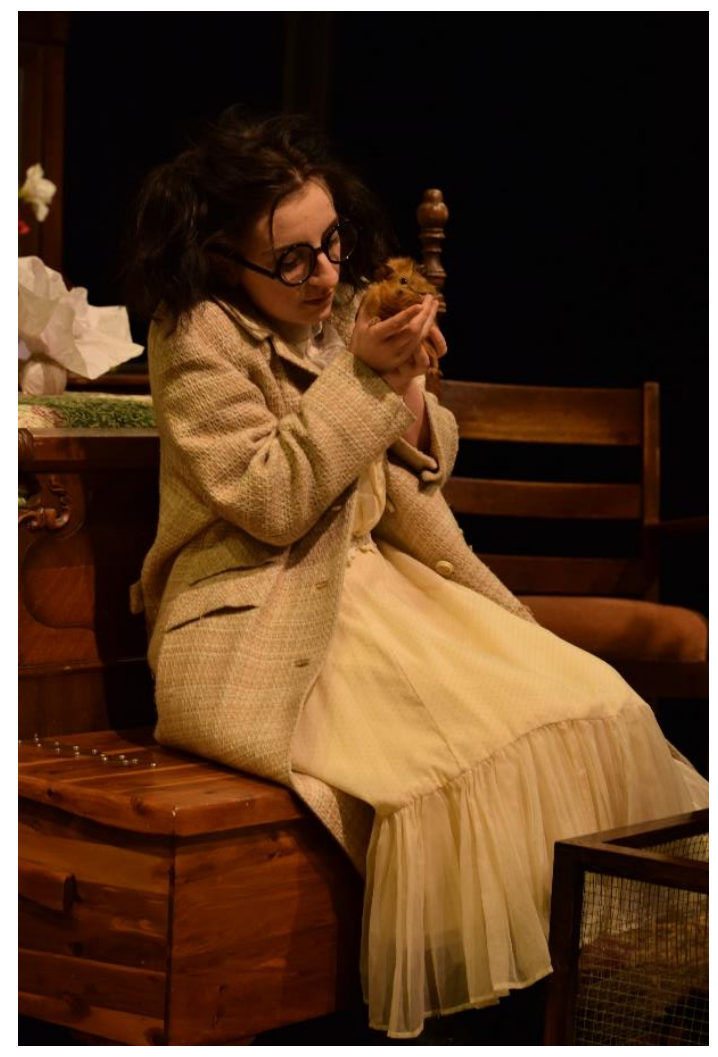

Figure 56: Bessie (Katie Boothby) in Valentine's Day, scene 2.

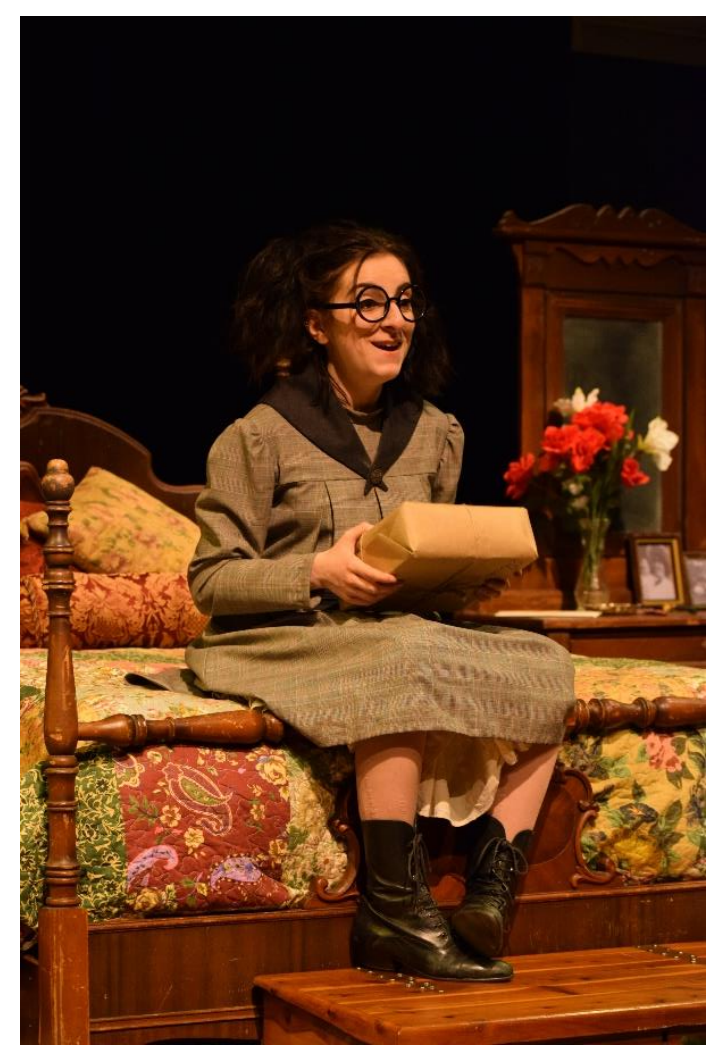

Figure 57: Bessie (Katie Boothby) in Valentine's Day, scene 1.

George Tyler

Valentine's Day

George Tyler is a wealthy man, and is kin to Horace by marriage. He was in love with Horace's Aunt Mary, but he married Horace's cousin Sarah instead. Mentally, George is not all there, but the town lets it slide. He has fits of craziness which have caused him to believe that his wife was poisoning his food, to run around naked in the front yard, and to take $\$ 15,000$ out of the bank to divide and give as gifts to his colored friends and family for Christmas. When George finds out from Horace that Aunt Mary is dead, he falls into one of his fits brought on by grief and runs off to the river bottoms. George is difficult to track down because he knows his way around the river bottoms so well, but once the authorities finally have a hold on him, he is overwrought with guilt for how his life has turned out, and kills himself.

George Tyler's character offers the opportunity to show an extreme visual transition in a short amount of time. Although he is mentally unstable, this key fact is not necessarily apparent on his good days. George's look should therefore mirror the styles worn by everyone else in the 
lower middle class on any given day. His suit is mismatched, which showcases his station in the social hierarchy, and the fit of his clothing is not entirely correct, which shows a fluctuation in weight within a short period of time, perhaps related to his mental illness. In scene 1 of Valentine's Day, George's costume is as stylish as a man of his station would normally appear, so as not to cause alarm in the audience as they first see him. The fabric of his suit is woolen, with loosely spun fibers which give the look an organic texture. The suit's clean appearance and decent quality indicate that some amount of care has been taken in the purchasing of this outfit. Through his conversation with Elizabeth, George eventually begins to display signs that he is nearing another mental break. This directs the audience's attention towards George. The next time that he enters, George looks much the same, perhaps a little sweatier than before, and a little less well kempt with the top button on his shirt opened, a pant leg tucked up, and a suspender which has become partially detached from his pants. For George's final appearance, his look is as disoriented as his mental state. He has been running through the river bottoms, and so his clothing must be muddy, torn, and sweaty. He is missing a shoe, one side of his suspenders has come completely undone. In short, this final look is the culmination of his mental illness manifesting itself in a physical situation. His look must be extreme and express the great struggle happening within his head, as the audience must believe that this character is on the brink of taking his own life. The audience must also, however, feel badly for the man, which can be cued by the reaction of others in the scene towards him, but also by the way he dresses. George Tyler's final costume appears almost as if a child has been charged with dressing himself. George, in his crazed state, unable to think things fully through, looks pitiful, as if he is barely capable of putting together a simple outfit for everyday wear. 


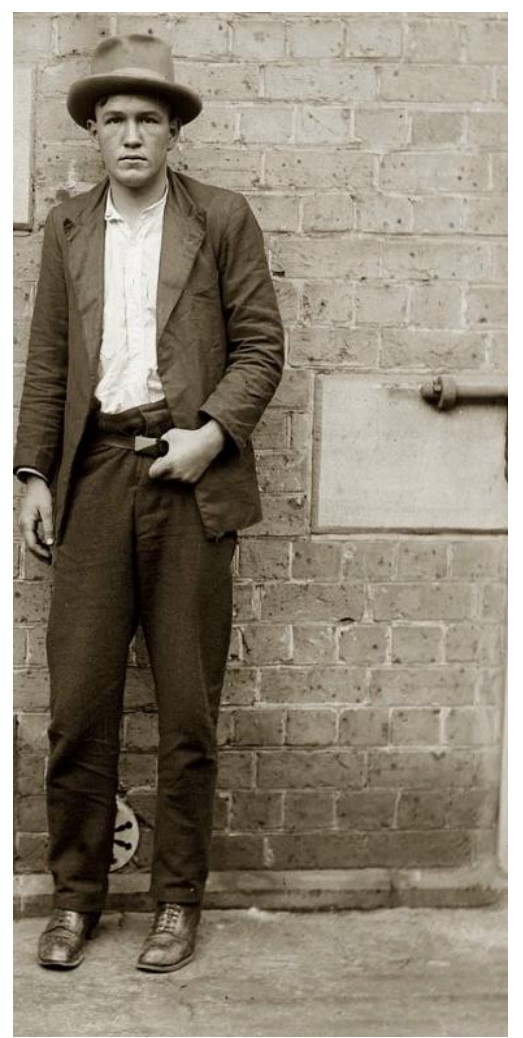

Figure 58: Research image for George Tyler in Valentine's Day.

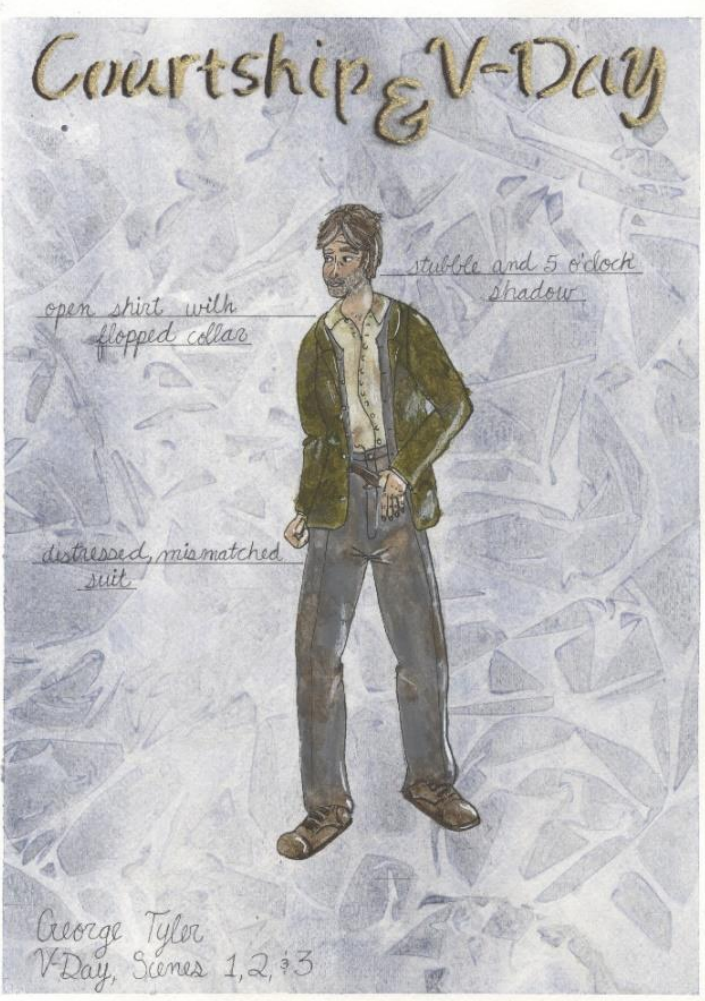

Figure 59: Final rendering for George Tyler.

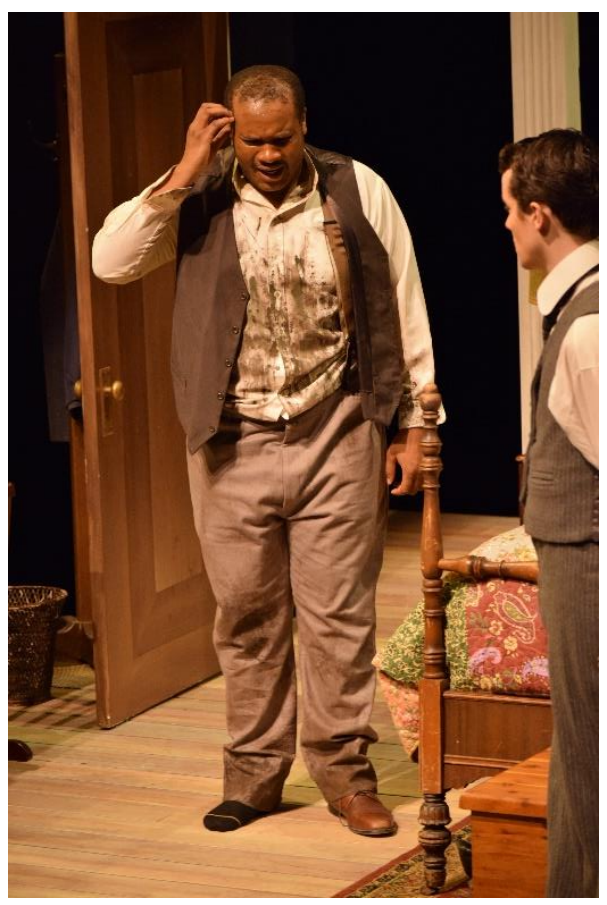

Figure 60: George Tyler (Lonnie Simmons) in Valentine's Day, scene 3. 


\section{Bobby Pate}

\section{Valentine's Day}

Bobby Pate is the son of Mrs. Pate, the owner of the house where Elizabeth and Horace are renting a room. Bobby is a drunk who comes around whenever he feels the urge, and tells stories, some of which are true, and some of which are perhaps confused versions of the truth, if not outright lies. Bobby is a whisky drinker and a gambler, and sometimes sleeps with no clothes on, but according to a fellow tenant in the Pate house, Miss Ruth Amos, he is gentlemanly when sober. Bobby is a short man, and had a very tall wife who left him because she could not stand the "climate" in Texas. Bobby's mother told him that she considered his wife to be common folk, and was not surprised when she left. When World War I began, Bobby tried to enlist, but the army would not take him, not even as a volunteer. They told him he was too much of a drunk to be taught new skills.

As Bobby Pate is a drunk of the lower middle class, I chose a brown suit with a nubby, woolen texture that would appear old and well-worn from a distance. As Bobby is a perfect gentleman while sober, I wanted to show the transition from slightly sober Bobby to drunk Bobby in the way that he wore his clothing. Bobby does not present himself to be the type of person who cares much for the latest fashion trends, so I kept him in the same outfit, but in various stages of undress throughout the play. Bobby starts out fully and correctly clothed, but as he is already drunk upon entering the stage in scene 1 of Valentine's Day, he almost immediately opens his suit jacket. Each time he enters the scene anew, Bobby has changed his appearance somewhat by unbuttoning the neck of his shirt, undoing his vest buttons, releasing a suspender, untucking a shirt tail, or mussing up his hairstyle. In terms of makeup, I decided that Bobby should have a perpetually red nose from all of his drinking. Since undergraduate actor, $\mathrm{Mr}$. Zachary Powers has a very slim frame, I decided to round out his stomach area with some padding in order to give Bobby a beer belly. The excessive weight in his stomach on top of Mr. Powers very small frame offers the audience a comical juxtaposition. This gives the character an awkward and clumsy feel, which translates wonderfully into his drunken nature. 


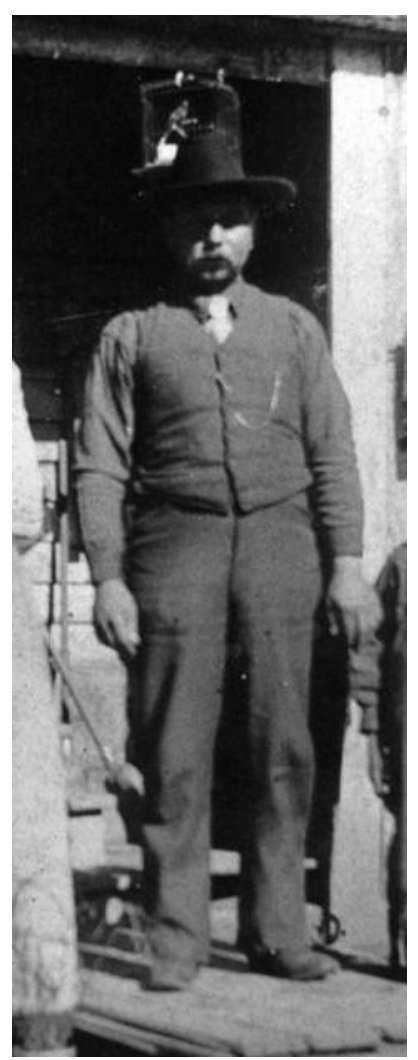

Figure 61: Research image for Bobby Pate.

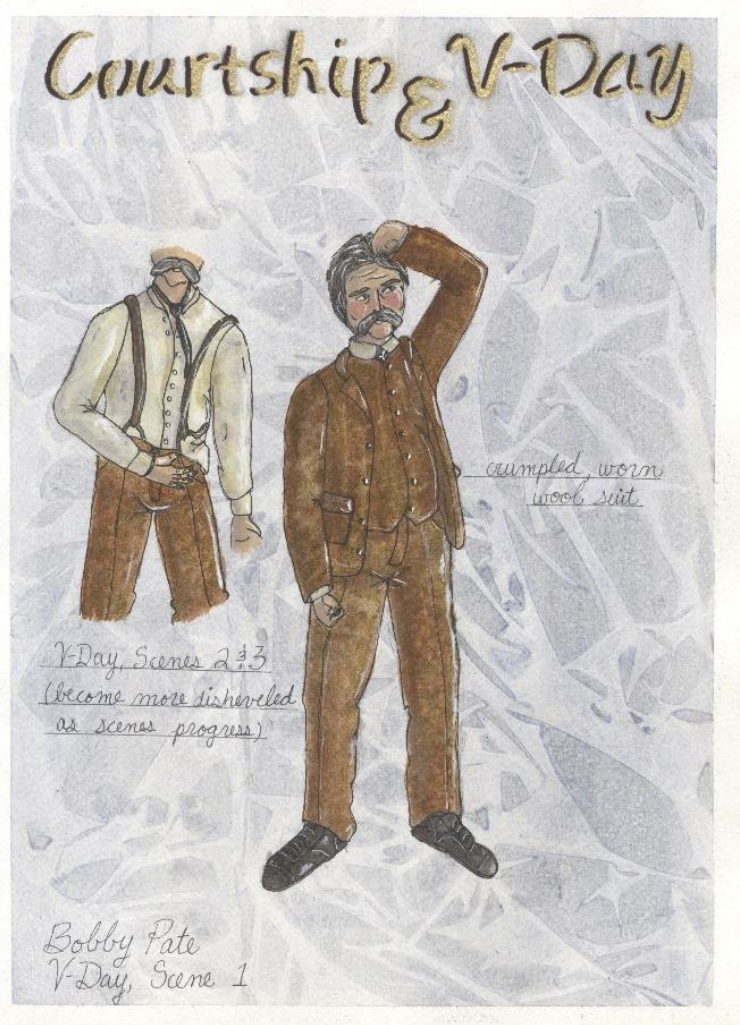

Figure 62: Final rendering for Bobby Pate.

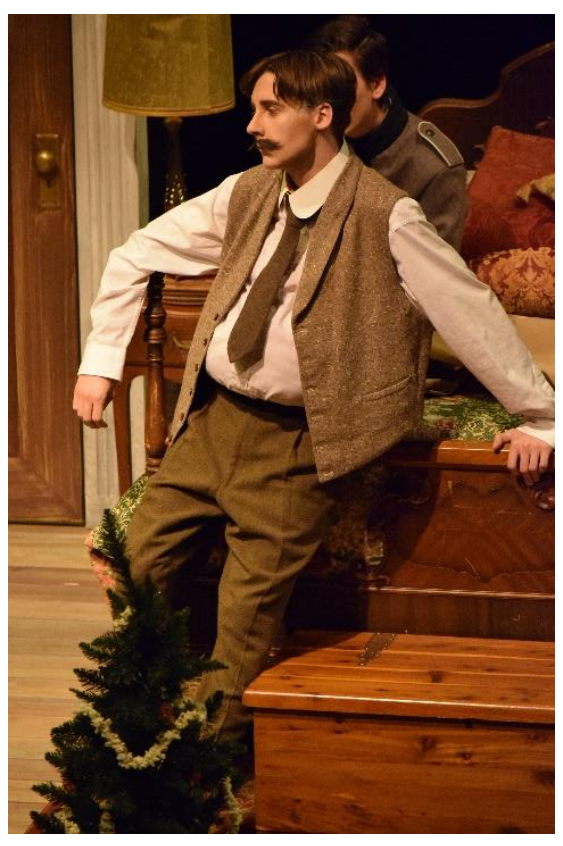

Figure 63: Bobby Pate (Zachary Powers) in Valentine's Day, scene 1. 


\section{Ruth Amos}

\section{Valentine's Day}

Miss Ruth Amos is a tenant in the Pate house. After singing at the soldier's benefit, she was pronounced the "Songbird of the South." She is constantly practicing her singing and performing whenever she can. She is a soprano, though it is unclear whether Miss Ruth is truly a great singer, or if her talents are merely mediocre, as it seems that her neighbors poke fun of her singing.

Miss Ruth is a fairly unobtrusive character, therefore her costume must not draw her out visually. Keeping with beige, grey, and muted blue tones, her costumes were appropriate to the period without being necessarily fashionable. As a member of the lower middle class, Miss Ruth does not have a lot of extra money to spend on dresses, blouses, or skirts with much detail, and so what she is left with is quite plain. As Miss Ruth lives in a room in the same house where Valentine's Day is set, her look and clothing is a little less ready to present to the public than some of the other characters who do not live in the same building. As I wanted to showcase her role in the little family's home, I gave her a bathrobe and slippers to wear for scene 3 , as she is meant to join the group in Horace and Elizabeth's room in a comfortable state, as if she is one of the family. Noting the wonderful wrinkled quality of the dress in Figure 59, I put the approximate style to use as Miss Ruth's outfit for Christmas Day. The look is nicer than her other, duller grey dress, while remaining down-to-earth and simple. This look had to be purchased as a new garment for the production, and so it was especially important to add some wear and tear, including some sun damage in the form of fading. Though this is meant to be Miss Ruth's nicest dress, her lower social class still shows in the quality of the fabric as well as the evident wear and tear from a good deal of use over the years. In terms of hairstyle Miss Ruth was to look as if she had made an effort with her hair, but that she did not quite have the means to figure out the nicest manner in which to work with her hair, and so her look was to be fairly loose, a little odd looking, and much less precise than the hairstyles of other women of higher social standing. 


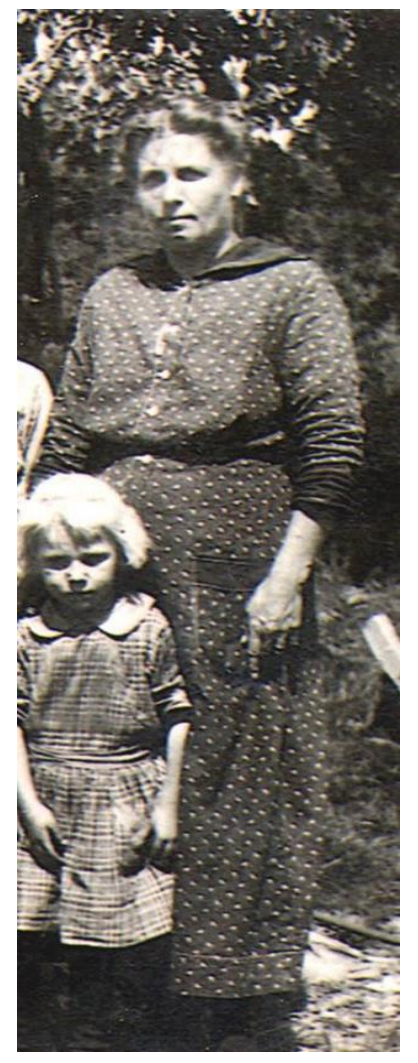

Figure 64: Final rendering for Miss Ruth in Valentine's Day, scene 2.

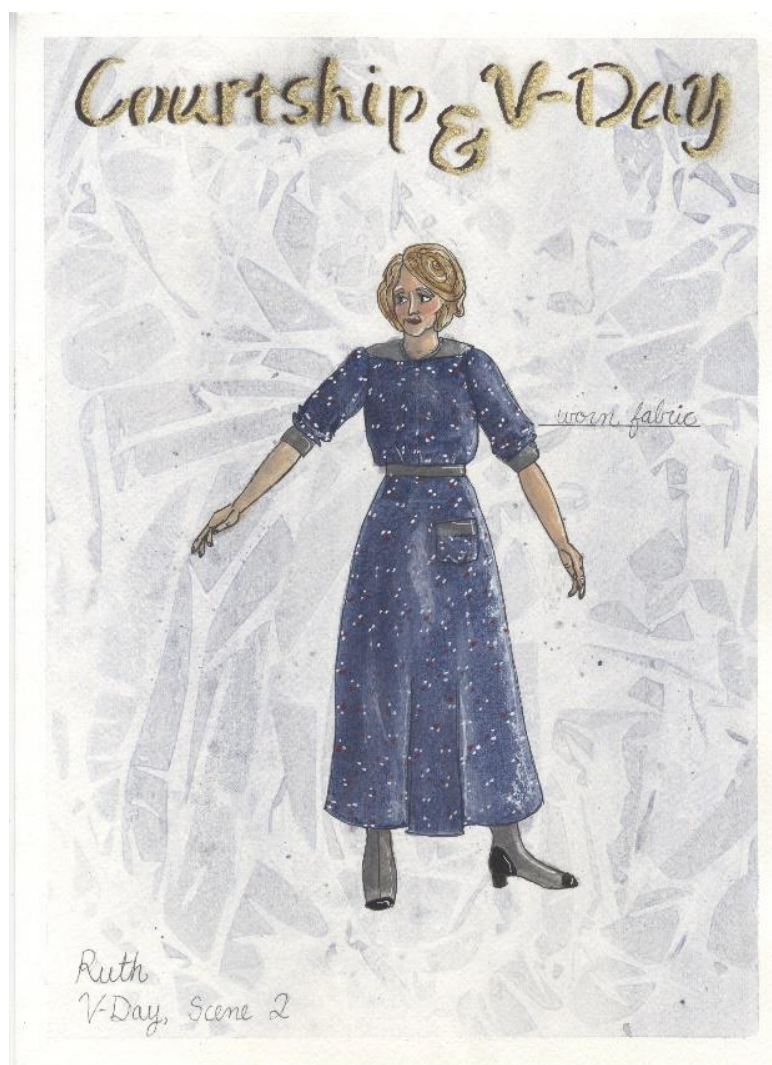

Figure 65: Research image for Miss Ruth's dress in Valentine's Day, scene 2.

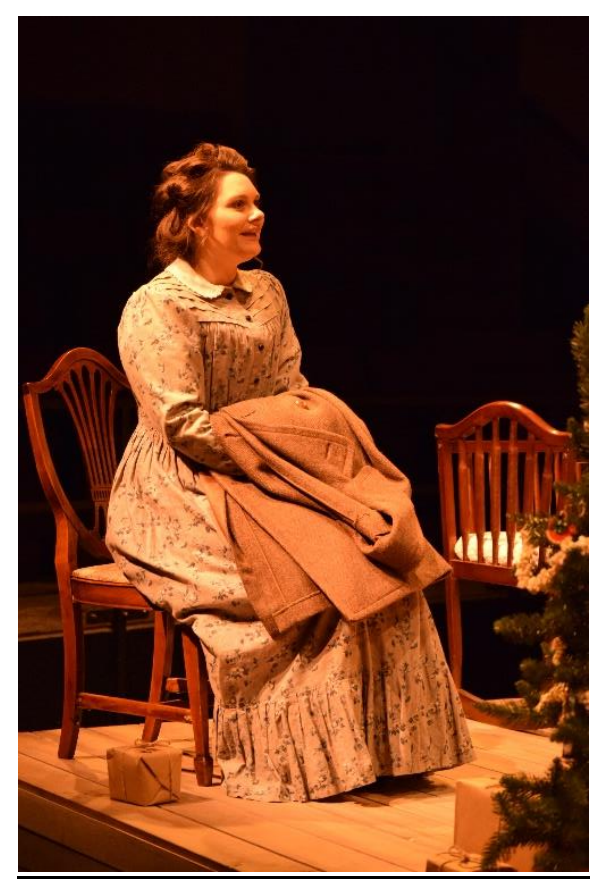

Figure 66: Miss Ruth Amos (Brianna Bowers) in Valentine's Day, scene 3. 


\section{$\underline{\text { Brother }}$}

\section{Valentine's Day}

Brother Henry Vaughn, who goes by Brother for short, is studying at A\&M, a military academy which his parents force him to attend. While he is attending school, it is clear that he is not there by choice, as he does not apply himself to his academics. He was kicked out of his first college, Allen Academy, for gambling, an addiction from which he says he is trying to recover. Brother drinks more than he will admit to his family, and still gambles some, which enrages his father. His father wants him to study to be a lawyer, but Brother says that he would rather do what his father does, as he wants to make as much money as his father.

Perhaps one of the more challenging items to research was a military uniform for Brother Vaughn. This is most certainly due to the last minute change in his design, which occurred after the final renderings had been presented. His initial design stemmed from images in yearbooks of preppy school boys wearing knickers and Norfolk jackets, their hair parted distinctly to the side (Figure 61).

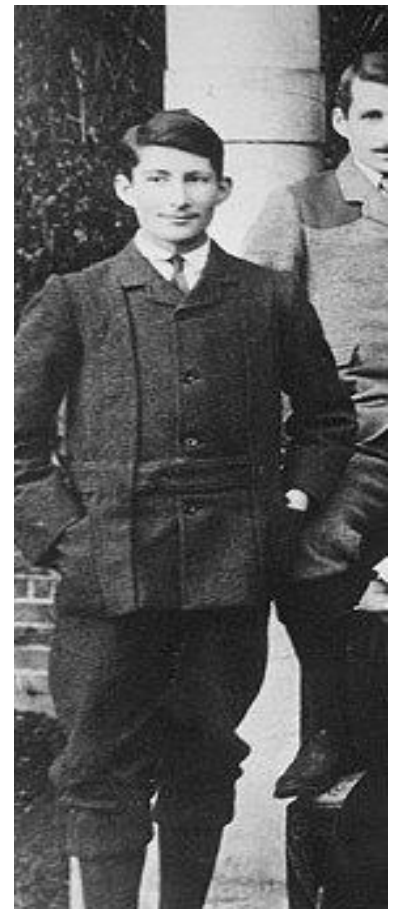

Figure 67: Research image for Brother Vaughn in Valentine's Day, scene 2 (as originally designed).

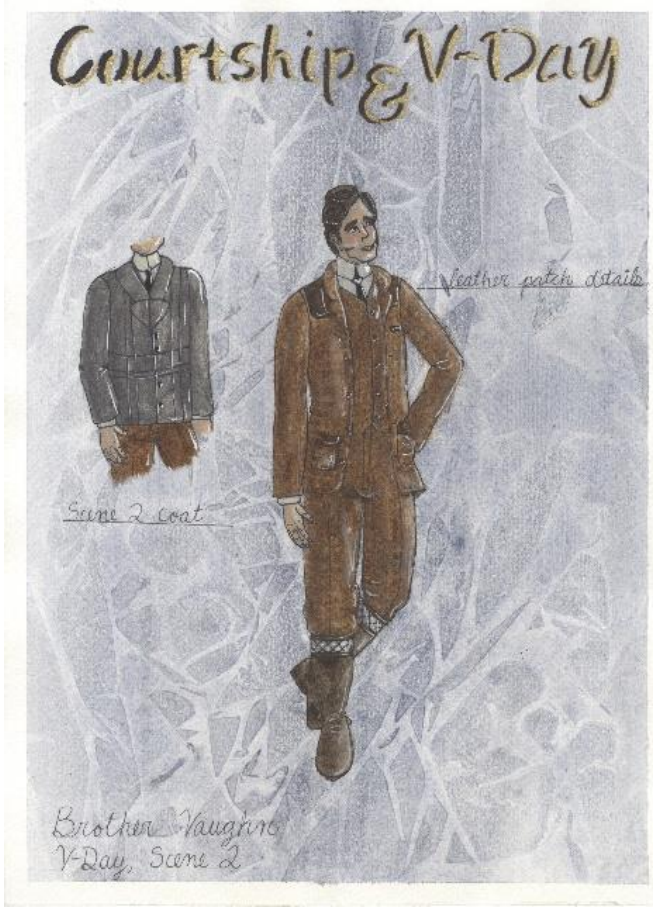

Figure 68: Final rendering for Brother Vaughn in Valentine's Day, scene 2 (as originally designed). 
This distinct look was perfectly suited to Brother's personality, but when we realized that he was supposed to be in military school, and would be wearing his formal uniform to the Christmas gathering, a slew of research around military school uniforms commenced. I looked at army websites, specific military academies such as West Point, as well as through other sources in search of different styles which might fit the character (See Casting Issues and Ongoing Design Challenges)

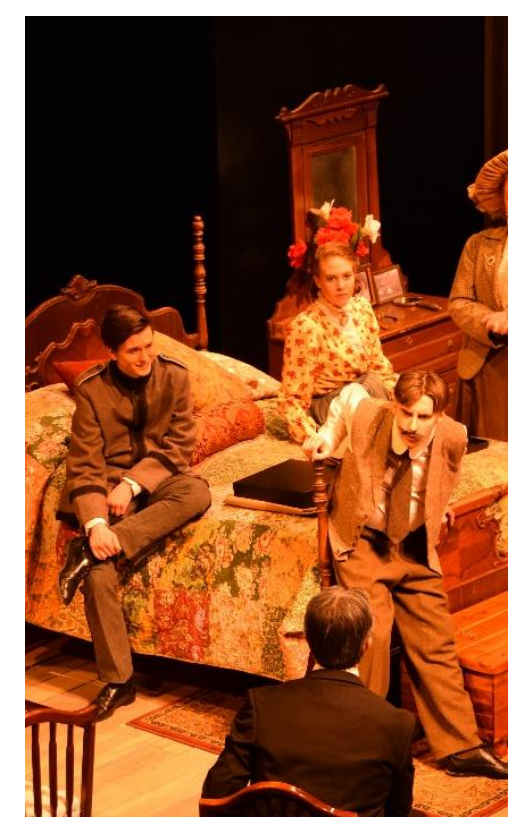

Figure 69: Mr. Vaughn (Joseph Bussey), Brother Vaughn (Woody Pond), Bobby Pate (Zachary Powers), and Elizabeth (Margaret Dransfield) in Valentine's Day, scene 2.

\section{Dr. Goodhue}

\section{Valentine's Day}

Dr. Goodhue is a small character who is not listed in the character breakdown in the script. Goodhue enters in the second scene of Valentine's Day to help sedate Mr. Bobby Pate, who is drunk and unpredictable. Dr. Goodhue is described as small, and gives hints that he might be an older man, or at least that he is not extremely strong, as he indicates that he cannot hold Bobby down to administer medication to him on his own. With the help of the other men in the house, Dr. Goodhue exits the room to tend to Bobby, so his presence on stage is minimal. When designing Dr. Goodhue's costume, I took into account his probable social status as the local doctor in the poorer area of the town. I imagined that Dr. Goodhue would not care much about 
his appearance, so perhaps his suit was not properly buttoned or fitted. I liked the idea of his suit and coat overwhelming his small frame and exaggerating his slouched posture much like the looks shown in Figures 63 and 64. The curvature at the front hem of the suit jacket in Figure 63 was also of interest to the design of the costume, as I felt that adding a curve to the front of the jacket would exemplify the soft edges of the character, both in terms of personality and in visual appeal. Because he is a short man, his pants were designed to be longer than is fashionable, but Dr. Goodhue is not the type to be bothered by fashion, so he chooses to wear his pants with the hem as is, instead of attending to this simple detail. Details such as this hint that the doctor is a man whose work is more important to him than his appearance.

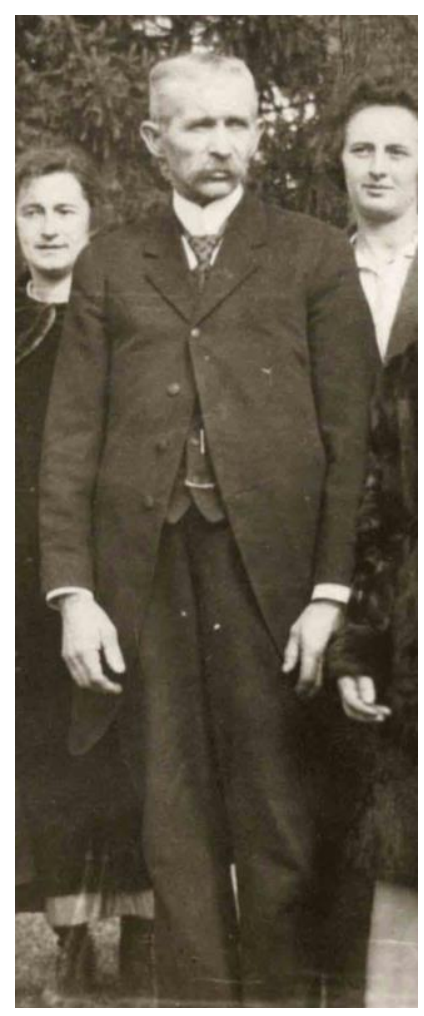

Figure 70: Research image for Dr. Goodhue suit in Valentine's Day, scene 2.

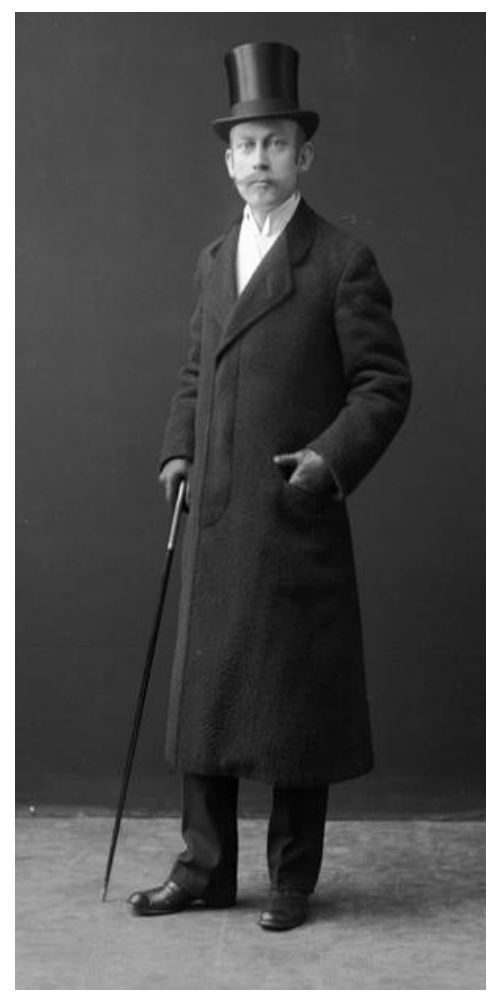

Figure 71: Research image for Dr. Goodhue's coat in Valentine's Day, scene 2. 


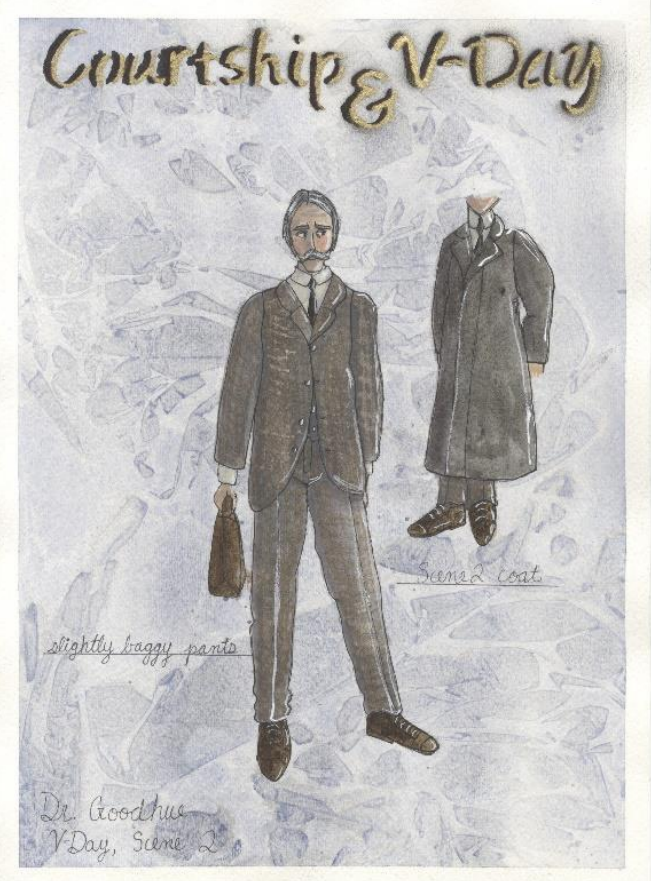

Figure 72: Final Rendering for Dr. Goodhue.

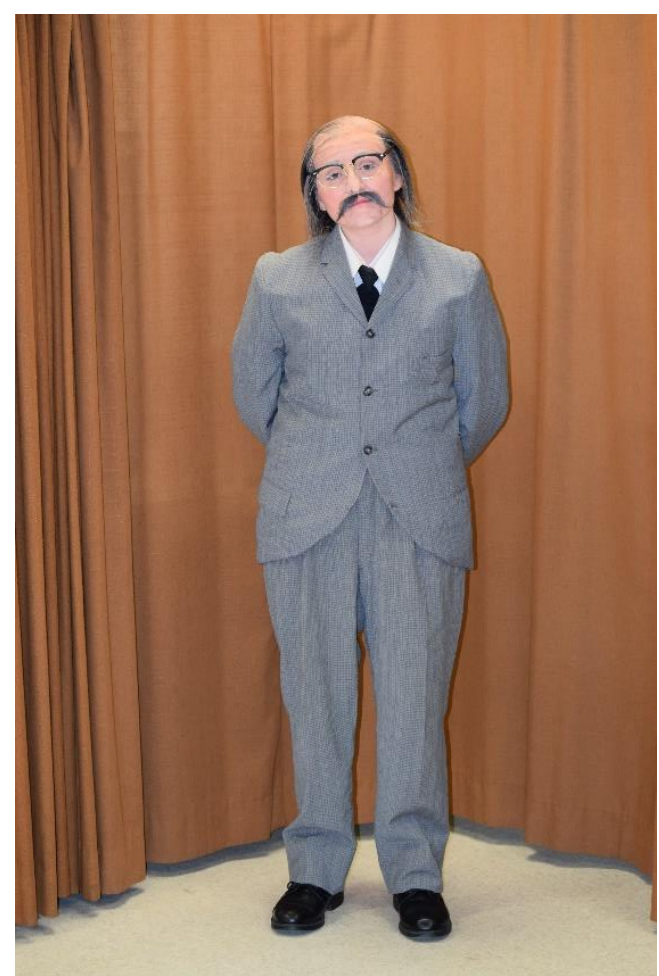

Figure 73: Dr. Goodhue (Mallory Robson) backstage

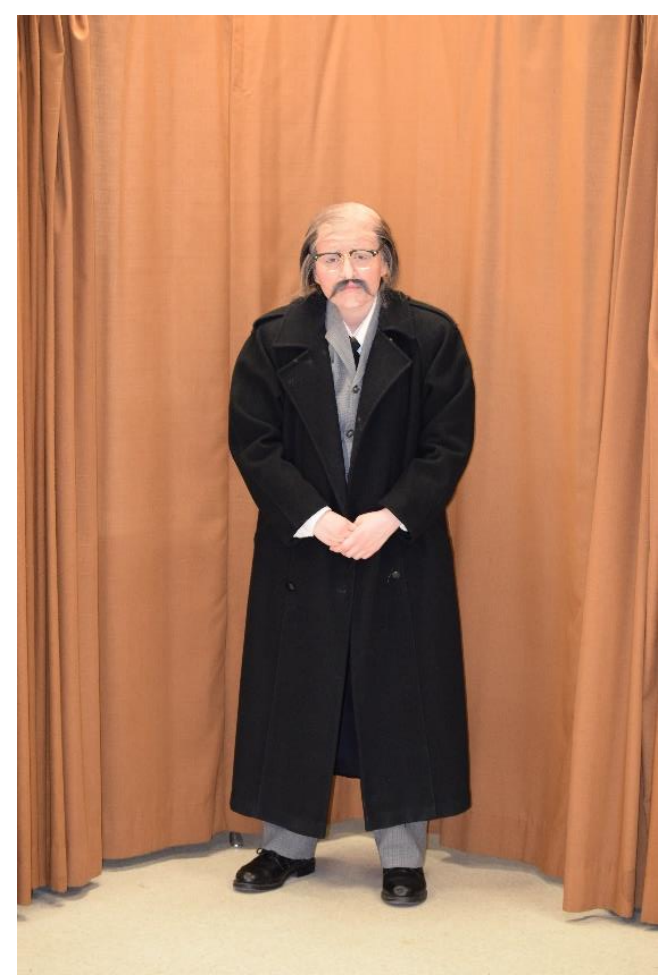

Figure 74: Dr. Goodhue (Mallory Robson) backstage wearing coat 


\section{The Dancers}

\section{Courtship}

There are three sets of dancers who enter the periphery of the stage area at different times throughout the play. They enter dancing, cross, and exit the stage in the same manner, all without saying a word. The dancers are assumed to be unnoticed by the actors, and therefore could be considered a figment of the characters' - and perhaps the audience's - imaginations. The dancers punctuate certain moments by anthropomorphizing the hopes and dreams of the sisters, Elizabeth and Laura Vaughn. These figments of their imagination represent everything that the two girls want in their lives but cannot have. For this purpose, the design concept for these roles was that each dancer should be impeccably dressed, in stark contrast with the rest of the onstage world through which they glide. The dancers were designed to wear the most fashionable styles of the period. They were placed in richer fabrics, and far brighter colors than the Vaughn family would ever allow for their children. As research, I found Ragtime era posters and chose colors and silhouettes directly inspired by these stylized drawings.
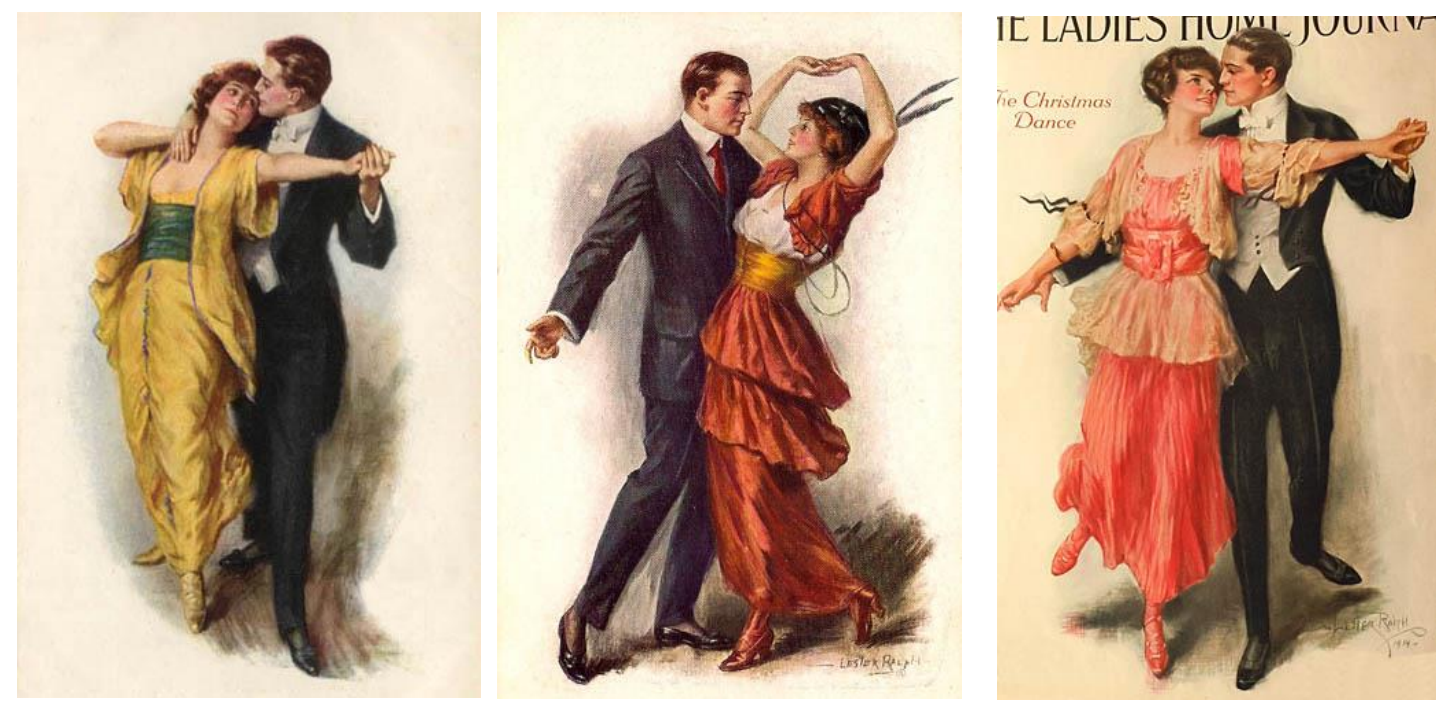

Figures 75-77: (left to right) Research images for the Dancers in Courtship.

While Professor McGonigle was satisfied with the given concept for the dancers' looks, he struggled throughout the design process to pinpoint the significance of their role in the play without creating a distraction for the audience. When asked for my thoughts on their purpose, I explained that the dancers create an air of magic that breaks from the "slice of life" mold. They create dreamlike, mystical moments in an otherwise grounded play. This mysticism is also an 
omen for what is to come within the action of the play. The dancers serve as a constant reminder that Elizabeth and Laura have been denied the pleasures that they seek in life. In this sense, the dancers create a point of tension which breaks when Elizabeth defies her parents to elope with Horace in Valentine's Day. The mysticism of the dancers could also be useful in tying the set design concept together with the realistic nature of the rest of the play. The set was designed as a deconstructed version of a house, which transforms into a room in a boarding house for the second play before the audience's eyes (albeit during intermission). There is some magic in the way that the set is constructed. This magic, along with the use of baby blue as an accent color creates a dynamic contrast within the play. The coloring is lighter than the mood of the play feels. This contrast could have been further supported by the dancers' colorful, flowing dresses and crisp, clean tuxedos.

Despite usurping a large portion of the conversation throughout the design process, we were unable to incorporate the dancers into the show when it came time to make the final decision (see Casting Issues and Ongoing Design Challenges). Although I was disappointed that the designs were not used, I respect Professor McGonigle's decision to cut something which he felt unable to justify within our particular production.
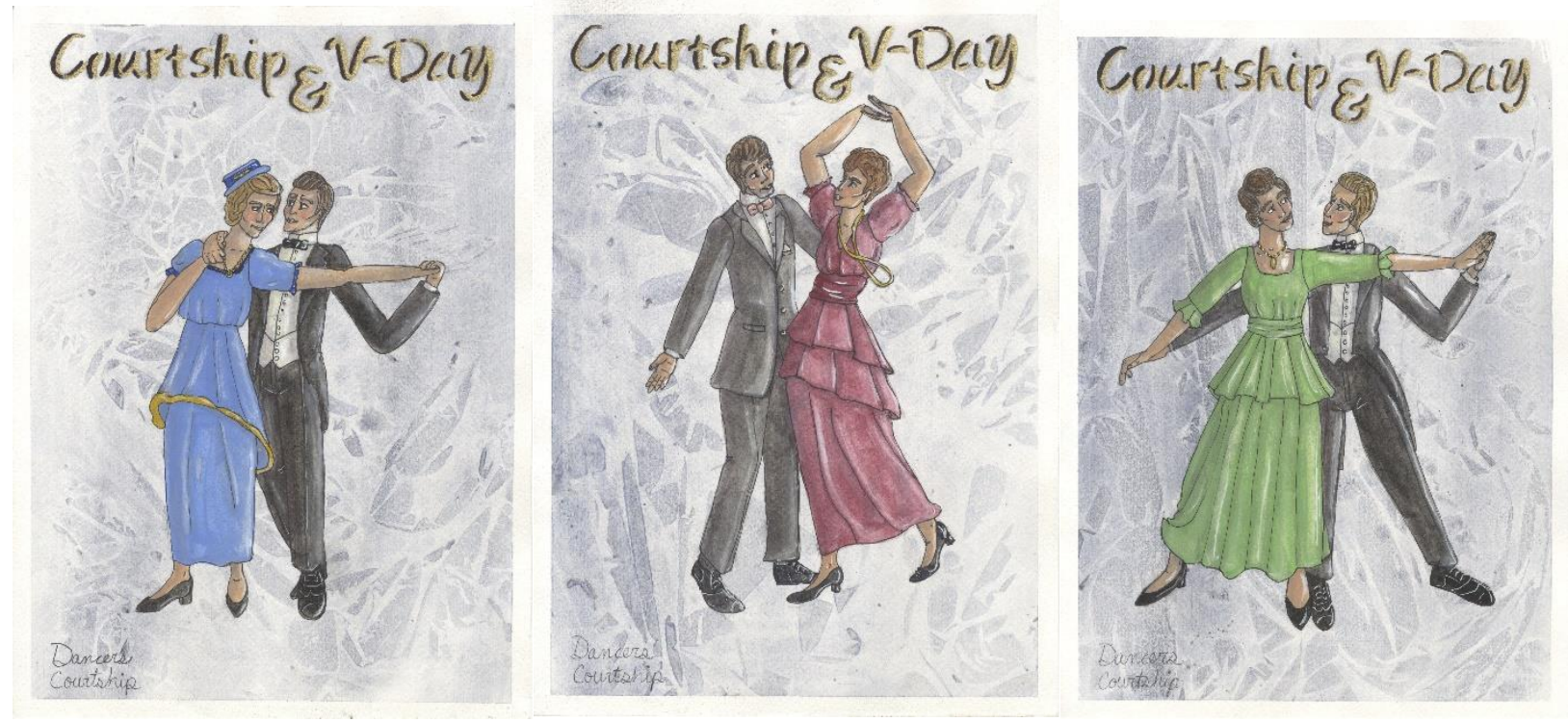

Figures 78-80: Final renderings for the dancers. 


\section{PROJECT PROCESS}

\section{Casting Issues and Ongoing Design Challenges}

After final designs were due, there were a few costuming issues left unresolved. I was already aware that a decision had yet to be made on whether or not the dancers would be utilized in our production. Having advised Professor McGonigle to limit the number of dancers to fit the production's budget, I presented designs for three pairs of dancers. Professor McGonigle approved the designs for the dancers at the design presentation, but continued to grapple with their purpose in the production. Once the show was cast, I realized that no performers were listed in the roles of the dancers. The small role of Dr. Goodhue was also left uncast. Filling the role of Dr. Goodhue was a quick and simple fix in comparison to the question of the dancers. Professor McGonigle wanted to cast internally from the company of actors already taking part in the shows. Professor McGonigle suggested filling the small role with either undergraduate actor, Joshua Clevenger, who would be playing the role of Steve Tyler in both Courtship and Valentine's Day or undergraduate actress, Mallory Robson, who was set to play Laura Vaughn in Courtship. After studying the script to determine the maximum length of time that could be allotted for each actor to make the change from one character to another, Professor McGonigle settled on Ms. Robson. Giving the role to Ms. Robson offered her a unique challenge in that she was to play the role as a man. Casting Ms. Robson over Mr. Clevenger also simplified the urgency of the changing process, thus giving the backstage crew more time to transform her into a completely new character. While Mr. Clevenger would have been able to play the role, he would have had to change back and forth between characters in very quick succession. Professor McGonigle expressed the desire to avoid extremely quick changes during the show unless absolutely necessary.

Regarding the dancers, weeks passed and a decision had yet to be made. I repeatedly requested a finalized cast list that included the dancers, insisting that the more time that passed, the less splendor and variety the costume shop would be able to provide in terms of clothing for the dancers. The costume stock at WVU does not have dresses that would remotely look like the designs that I had presented, so the female dancers' costumes would become forcibly less bright and whimsical the longer the final decision took. As for the male dancers, WVU stock does have some tuxedos, but the sizing of those tuxedos is limited, which might prove troublesome if 
enough time was not allotted to order new ones. Once enough time had passed, it became clear that the only option left for the dancers would be to pull clothing from stock once the roles were cast. I was hesitant to do this, as I felt that using the dancers without beautiful, flowing, and colorful costumes from the time period would compromise their purpose in the play. In order to be successful, the dancers' costumes would have needed to starkly contrast the costumes of the Vaughn sisters. With this in mind, Professor McGonigle finally opted to cut the dancers since we were no longer able to produce a satisfactory look for them.

In addition to the above casting issues, at the final design presentation, Professor McGonigle brought to my attention that we had missed a hint about Brother Vaughn's costume in the design process. The stage directions in the Valentine's Day script indicate that Brother wears a military school uniform when the Vaughn family visits Elizabeth and Horace at Christmas. Believing this to be an important aspect of the character, Professor McGonigle asked that I look into military school uniforms of the time. Not having much knowledge on the subject, I initially found information through an official army website which chronicles the development of United States army uniforms in detail. This source lead me to believe that a military school uniform would look much the same as a combat soldier's at the time. In 1917, America was in the midst of World War I, so the U.S. military was only issuing one type of uniform. In addition, this means that specific uniforms for formal events were no longer being distributed.

Despite the information that my research yielded, Professor McGonigle hoped to give Brother Vaughn a more dignified appearance for the Christmas holiday. At a loss for direction, I struggled to find more information on other types of military school uniforms that might have been in use around 1917. Professor McGonigle did some research on the subject alongside my own, and discovered West Point Academy's uniform from around the time period. 


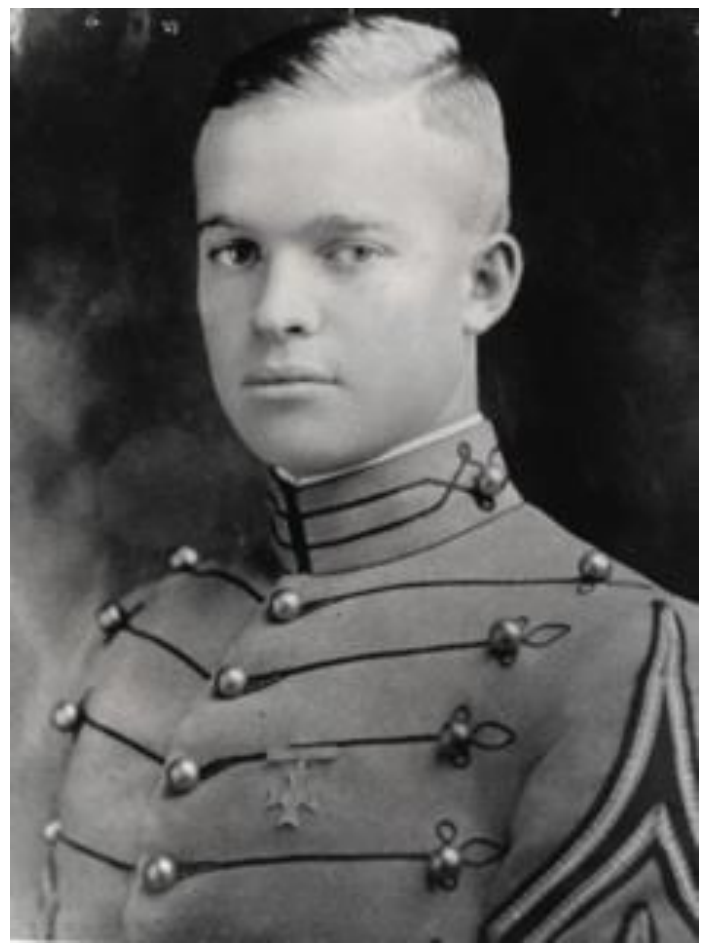

Figure 81: Dwight D. Eisenhower's West Point Academy graduation photo in 1915.

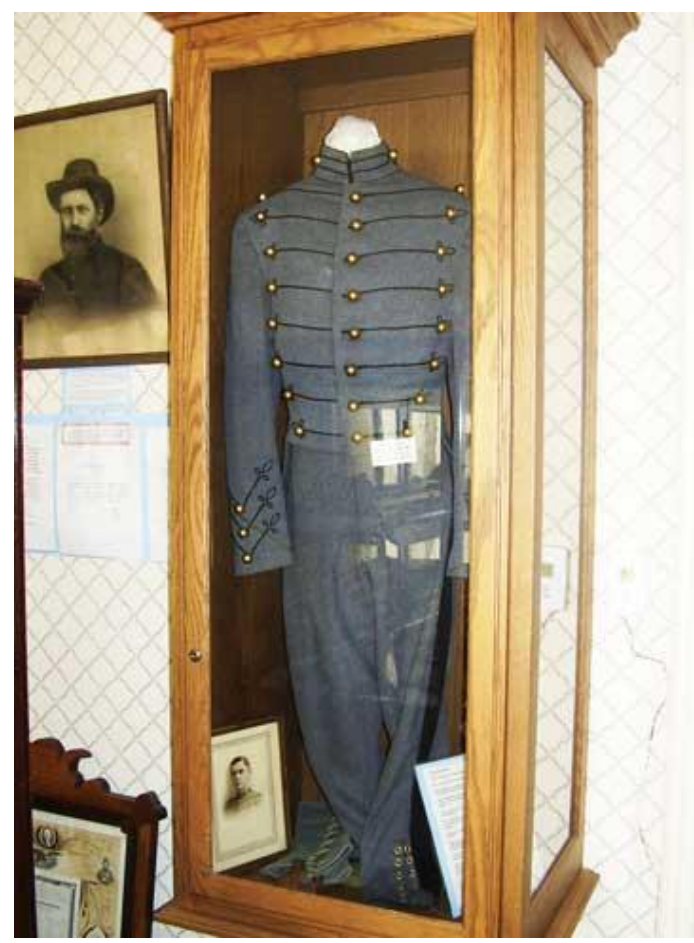

Figure 82: West Point Academy uniform of the period, on display in an exhibit.

The blue, woolen uniform is beautifully detailed, and has quite clearly served as inspiration for the modern day marching band uniform.
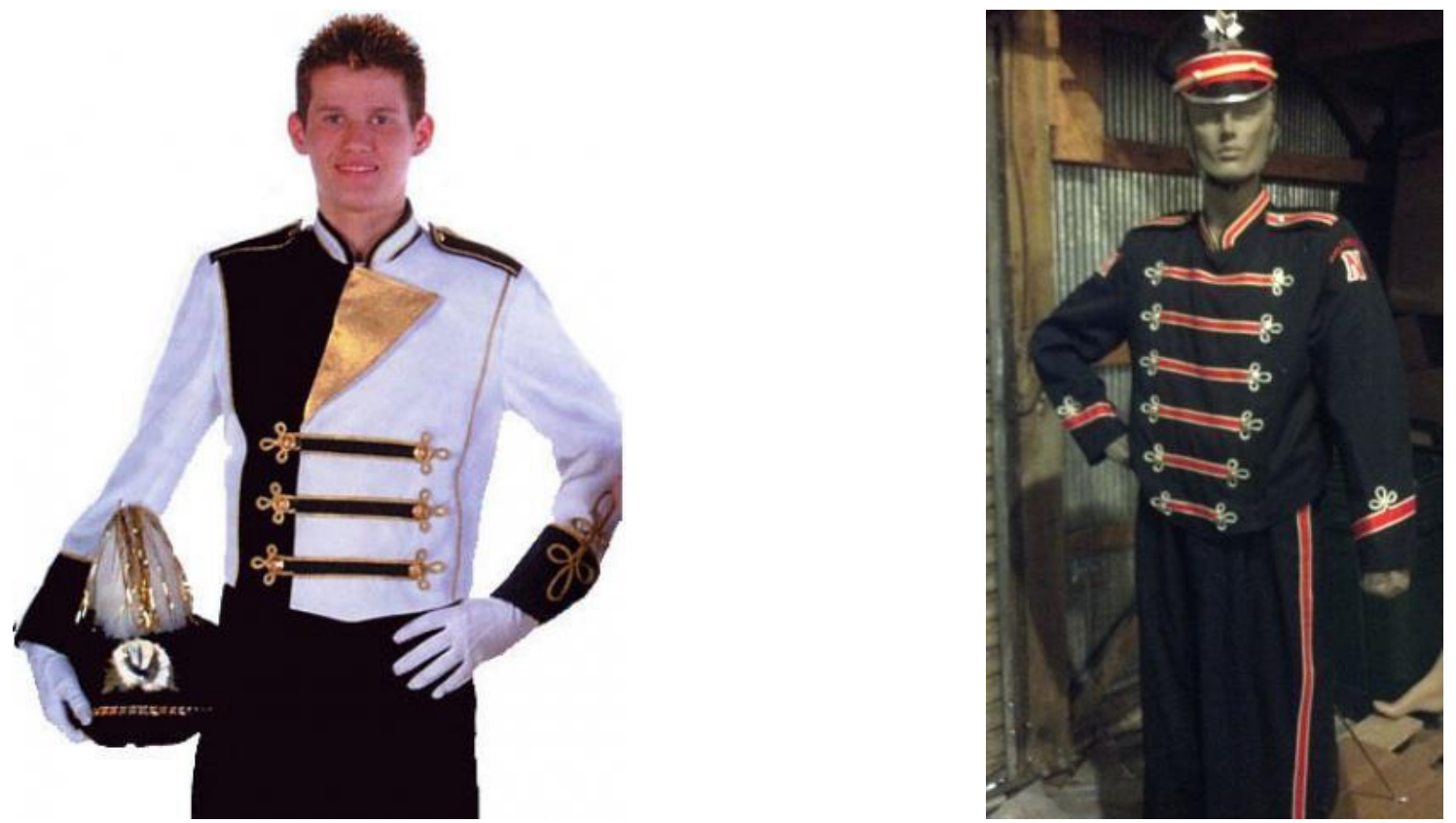

Figures 83-84: (left to right) Examples of modern day marching band uniforms. 
Due to time constraints, the costume shop would not be able to construct a uniform for Brother. I expressed my concern that finding something to alter into the style of a West Point uniform would be both prohibitively expensive and difficult to accomplish, and thus would most likely give us an unsatisfactory look. An additional concern was the color and style of the uniform, I feared that it would be distracting once it was placed in the drab, neutral, and minimalistic world of the Valentine's Day set and costumes. Having rejected a few other research options that were still too close to the combat uniform style, Professor McGonigle finally came across a uniform which appeared oriental-inspired. The jacket had a mandarin color and large blocks of trim down the center front and around the neck, hem, and sleeves.

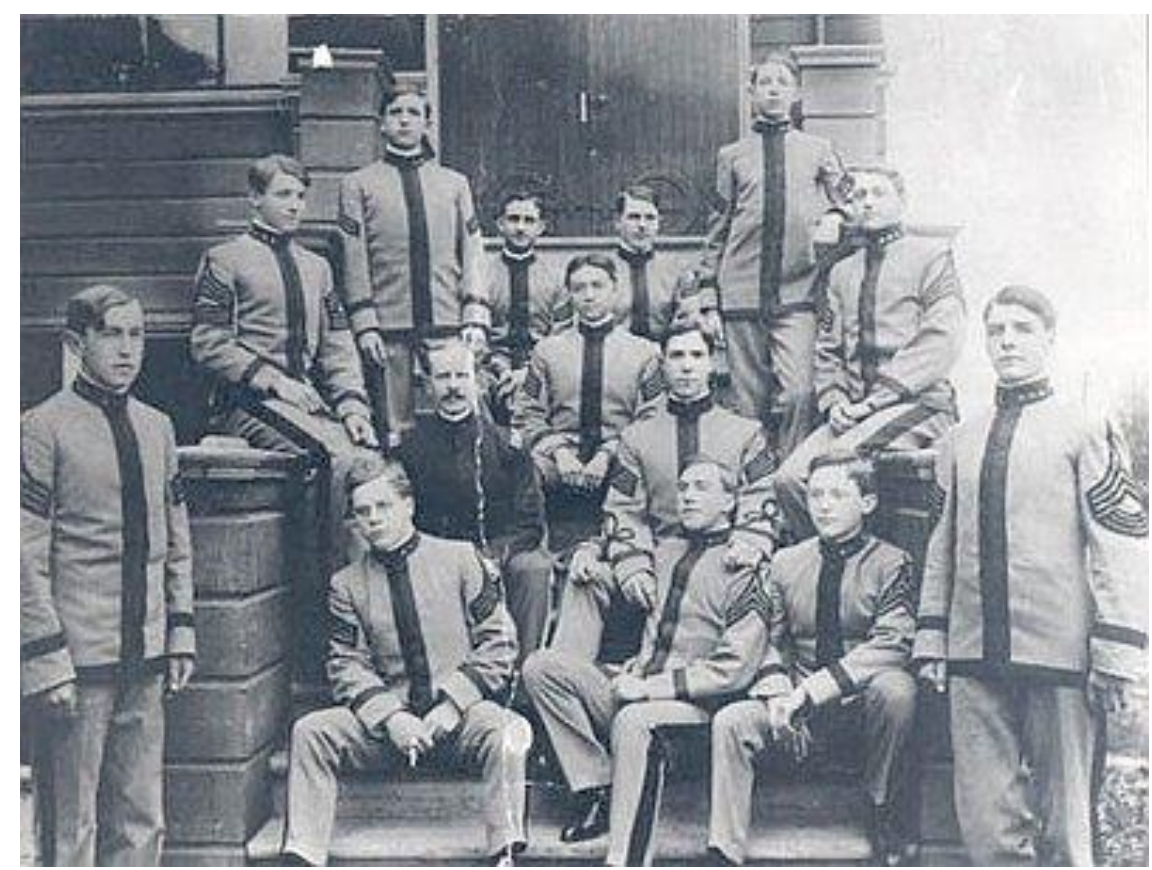

Figure 85: Research image for Brother Vaughn's military school uniform.

There were no visible pockets on the coat, which alleviated Professor McGonigle's worry that Brother would look too much as if he were going into combat. This newest look was not one that I was convinced would work at first, but after some negotiation on color, and toning down the contrast between the light colored jacket and the black trim from the research image (Figure 76), we were able to compromise on a steel grey uniform with black or dark grey trim. The end result was a look in a more formal style which would not distract onstage. Although I still believe that 
my original design would have suited Brother's personality equally as well, the end result fit the needs of the production.

\section{Costume shop organization}

Having learned from previous experiences in the WVU costume shop working on designs for both the Fall 2015 Dance Now concert and the Spring 2015 production of The Beaux' Stratagem I felt much more organized and prepared for the build of Courtship and Valentine's Day than ever before. Having stayed nearly $\$ 1,000$ under budget after initial purchases for all characters were made, I was happy to have a safety net if an issue should arise. The costume shop pushed through the production's build in a much more organized fashion than usual due to the excellent organizational skills of the production's cutter-draper: graduate student, Cecelia Hill. Ms. Hill was constantly aware of her timeline, and had a schedule in place for each build item. Ms. Hill also budgeted overtime hours for the shop from the beginning of the process. While the shop did not need to utilize all of these extended hours, having a contingency plan to account for any projects that might fall behind schedule was reassuring. Ms. Hill also worked quite a bit on her own time in order to make sure that projects were ready to be worked on during regular shop hours. Ms. Hill's diligence in time management was instrumental in the undeniable efficiency of the shop for this production.

With a little more experience under my belt, I was better able to keep on top of both myself and the build schedule than in previous years. Through practice, and the intelligent recommendation of my advisors I have learned that one of the simplest ways to keep projects flowing through the shop is to make sure that alterations involving additions of trim have the trim pre-selected and placed with the garment to which it corresponds directly following the fitting. The use of this method saved time for both myself and my fellow shop workers during lab hours. Those working on the alterations were no longer forced to ask me what trim to use on a given garment. In addition, this occasionally saved my colleagues the aggravation of searching for and pulling an appropriate trim on their own with only vague guidelines to direct their search. This simple organizational task aided in the smooth flow of build items and alterations through the costume shop, and ultimately helped a great deal in keeping the show on schedule.

Having a safety net in my show budget proved to be extremely convenient when a costume that I had ordered slightly later than the rest ended up not working as anticipated. I had 
originally purchased two identical pairs of pants for the character of George Tyler in Valentine's Day. In the third scene of the play, Mr. Tyler needed to appear as if he had worn his once clean pants down to the river bottoms following a psychotic break. The first pair of pants would remain pristine, while the second pair would be made into a permanently distressed version of the first in order to create the illusion of the passage of time. Unfortunately, the period-style pants that I had originally ordered from Wild West Mercantile for graduate student actor, Mr. Lonnie Simmons did not fit as I had hoped. Online, the pants appeared to be perfect for the era; they boasted a high waistline and suspender buttons on the outside of the waistband with the wonderful, nubby texture of a natural fiber. Unfortunately, during Mr. Simmons' fitting, it became apparent that the style of the pants was somewhat off from the period, as the legs were a fairly slim fit, while the waist fit well. As excess money remained in the budget, and there were absolutely no appropriately styled pants in costume stock that would fit Mr. Simmons, I reordered the same pants in a size larger with the hope that the legs might fit more loosely. Unfortunately after placing this second order, Wild West Mercantile shipped one of the two pairs of pants, while the other was marked as backordered. I called to cancel the backordered item, and proceeded to order two more pairs of the same pants, this time two sizes larger than the original purchase. As time before technical rehearsals was running out, I remained on the phone with the company until they had checked the warehouse to make certain that both pairs were available in stock and would be able to be shipped immediately.

In total, $\$ 270.75$ was spent in order to provide Mr. Simmons with two pairs of pants. Though I was able to return the pair that arrived without its backordered counterpart, the costume shop kept the originally purchased sizes, as stand-ins were ultimately needed during technical rehearsals before the larger sized pants arrived. The hurried struggle to acquire pants that fit properly was partially due to my initial delinquency in finding the right pants for Mr. Simmons. Had I been more diligent in my purchasing process, there would have been much less urgency around the details of his costume. Had I been more attentive, more money could have been saved on my budget to be turned over to the next show. The return receipts and cancellation paperwork for the transactions with Wild West Mercantile was nightmarish. The return process became muddled due to the small size of the company and their inability to provide satisfactory invoice documentation for both purchases and the returns. Fortunately, the WVU business office staff was very kind, and patient in sorting out all of the issues, so all was eventually resolved. 


\section{Costume Shop Build}

Regarding the costume build process, it became apparent that I still had much left to learn about better expressing what I want from the final costume while in mock up fittings. I learned through this design experience that it is best to speak up and question the details of a costume in the mock up fitting rather than to assume that a component of a garment will work once it is built in fashion fabric. Avoiding voicing any concerns until this point leads to the inability to adjust certain elements of the garment. Quite often, these elements could have easily been adjusted at an earlier stage in the process. In mock-up fittings, I noticed that I consistently gave up on style lines and detailed preferences when it seemed like what was already there would work even when the look was not exactly what I had hoped it would be. This communication issue stems from both a fear of insulting my collaborators' work, as well as from the desire to allow some creative license with my designs. While I am deliberate in my drawings, and can generally discuss my style choices in detail, I am not always firmly attached to the minutia in my renderings. I enjoy seeing how others interpret my designs, and have found in past work environments that allowing the input of my collaborators has the potential to enhance my designs in a way that I could never have fathomed. I have learned, through this particular build process, that this attitude is not necessarily suited for every shop. Ms. Hill was not comfortable making small decisions about garments without my specific direction. For example, Ms. Hill asked my preference on the direction in which the striped pattern on both of Mrs. Vaughn's skirt waistband should lay. My initial reaction was to allow her to make the decision based on whether one direction made more sense structurally, as visually, both options were valid to my eye. Ms. Hill was not, however comfortable making this decision, and so I made the choice to allow her to move forward. It was brought to my attention that this occurred a few other times throughout the build process, either in fittings or in general discussions about costume pieces. My design mentor, Professor Mary McClung eventually spoke to me about the fact that my attitude towards style details occasionally sent the message that I did not care. This was an unfortunate misunderstanding, as it did not occur to me in the moment that my attitude could be perceived as uncaring. Through discussion with Professor McClung, I have come to better understand the importance of word choice and clear communication as a designer.

The spring 2016 semester marked a transitional time for the WVU costume shop, as the School of Theatre and Dance was in the process of hiring a faculty member to replace our 
Clinical Professor of Costume Technology and Staff Cutter Draper, who had discontinued her contract after the fall semester. Professor McClung, who was extraordinarily overworked at the time, attempted to step in as a mentor to Ms. Hill in the cutting and draping process. However, due to the nature of the rest of her responsibilities as the director of the costuming department, Professor McClung was not able to afford as much attention to the entire process as someone in the then empty faculty position. The largest drawback to having a student draper without a fully dedicated faculty mentor was that the mock-up garments that were created for the costume builds were vague. This vagueness was due to the minimalistic method that Ms. Hill employed in the creation of the mock-ups, as she did not include style details such as godets, pleats, or decorative seam lines. Ms. Hill made generic, sloper-like mock ups which she later manipulated to create the more complex garments that the designs called for once the general shape had been fit on the actor. In the fittings, Ms. Hill asked me to draw in where I might like to see stylistic details in permanent marker. Professor McClung pointed out to Ms. Hill that it is best to include the details of the garment in the mock-up so that the designer can have a more complete preview of the final product. This information, however, was conveed too late, as all of the mock ups had already been created in the same, vague fashion by the time this warning came along.

A prime example of how this minimalistic draping method caused problems for a final garment was regarding the godets that I had requested in Elizabeth's skirt for Courtship. Ms. Hill had me draw the height and shape of the godets onto a plain A-line skirt mockup in the mock up fitting, so I did not see that the effect of the godets in the skirt was not what I had hoped until it was in its final fabric. If Ms. Hill had set the godets that I requested into the mockup fabric I would have realized before the skirt was fully completed and ready to go on stage, that it was not godets that I had wanted at all, but rather inverted box pleats. The fact that the mockups lacked the styling details from my renderings made it difficult to envision the final product while fitting the mock-ups, which ultimately impeded my decision making process within those mock-up fittings.

Once patterned, the remainder of the build process was generally smooth. There were a few issues with seam allowance being cut unevenly by mistake, which, for some garments, did not prove to be a problem. This cutting error did, however, lead to a serious issue on Elizabeth's Courtship skirt. Due, perhaps to the initial hem mark that I pinned on the mock-up, the skirt's hem was far too short once it was put together in fashion fabric. While some of the skirt panels 
had been cut with the usual three inches of seam allowance at the hem, a few of the panels were cut with only one inch at the hem. In terms of being able to lengthen the skirt, this simple mistake was debilitating. There was no extra fabric with which to recut the panels of incorrect length, so Cutter Draper, Cecelia Hill had to improvise a solution. The skirt was eventually lengthened using a three inch wide strip of bias made from the fashion fabric which was originally stitched to the short hem in order to give more weight to the otherwise very slight hem. Trim was added in order to cover the seam line between the original hemline of the skirt and the top of the bias strip which lengthened the skirt. Ultimately this look solved the problem, and added a sweet element to the skirt which neatly tied into Elizabeth's lace-trimmed blouse.

One of Professor McGonigle's stipulations for casting undergraduate actor, Isaac Snyder, in the role of Horace, was that we fill out the actor's slender frame with padding in order to give Horace a more substantial stage presence. Professor McGonigle felt that Mr. Snyder's natural build was too scrawny for such a hefty role. Being very wary of telling actors that their body's shape and size is not good enough, I knew that it was necessary to be extremely delicate in how I spoke to the actor about using padding on him to change his physique. So while Professor McGonigle's language in describing how he wanted Horace to look was clear, using those words would have been considered fairly insensitive if conveyed directly to the actor. With this in mind, I took the time to think out the proper phrasing to communicate our plans to the actor in a tactful, professional way. When we first had Mr. Snyder in to be fit, I explained to him that we would be filling out his hips and buttocks in order to change up his usual look for the role. Mr. Snyder is a slender, fit young man, and adding a little more weight to his hips and buttocks would make him look slightly older. Adding extra weight to his bottom half would also ground him more than usual, an effect which Mr. Snyder could use that to his advantage in the ongoing development of his character.

One of the builds that the costume shop took on for this production was Horace's matching grey pinstripe vest and pants for Valentine's Day. The decision was made to offer this build as a practicum project to one of our more advanced undergraduate students looking to focus on costuming. The student, Ms. Mikayla O'Neill was to construct the clothing set from start to finish, including the body padding that Mr. Snyder was to wear beneath all of his costume pieces. Ms. O'Neill sat in on the first few fittings for Mr. Snyder's padding and mockups. She helped to create the shape of the body padding on Mr. Snyder using pre-determined 
pockets on a unitard and polyester batting as filler. Ms. O'Neill was in charge of filling out Mr. Snyder's form with the batting while I stood back and directed adjustments on the overall shape. Unfortunately, soon after this fitting, Ms. O’Neill became overwhelmed with her schedule and bowed out of the project in a rather unprofessional manner. She continuously missed her set work hours with no warning, and eventually stopped coming to work in the shop altogether. Ms. O'Neill's delinquency caused the project to get behind in the build schedule. Luckily, Costume Shop Manager, Ms. Sharon Goeres stepped in and took over the build for this pair of garments. Ms. Goeres supervised the costuming lab and practicum students through the remainder of the build process for those two items. Ultimately, nothing was sacrificed in the look of the final product; the fit was perfect, and the look was completed as designed. This simple fact is a testament to the excellent organizational structure of the costume shop throughout this production.

The padding used for Elizabeth in Valentine's Day was much more straightforward, and a much less delicate topic, as a pregnant belly is expressly called for within the script. WVU's costume stock has a good amount of preexisting padding, so I was able to pull a circular pad with an elastic strap that seemed to be the correct shape and size for a five month pregnant belly. When used in rehearsal underneath of her rehearsal skirt, undergraduate actress Ms. Margaret Dransfield noted that the belly pad kept sinking, and moving around due to the way that it strapped around her middle. To solve this issue, I pulled a leotard, and called Ms. Dransfield into a fitting where I pinned the pregnancy bump in place on the outside of the leotard. Following the fitting, I covered the padding with a piece of spandex to match the white color of the leotard, and had the costuming lab stitch the spandex, and thus the padding in place. With the padding anchored securely to the leotard, the belly no longer fell or moved around under Ms. Dransfield's skirt, and maintained a realistic shape when she bent over or contorted in any way. The one issue that remained was the actress's lack of knowledge on how to put the weight into her movements that she needed as a pregnant woman. In the costuming critiques that I read about the show after it had closed, I noticed quite a few remarks that the pregnancy belly did not seem real. I had thought this as well when first seeing runs of the show. However, after more research, it became clear to me that it was not necessarily the shape of the belly that was the problem, but rather, the ability of the actress to walk and generally move as a pregnant woman would. Though I did have a few discussions with her about walking as if she were pregnant, Maggie expressed difficulty 
mastering the skill, as pregnancy was not something that she had ever experienced. There were moments within the rehearsal process and the final performance, where I noticed that Maggie was performing tasks that a pregnant woman would not necessarily be able to accomplish with quite as much ease, most notably: bending over at the waist to tie her own shoes.

One of the more painful changes that had to be made was the eventual decision to strike Mrs. Mary Vaughn's Christmas suit for Valentine's Day. The suit, as designed, was perfect for the character, but most unfortunately, the fabric that I ordered, and which was used to build the suit had some flaws. When I placed the order, I did not realize that the hand of the fabric would be quite so stiff, nor did I realize that the sheen of the fabric would be quite so noticeable, especially under stage lights. When the fabric arrived, I realized immediately that what I had received was not what I had hoped it would be. However, given the short time frame left to get Mrs. Vaughn's Christmas suit built, I decided to make modifications to the fabric as I could and push forward with the project. The fabric was extremely yellow, so I purchased a light brown polyester dye, in hopes of creating a tea dyed effect on the fabric. After two attempts, I had brought the color down to a more palatable ochre color. After doing a test of the newly dyed fabric under stage lights with the help of Lighting Designer, Professor Alan McEwen, I was satisfied with the color tone as well as with the muted intensity of the fabric's sheen. In the shop, we pushed ahead and built the suit. Fittings with graduate student actress, Ms. Madeline Hintz, went well for this costume, and it appeared that the suit would work very well within the context of the show. It was not until the piece was completed and on stage in first dress rehearsal that our Director first expressed some dissatisfaction with the suit. Professor McGonigle pinpointed the sheen of the fabric as his biggest complaint, calling it a distraction from the intimacy of the scene. In hopes of countering the sheen on the suit, I created a test swatch by misting brown spray paint in various intensities on a large scrap of the fabric. I took this swatch back to Professor McEwen for another test under stage lighting. After determining the most satisfactory concentration of the spray mist, fellow graduate student, Ms. Cody Lorich and I wrapped a mannequin in plastic and carefully misting the suit with as even a layer as possible of the brown spray paint. To my eye, this helped enormously in the next dress rehearsal. However, while he felt the look was an improvement, Professor McGonigle still felt that something was off in the costume, and that perhaps the suit was too formal for the situation. I could tell that, at this point, Professor McGonigle was struggling to find a way to ask for a new look for this particular scene 
without upsetting me. I politely expressed my disagreement with Professor McGonigle's interpretation of the costume in context, but suggested that I go to costume storage to look into other options.

The next afternoon, I searched through costume storage with the help of Professor Mary McClung, and found some items to mix and match in order to create a new, less glamorous look for Mrs. Vaughn. In the costume shop, I used a mannequin to test out some combinations of garments that I had pulled so that I would be ready for a fitting with Ms. Hintz later that afternoon. During the fitting, we were able to tailor a men's suit coat to look like a fitted women's jacket from the period, mimicking a few of the style details from my original design. We were also able to let out a previously unfinished brown corduroy period skirt to fit Ms. Hintz, which completed the new look. The costume shop quickly pushed through the alterations on both garments, and by the evening's dress rehearsal, Ms. Hintz was onstage in a brand new outfit. Professor McGonigle loved the look, and we ultimately kept this new, more conservative version of what I had originally designed.

While I stand firmly behind my original design, I now understand the importance of having time to swatch fabrics if possible. If I had realized what the striped fabric felt and looked like in person before I purchased the full yardage, I most certainly would have searched elsewhere for other options. Oddly enough, during a visit with my family a few months after the show had closed I found that my parents had a sheet set that was exactly what I had originally envisioned for Mrs. Vaughn's Christmas suit. If only I had realized that the fabric that I was looking existed in a nontraditional form right under my nose in the nearest department store! Though this information came too late this time around, I have certainly learned a lesson, and made a mental note for the next time I work in this period.

\section{Rental Process}

While searching for costume pieces for Miss Ruth Amos, I found it increasingly difficult to find dresses in styles that would be appropriate for an early 1900s look. For this reason, I began to explore the idea of using rentals. I perused the Oregon Shakespeare Festival (OSF) website, where I found a dress that was similar to one of my designs for Miss Ruth. The dress in question was grey, in lieu of the navy blue that I had originally designed, but the measurements were nearly perfect to fit undergraduate actress, Ms. Brianna Bowers. After receiving approval 
on the slight change to the look from Professor McGonigle, I went ahead with the rental process. For just one item, the process was not difficult, though there was quite a bit of paperwork to navigate in order to get the request through to the company. At first, I was somewhat concerned with the price of the rental as it was quoted on the website, but with an educational discount, the price was much more reasonable, and fit comfortably into the show budget. Once the rental package arrived in the shop, I set up a fitting with Ms. Bowers. When Ms. Bowers first attempted to try on the dress, it would not come close to buttoning. Perplexed, I inspected the back of the dress, to find that two temporary tucks had been taken in the waistline of the dress. Relieved, I was able to release the tucks to bring the dress back to the size as it was advertised on the website. Though the OSF website and rental paperwork claims that all returned items are examined with the utmost scrutiny to check for damage or unrestored alterations, it appears that this was not the case for the last company that rented this particular garment. 


\section{EXECUTION OF PERFORMANCE}

\section{Technical Rehearsals}

The beginning of the technical rehearsals marked the first moment in a long while that the WVU costume shop was completely prepared for the costumes to go on stage. Although the costume shop had lost one team member (Clinical Professor and Cutter Draper Andrea Washington-Brown) from the previous semester, the rest of the costume shop team banded together for the most successful build process of my graduate career. Days ahead of schedule, every single costume was complete and ready to be seen at the first dress rehearsal.

All organizational paperwork for the crew had been put together well in advance. The tracking of costumes throughout the shows was simple enough that the plot and the piece list were very similar in style, with only a slight variation in formatting. Due to the fact that I wanted to be sure that every single item was accounted for before the build of the show began, I created a preliminary costume plot, which I later converted into a piece list. Once all items had been accounted for on the costume rack, I reconverted my piece list back into the formatting of a plot. In addition to the costume plot, I had created a character entrance and exit plot in order to keep myself on track throughout the design process. I distributed the entrance and exit plot to the Wardrobe Supervisor in case he found it useful for tracking quick changes. (See Appendices I-IV for samples of paperwork)

Although the undergraduate Wardrobe Supervisor for the production seemed to be a promising candidate for the position based on his superior level of work in the costume shop the previous semester, he did not turn out as well as the costume shop team had hoped when placed into a leadership role. On the very first day of his duties, he arrived late to a meeting that he was supposed to lead. The student supervisor was completely unprepared, having forgotten to make copies of the paperwork for his crew. I therefore took it upon myself to make the rest of his copies while Graduate Wardrobe Manager Ms. Cody Lorich supervised his discussion on the responsibilities of working as a dresser with the crew. Ms. Lorich reprimanded her subordinate for his mistakes following this meeting. Lorich informed him that his tardiness and unpreparedness were unacceptable, and should not be repeated. The student supervisor promised to do better moving forward. 
The morning of the first dress rehearsal, I talked through each of the costumes on the show rack with my run crew. I showcased each costume piece, its purpose, and explained how the piece was to be layered with the rest of the costumes for each individual scene. During this time, I explained to the crew that many of the items on the rack were made of natural materials, such as cotton and linen, and that cottons and linens wrinkle very easily. I requested that the crew steam or press each garment diligently before each show. In addition, I requested that they not allow the actors to dress earlier than necessary in order to maintain a fresh look for the costumes at the top of the show. I explained that the wrinkling of the fabric throughout the show was both natural and inevitable. The costumes' progression from pristine to wrinkled would simply indicate the passage of time on a realistic level. The linen skirts of both Elizabeth and Mrs. Vaughn were the costume pieces most affected by this issue, as both skirts' fiber content was $100 \%$ linen. As Mrs. Vaughn's skirt was constructed with a lightweight linen, the wrinkles produced by sitting at the front of the skirt became very pronounced very quickly once the actress, Ms. Madeline Hintz donned her costume.

The extreme ease with which Mrs. Vaughn's blue skirt wrinkled became an issue once the show opened. While attending a paid performance as an audience member, I noticed that the skirts and blouses, and in particular: Mrs. Vaughn's blue linen skirt, were terribly wrinkled from the very beginning of the show. The costumes looked as if they had not been pressed after the previous night's performance. As an audience member, this distracted me from the play's action, which I had not yet been able to enjoy due to my constant scrutiny of the costumes during technical rehearsals. It was clear that the dressers had either failed to do a satisfactory job of preparing the costumes for the show, or that they had allowed their actors to get into costume too early. Although it is the dressers' responsibility to make sure that all of the costumes look as they should at the top of, and throughout the show, it is the undergraduate Wardrobe Supervisor's responsibility to enforce the standards that have been set by the designer and the graduate Wardrobe Manager. The show's Wardrobe Supervisor, was therefore considered the leading cause of this disorganization. The student supervisor's ineptitudes in a leadership position had been noted during the technical rehearsal process, and although I did not deal with the student directly throughout the run of the performance, I was kept abreast of his missteps through the graduate Wardrobe Manager. The student supervisor was an abominable role model for his dressers, which in turn created a less effective team than usual. The individual undergraduate 
dressers were dedicated students and exemplary workers, however it was apparent that without proper guidance, the group struggled to perform their tasks as efficiently as possible. Without a leader to serve as a role model and to enforce the rules once the technical rehearsals had ended and graduate Wardrobe Manager, Ms. Lorich had stepped back from the process, the team of dressers was very clearly left to make decisions and figure out the responsibilities of a dresser on their own.

One of the undergraduate Wardrobe Supervisor's chief inadequacies as an authority figure included his chronic tardiness to each and every one of his call times. His crew of dressers was almost always present and ready to work before he arrived in the costume shop. Although the student supervisor offered some excuses for his lateness which, at first, seemed legitimate when technical rehearsals first began, these excuses soon came far too frequently for all of them to be considered legitimate. In one instance, the student supervisor claimed that his car had broken down. This caused both himself, and the dresser who was riding with him to be a full half hour late to their call, putting both behind on maintenance duties. In addition, the Wardrobe Supervisor was unskilled at managing his time well, as Ms. Lorich would often call him, only to awaken him from sleep 15 minutes past his call time. Along with his tardiness, the student supervisor did not have a strong presence in the dressing rooms with his dressers or with the actors. A skilled wardrobe supervisor makes rounds, and is constantly trying to find and solve problems before they occur. This particular wardrobe supervisor, however, was lazy. He was often found sitting in the costume shop, clueless as to how to seek out and prevent potential issues. He did not make the effort to correct student dressers who were not putting their full effort into their work. Throughout the technical rehearsal process, and even during the shows, I exchanged messages with Ms. Lorich alerting her that he and the crew were still not properly keeping an eye of the costumes on the actors in between scenes. There were many small issues which could have easily been remedied when the actors exited stage had a dresser been waiting and alert. There were far too many avoidable instances of flipped up collars, tucked up hems and open skirt plackets to deem them all accidental.

Although I had meticulously prepared my costume plot based on my close readings of the script, occasionally muddled paperwork is unavoidable within the technical rehearsal process. During the first dress rehearsal it became apparent that my understanding of the transitions within and between the scenes in Valentine's Day were not quite accurate. While I had hoped to 
be able attend a full run through of Valentine's Day before entering technical rehearsals in order to verify the accuracy of my costume plot, this did not turn out to be possible. Due to the expedited rehearsal process, Professor McGonigle did not get into full runs of the shows until the evening before the pre-tech performance for the crew. I gathered what information I could from these run-throughs and adjusted my costume plot according to what I had observed. Though there remained some grey areas in terms of where and how some costume changes would take place in Valentine's Day, I felt confident that these discrepancies could be remedied during quick change rehearsals at first dress.

The most worrisome transitions were Elizabeth and Horace's onstage and offstage changes between scenes. In the end, Elizabeth's changes were simple enough to figure out with some direction from myself, and some additional quick rigging on costume pieces along with quick change help from the crew backstage. However, figuring out how Horace was to dress himself on stage was a slightly more involved process. The discussion previous to the rehearsals had indicated that Horace would be taking his time to get out of his pajamas and into his everyday clothing for a trip to Mr. Dickerson's store. Unfortunately, this transition took too long within the action of the scene. As Professor McGonigle was already concerned about the length of the production, he hoped to eliminate a few minutes overall. For this reason, I had to adjust the order in which Horace wore his various costumes beginning in scene 1 of Valentine's Day. At the top of the play, Horace was seen half dressed in his Christmas suit instead of halfway between his pajamas and his second, less formal suit. Since no time could be wasted in getting him fully dressed, when Horace left the stage quickly to go pick up gifts for the Vaughn family's impending visit, he grabbed the rest of his clothing and presumably dressed himself on the way to the store. This is where the dressers came into play and helped the actor, Mr. Isaac Snyder to get himself fully dressed and looking put together before his return from his brief trip to the store. By coming back from the store already dressed to see the family, we no longer needed to allow the time for Horace to prepare himself before the entrance of the Vaughn family, which helped the plays action to more quickly unfold.

In terms of the fit of the final costumes, most were excellent. Mrs. Vaughn's Courtship look in particular looked beautiful, however we neglected to test the fit of the skirt while in a seated position in fittings with the actress, Ms. Madeline Hintz. The realization came too late in the process that Ms. Hintz's skirt for Courtship was too tight by a very small amount around her 
hips. Whenever Ms. Hintz would sit, the skirt's placket would occasionally pop open and stick out quite obviously from Ms. Hintz's back side. There was no viable solution to this problem as no additional seam allowance remained at the side seams following the alterations made after the final fitting on the skirt. In hopes of discovering an alternative solution, the costume shop tried everything from stronger snaps, to hooks and bars in order to keep the back placket shut. Simply pinning the placket shut with safety pins for each show was suggested by one of the dressers, however, this solution was eventually vetoed for fear that the strain put on the pins would cause them to pop open mid-scene, which might inadvertently injure the actress. Unfortunately, all efforts made to resolve this issue were futile, as the skirt placket continued to pop open onstage anytime that Ms. Hintz sat down. In the end, we worked with Ms. Hintz to find ways for her to sit which would minimize the chance that the placket might open onstage. Her dresser, undergraduate student Sydney Yates, was also charged with keeping an eye on the back of Ms. Hintz's skirt every time she walked off stage, so that if it had opened, the malfunction would at least be remedied before her next entrance.

\section{Hair, Wigs, \& Makeup}

One of my biggest concerns from the beginning of the design process was the fact that leading actress, Ms. Margaret Dransfield, had a patch shaved into the side of her head. My first instinct was to wig Ms. Dransfield in order to hide her extremely modern haircut. Professor McGonigle, however, was very much enamored with the look of Ms. Dransfield's natural hair, and hoped to find a way to work with her hair so that it might suit the period. From this point forward, Ms. Dransfield began to grow out her shaved patch, which helped to camouflage the shorter section of her hair once I had chosen an appropriate hairstyle for the character. Though I had originally designed a more sweeping up-do for Elizabeth, with Ms. Dransfield's uneven haircut in mind, I tested a look which swept the hair back while keeping it closer to the neck for the press release photo shoot a few weeks prior to dress rehearsals. 


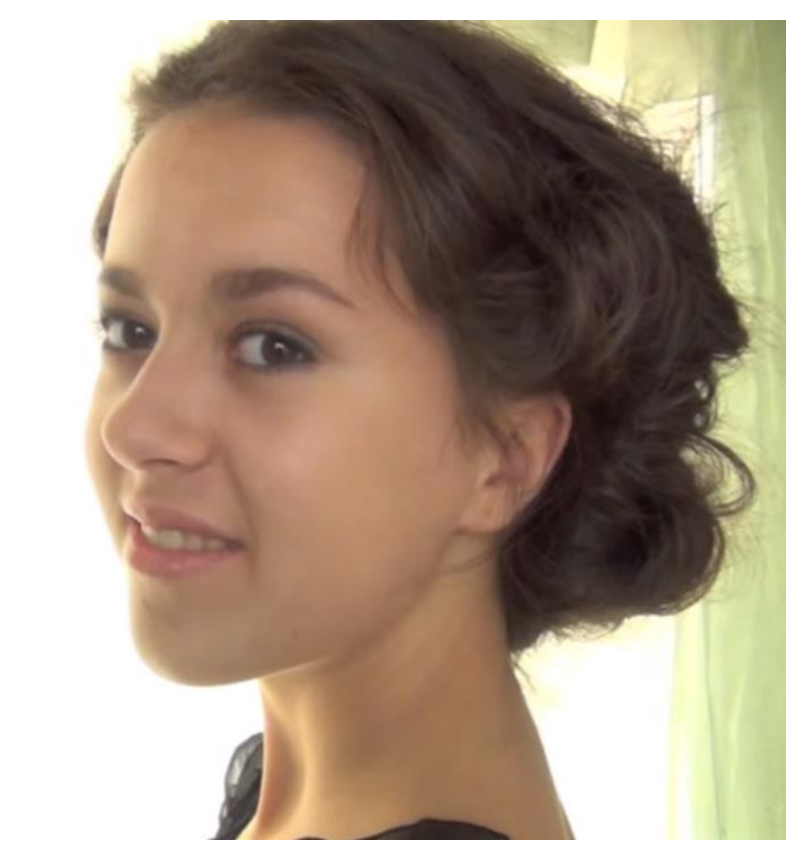

Figure 86: Image captured from video tutorial sent to Ms. Dransfield for Elizabeth's hairstyle.

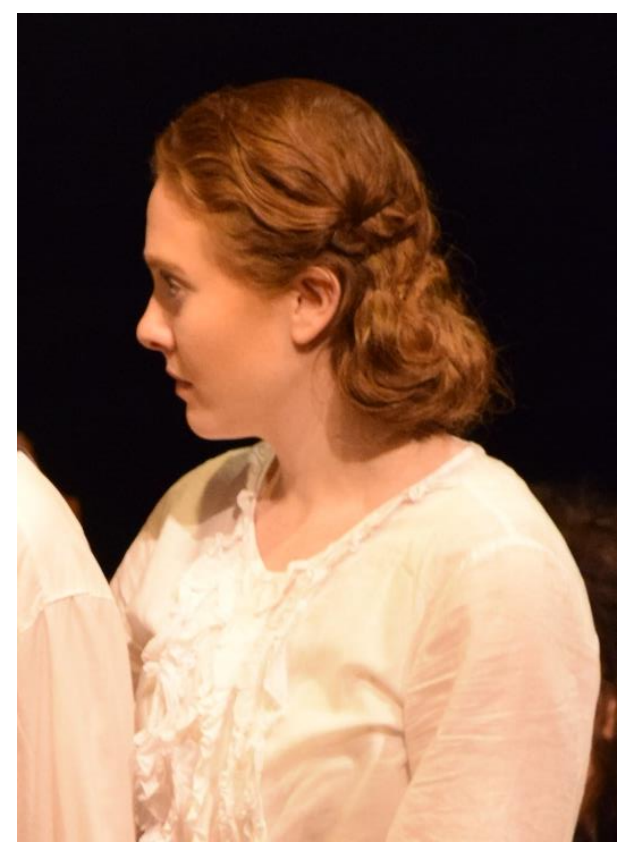

Figure 87: A look at the side of Ms. Dransfield's head where her hairstyle covers her shaved patch of hair in Valentine's Day.

This modified hairstyle was simple, and worked surprisingly well to mask Ms. Dransfield's patch of shorter hair. The twists at the side front could be pulled forward and draped over the shorter area, creating the illusion that her hair was all the same length. Ultimately, this style was retained for the run of the show, and proved to be both simple and elegant, making it a very appropriate choice for the character.

It was decided early on in the design process that we would use the natural hair of the actors whenever possible to create their hairstyles. Finding a style which worked for Ms. Dransfield was a challenge, which made the rest of the style and tutorial research seem quite easy in comparison. I compiled video tutorials on various period hairstyles which I sent out in a PowerPoint to the female actors a few weeks prior to technical rehearsals. I invited each actress to practice before dress rehearsals so that they could work through any issues with the style and ask for my advice or help when I would have time to give them uninterrupted individual attention. It was my hope that this would save some time during the wig, hair, and makeup training session, but unfortunately not all of the actresses had time to work with their styles ahead of time. In the end, however, the styles were simple enough that the actresses were able to achieve them without taking up too much extra time during the technical rehearsal. 
The decision was made to wig actress Katie Boothby and Brianna Bowers due to the fact that it would have been unnecessarily difficult for both girls to create two separate hairstyles using their own hair for each of their two separate characters. Since Aunts Sarah and Lucy are older ladies, they require greying hair. Rather than force Boothby and Bowers to apply hair white on their own hair, which would have needed to be completely washed out for the hairstyles of their second characters, I pulled and styled some pre-ventilated wigs.

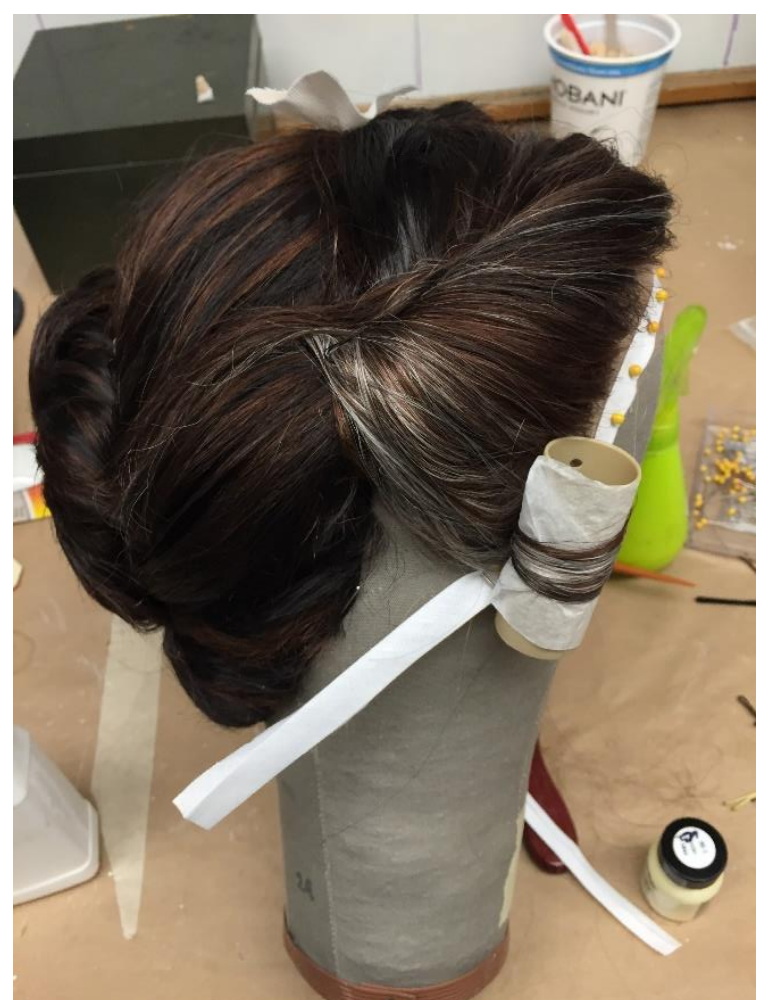

Figure 88: Side view of Aunt Lucy's wig with tendrils in curlers.

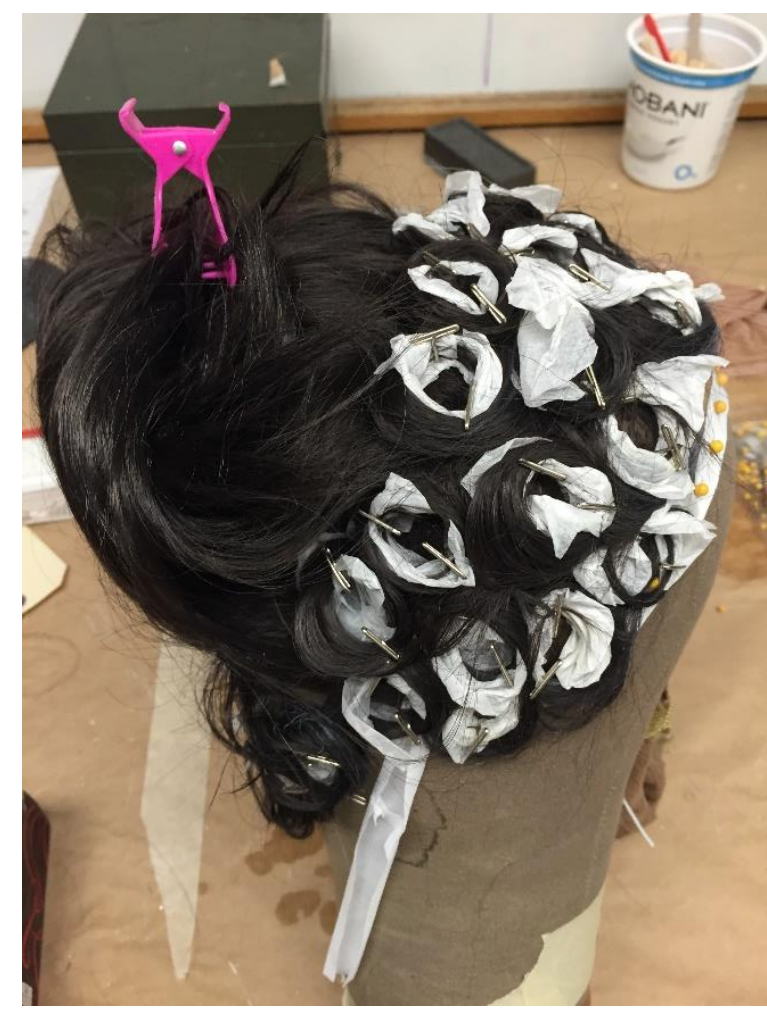

Figure 89: Side view of Aunt Sarah's pin curl set to create natural looking waves.

This meant that both Ms. Boothby and Ms. Bowers needed to have their hair pin curled to wear the wig, and then they could take down their hair and use their backstage time between shows to work their hair into its style for Bessie and Miss Ruth, respectively in Valentine's Day. In addition to making their transition easier backstage, the use of these wigs made the actresses completely unrecognizable from play to play, which helped to avoid confusion from the audience's perspective. 


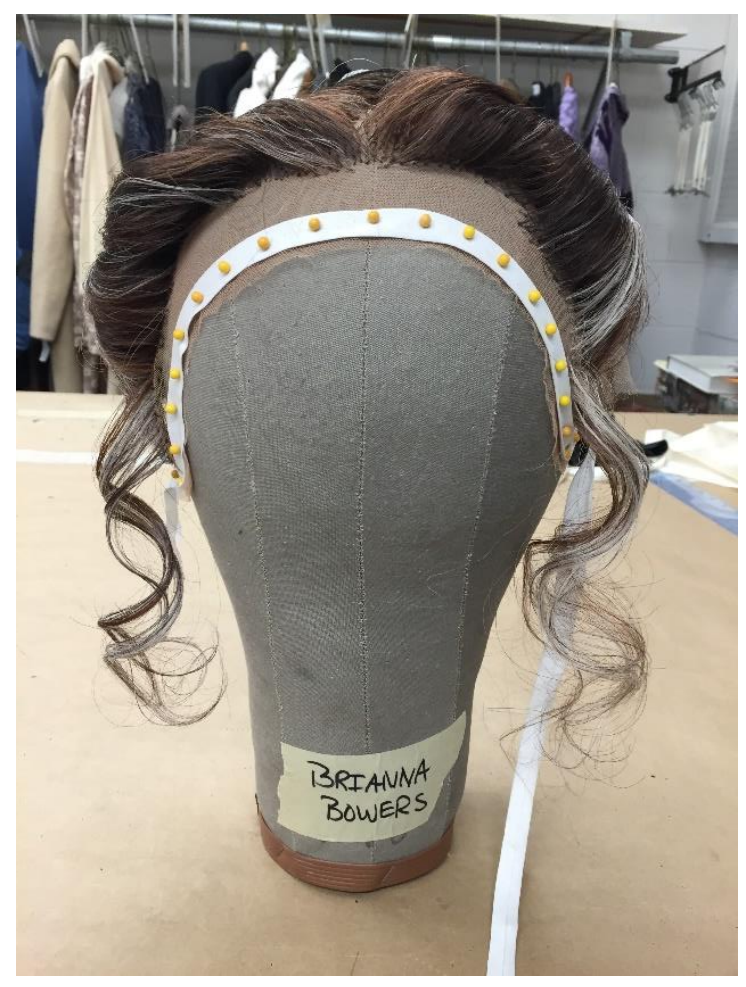

Figure 90: Front view of Aunt Lucy's finished Wig.

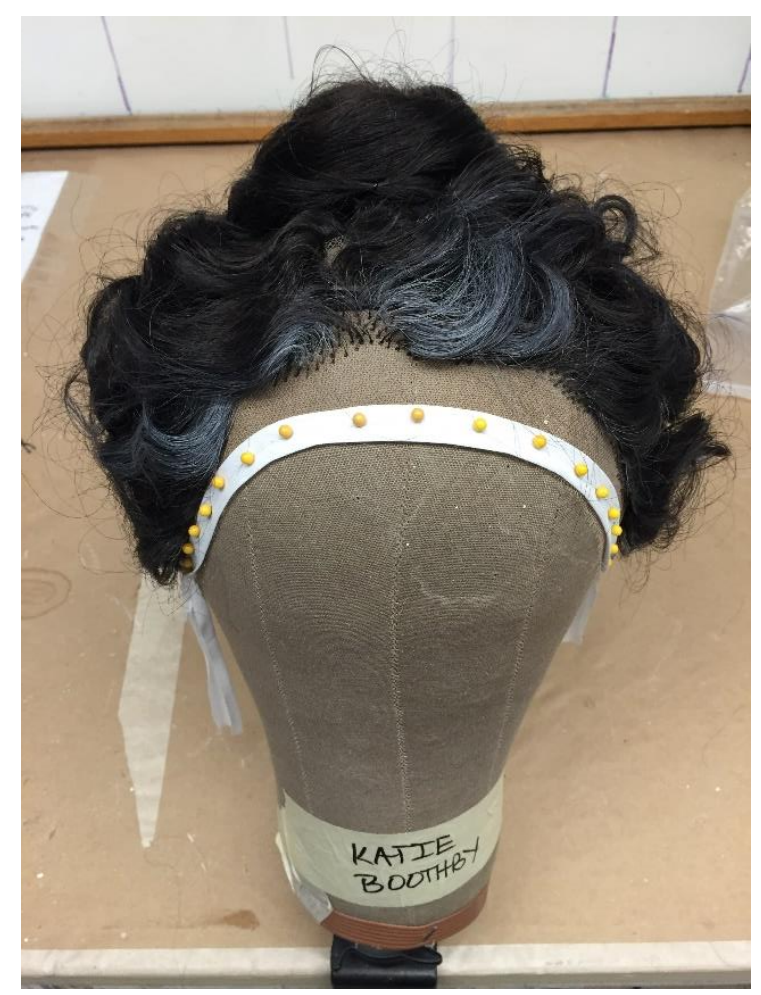

Figure 91: Front view of Aunt Sarah's finished wig.

One of the most enthralling parts of the technical process was the application of latex prosthetic and a balding wig on Ms. Mallory Robson to transform her from Laura Vaughn in Courtship to Dr. Goodhue in Valentine's Day. This transformation involved effort on behalf of Ms. Robson herself, her dresser, undergraduate student Ms. Micah Beachy, and specifically designated wig and makeup assistant, undergraduate student Ms. Katie Meighan. When first discovering how to apply all of the makeup as well as the wig, the process took one and a half hours to complete. However, with practice the wig and makeup team had the change down to approximately 30 minutes, leaving Ms. Robson time to spare before her entrance as Dr. Goodhue. Directly following her exit from the stage, Ms. Robson had her prosthetics and wig removed and transformed herself back into Laura. Ms. Robson requested to bow at curtain call as Laura instead of Dr. Goodhue, as the former role was decidedly more substantial in comparison. While the application of the wig and prosthetics went more and more smoothly as time progressed, during the technical process there were a few issues which arose with the style of the wig chosen for Dr. Goodhue's look. Because Ms. Robson was a female playing a male, Professor McGonigle was not convinced by the longer slicked back men's wig that had been chosen to 
match Dr. Goodhue's rendering. McGonigle expressed his desire for a shorter wig, as the longer men's style looked too much like Ms. Robson had simply pulled her own hair back into a low ponytail. Knowing that it would not be possible to cut the wig any shorter due to the manner in which the wig was constructed, I attempted a different style with the wig, with no success. When it became clear that a different wig was needed for the character, I proposed that we try a premade balding wig from WVU's stock. This balding wig, while meant for a larger venue, fit Ms. Robson well, and served the purpose of transforming Ms. Robson from a young female to an older male with little room for misunderstanding. (See Appendix VI)

\section{Paid Performances}

Dealing with severe illness in a cast without pre-designated understudies is an extraordinarily challenge. Throughout the technical rehearsal process, graduate actor, Mr. Joseph Bussey began to show signs of illness. Mr. Bussey pushed through his symptoms for most of the rehearsals in order to keep the show moving forward. There were a few days where Mr. Bussey's role in the rehearsal process was reduced to keep him from exhausting himself in his the face of his weakened health, but he persevered through rehearsals in spite of extreme fatigue. As the opening of the production approached, Mr. Bussey realized that his illness was not a simple cold, but rather a bout of influenza. Unfortunately, by the time that his exact illness was pinpointed, the rest of the cast and crew had already been exposed. Luckily, the majority of the cast and crew were able to avoid illness through good hygiene practices. All but two other actors and one dresser managed to avoid falling ill. Graduate actress, Ms. Madeline Hintz, and undergraduate actress Ms. Margaret Dransfield both fell ill at the beginning of the run of the paid performances of the show. Due to the fact that all three of the actors stricken by the flu were playing lead roles, the last minute decision was made to cancel two shows in order to give those actors some time to rest, and hopefully recover. Luckily, Ms. Dransfield recovered rather quickly, and was able to continue the performances without issue, as her illness turned out to be more related to stress and overwork than viral infection. Ms. Hintz and Mr. Bussey, however, did not recover quite so quickly, which raised the idea of creating last minute understudies for their roles in case either actor was unable to perform.

Since understudies were not cast in forethought, there was no one other than the professors who had worked closely on the show who could remotely comfortably take over the 
roles of the actors who had fallen ill. Professor McGonigle was set to step in for Mr. Bussey if need be, and Professor Cathy O’Dell was set to step in for Ms. Hintz. Since Mr. Bussey had more time to recover than Ms. Hintz given that his illness has begun weeks prior, Bussey was much more confident in his ability to perform following the cancelled shows. Ms. Hintz, however, was on the fence about whether or not she would be able to perform. For this reason, I prioritized pulling costumes for Professor O’Dell over Professor McGonigle. I called Professors McGonigle and O'Dell in for quick measurements, and then set up a fitting with Professor O'Dell later the next day. For this fitting I had pulled multiple options for outfits along with the proper undergarments, including a corset. For Mrs. Vaughn's look in Courtship, a simple blue striped blouse with a matching neck cloth was chosen along with a subtly striped long brown skirt. For Mrs. Vaughn's Christmas look in Valentine's Day, I pulled and fit Professor O'Dell in a loosely woven green skirt and jacket with a simple white high necked blouse underneath. O'Dell was able to wear Ms. Hintz's shoes, feather hat, and winter coat, and thus the understudy costume was set. A few minor alterations were needed to get the green skirt and jacket ready for O'Dell to wear, but these went quickly through the shop, and the look was ready to be used that very evening. Neither Professor McGonigle nor Professor O'Dell ended up going on for their ill students, who persevered through exhaustion, and in some cases nausea, to perform each night.

The illness took a little longer to hit the crew, but eventually affected undergraduate student, Ms. Micah Beachy, a hard working dresser who played an integral role in the fast paced wig and makeup transformation of Ms. Mallory Robson for the role of Dr. Goodhue. Ms. Beachy attempted to stay on and work for as long as possible, but it soon became apparent that she had contracted the flu, and needed to be sent home both to rest, and to prevent further spread of the illness. In her stead, a couple of trustworthy dressers were asked to step in to help Ms. Katie Meighan with Ms. Robson's makeup transformation. Luckily, the team of dressers worked well together, and were happy to step in and assist as needed.

Once the shows looked to be back on track in terms of roles being performed as cast, it became apparent that actor Joseph Bussey had lost a considerable amount of weight due to his illness. This realization was made very close to show time, and therefore his costume's newly baggy fit was not able to be resolved right away. However, following the evening's performance, Bussey was put into both of his costumes again to be refit. Both his vest and his pants for Courtship had become so large on him that they no longer reflected the polished nature of the 
character. Likewise, his costume for Valentine's Day left him swimming in too much fabric. Although it is normally the crew's responsibility to take care of notes that occur once the show has opened, the costume shop made an exception due to the circumstances and took on the alteration of the garments the next afternoon. The garments were taken in so that the fit was slightly looser than they were pinned in case Mr. Bussey gained back any of the weight that he had lost during his illness throughout the remainder of the show's run.

In addition to hurting the energy of the acting in performances, the bout of illness spreading through the cast caused some of the actors to give less effort to their appearance when preparing for shows. Though much of the disarray of the costumes could be attributed to the wardrobe supervisor's lack of professional skills, I believe that the actors who were ill were also less able to put in the necessary effort to present themselves nicely. Ms. Hintz, in particular, suffered because she had to style her own hair through her illness-induced exhaustion. This caused her hair to appear frizzy, messy, and out of control, while I knew that she was capable of doing better. Unfortunately, Ms. Hintz's dresser was not brave enough to ask her do the hairstyle over again, nor was she equipped with the proper skills to help Ms. Hintz with the hairstyle when Hintz was feeling tired and overwhelmed. Because of this, the photo call for the show was not as crisp and nicely put together as it could have been. Mrs. Vaughn's looks are sullied by the wilted, frizzy hairstyle that Hintz was not able to pull together for the show preceding the photo shoot, and the costumes themselves were not prepared for photo call as they came off stage, so when the actors changed back into them, they were more wrinkled than they had been on the actors. This compromised the quality of many of the production photos from that evening. Unfortunately, there was no time to demand that the costumes be pressed and the hair be fixed once the issue was identified, as there is a limited time allotted for photo call, and attempting to fix the crumpled hairstyles and costumes would have cost a good many of the shots that the rest of the production team were looking to take. 


\section{CONCLUSION}

\section{Positive Learning Outcomes}

My experience with Courtship and Valentine's Day has helped to develop my understanding of what it means to work successfully as a costume designer. One of the largest factors in the success of this production was the efficiency with which the WVU costume shop was able to work in this given semester. In addition to team efficiency, the lessons that I had taken away from past shows in both the professional and academic worlds, helped me to navigate difficult situations pertaining to this production without losing my composure. The best example of this is the manner in which I encouraged Professor McGonigle to officially cut the original design for Mrs. Vaughn's Christmas suit in Valentine's Day. Once I realized that Professor McGonigle was not happy with the look, I made sure to relay to him that cutting the costume would not be a problem if that was what he felt was necessary. Although the decision to cut the look pained me, I was able to move calmly past this personal bias to do what was best for the show. In addition to maintaining composure, staying well below my budget created a safety net for emergencies which might have otherwise caused myself and my team in the costume shop unnecessary stress. While this emergency fund was not used in the instance of the last minute switch in Mrs. Vaughn's Christmas look, the security of having the money to go out to buy something new if needed helped keep the expedited replacement process smooth and without too much undue stress on my shoulders.

Through the design and production process for Courtship and Valentine's Day, I learned the importance of self-care. Balance is important when it comes to any job. Costume design, in particular, can be demanding. If not properly organized, a designer can find themselves pulled in all directions and thus stretched extremely thin. This type of exhausting experience was the only one that I had known for quite some time, but through feedback and self-evaluation, I began to discover how to make myself work most efficiently. There are people who are sustained by their work, and who work well under pressure. This production process has helped to solidify that I am not that type of person. Finding a balance between work and personal life is important to keeping myself level headed throughout a large project. It was not until I rediscovered the power of a yogic mindset that I began to gain better control of my life and my responsibilities at work. By allotting a window of time for myself to clear my mind and reset my focus, I was more 
readily able to detach myself from outside stressors, allowing only the most pertinent issues to the come to the forefront. In putting my own needs first, I was better able to serve my colleagues both during and after work hours. Even when the workload became overwhelming, I was able to pause and reshape my thinking and attitude to promote productivity. In turn, this mindset lead to the creation of a more efficient designer who put forth a higher quality of work.

\section{Considerations for the Future}

An important take away from this process is that, as a designer, it is important to allow enough time to order swatches of fabrics before placing the final fabric order. Though I chose my fabrics early in the design process, I hesitated to "waste" money on ordering swatches. For this reason, I blindly ordered fabrics based on their descriptions online. This method worked out for some fabrics, but others provided me with quite a surprise. Most notably, the fabric for Mrs. Vaughn's Christmas suit could have been revisited, and perhaps I could have found a better material which would have prevented the suit from being cut from the show. The other notable example, which did not turn out to be a problem, but which still came as quite a shock, was the pinstripe wool purchased for Horace's vest and pants in Valentine's Day. When the wool came in, I was surprised to note that there was a glittery fiber woven into the lengthwise grain of the fabric. I checked back through the website to see if there was any indication that the wool might have some sparkle to it, but there was no hint at this detail. The website was misleading, so there was no way to know that the fabric would have a sparkle to it without first having a swatch. From far away, this sparkle did not show unless you were looking for it, so I decided to proceed with the use of that wool, which worked perfectly well for the character. However, when actor, Isaac Snyder, was backstage, or in a lower level light, the sparkle did become more pronounced. I avoided mentioning this fact to Professor McGonigle in hopes that I was noticing the sparkle simple because I knew to look for it. Luckily, this did, indeed, turn out to be the case, as no one else on the production team mentioned the gleaming wool throughout the technical rehearsals and the final performances. Given the opportunity to make a switch, I most certainly would not have chosen this fabric because of its potential to inadvertently draw focus, and while the costume worked in this instance, there is a chance, as evidenced by Mrs. Vaughn's Christmas suit debacle, that taking a chance on a fabric which is not quite right may not always work out in the end. 
Another important lesson that I have taken from this process is the importance of pushing to see the details of built garments in mockup fittings before moving into real fabrics. As previously mentioned, the production's Cutter Draper, graduate student Cecelia Hill, did not provide me the full detail in her mockups, which damaged my ability as a designer to make and change certain design choices in fittings until it was too late to make changes. In the future I would insist that more detail be included in mock ups much earlier in the process once I noticed that details were being excluded. This is a request that I would never have considered important enough to demand before seeing the outcome of this production. I am now acutely away of how the initial lack of detail affected the interpretation of my renderings in the costume shop.

Last, but certainly not least, the challenge of working on a show which is not to the designer's personal taste is undoubtedly a difficult task. In the case of Courtship and Valentine's Day, the ease with which the design process filtered through the costume shop, as well as the spectacular performance by the actors, helped to feed and develop my appreciation for the plays and their beautifully nuanced characters. For any moments within the plays that I disliked, I forced myself to find aspects of those moments which I found likeable, or which intrigued me. Overall, I am grateful for the opportunity to learn and grow with a piece which was outside of my comfort zone. Working on Courtship and Valentine's Day has taught me a great deal about myself, my strengths, and my creative abilities as a designer. 


\section{APPENDIX I: RESEARCH IMAGE PLATES \& FABRIC SWATCHES}

Note: See Appendix II for individual citations for each research plate. All images for fabric swatches were pulled from Fabric.com.

\section{Elizabeth Vaughn Research}

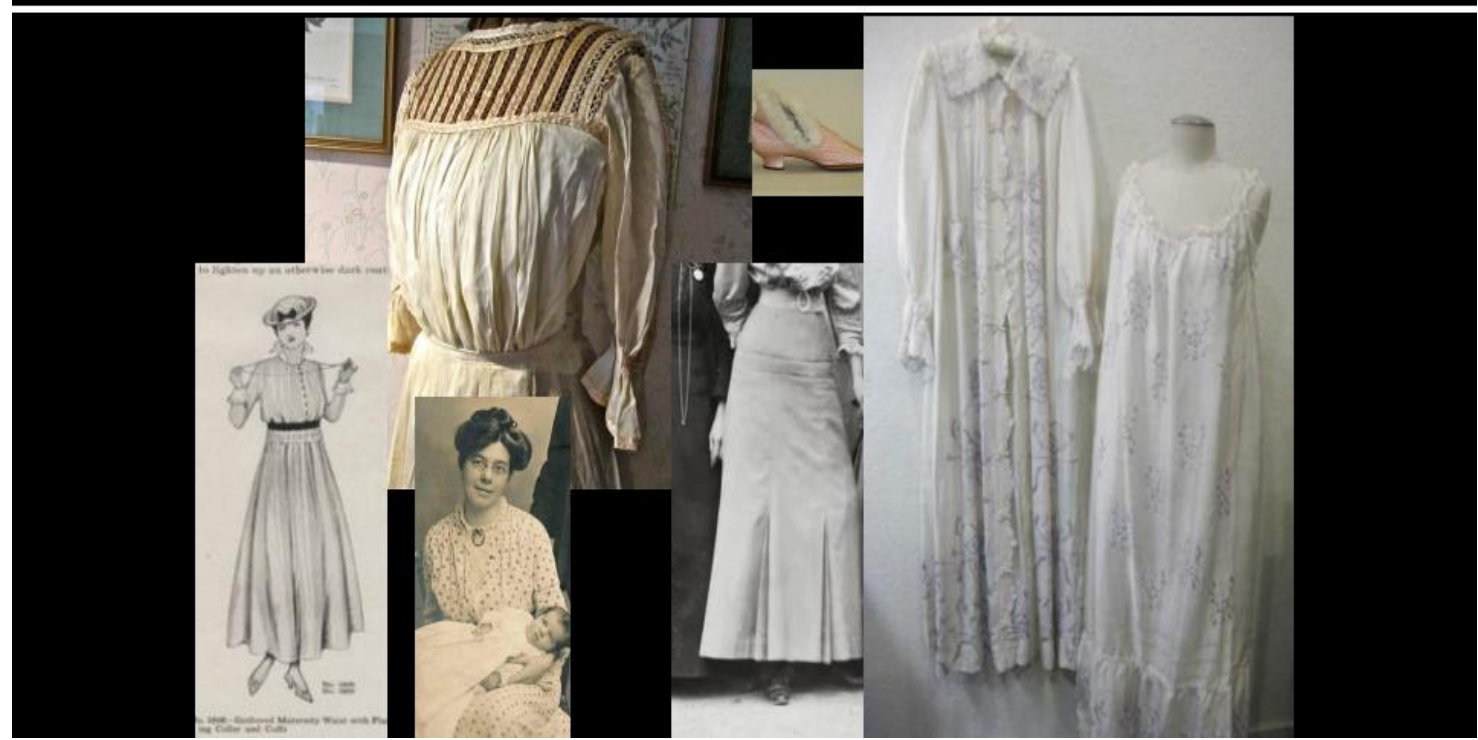

Plate 1: (Above) Research image plate for all looks for Elizabeth Vaughn. Plate 1a: (Below) A preliminary look at fabric options for all looks for Elizabeth.

\section{Elizabeth Fabric Swatches}

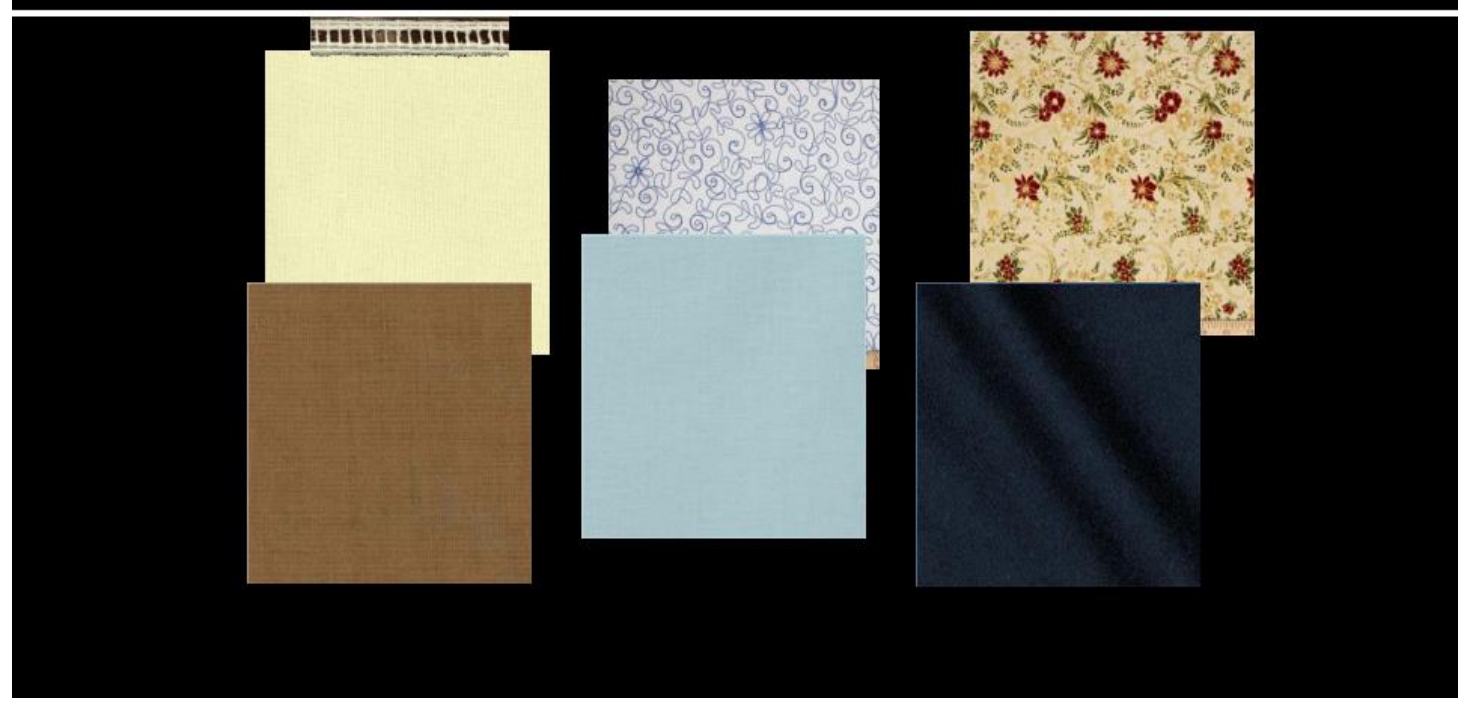




\section{Horace Robedaux Research}

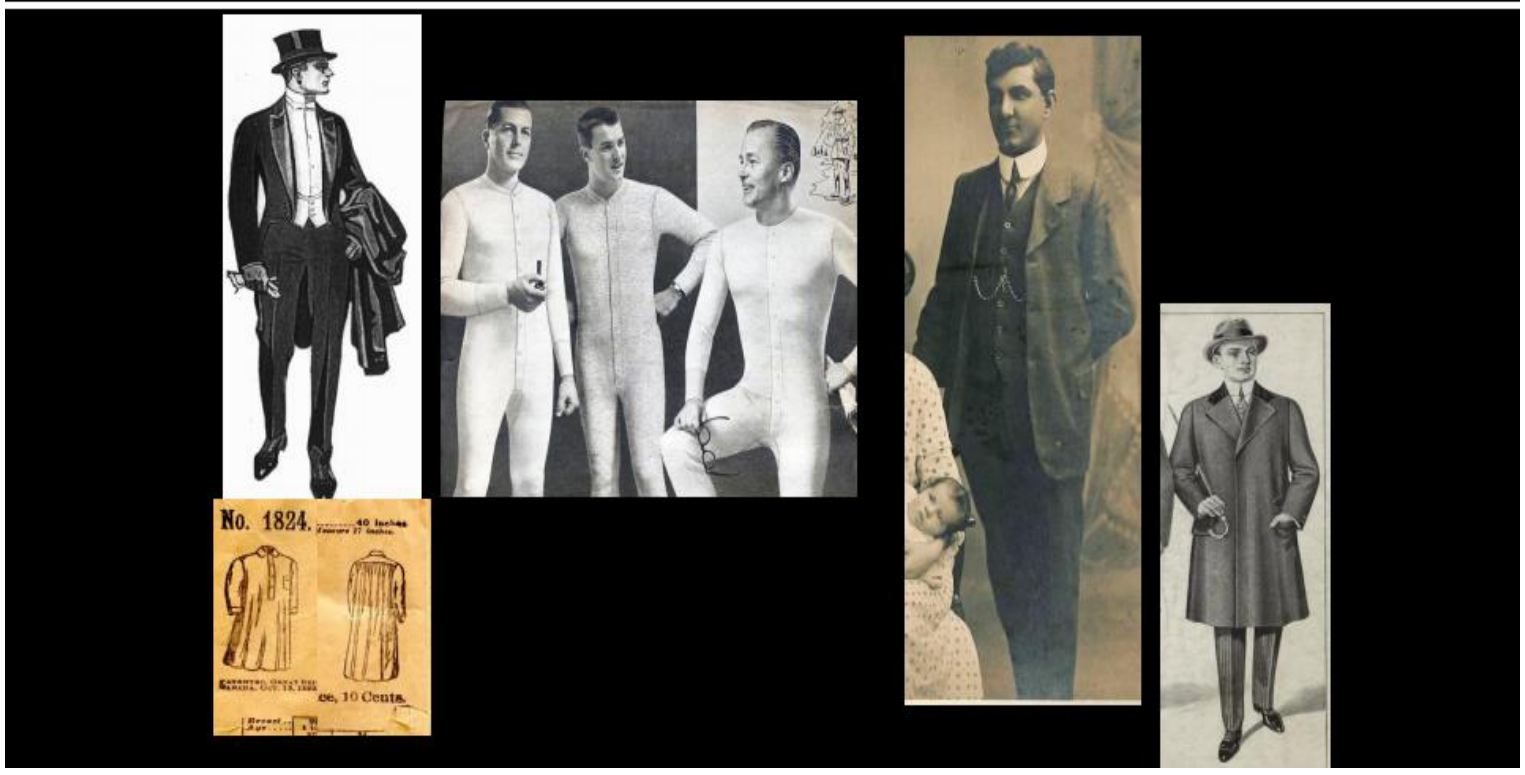

Plate 2: (Above) Research image plate for all looks for Horace Robedaux.

Plate 2a: (Below) A preliminary look at fabric options for all looks for Horace Robedaux.

\section{Horace Fabric Swatches}

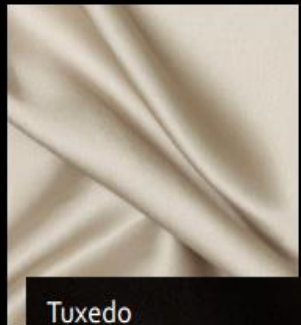

Xmas day

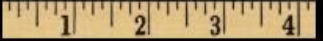

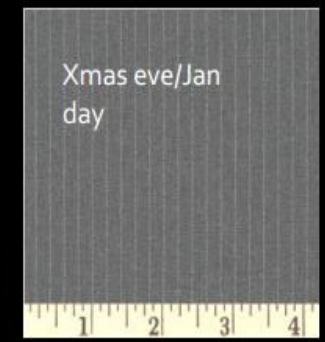




\section{Mr. Henry Vaughn Research}

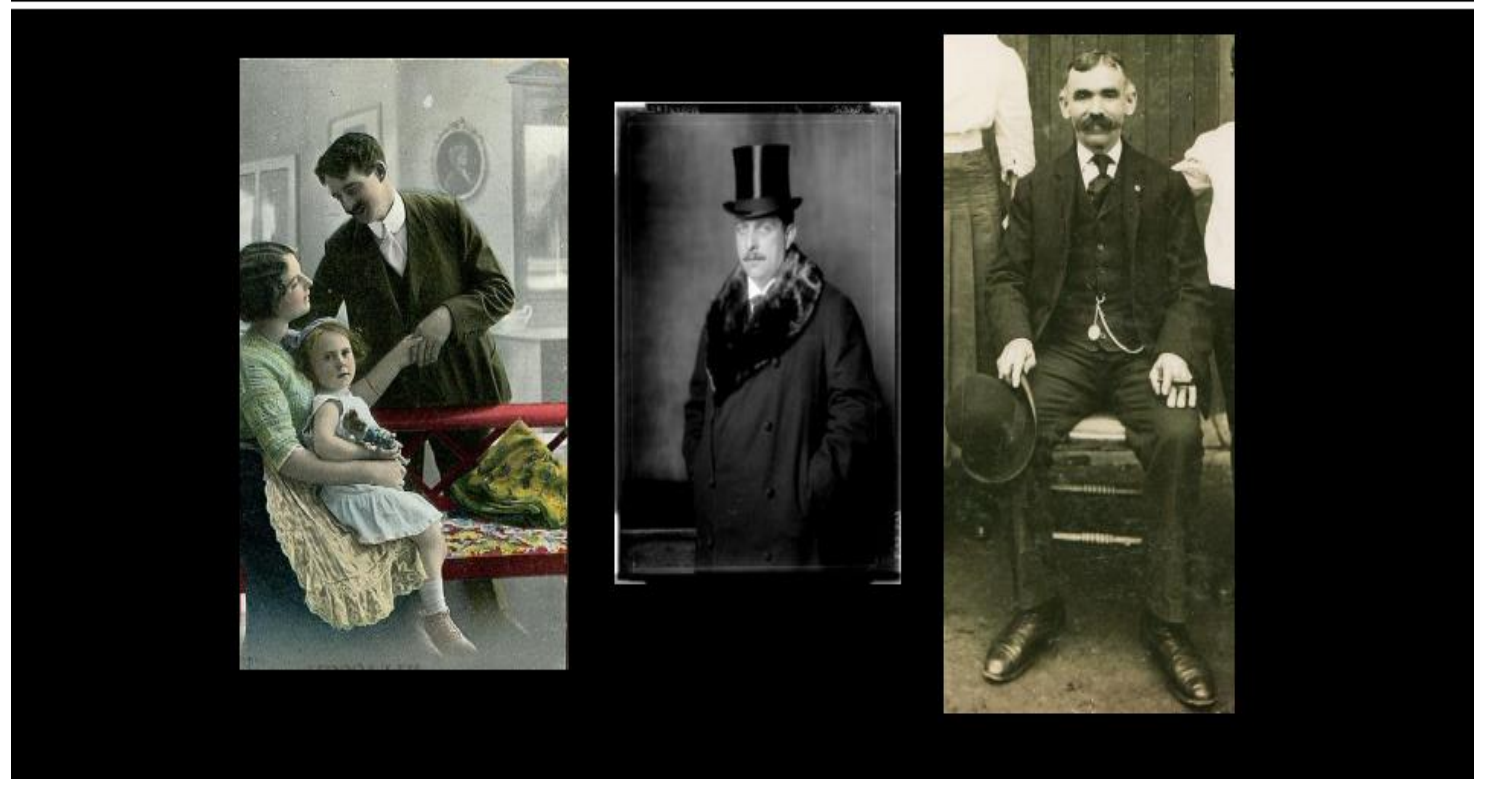

Plate 3: (Above) Research image plate for all looks for Mr. Vaughn.

Plate 3a: (Below) A preliminary look at fabric options for Mr. Vaughn.

\section{Mr. Vaughn Fabric Swatches}

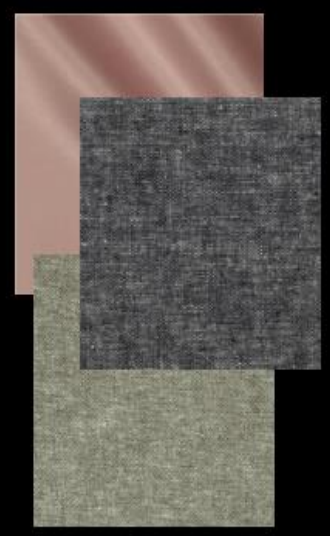




\section{Mrs. Vaughn Research}

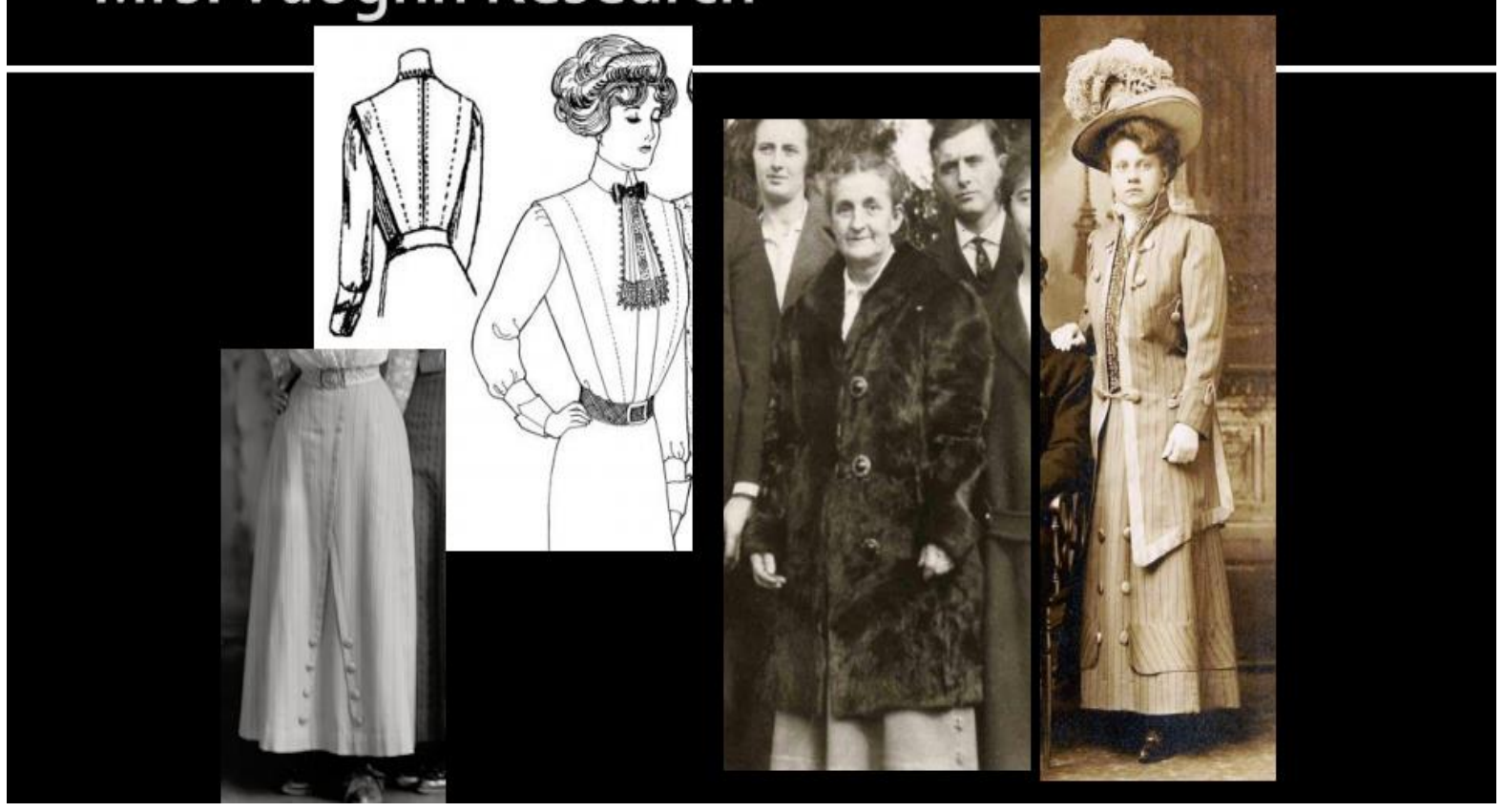

Plate 4: (Above) Research image plate for all looks for Mrs. Vaughn.

Plate 4a: (Below) A preliminary look at fabric options for Mrs. Vaughn.

\section{Mrs. Vaughn Fabric Swatches}
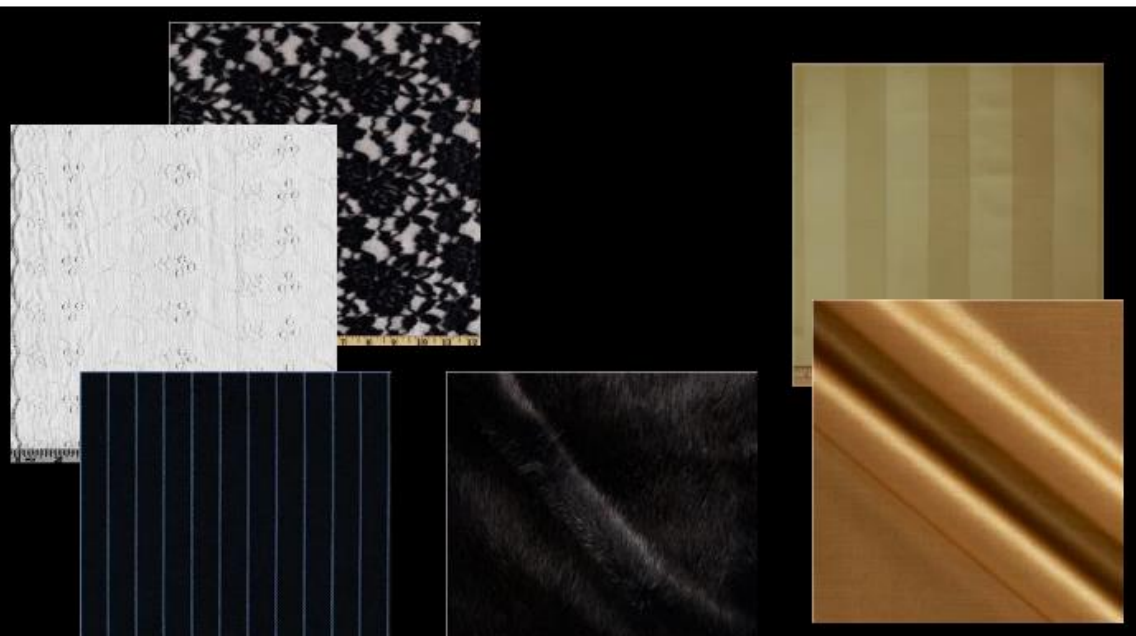


\section{Laura \& Brother Henry Vaughn Research}

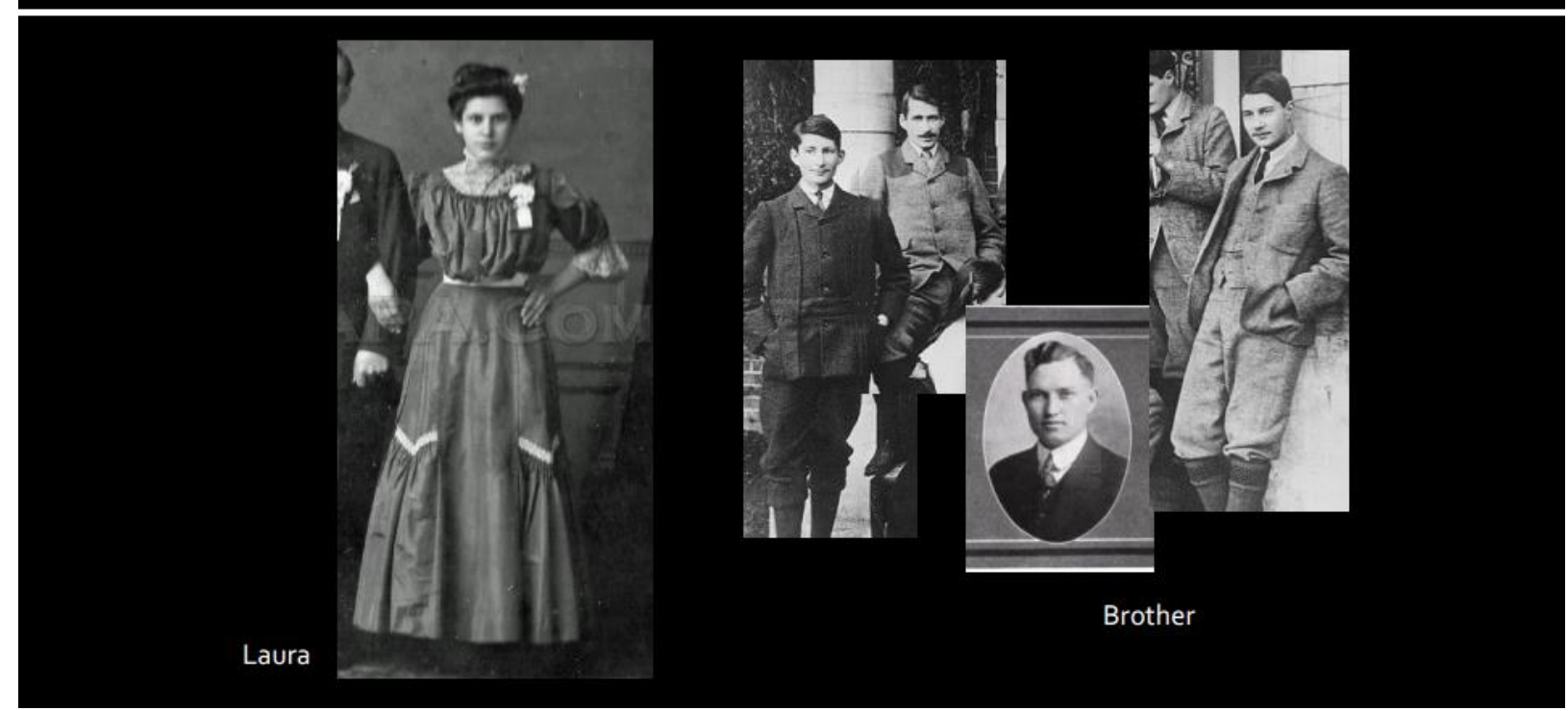

Plate 5: (Above) Research image plate for Laura and Brother Vaughn.

Plate 5a: (Below) A preliminary look at fabric options for Laura and Brother Vaughn.

\section{Laura \& Brother Fabric Swatches}

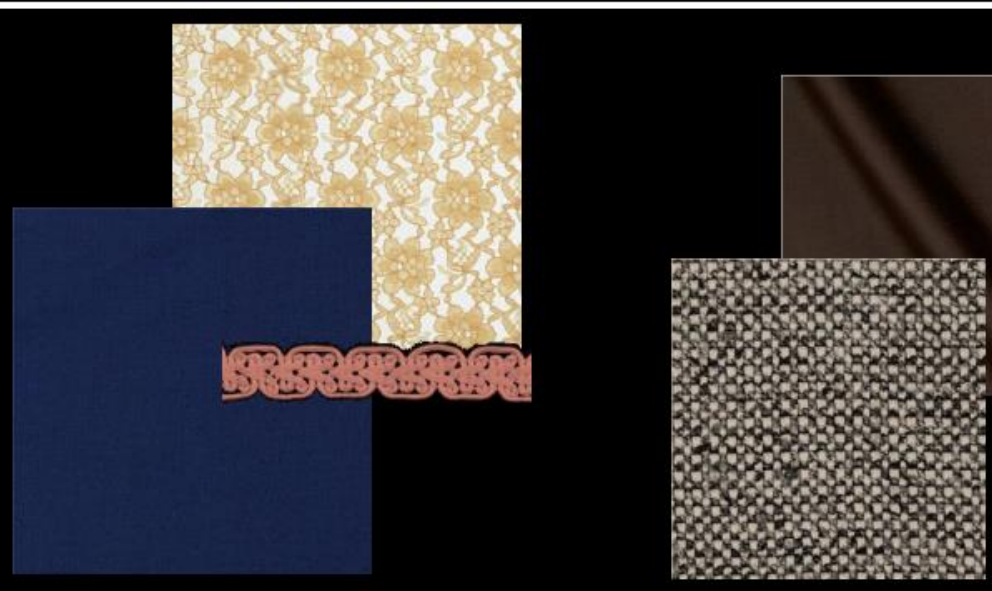




\section{Aunts Sarah \& Lucy Research}

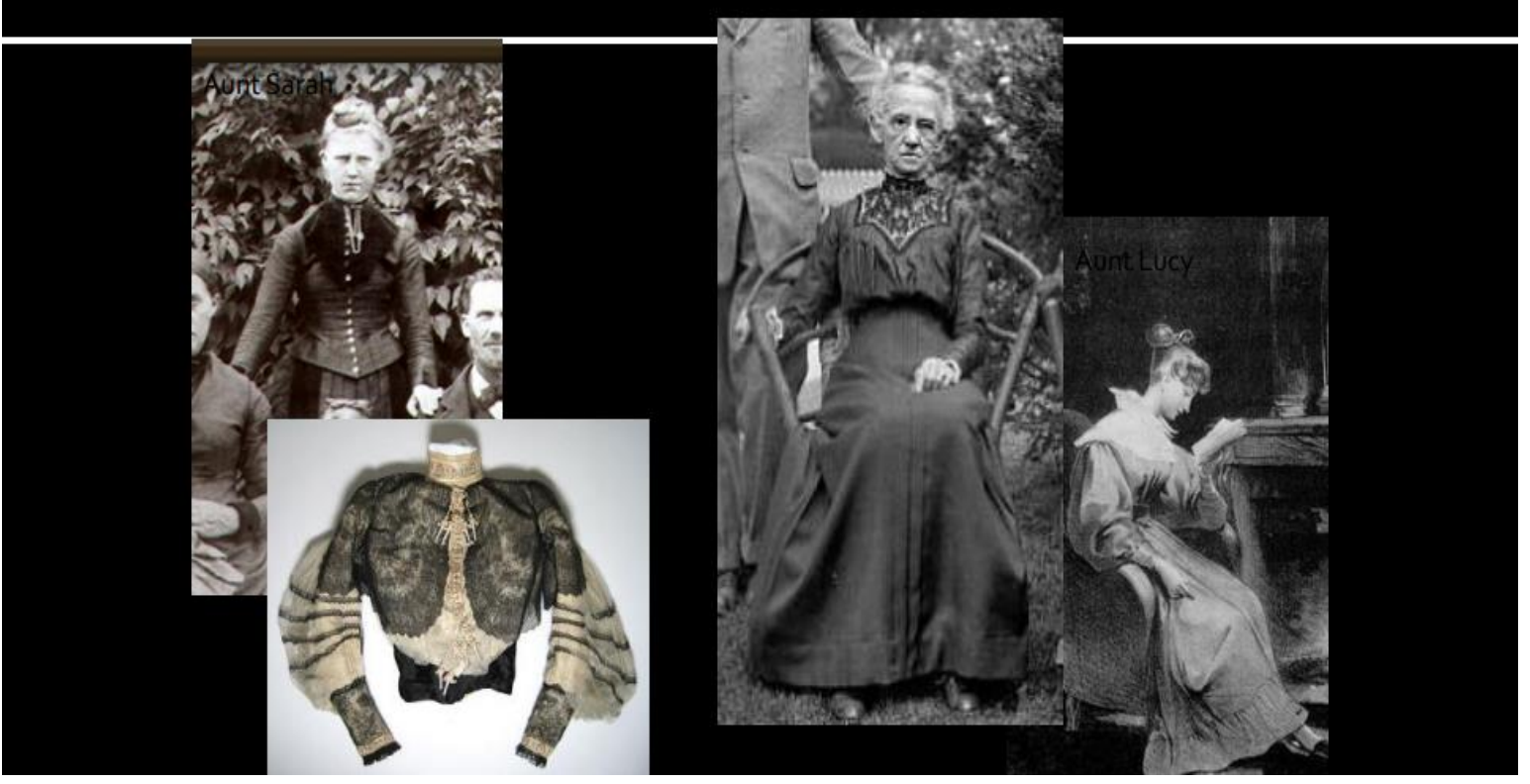

Plate 6: (Above) Research image plate for Aunts Sarah and Lucy.

Plate 6a: (Below) A preliminary look at fabric options for Aunts Sarah and Lucy.

\section{Aunts Sarah \& Lucy Fabric Swatches}

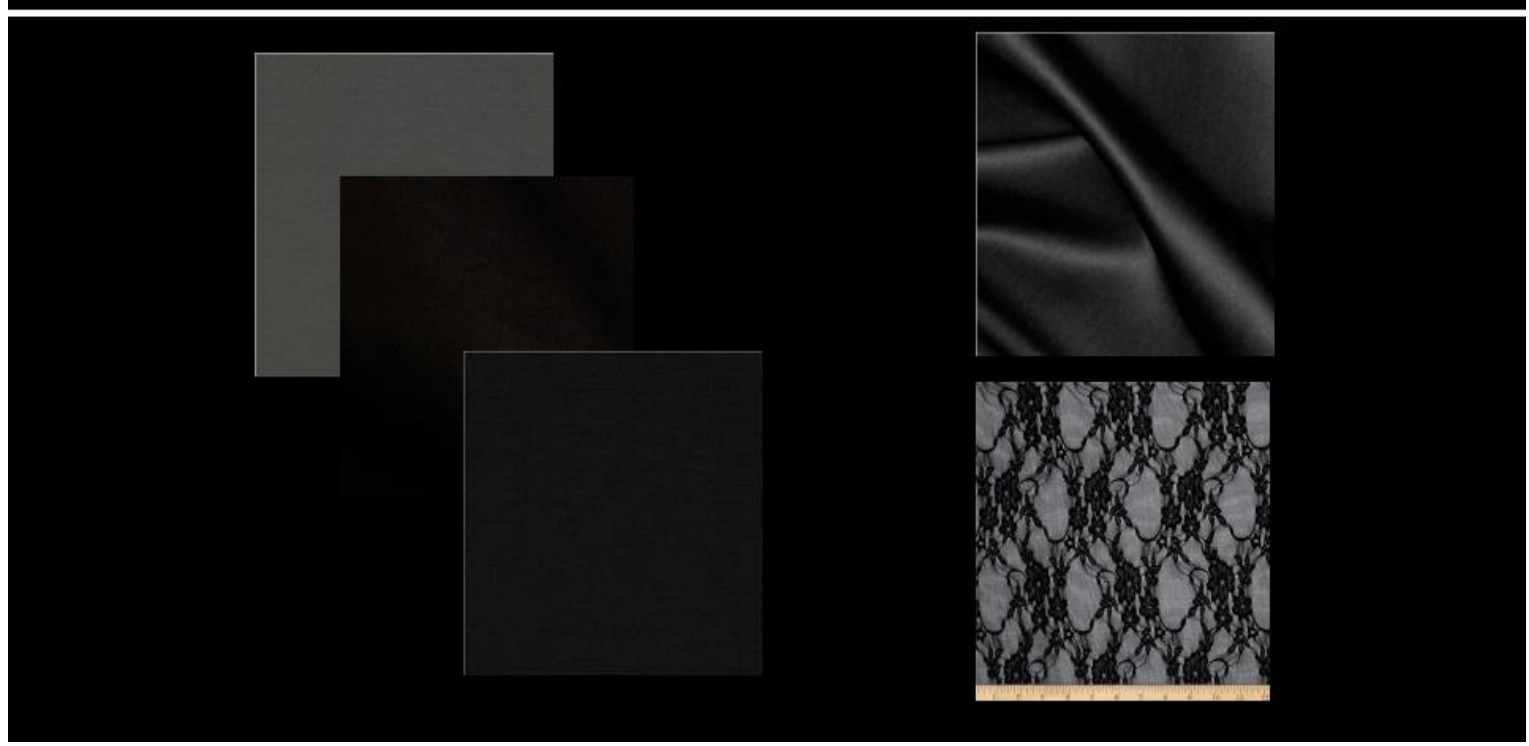




\section{Steve \& George Tyler Research}

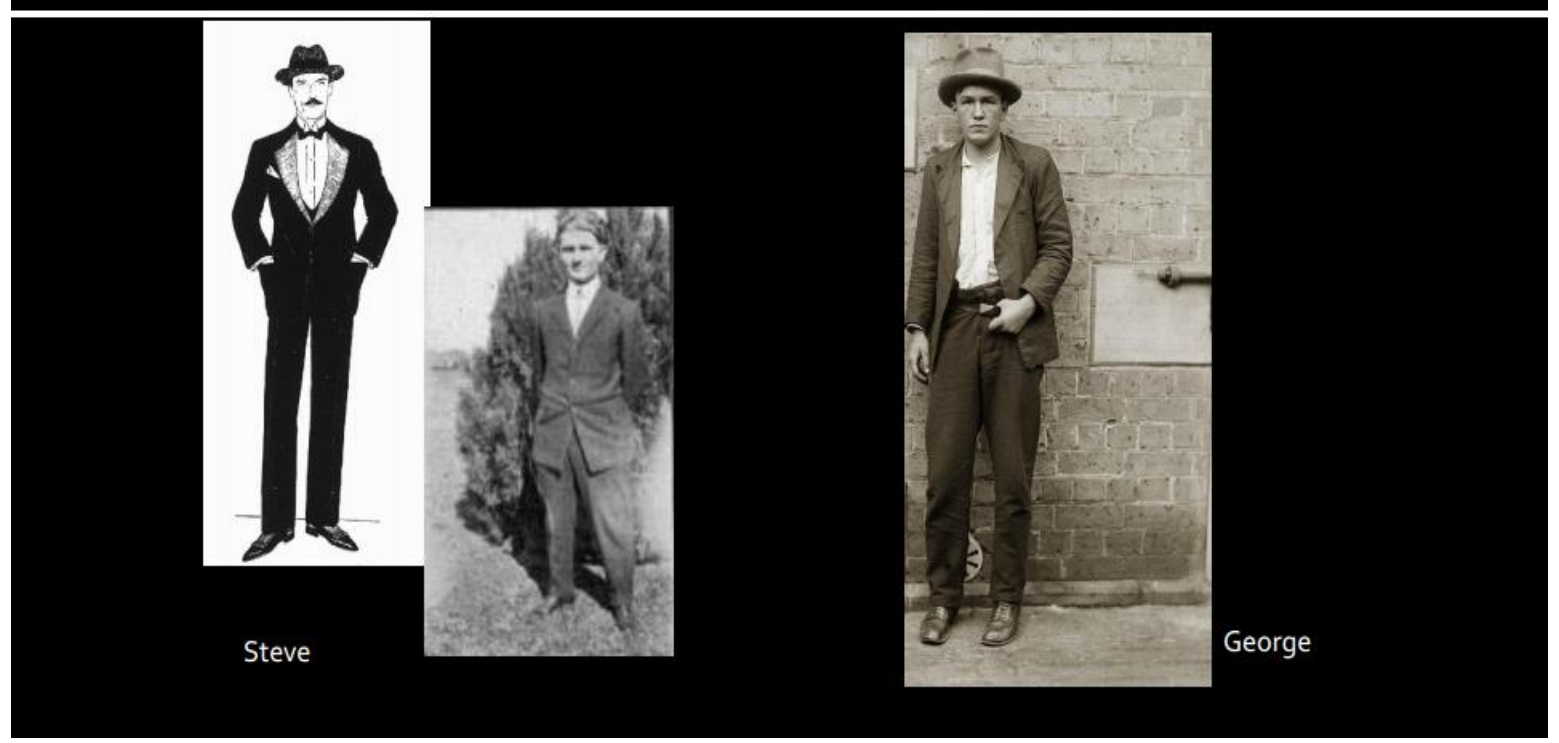

Plate 7: (Above) Research image plate for Steve \& George Tyler.

Plate 7a: (Below) A preliminary look at fabric options for Steve \& George Tyler.

\section{Steve \& George Typer Fabric Swatches}

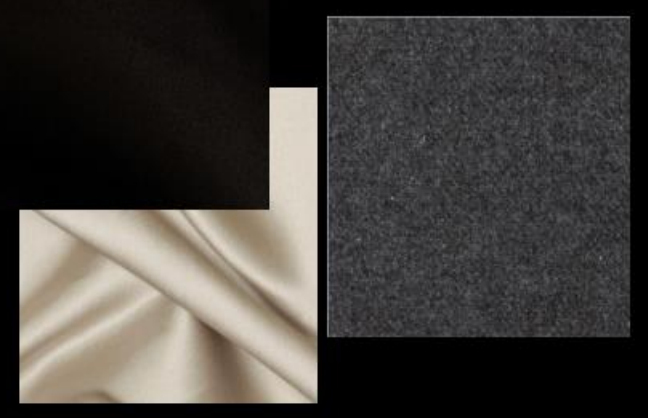




\section{Bobby Pate \& Dr. Goodhue Research}

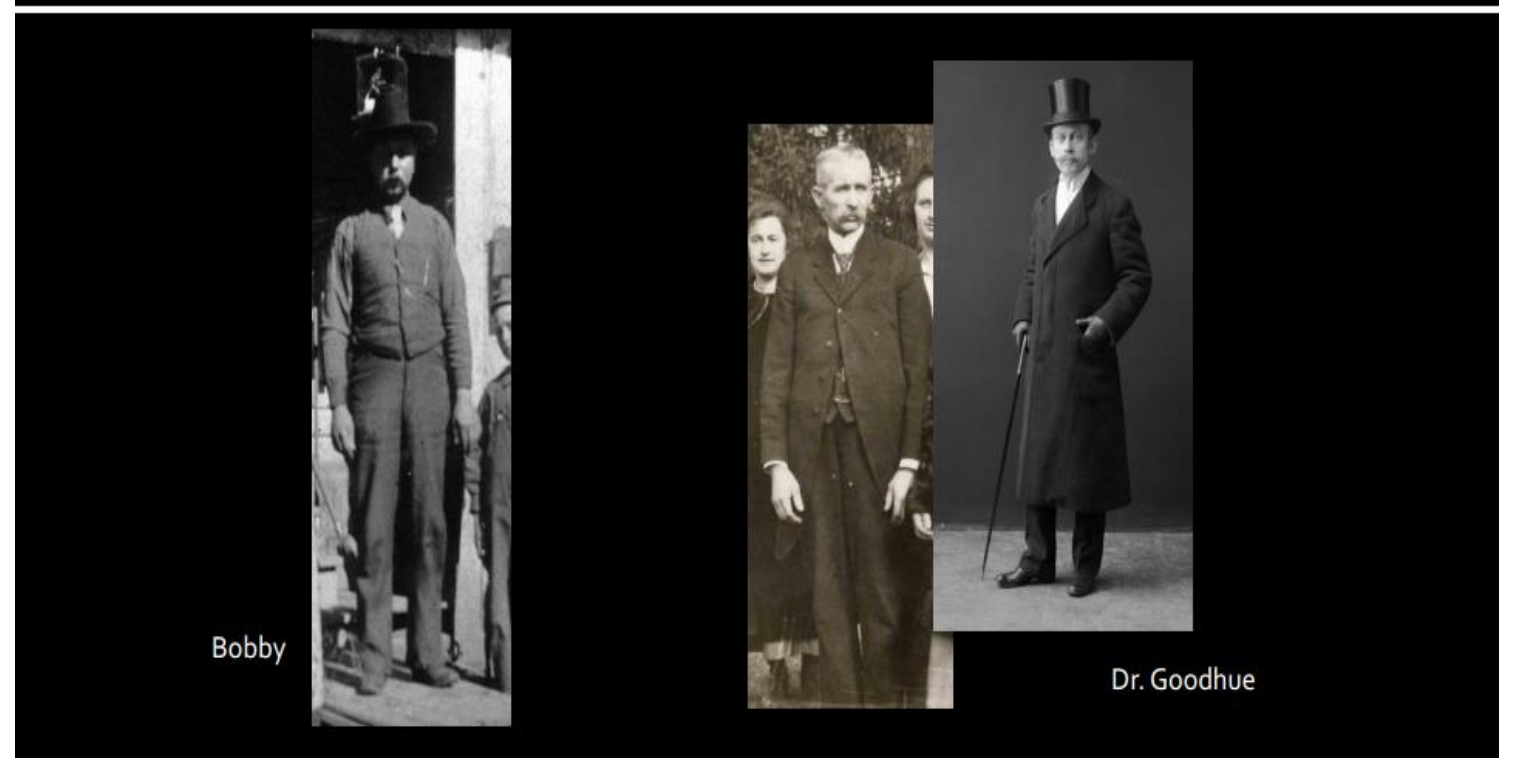

Plate 8: (Above) Research image plate for Bobby Pate and Dr. Goodhue.

Plate 8a: (Below) A preliminary look at fabric options for Bobby Pate and Dr. Goodhue.

\section{Bobby Pate \& Dr. Goodhue Fabric Swatches}




\section{Bessie Stillman \& Ruth Amos Research}

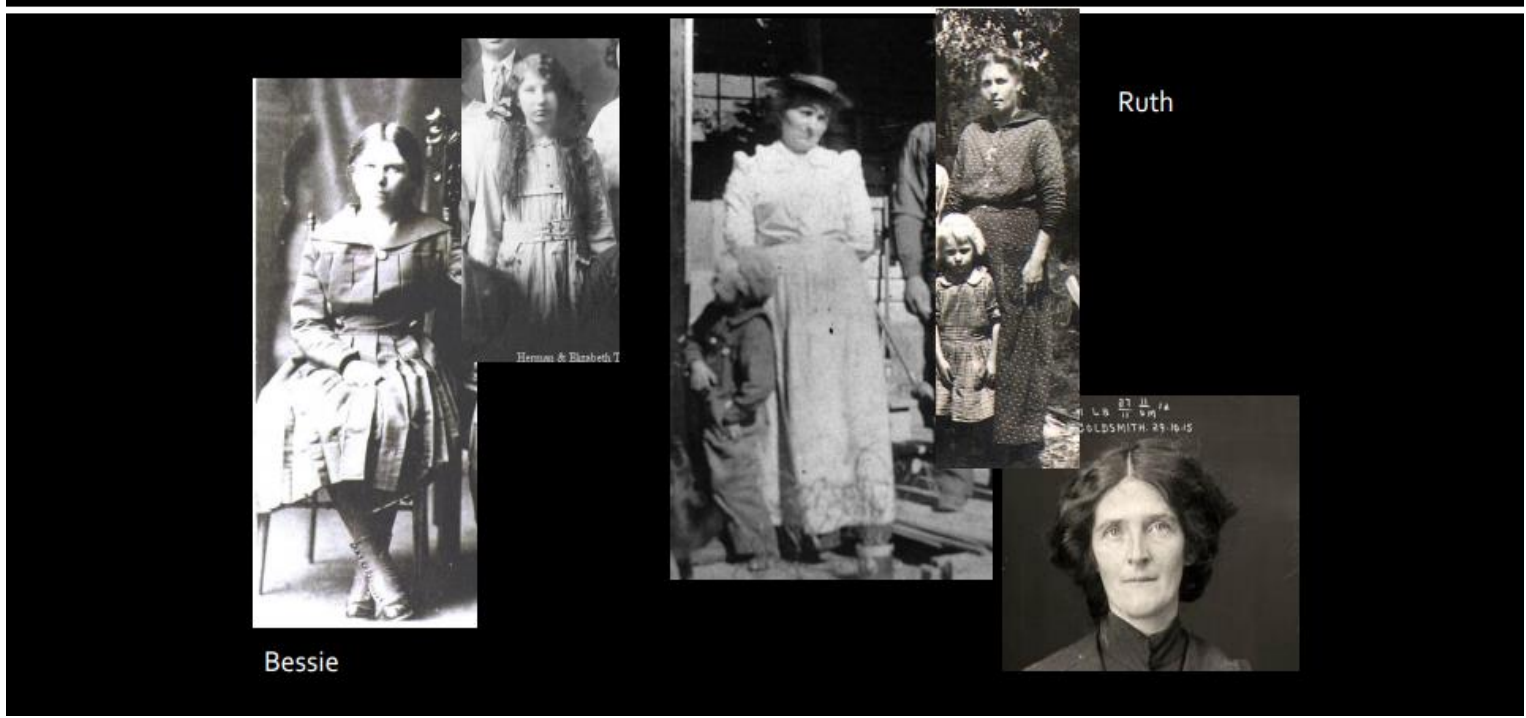

Plate 9: (Above) Research image plate for Bessie Stillman and Ruth Amos.

Plate 9a: (Below) A preliminary look at fabric options for Bessie Stillman and Ruth Amos.

\section{Bessie Stillman \& Ruth Amos Fabric Swatches}
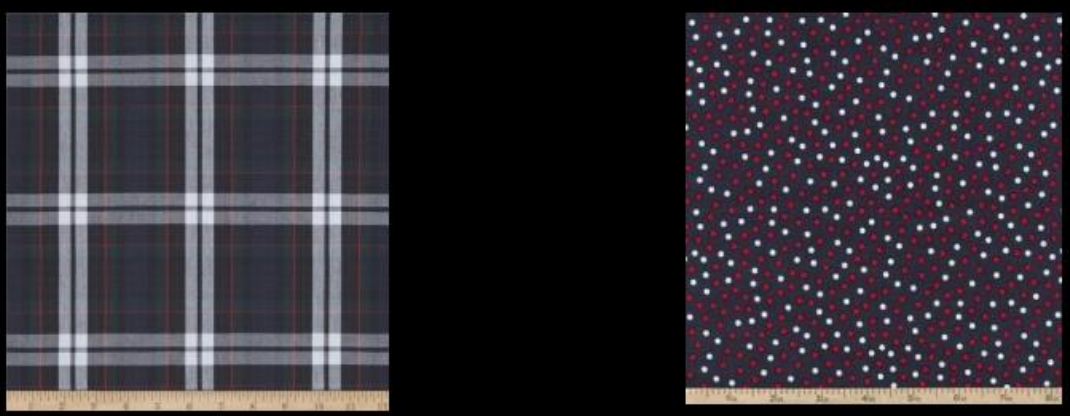


\section{Dancer Research}

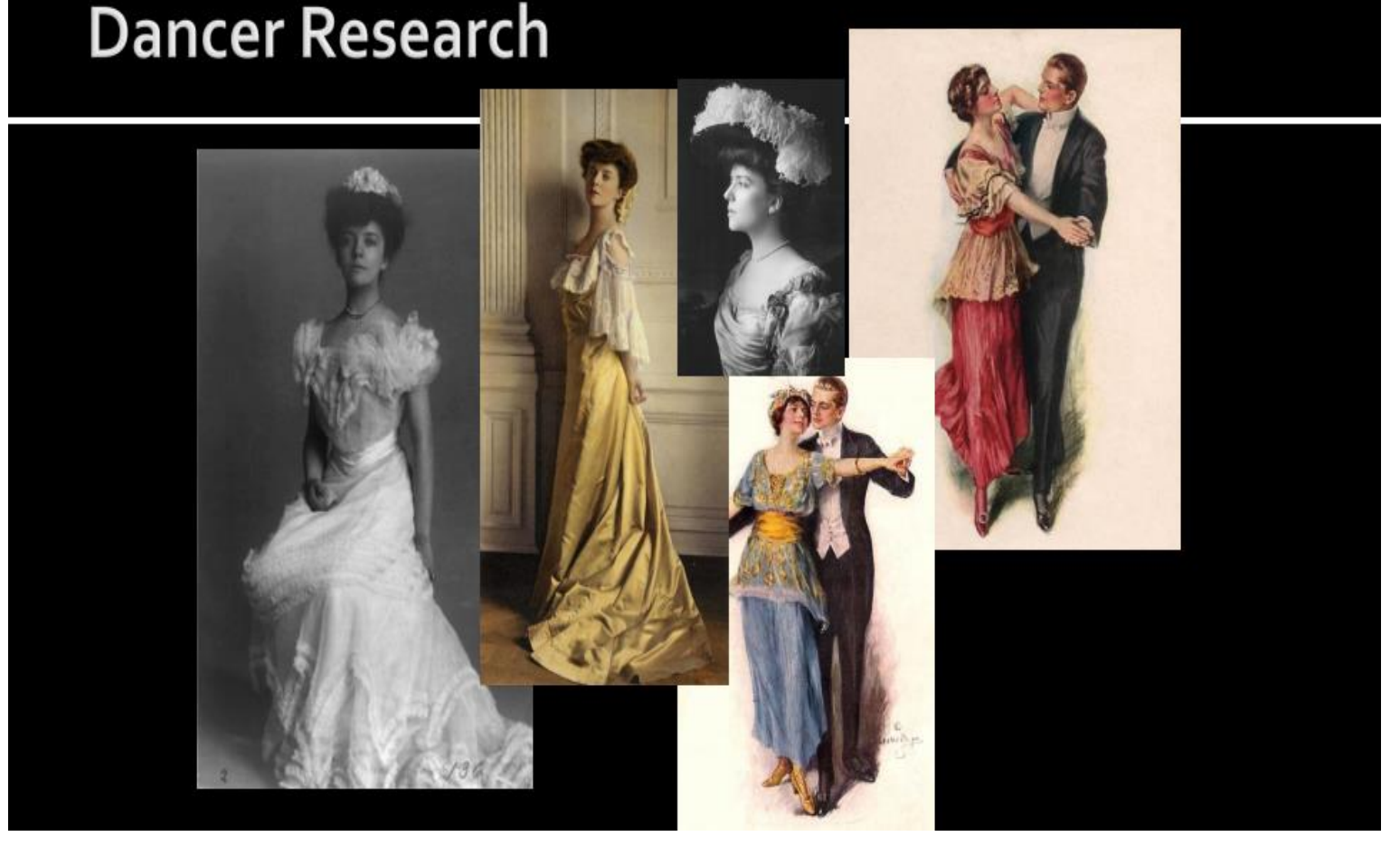

Plate 10: (Above): First research image plate for dancers.

Plate 10a: (Below) Second research plate for dancers.

\section{Dancer Research cont..}

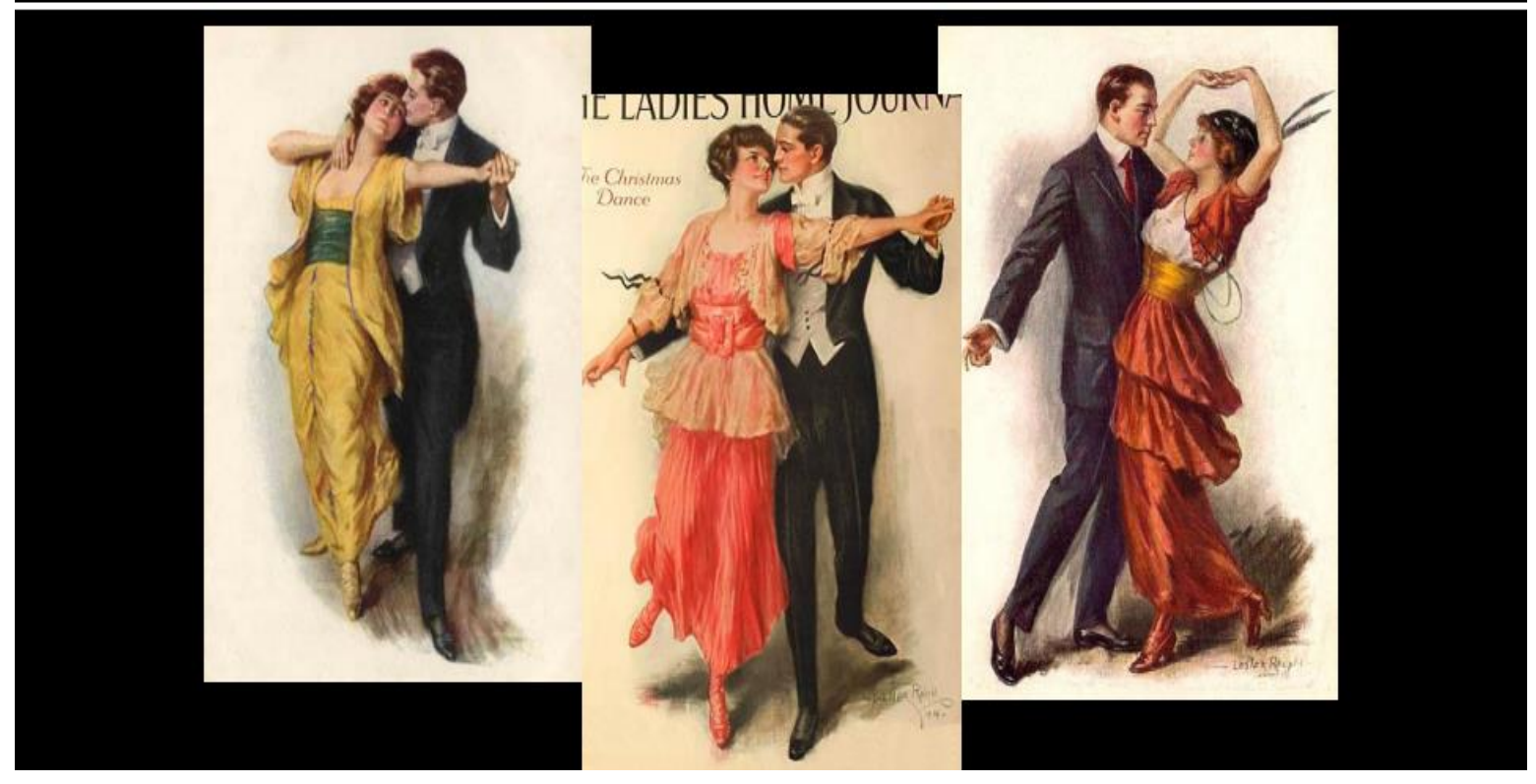




\section{Dancer Fabric Swatches}

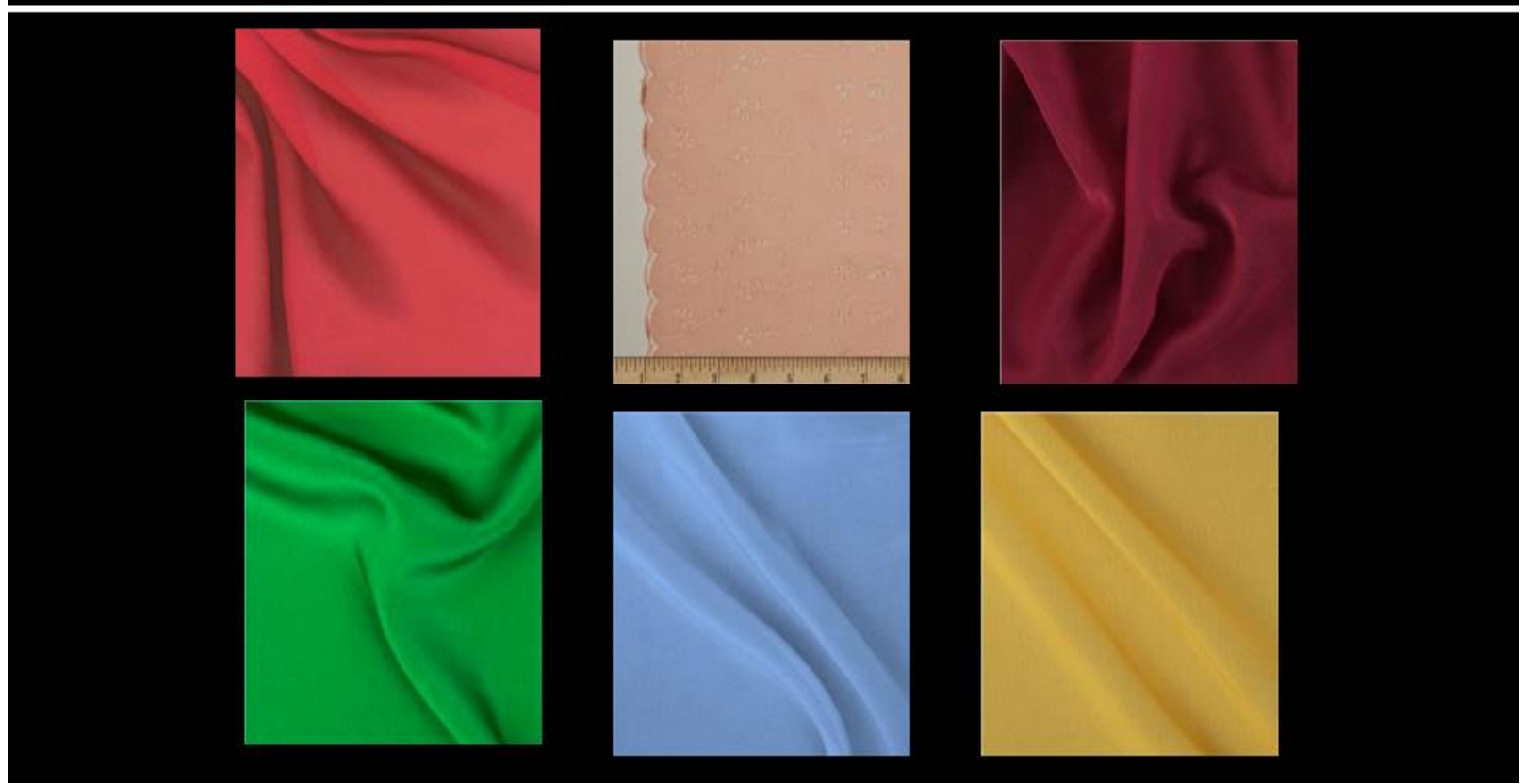

Plate 11: A preliminary look at fabric options for the dancers. 


\section{APPENDIX II: IMAGE SOURCES FOR RESEARCH PLATES}

119. Elizabeth Vaughn Research Plate Images:

a. Bottom left: Clothes for Maternity Wear. Women's Home Companion. July: 1915. Print.

b. Top left: Late Edwardian Summer Dress with Fabulous Embroidered Trim. Digital Image. Extant Gowns. Isabella D’Angelo, 27 Oct. 2015. Web.

c. Top center: 1900s Slippers at the Metropolitan Museum of Art. Digital Image. OMG that Dress!. Tumblr, 9 Jan. 2013. Web.

d. Bottom left center: Mabel, Ben, and Fred Hoyle. 1915. Fred Hoyle: An Online Exhibition. St. John's College, University of Cambridge. Web.

e. Bottom right center: Edward Charles Pickering and His Computers. 1913. Photograph. Harvard College Observatory Collection, Cambridge. Edwardian Promenade. Web.

f. Right: Turn of the Century Nightgown Set. Digital Image. Extant Gowns. Isabella D’Angelo, 10 Jan. 2012. Web.

120. Horace Robedaux Research Plate Images:

a. Top left: 1912 Tuxedos. Digital Image. Demode Couture. N. p., 2011. Web. Demodecouture.com/titantic-trends

b. Bottom Left: Butterick Pattern \#1825 Men's or Boys' Yoke Nightshirt. Unsung Patterns. Web.

c. Left center: Men in Union Suits. Digital Image. Art of Manliness. N. p., 21 Dec. 2011. Web. www.artofmanliness.com/2011/12/21/cold-weatherdressing.

d. Right center: Mabel, Ben, and Fred Hoyle. 1915. Fred Hoyle: An Online Exhibition. St. John's College, University of Cambridge. Web.

e. Right: "How Your Clothes Can Make You Look Stouter or Slimmer, Taller or Shorter." Omaha Daily Bee (1916): n.p. Click Americana. Web.

121. Mr. Vaughn Research Plate Images:

a. Left: Vroolijk Paaschfeest Greeting Card from 1915. Digital Image. Flickriver. Flickr, Feb. 2010. Web.

b. Center: Unidentified Photograph of Man in Coat. N. p., n. d. Web. 
c. Right: Brdlik Family Portrait. Digital Image. RootsWeb.Ancestry.com. n. d. Web. Freepages.geneaology.rootsweb.ancestry.com/ brdlik

122. Mrs. Vaughn Research Plate Images:

a. \#400 Ladies' Shirt-Waist: Circa 1914. Digital Image. Saundra Ros Altman's: Past Patterns. Past Patterns, n. d. Web.

b. Bottom left: Top left: Early 1900s Women in Starched Collars. Digital Image. The American Way of Business. Wordpress, 18 Nov. 2013. Web

c. Center: Heim, Richard A. Sam F. Heim Family. 1915. The Pennsylvania Colony of Nebraska Historical Society. Web.

d. Right: 1912-1913 Couple. Digital Image. Forgotten Faces and Long Ago Places. Blogspot, 23 Dec.2012. Web.

123. Laura and Brother Research Plate Images:

a. Left: PA Duryea 1900s Klink Nasiatka Family Friends 1. Digital Image. Dureyea PA. N. p., n. d. Web. www.duryepa.com/1900to1909/1900to1909.htm.

b. Left center: Queen Elizabeth as Elizabeth Bowes Lyon as a Young Child. 2001. Photograph. Popperfoto. Getty Images. Web.

c. Right Center: Intercollegiate Debaters. 1917. The Bronco, Yearbook of Simmons College, Abilene. The Portal to Texas History. Web.

d. Right: Queen Elizabeth as Elizabeth Bowes Lyon as a Young Child. 2001. Photograph. Popperfoto. Getty Images. Web.

124. Aunts Sarah \& Lucy Research Plate Images:

a. Top left: Allum: Maryland and Pennsylvania...Westward. Historic Photograph. N. p., n. d. Web.

b. Bottom left: Antique $19^{\text {th }}$ Century Victorian Bodice Blouse Embroidered Lace. Digital Image. Ebay. N. p., n. d. Web.

c. Center: Unidentified Family Portrait. Historic Photograph. N. p., n. d. Web.

d. Right: Octave Tasaerts, Le Roman 1832. Digital Image. The France of Victor Hugo. Mount Holyoke College, n. d. Web.

125. Steve \& George Tyler Research Plate Images: 
a. Left: Bishop, Katy. Men's Evening Dress for Ragtime Era. Digital Image. Vintage Victorian. N. p. 2011. Web.

b. Center:

c. Right: Mugshot of Harry Chapman. June, 1924. Photograph. Forensic Archives, Sydney Justice \& Police Museum. Digital Image.

126. Bessie Stillman \& Ruth Amos Research Plate Images:

a. Left: Kanalley, Craig. Kanalley Family Portrait. Digital Image. Journey into Genealogy. N. p., 25 Aug. 2012. Web.

b. Left center: Kanalley, Craig. Kanalley Family Portrait. Digital Image. Journey into Genealogy. N. p., 25 Aug. 2012. Web.

c. Center: Reimers Family, (c. 1900s) Photograph. N. d. Dublin Heritage Park and Museums, Dublin. Online Archive of California. Web.

d. Right center: Krause Family on the Farm - Calhoun Co, Illinois 1921. Digital Image. Origin Hunters. N. p., 21 Nov. 2011. Web.

e. Right: Muriel Goldsmith. 29 Oct. 1915. Photograph. Forensic Archives, Sydney Justice \& Police Museum, Wagga Wagga. Digital Image.

127. Bobby Pate \& Dr. Goodhue Research Plate Images:

a. Left: Reimers Family, (c. 1900s) Photograph. N. d. Dublin Heritage Park and Museums, Dublin. Online Archive of California. Web.

b. Center: Heim, Richard A. Sam F. Heim Family. 1915. The Pennsylvania Colony of Nebraska Historical Society. Web.

c. Right: Szacinski, L. Andreas Hanson. 1913. Oslo Museum. Oslobuilder.no. Web.

128. Dancer Research Plate Images:

a. Left: Johnston, Frances Benjamin. Mrs. Alice (Roosevelt) Longworth, Fulllength Portrait, Facing Left; Wearing Ball Gown. 1902. Photograph. Library of Congress, Washington D.C. Prints and Photographs Online Catalog. Web.

b. Left center: Johnston, Frances Benjamin. Alice Roosevelt Longworth, Fulllength Portrait, Standing, Facing Left. 1903. Photograph. Library of Congress, Washington D.C. Prints and Photographs Online Catalog. Web. 
c. Top right center: Alice Roosevelt Longworth. N. d. Photograph. Encyclopaedia Britannica. Web.

d. Bottom right center: Powers, Ricard. Ragtime Era Dancers with Blue Lampshade Tunic Dress. Digital Image. Stanford, n. d. Web.

e. Right: Powers, Ricard. Ragtime Era Dancers with Red and Gold Dress. Digital Image. Stanford, n. d. Web.

10a. Dancer Research Plate Images cont...:

f. Left: Powers, Ricard. Ragtime Era Dancers with Yellow Dress. Digital Image. Stanford, n. d. Web.

g. Center: Powers, Ricard. Ragtime Era Dancers with Pink Dress. Digital Image. Stanford, n. d. Web.

h. Right: Powers, Ricard. Ragtime Era Dancers with Red Dress. Digital Image. Stanford, n. d. Web. 


\section{APPENDIX III: PRODUCTION PHOTOS AND COSTUME RENDERINGS}

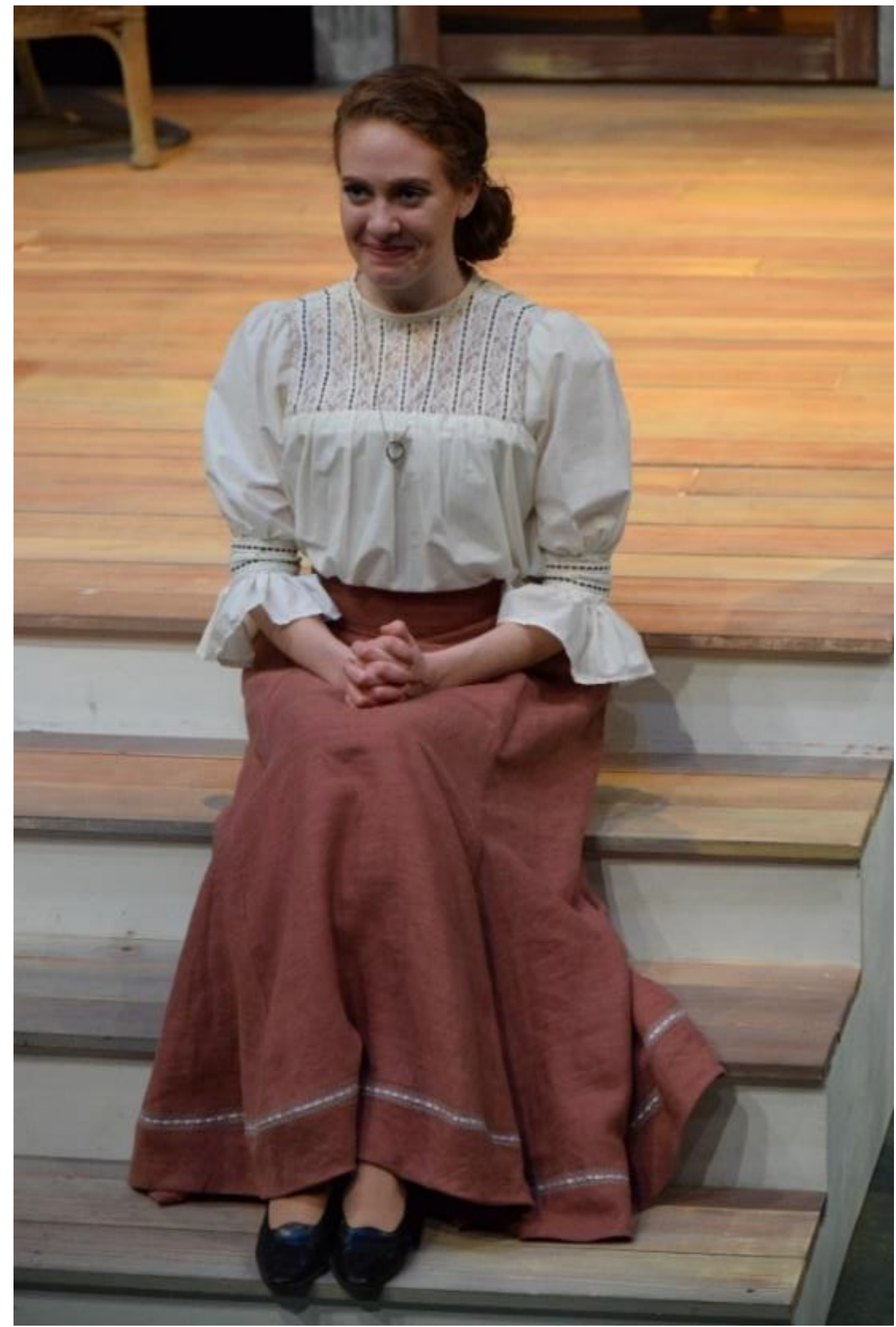

Elizabeth Vaughn (Margaret Dransfield) sits on the steps of the front porch in Courtship.

Brennan, Lauren E. Front View of Margaret Dransfield as Elizabeth Vaughn in Courtship. 2015. Photograph. West Virginia University School of Theatre \& Dance, Morgantown, WV. 


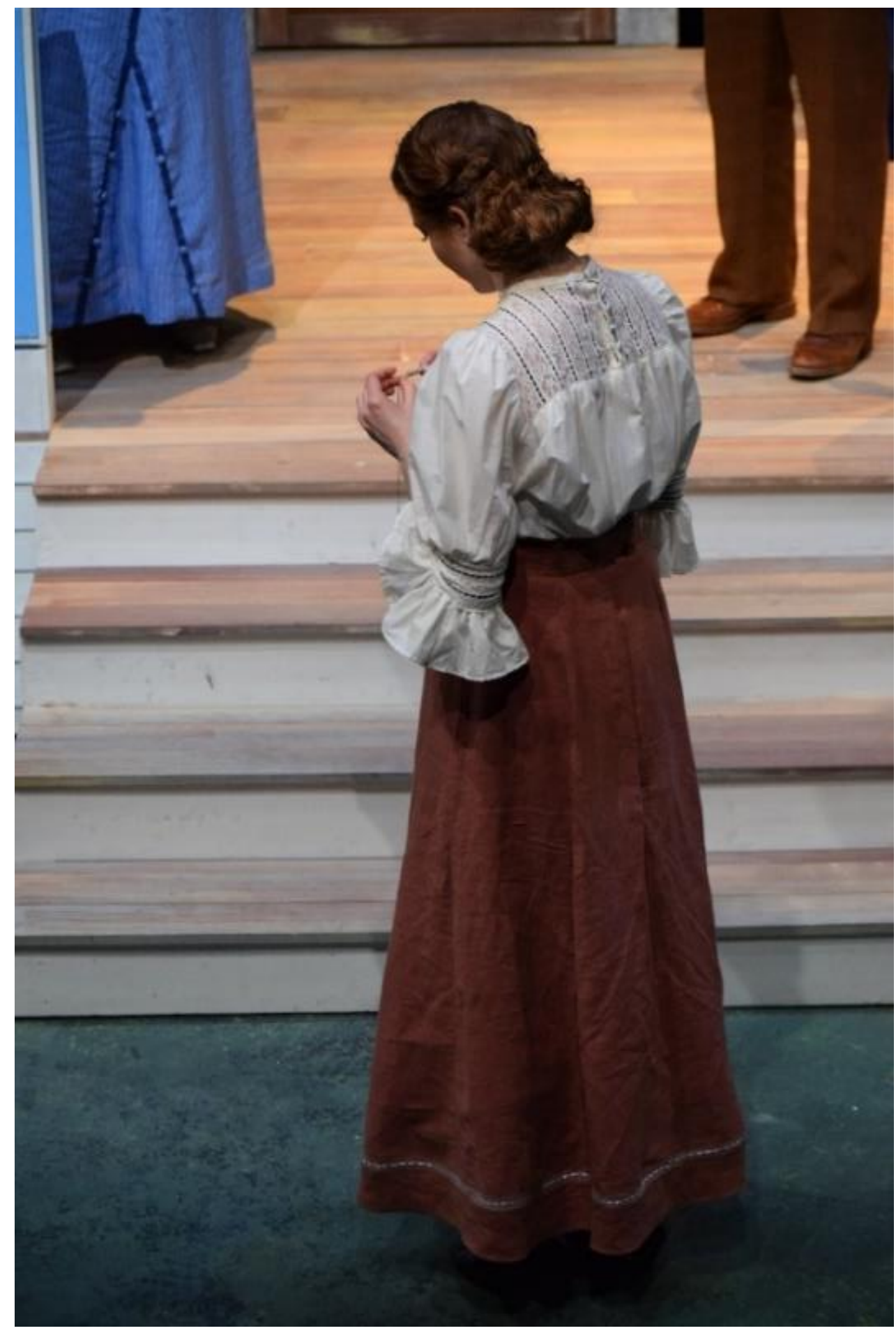

Elizabeth Vaughn (Margaret Dransfield) gazes at the ring that her true love has gifted to her in Courtship.

Brennan, Lauren E. Back View of Margaret Dransfield as Elizabeth Vaughn in Courtship. 2015. Photograph. West Virginia University School of Theatre \& Dance, Morgantown, WV. 


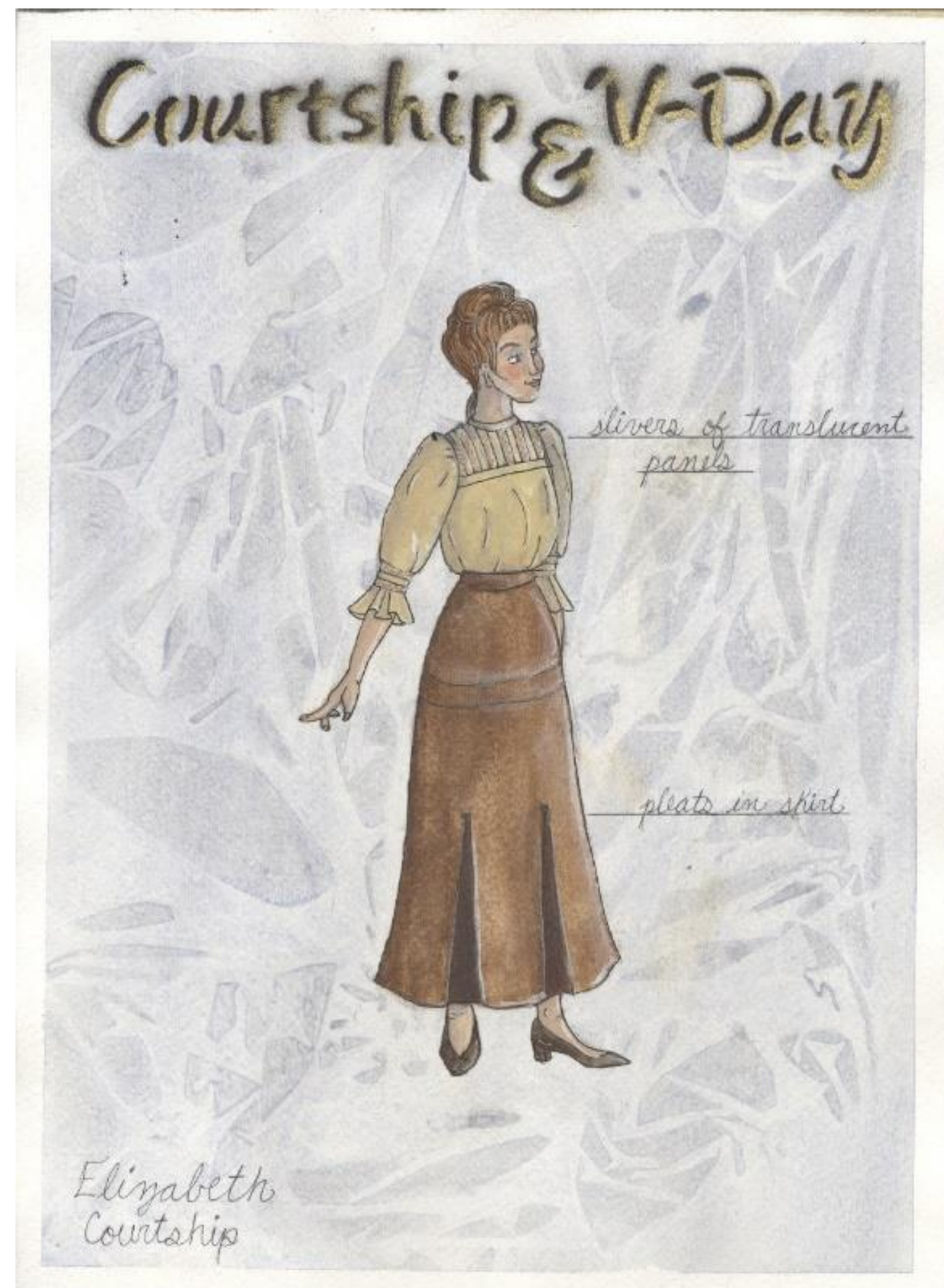

Elizabeth Vaughn in Courtship, final rendering

Brennan, Lauren E. Elizabeth Vaughn in Courtship. 2015. Watercolor \& Marker. West Virginia University School of Theatre \& Dance, Morgantown, WV. Digital Image. 


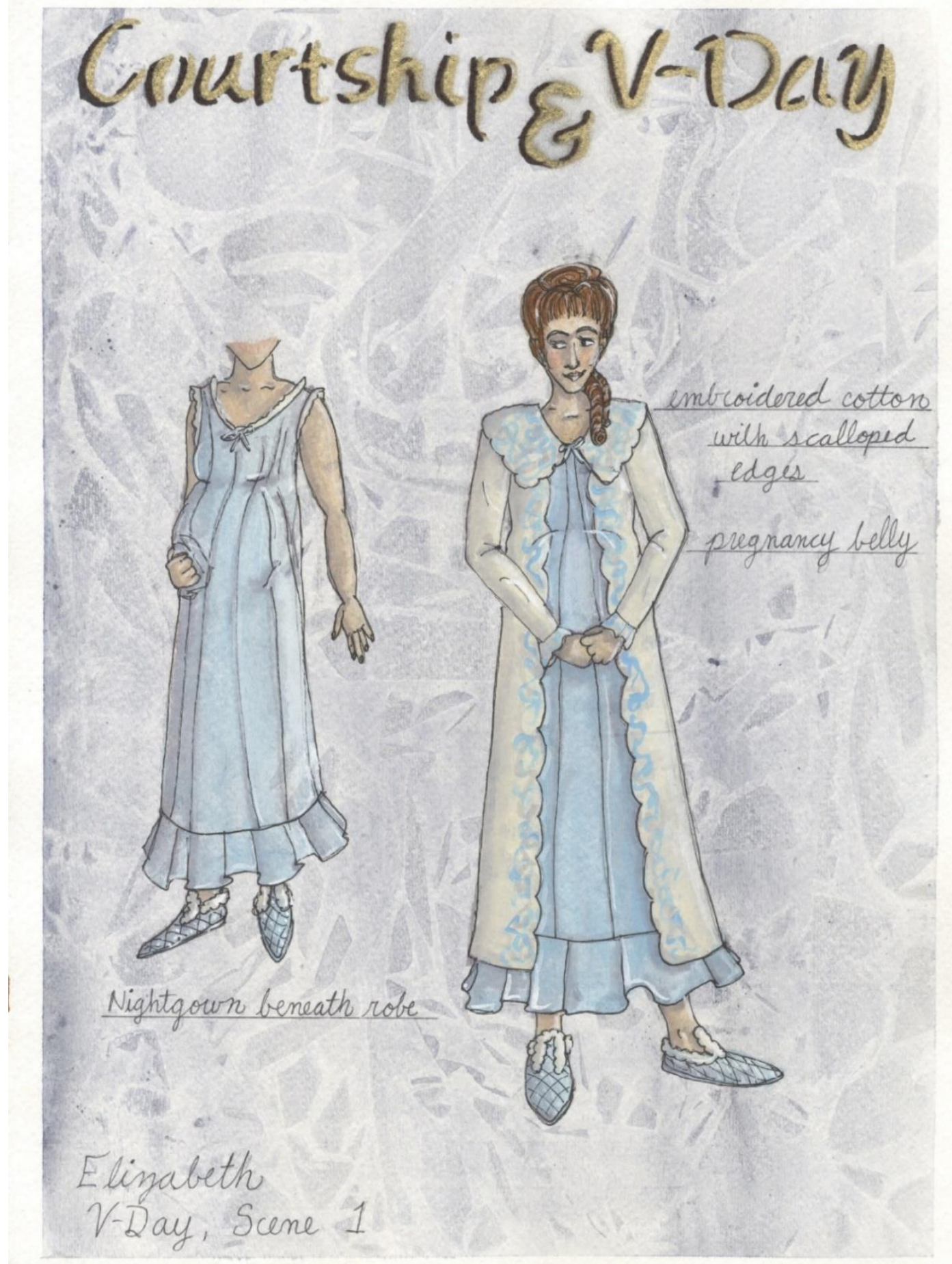

Figure 1: Elizabeth Vaughn in Valentine's Day scene 2 (originally designated for scene 1), final rendering.

Brennan, Lauren E. Elizabeth Vaughn's First Look in Valentine's Day, Scene 2. 2015.

Watercolor \& Marker. West Virginia University School of Theatre \& Dance, Morgantown, WV. Digital Image. 


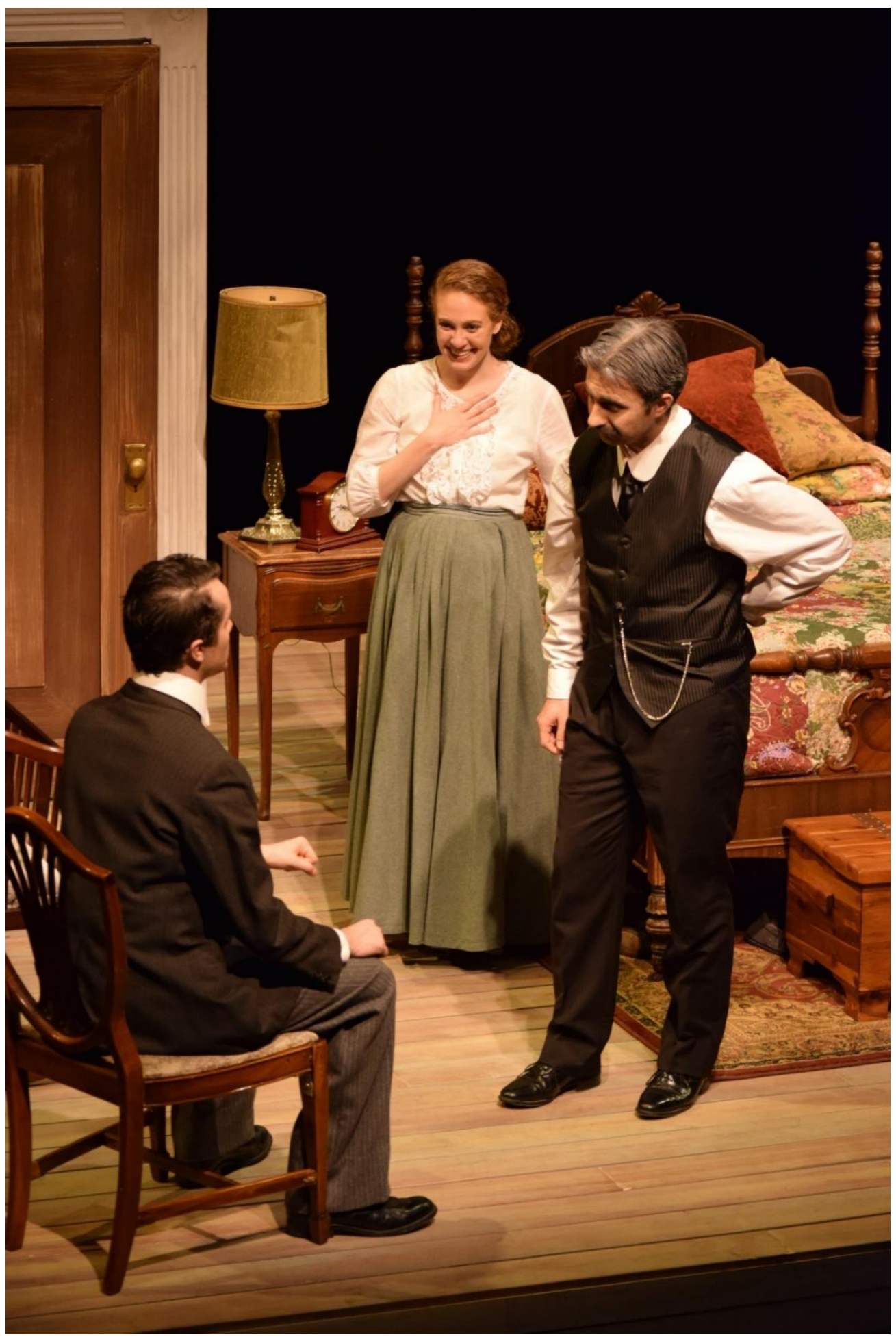

Mr. Vaughn (Joseph Bussey) reconciles with Elizabeth (Margaret Dransfield) and Horace (Isaac Snyder) in Valentine's Day, scene 3.

Brennan, Lauren E. Mr. Vaughn Reconciles with Elizabeth and Horace in Valentine's Day, Scene 3. 2015. Photograph. West Virginia University School of Theatre \& Dance, Morgantown, WV. 


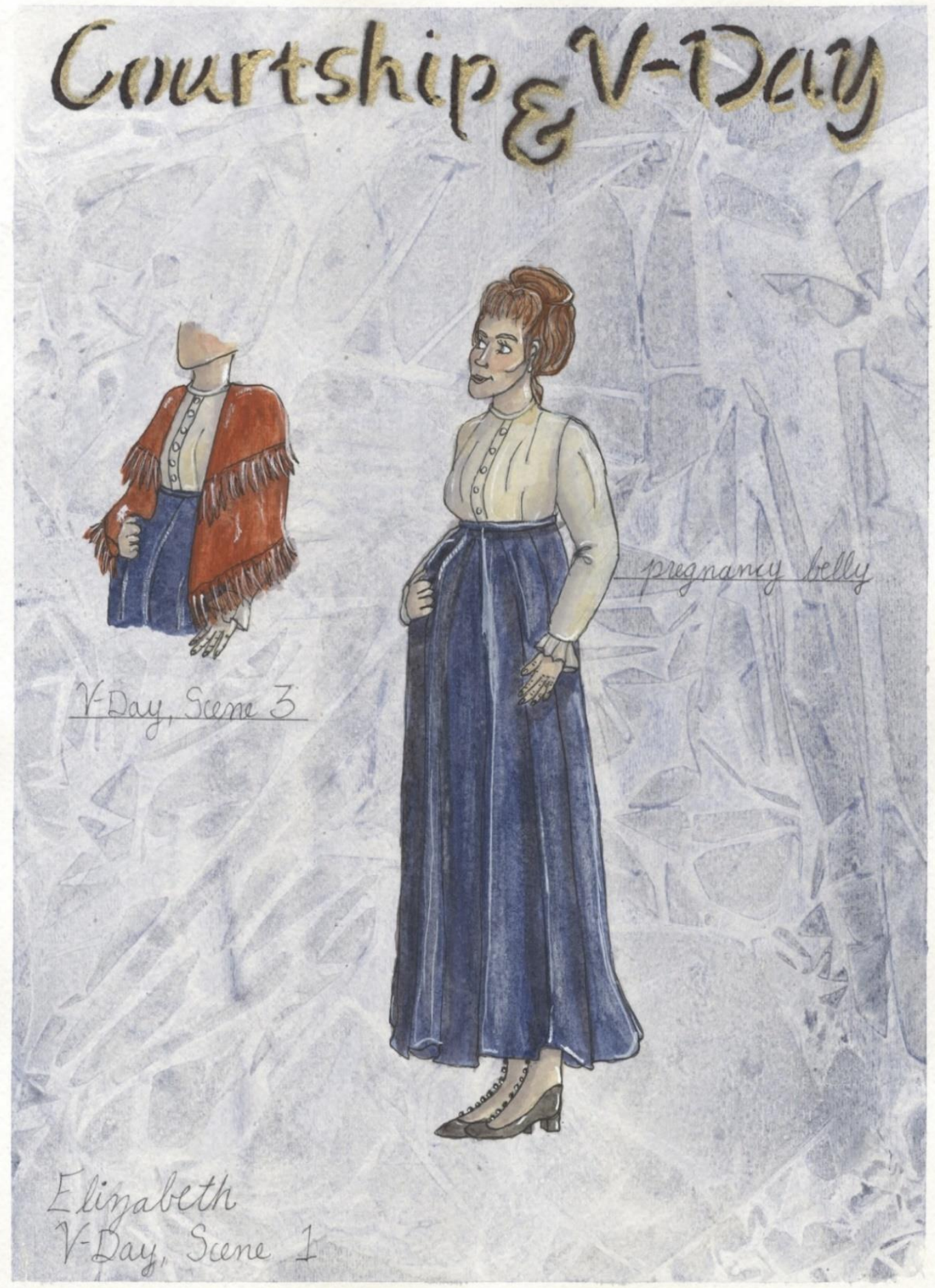

Elizabeth Vaughn in Valentine's Day scene 1 with shawl variation for scene 3, final rendering.

Brennan, Lauren E. Elizabeth Vaughn in Valentine's Day, Scenes 1 \& 3. 2015. Watercolor \& Marker. West Virginia University School of Theatre \& Dance, Morgantown, WV. Digital Image. 


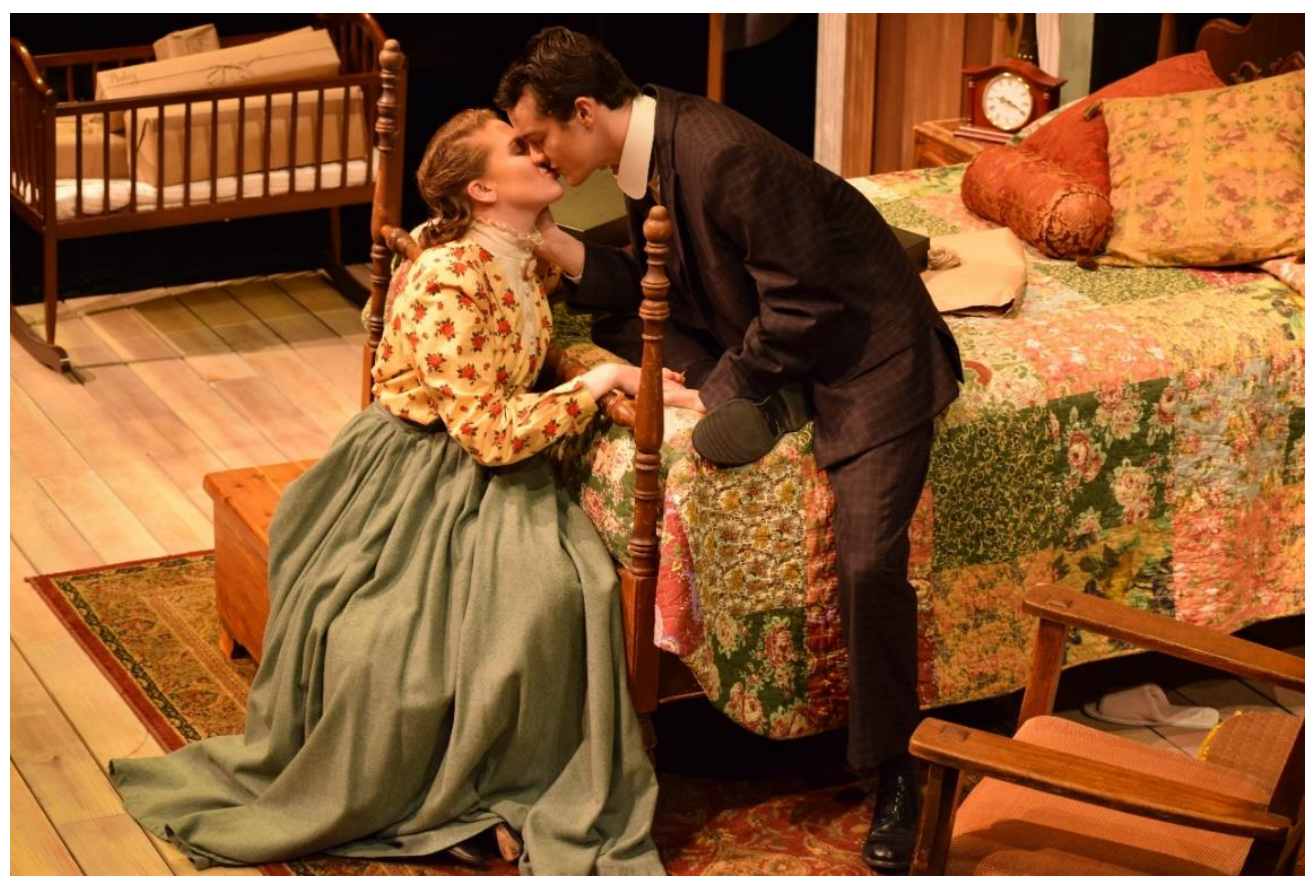

Horace (Isaac Snyder) gives Elizabeth (Margret Dransfield) a kiss in Valentine's Day, scene 2.

Brennan, Lauren E. Elizabeth and Horace in Valentine's Day, Scene 2. 2015. Photograph. West Virginia University School of Theatre \& Dance, Morgantown, WV.

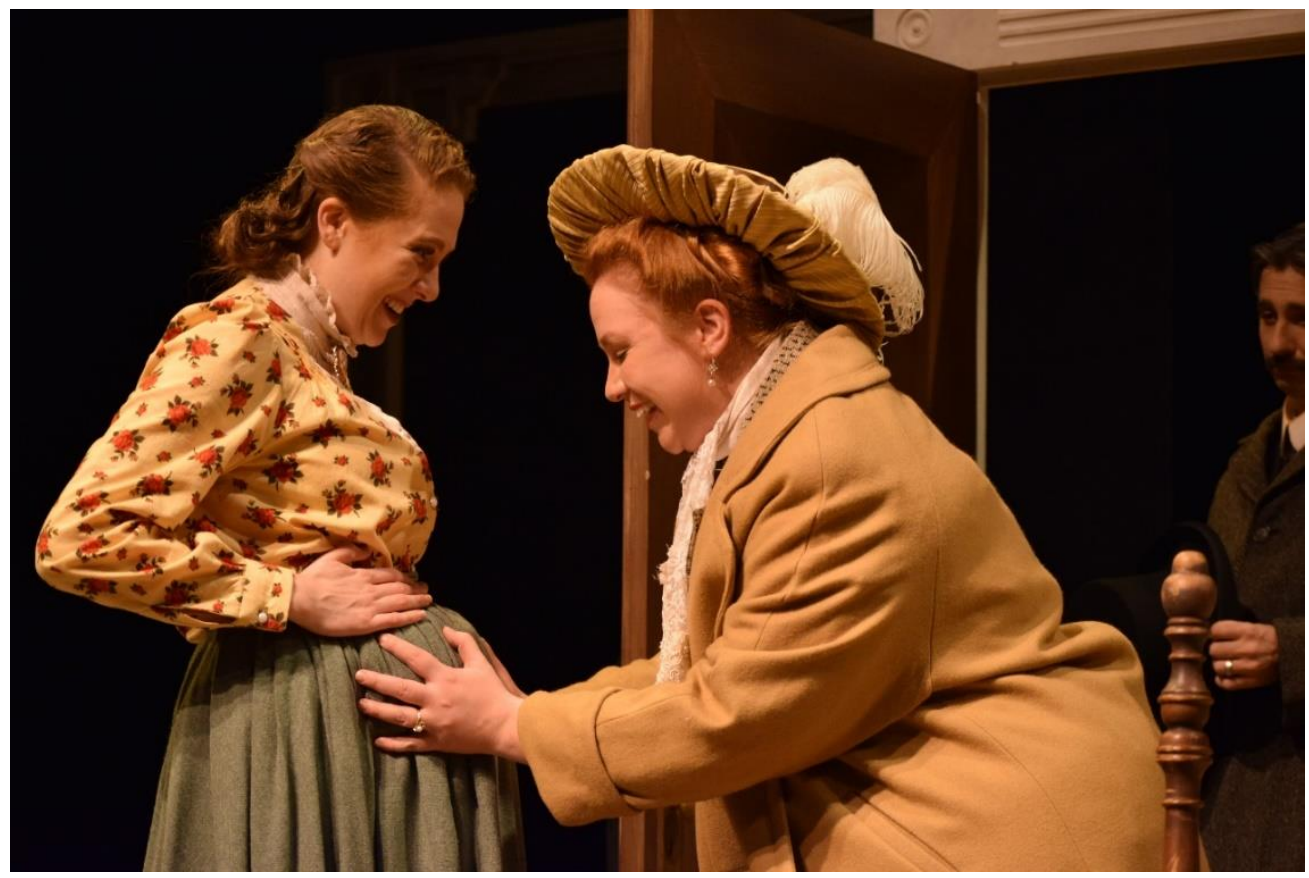

Elizabeth (Margaret Dransfield) and Mrs. Vaughn (Madeline Hintz) bond over baby in Valentine's Day, scene 2.

Brennan, Lauren E. Elizabeth and Horace in Valentine's Day, Scene 2. 2015. Photograph. West Virginia University School of Theatre \& Dance, Morgantown, WV. 


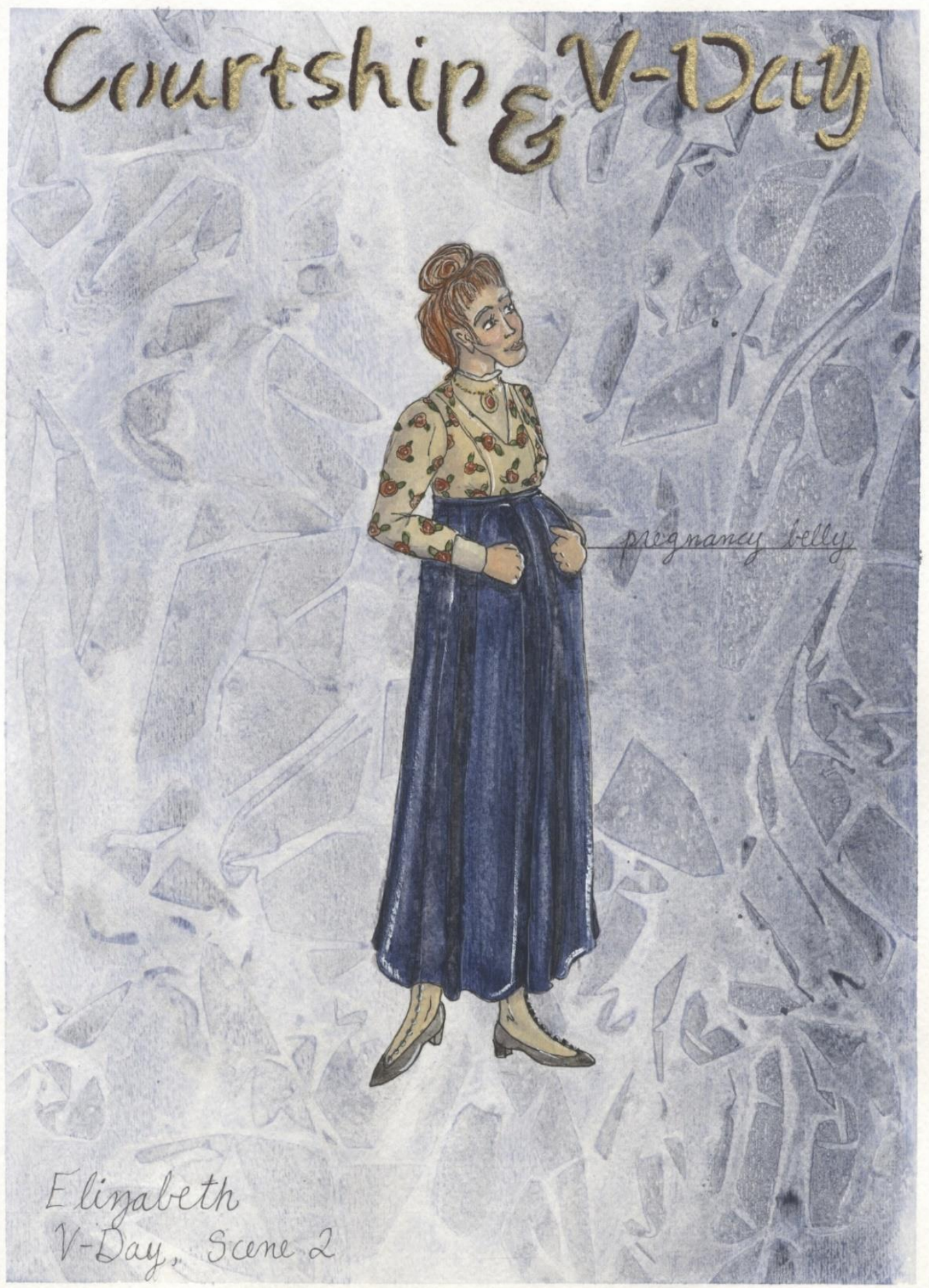

Elizabeth Vaughn in Valentine's Day scene 2, final rendering.

Brennan, Lauren E. Elizabeth Vaughn in Valentine's Day, Scene 2. 2015. Watercolor \& Marker. West Virginia University School of Theatre \& Dance, Morgantown, WV. Digital Image. 


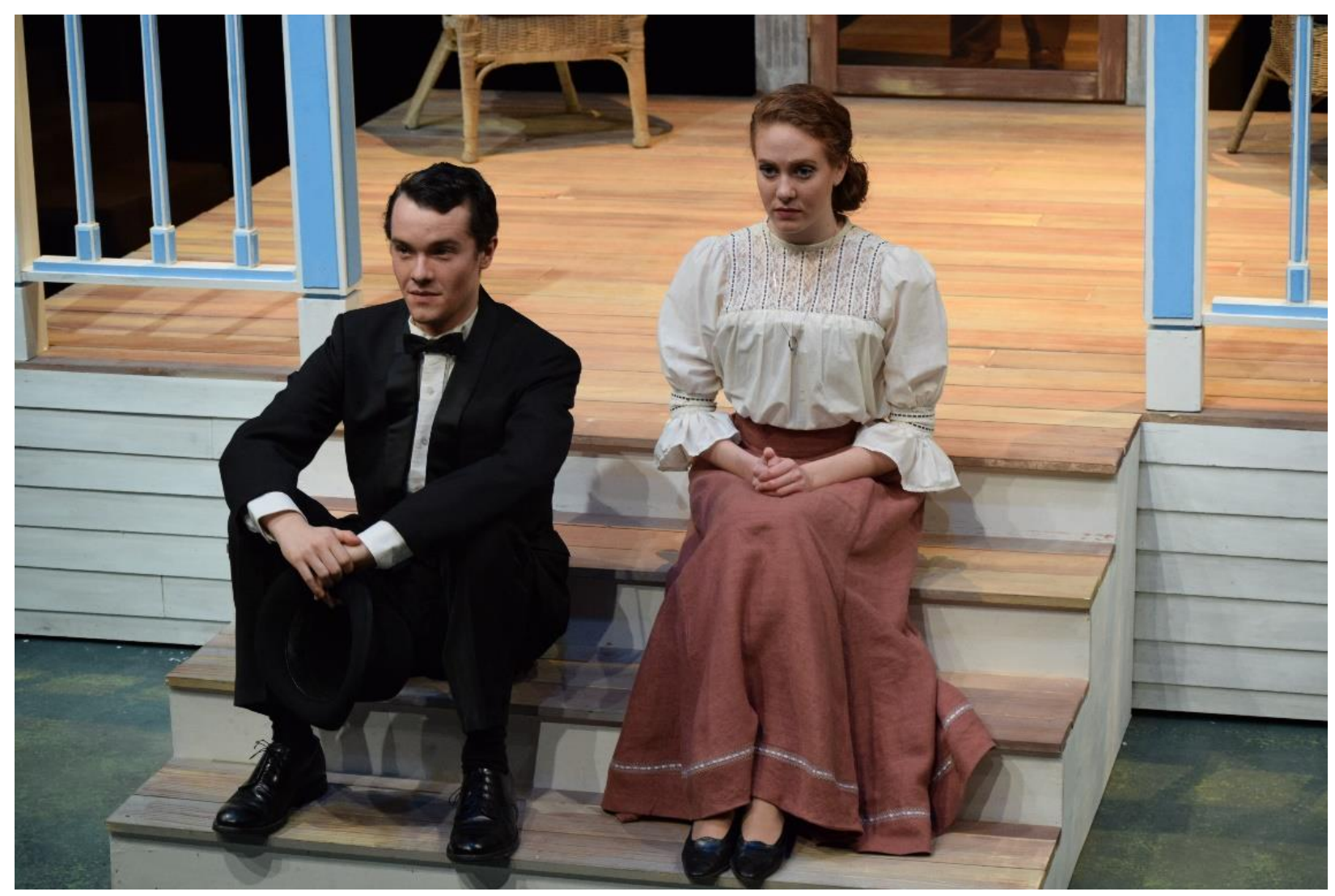

Horace (Isaac Snyder) and Elizabeth (Margaret Dransfield) sit together on the porch in Courtship.

Brennan, Lauren E. Elizabeth and Horace on the porch in Courtship. 2015. Photograph. West Virginia University School of Theatre \& Dance, Morgantown, WV. 


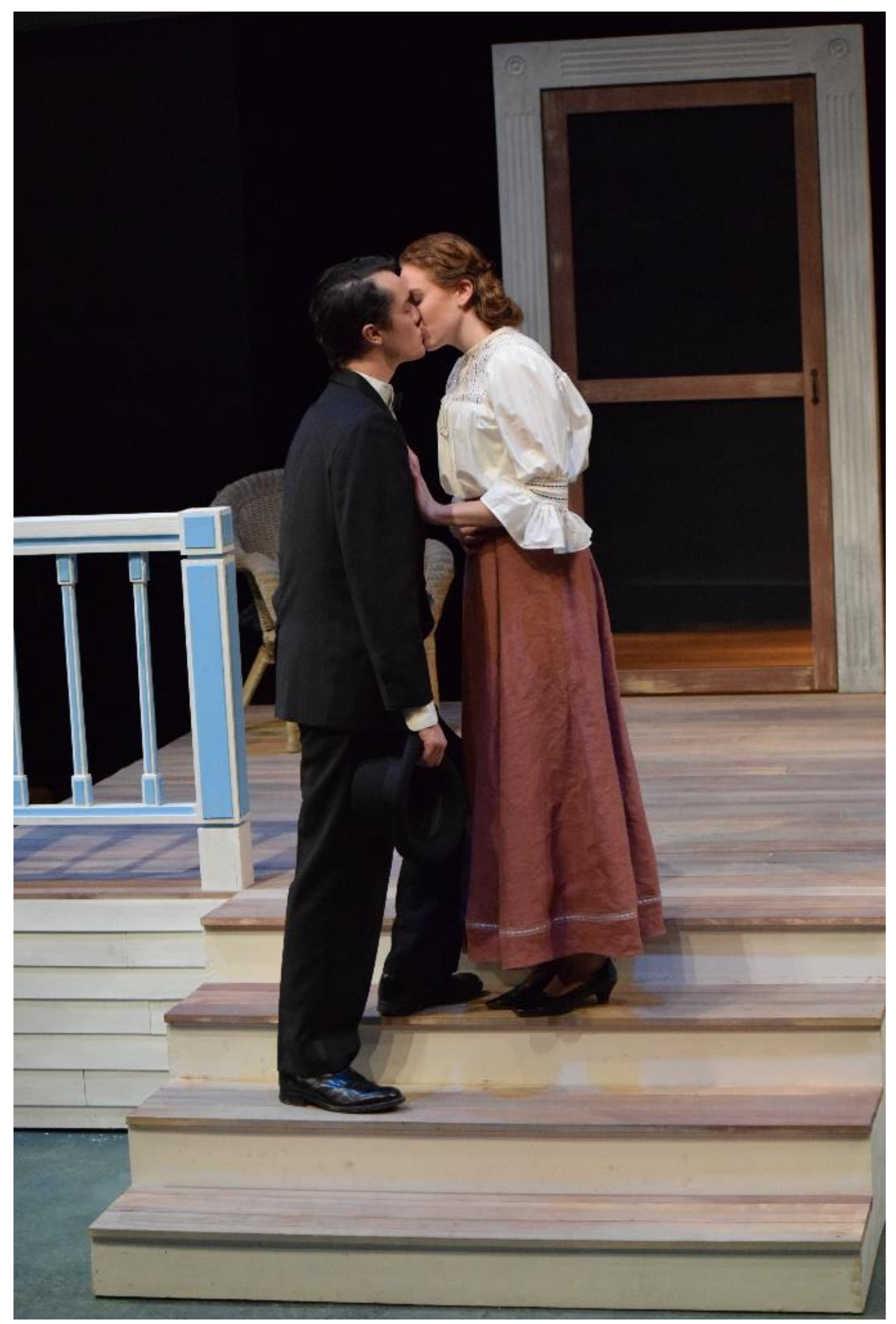

Horace (Isaac Snyder) and Elizabeth (Margaret Dransfield) share a kiss in Courtship.

Brennan, Lauren E. Horace and Elizabeth Share a Kiss in Courtship. 2015. Photograph. West Virginia University School of Theatre \& Dance, Morgantown, WV. 


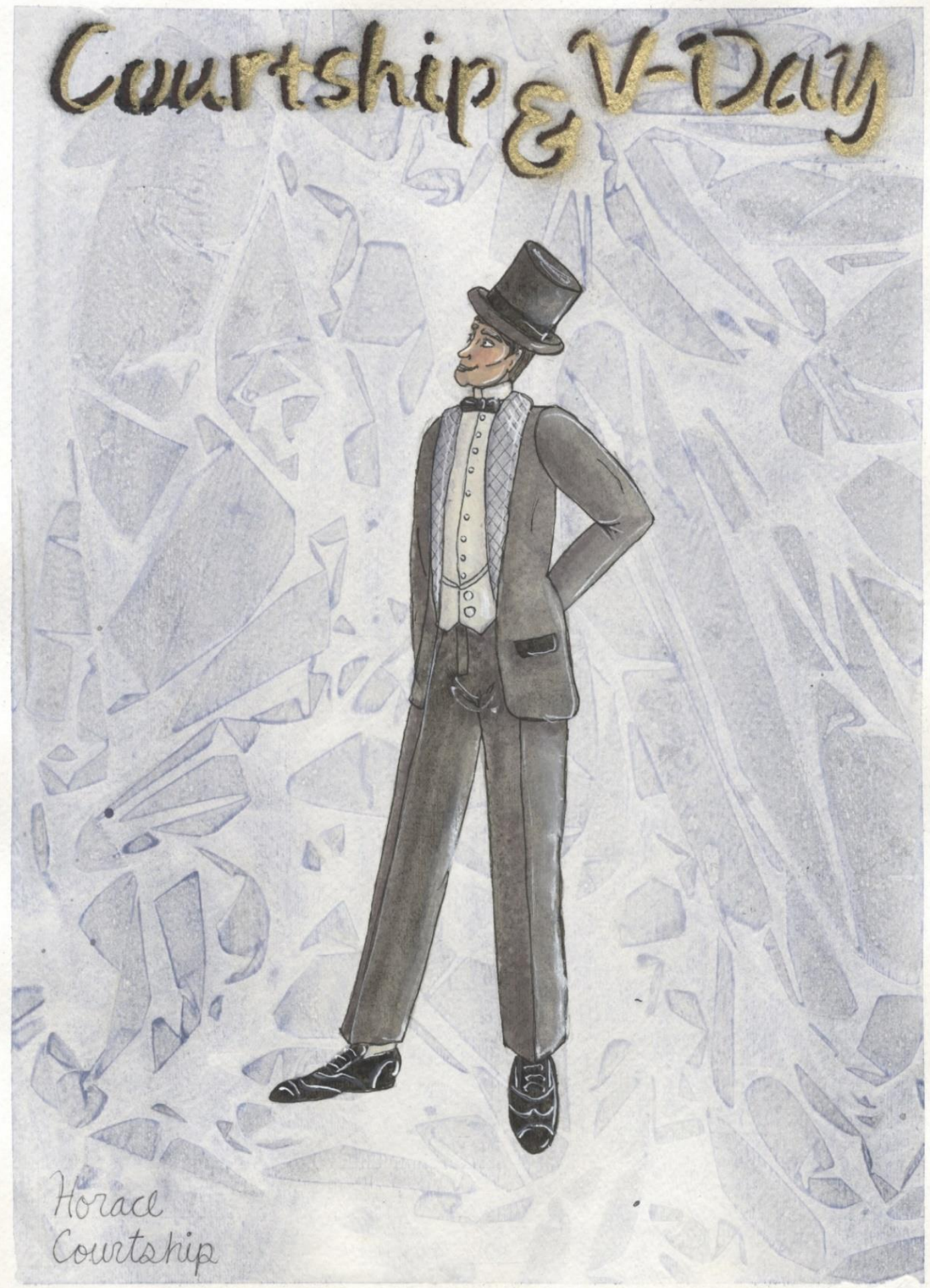

Figure 2: Horace Robedaux in Courtship, final rendering.

Brennan, Lauren E. Horace Robedaux in Courtship. 2015. Watercolor \& Marker. West Virginia University School of Theatre \& Dance, Morgantown, WV. Digital Image. 


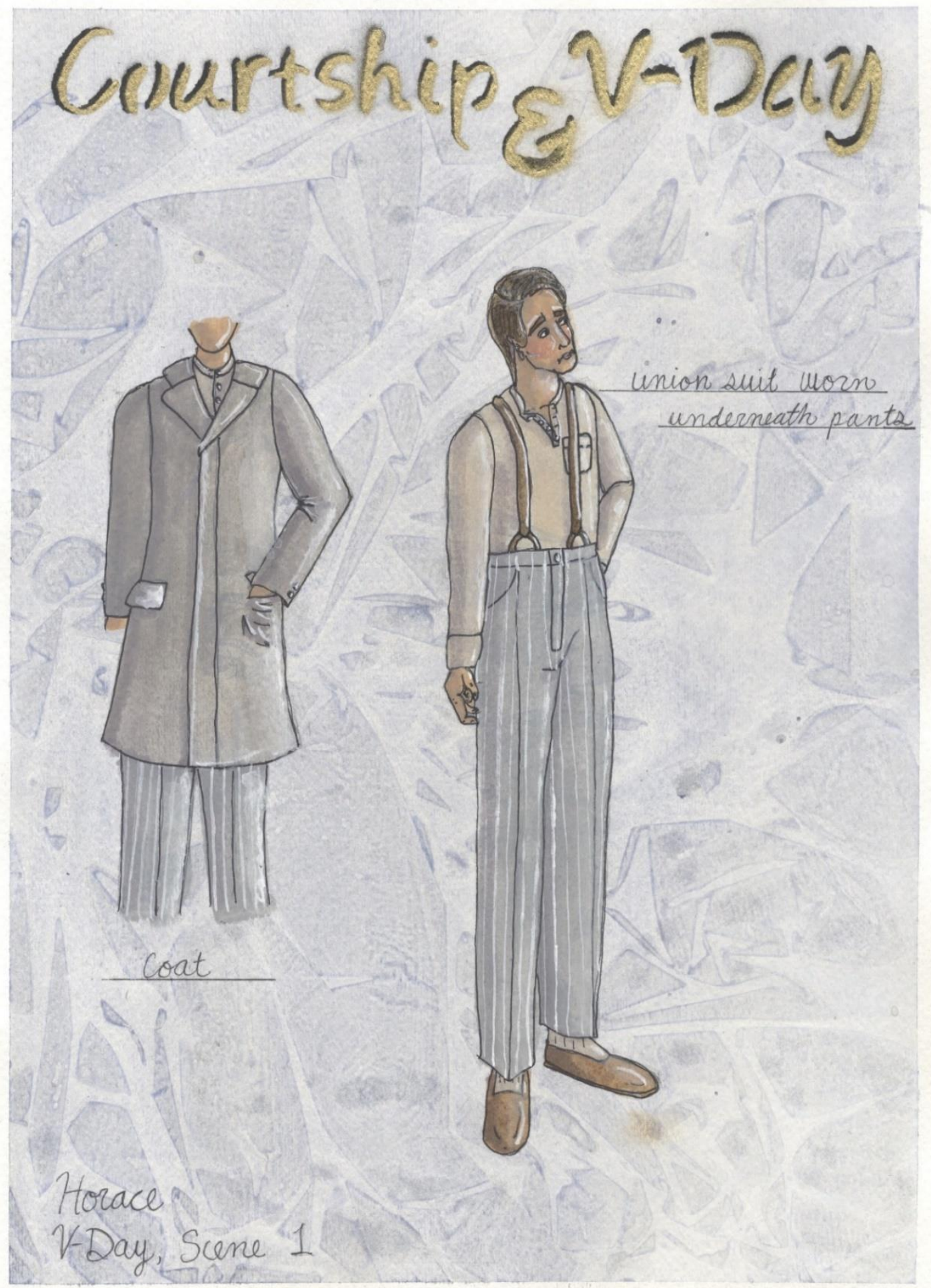

Figure 3: Horace Robedaux in Valentine's Day scene 1, final rendering.

Brennan, Lauren E. Horace Robedaux in Valentine's Day, Scene 1. 2015. Watercolor \& Marker. West Virginia University School of Theatre \& Dance, Morgantown, WV. Digital Image. 


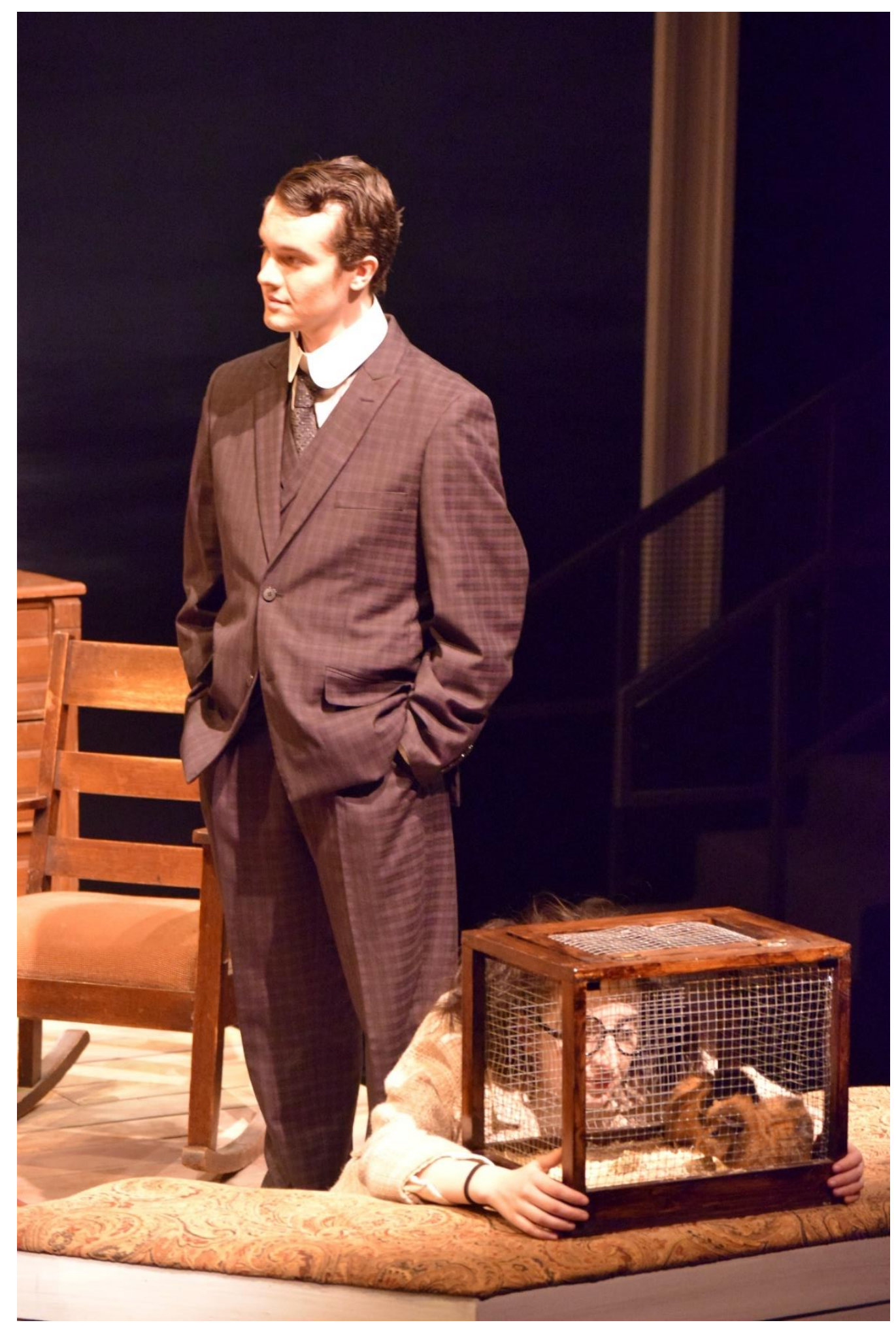

Horace as (Isaac Snyder) and Bessie (Katie Boothby) in Valentine's Day, scene 2.

Brennan, Lauren E. Horace on Christmas in Valentine's Day, Scene 2. 2015. Photograph. West Virginia University School of Theatre \& Dance, Morgantown, WV. 


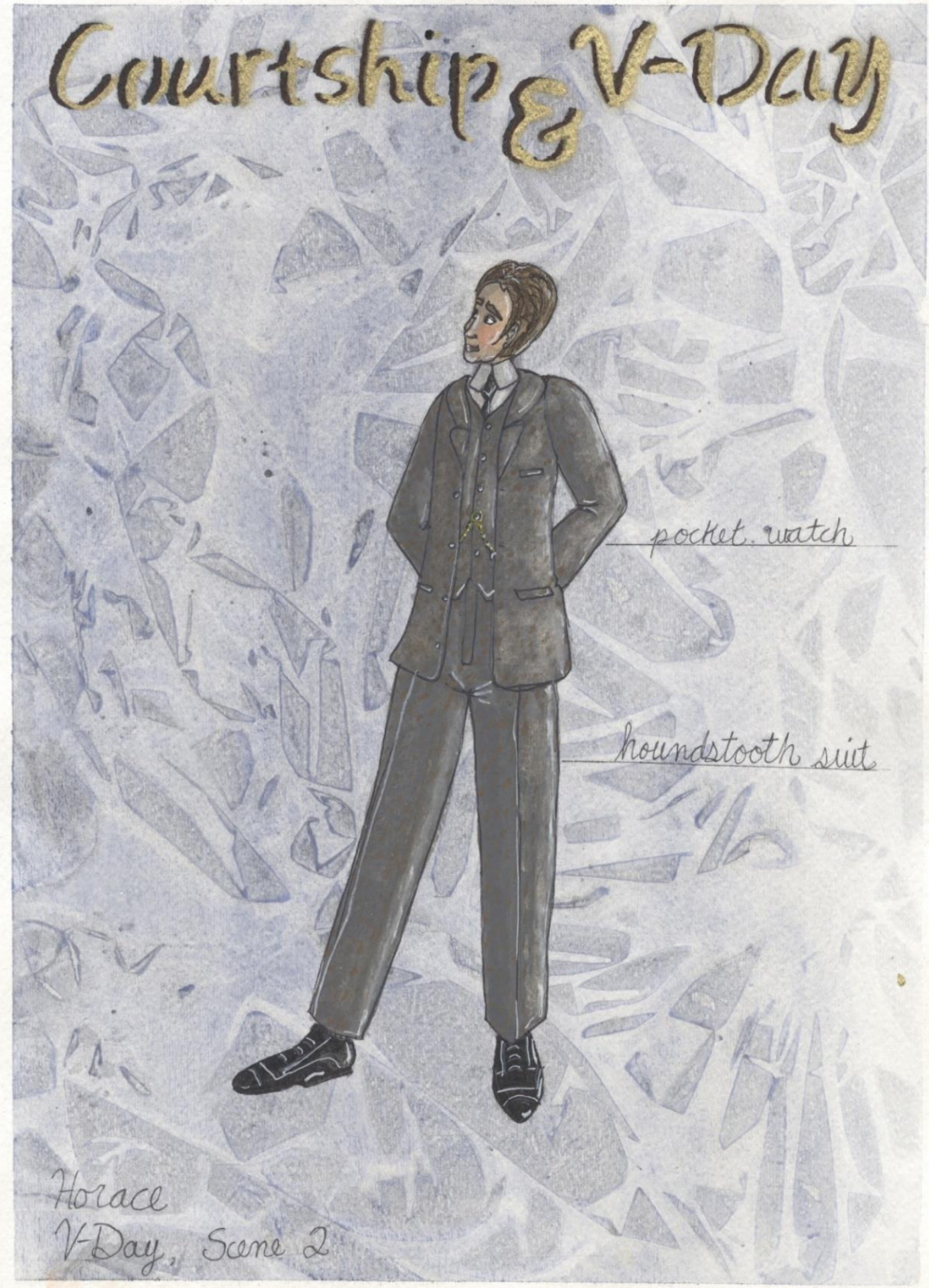

Horace Robedaux in Valentine's Day scene 2, final rendering.

Brennan, Lauren E. Horace Robedaux in Valentine's Day, Scene 2. 2015. Watercolor \& Marker. West Virginia University School of Theatre \& Dance, Morgantown, WV. Digital Image. 


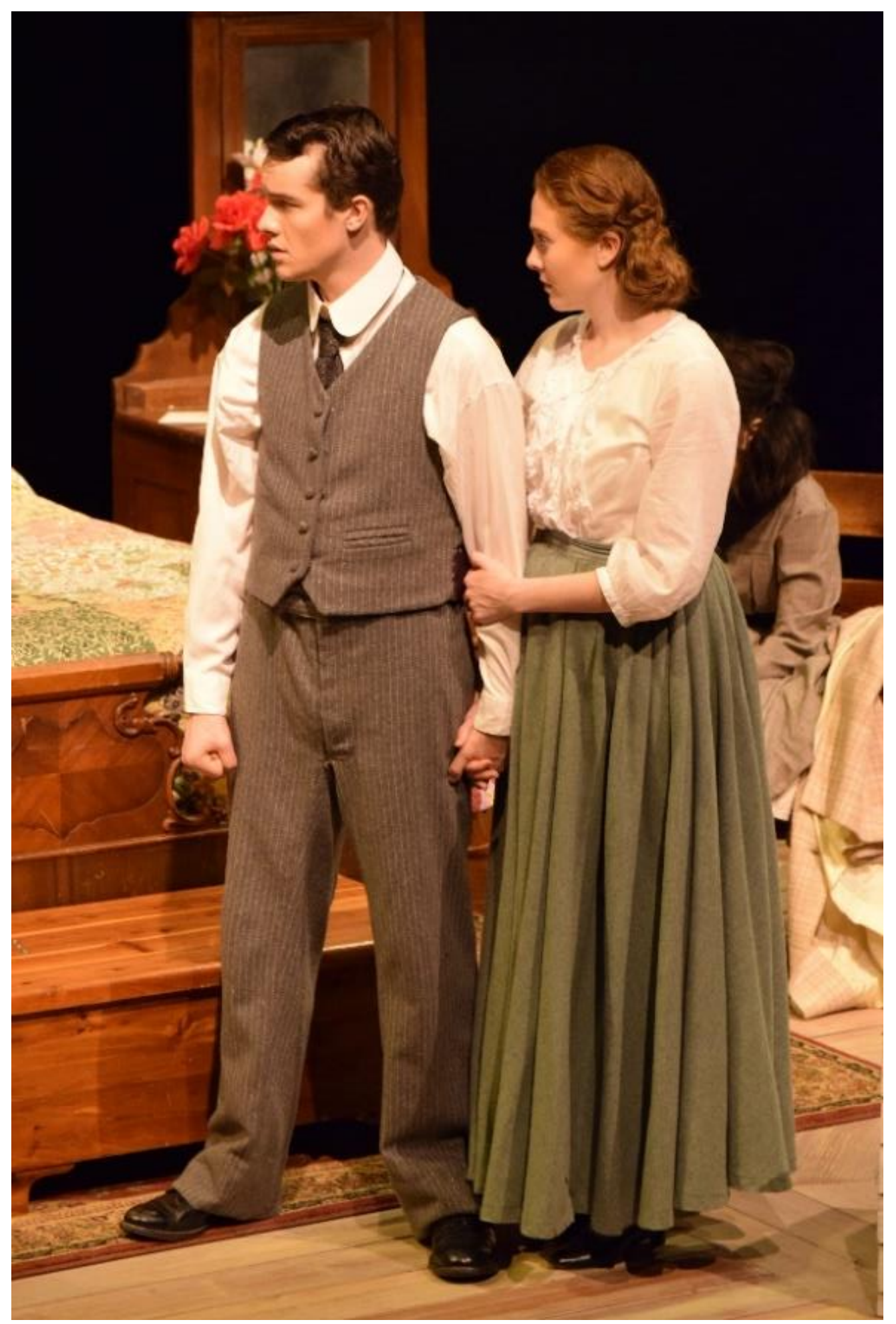

Horace (Isaac Snyder) and Elizabeth (Margaret Dransfield in Valentine's Day, scene 3.

Brennan, Lauren E. Horace and Elizabeth in Valentine's Day Scene 3. 2015. Photograph. West Virginia University School of Theatre \& Dance, Morgantown, WV. 


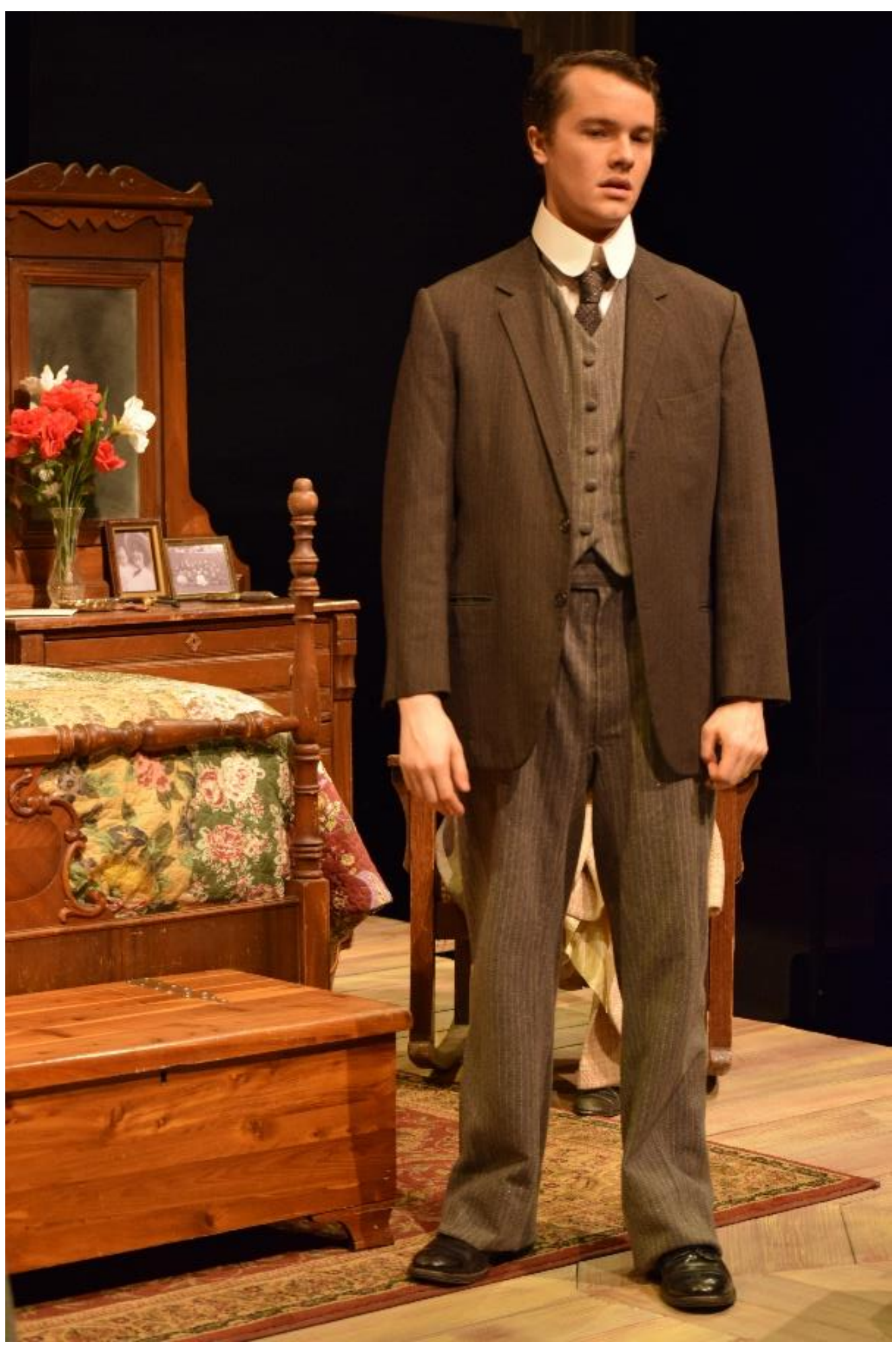

Horace (Isaac Snyder) in Valentine's Day, scene 3.

Brennan, Lauren E. Horace in Valentine's Day Scene 3. 2015. Photograph. West Virginia University School of Theatre \& Dance, Morgantown, WV. 


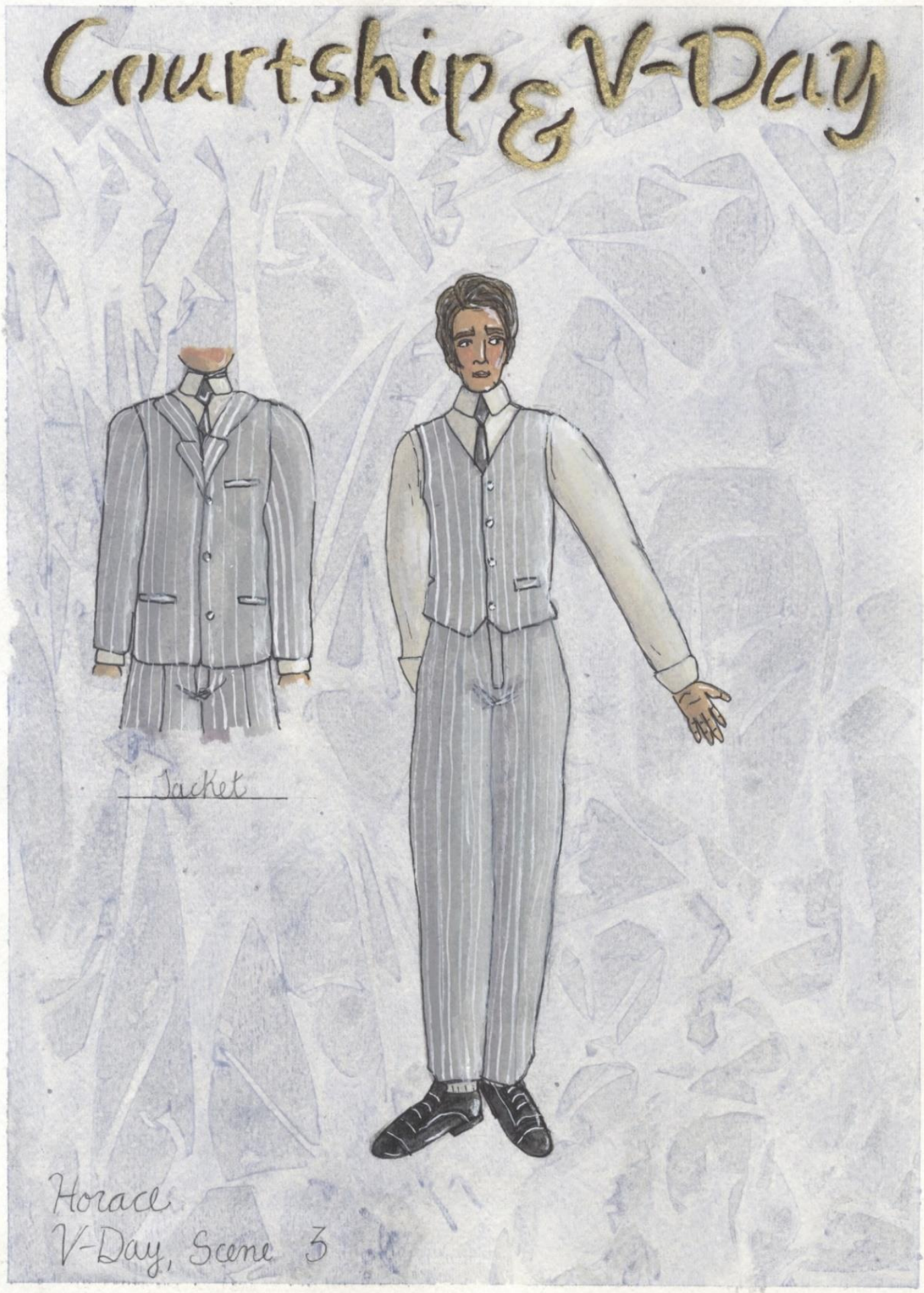

Horace Robedaux in Valentine's Day scene 3, final rendering.

Brennan, Lauren E. Horace Robedaux in Valentine's Day Scene 3. 2015. Watercolor \& Marker. West Virginia University School of Theatre and Dance, Morgantown, WV. Digital Image. 


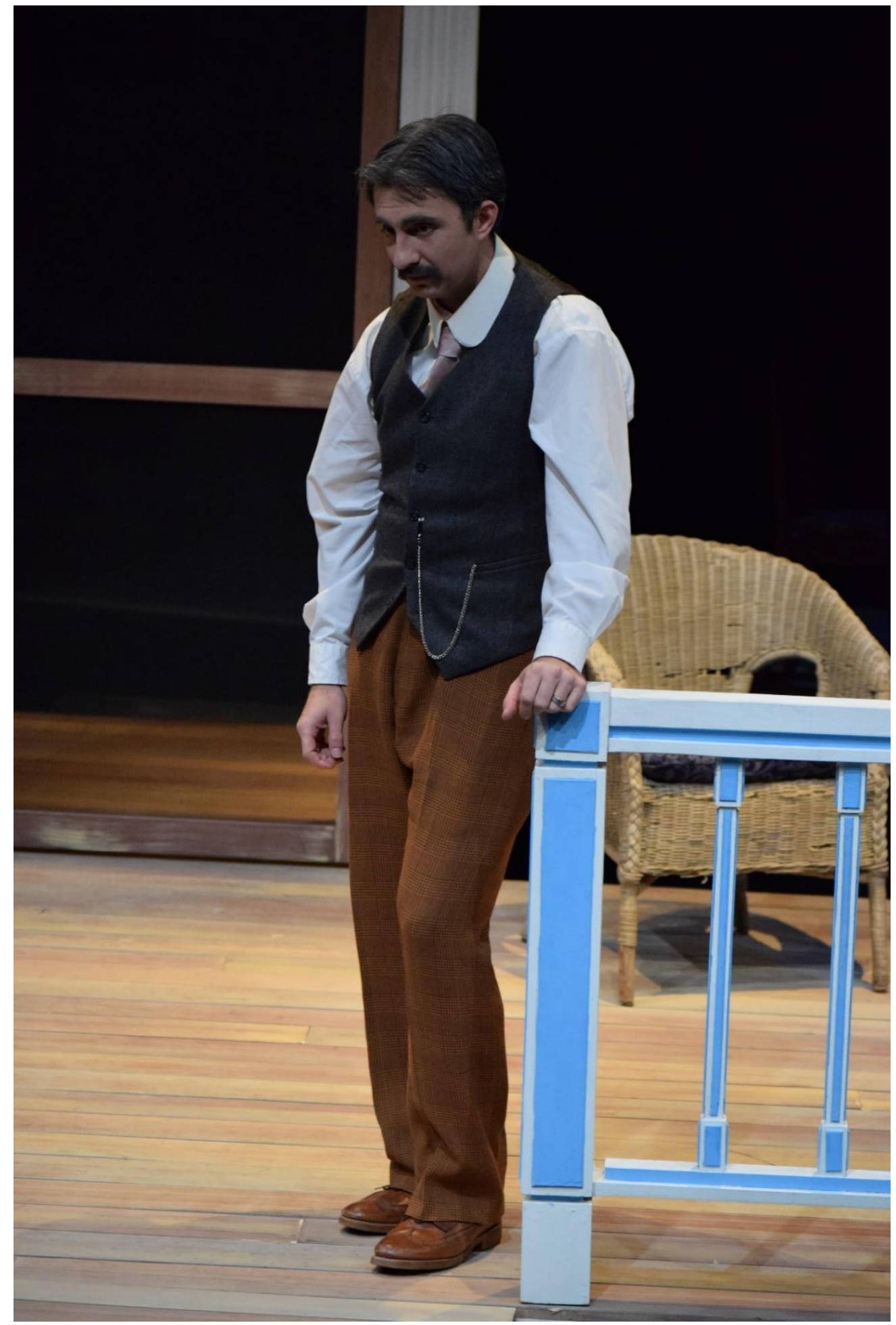

Mr. Vaughn (Joseph Bussey) stands on the porch in Courtship.

Brennan, Lauren E. Mr. Vaughn in Courtship. 2015. Photograph. West Virginia University School of Theatre \& Dance, Morgantown, WV. 


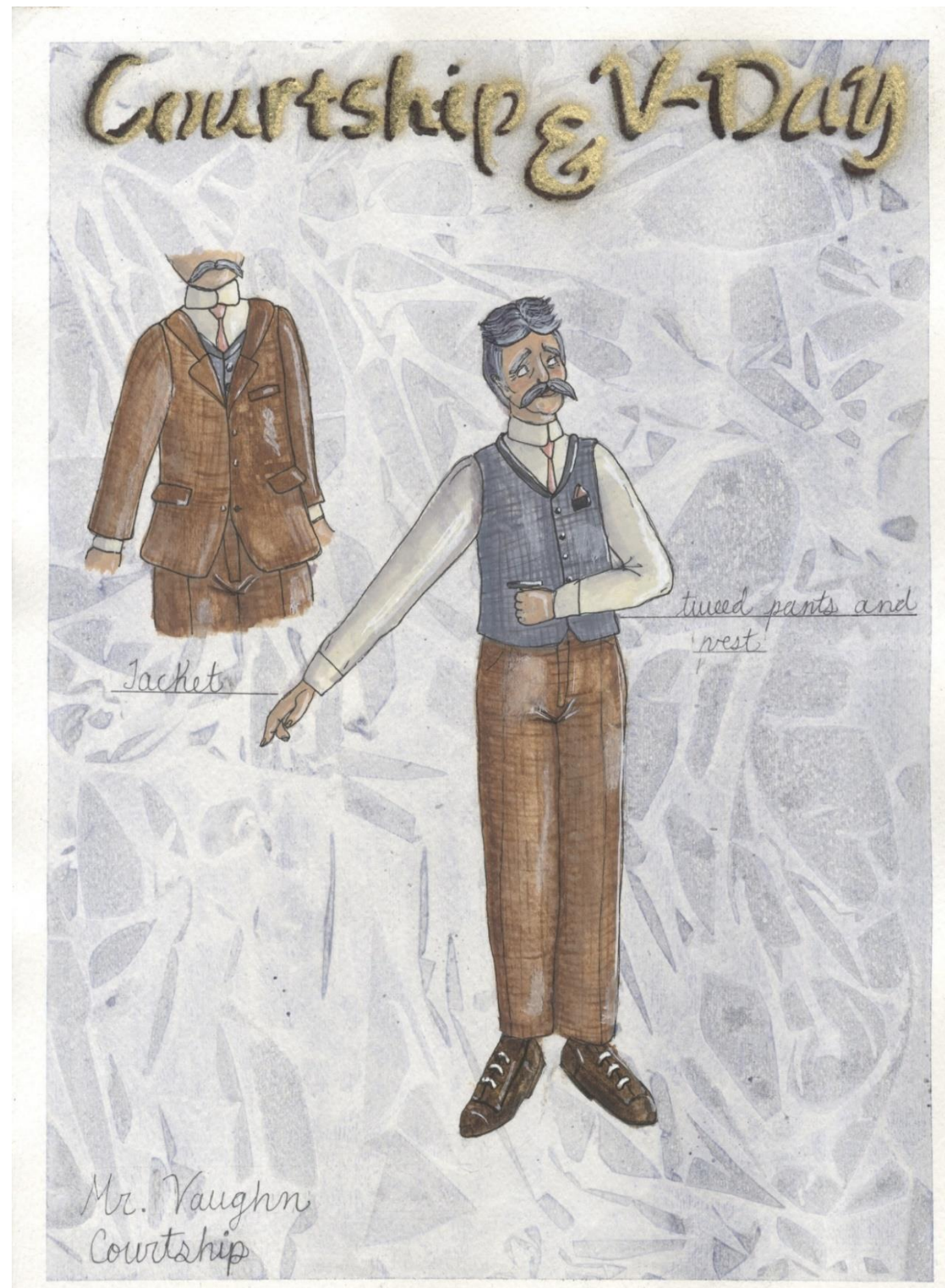

Mr. Vaughn in Courtship, final rendering.

Brennan, Lauren E. Mr. Vaughn in Courtship. 2015. Watercolor \& Marker. West Virginia University School of Theatre and Dance, Morgantown, WV. Digital Image. 


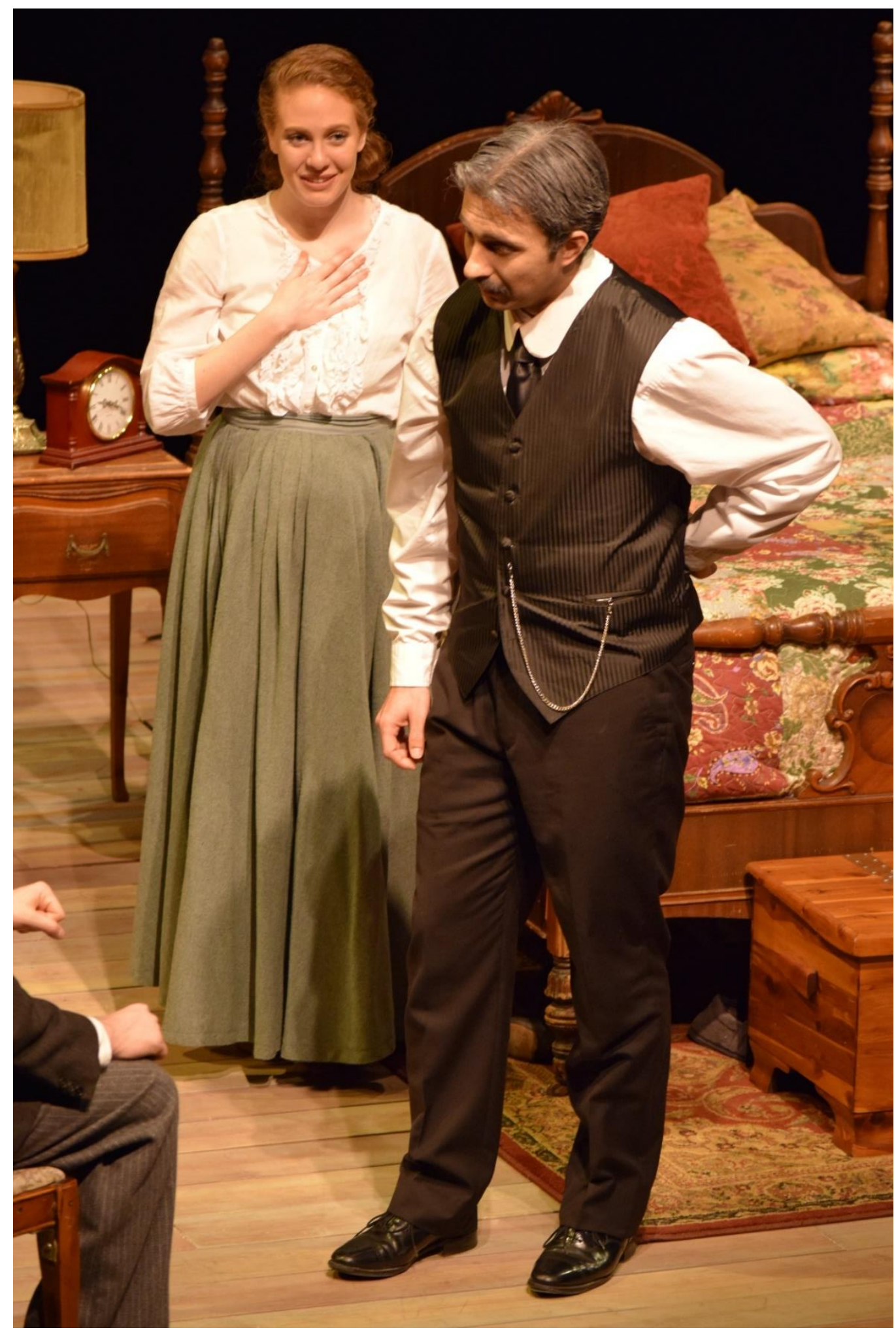

Mr. Vaughn (Joseph Bussey) and Elizabeth (Margaret Dransfield) in Valentine's Day, scene 3.

Brennan, Lauren E. Mr. Vaughn Reconciles with Elizabeth and Horace in Valentine's Day Scene 3. 2015. Photograph. West Virginia University School of Theatre \& Dance, Morgantown, WV. 


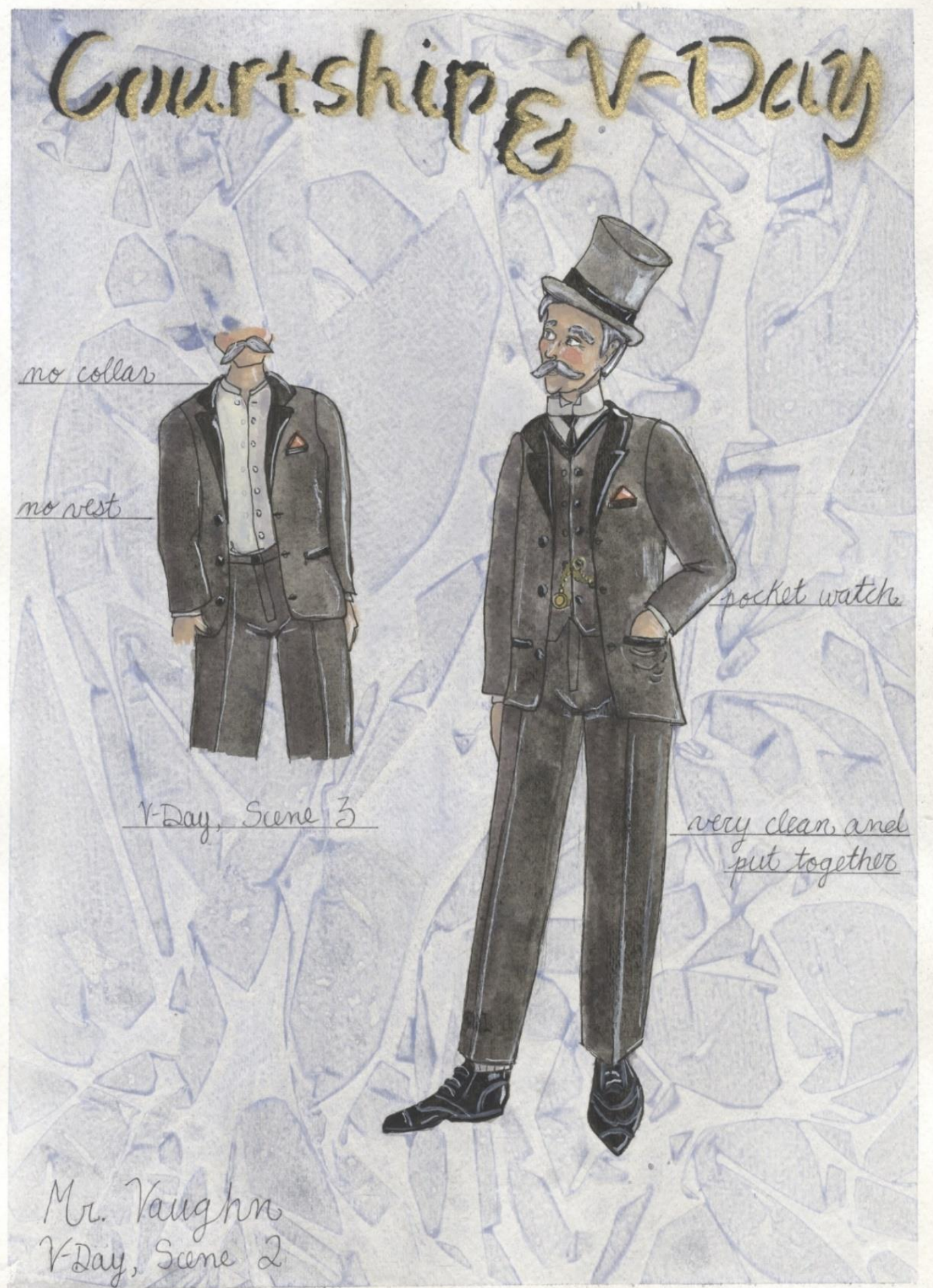

Mr. Vaughn in Valentine's Day, scenes 2 \& 3, final rendering.

Brennan, Lauren E. Mr. Vaughn in Valentine's Day Scenes 2 \& 3. 2015. Watercolor \& Marker. West Virginia University School of Theatre and Dance, Morgantown, WV. Digital Image. 


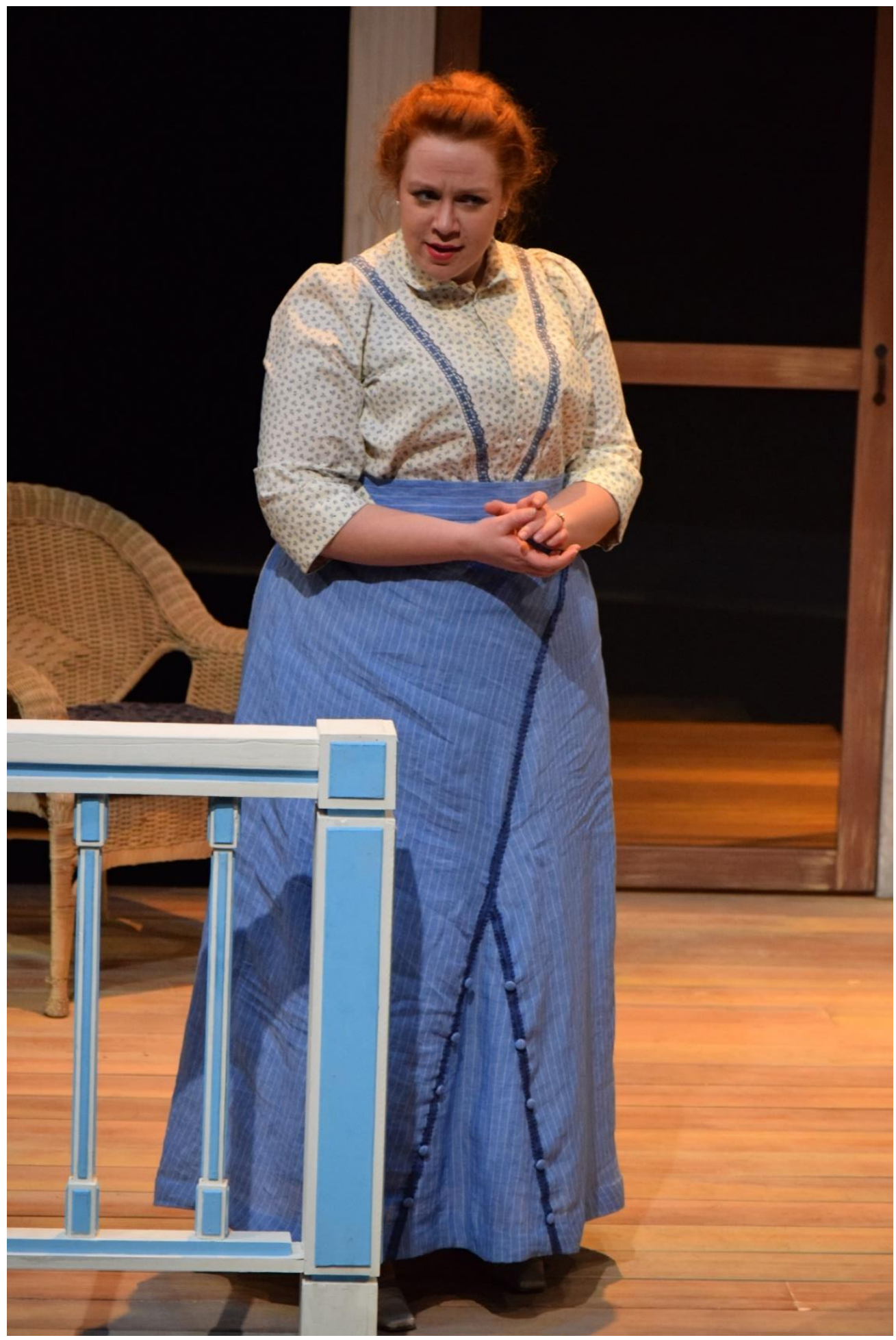

Mrs. Vaughn (Madeline Hintz) stands on the porch in Courtship.

Brennan, Lauren E. Mrs. Vaughn in Courtship. 2015. Photograph. West Virginia University School of Theatre \& Dance, Morgantown, WV. 


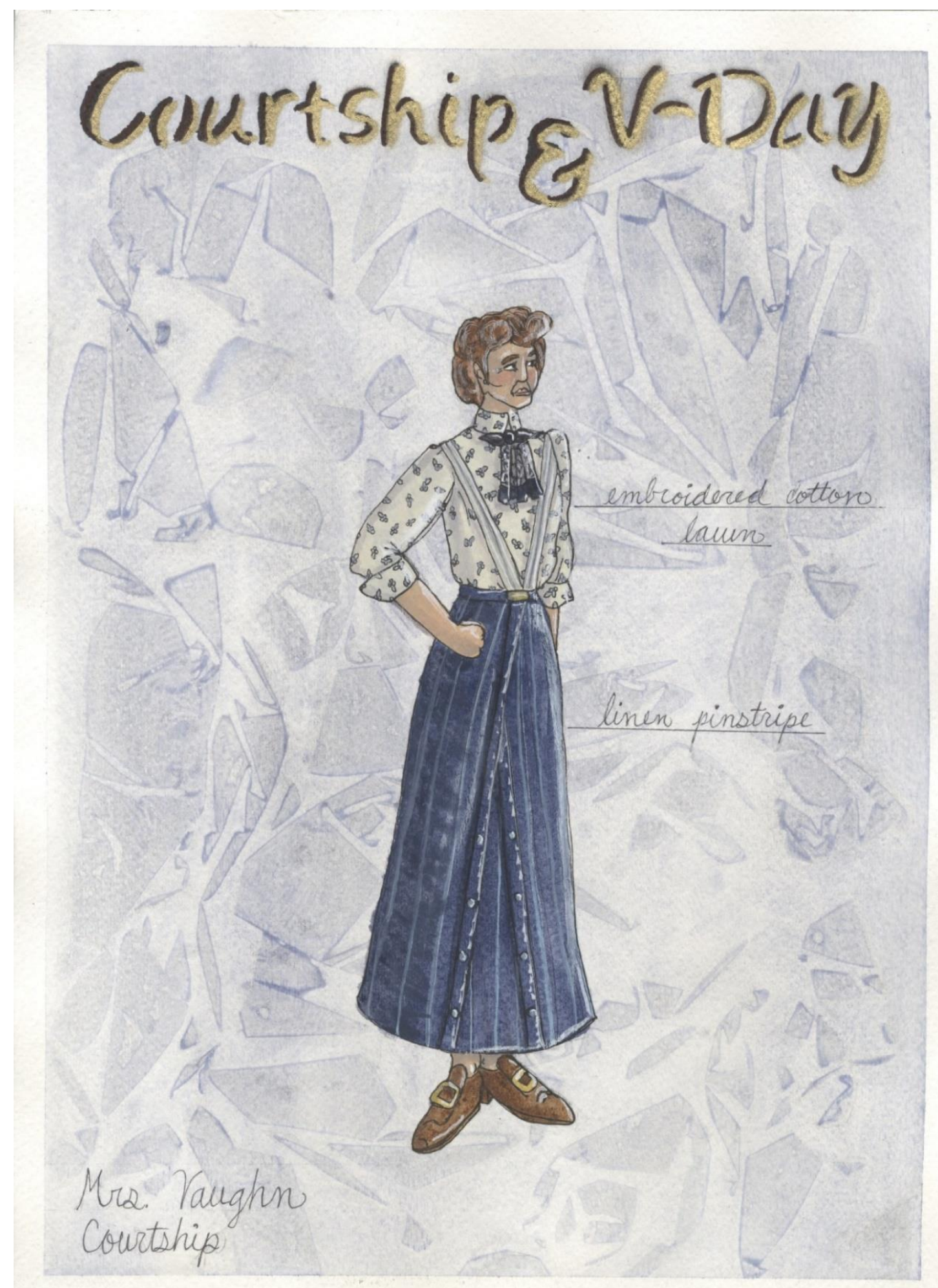

Mrs. Vaughn in Courtship, final rendering.

Brennan, Lauren E. Mrs. Vaughn in Courtship. 2015. Watercolor \& Marker. West Virginia University School of Theatre and Dance, Morgantown, WV. Digital Image. 


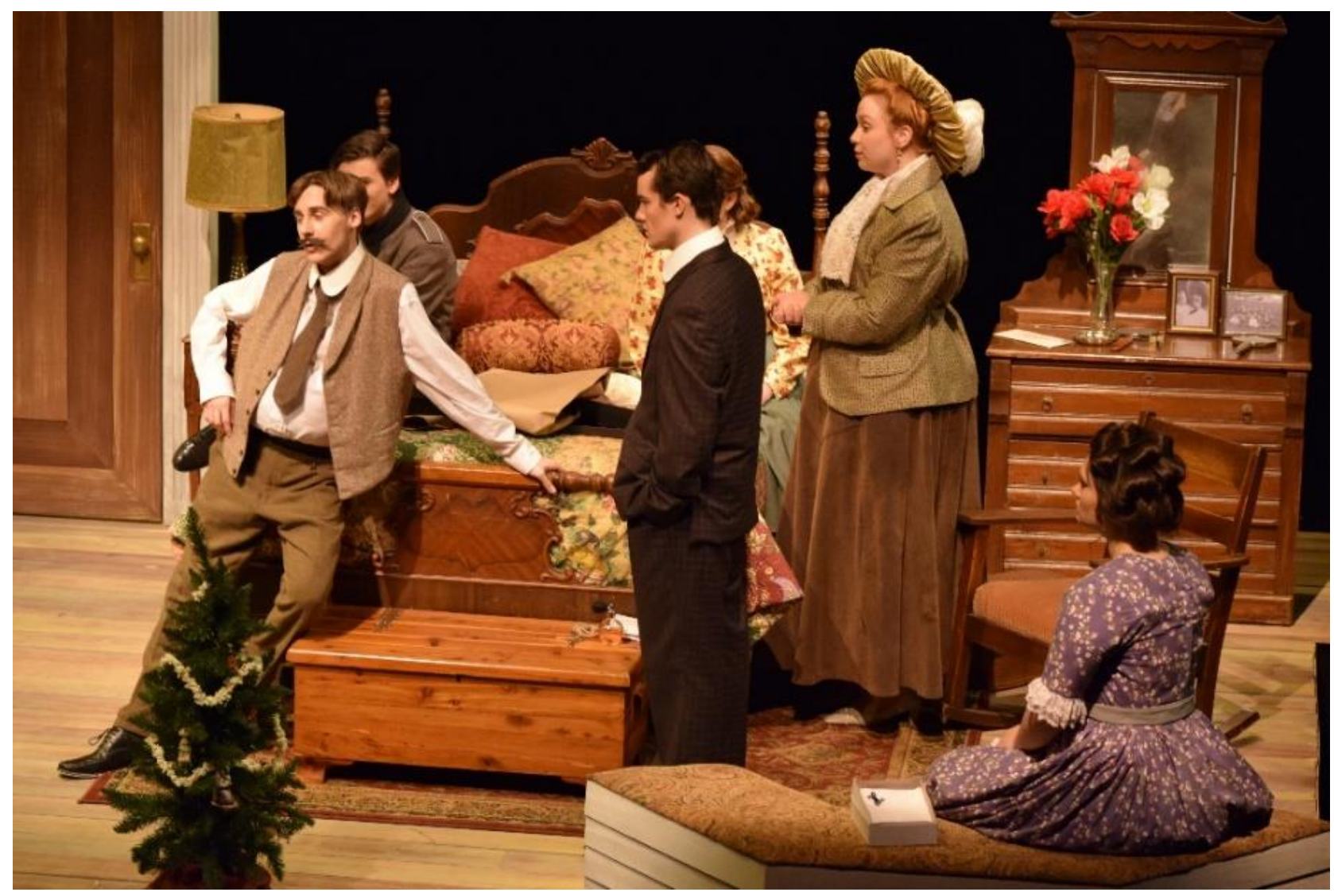

Bobby Pate (Zachary Powers), Brother Vaughn (Woody Pond), Horace Robedaux (Isaac Snyder), Mrs. Vaughn (Madeline Hintz), Elizabeth Vaughn (Margaret Dransfield), and Miss Ruth Amos (Brianna Bowers) in Valentine's Day, scene 2.

Brennan, Lauren E. Cast of Valentine's Day. 2015. Photograph. West Virginia University School of Theatre \& Dance, Morgantown, WV., Morgantown, WV. 


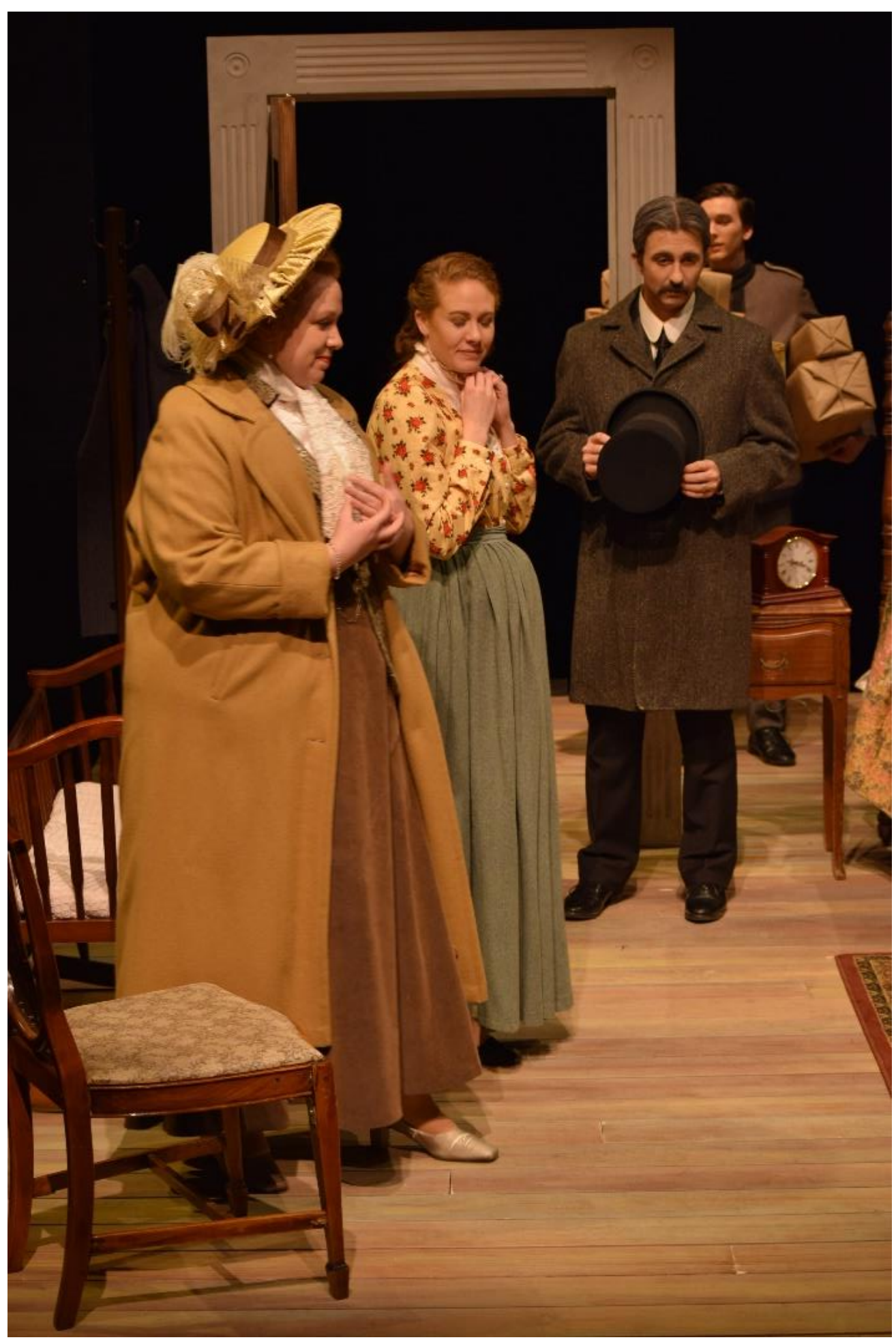

Mrs. Vaughn (Madeline Hintz), Elizabeth (Margaret Dransfield), Mrs. Vaughn (Joseph Bussey), and Brother Vaughn (Woody Pond) in Valentine's Day, scene 2.

Brennan, Lauren E. Mr. and Mrs. Vaughn Enter Elizabeth and Horace's new home in Valentine's Day Scene 2. 2015. Photograph. West Virginia University School of Theatre \& Dance, Morgantown, WV. 


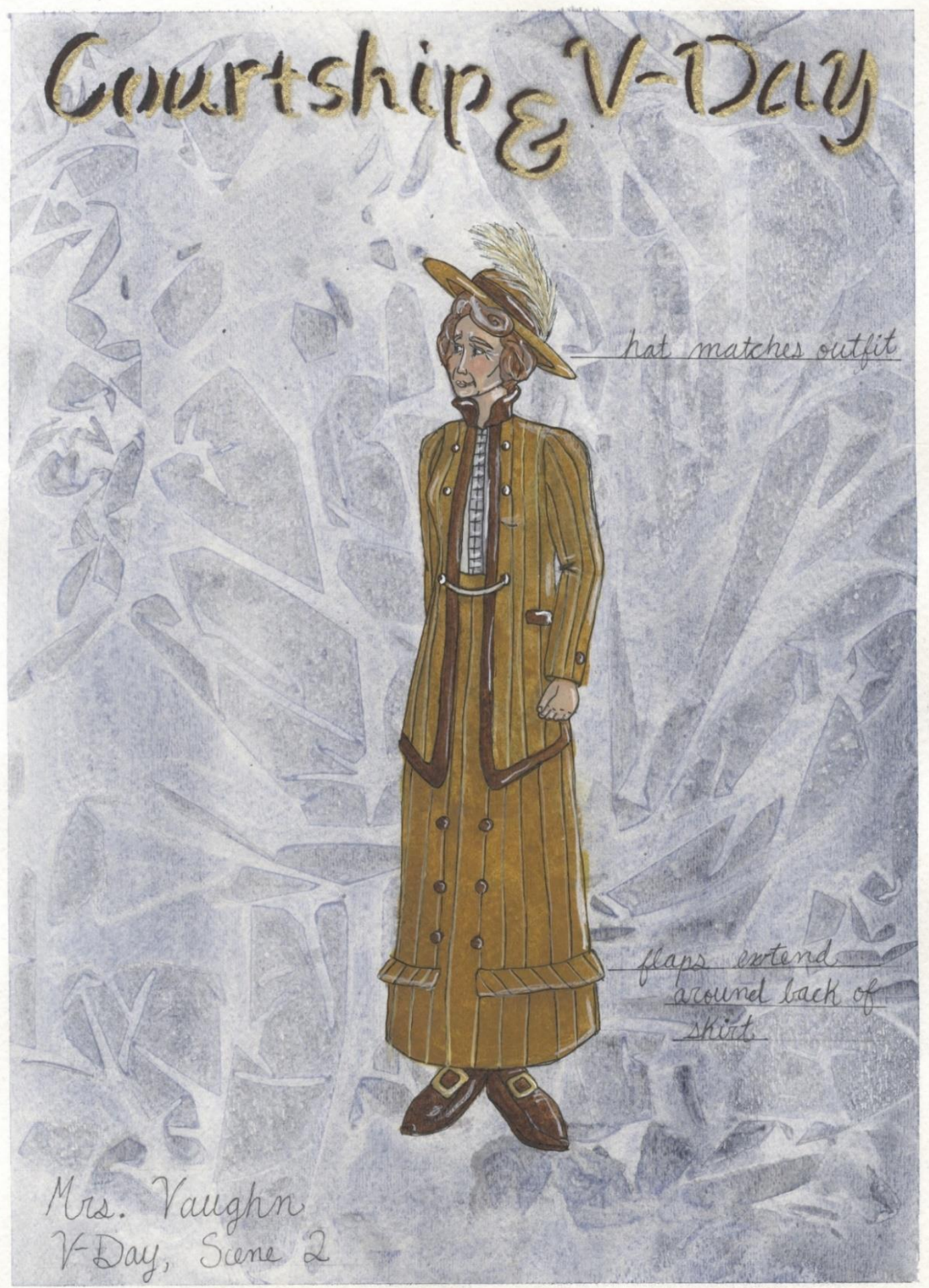

Mrs. Vaughn in Valentine's Day scene 2, final rendering.

Brennan, Lauren E. Mrs. Vaughn in Valentine's Day Scene 2. 2015. Watercolor \& Marker. West Virginia University School of Theatre and Dance, Morgantown, WV. Digital Image. 


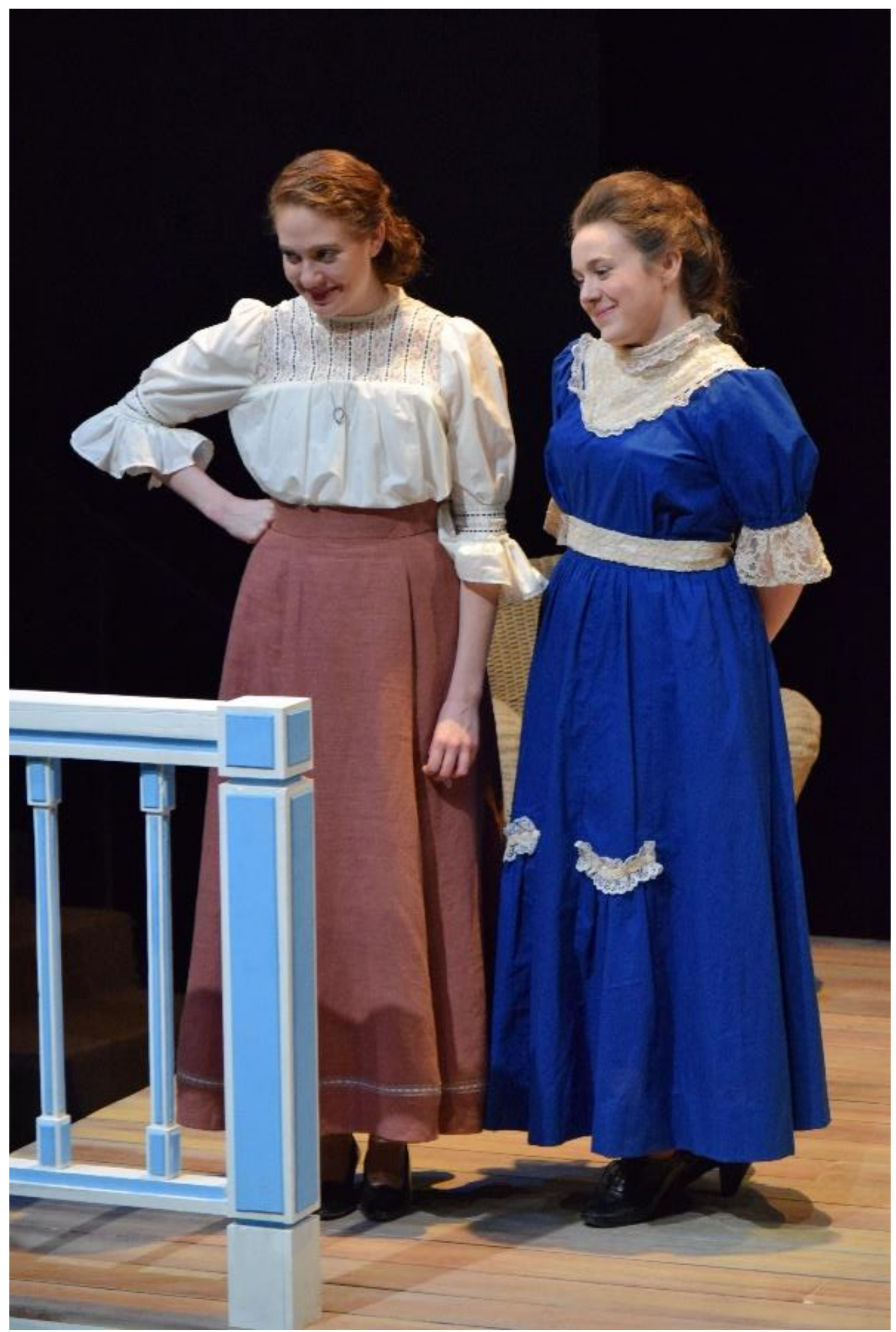

Elizabeth (Margaret Dransfield) and Laura (Mallory Robson) chat with Steve Tyler from the porch in Courtship.

Brennan, Lauren E. Laura and Elizabeth on the Porch in Courtship. 2015. Photograph. West Virginia University School of Theatre \& Dance, Morgantown, WV. 


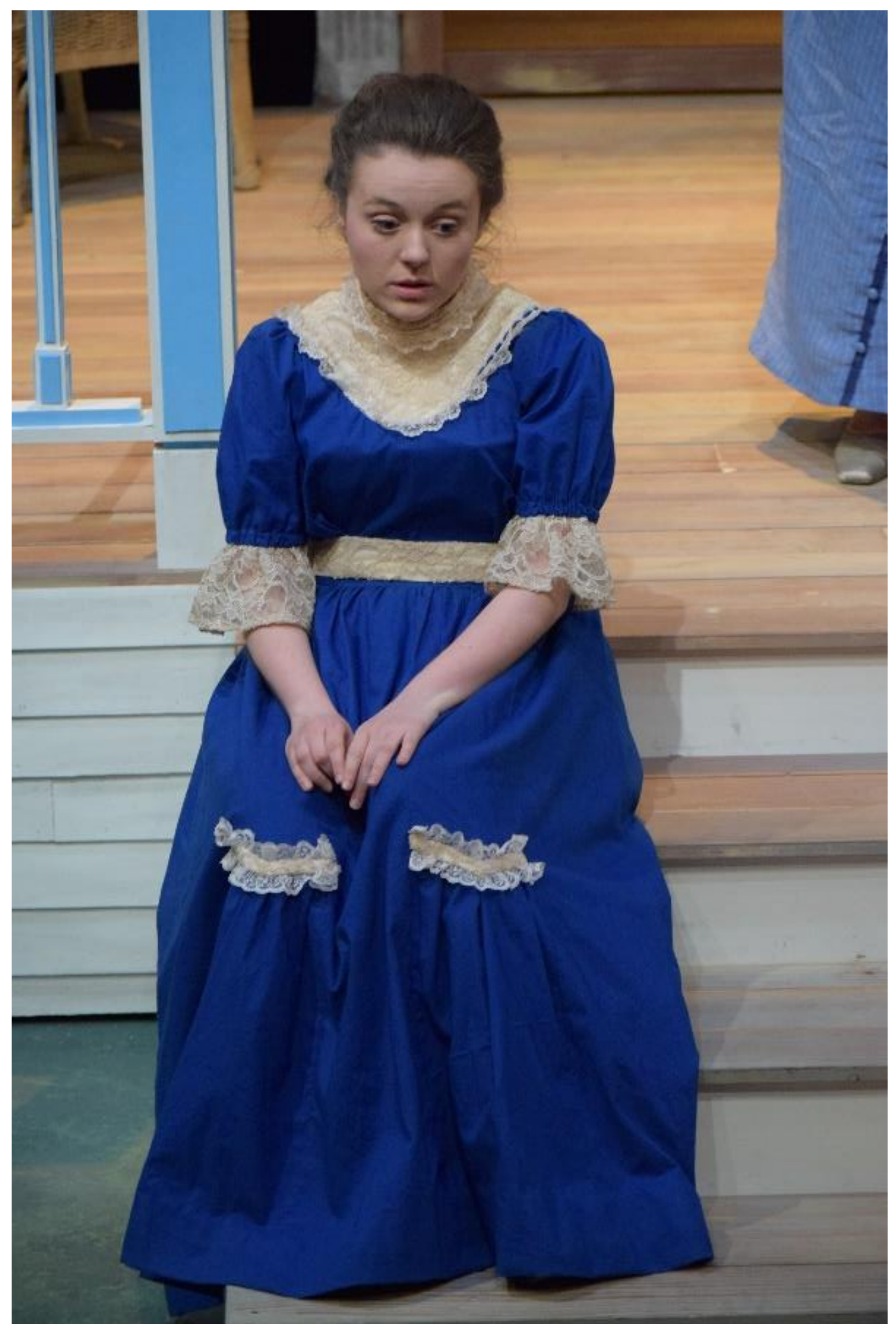

Laura (Mallory Robson) sits on the porch steps in Courtship.

Brennan, Lauren E. Laura Sits on the Porch Steps in Courtship. 2015. Photograph. West Virginia University School of Theatre \& Dance, Morgantown, WV. 


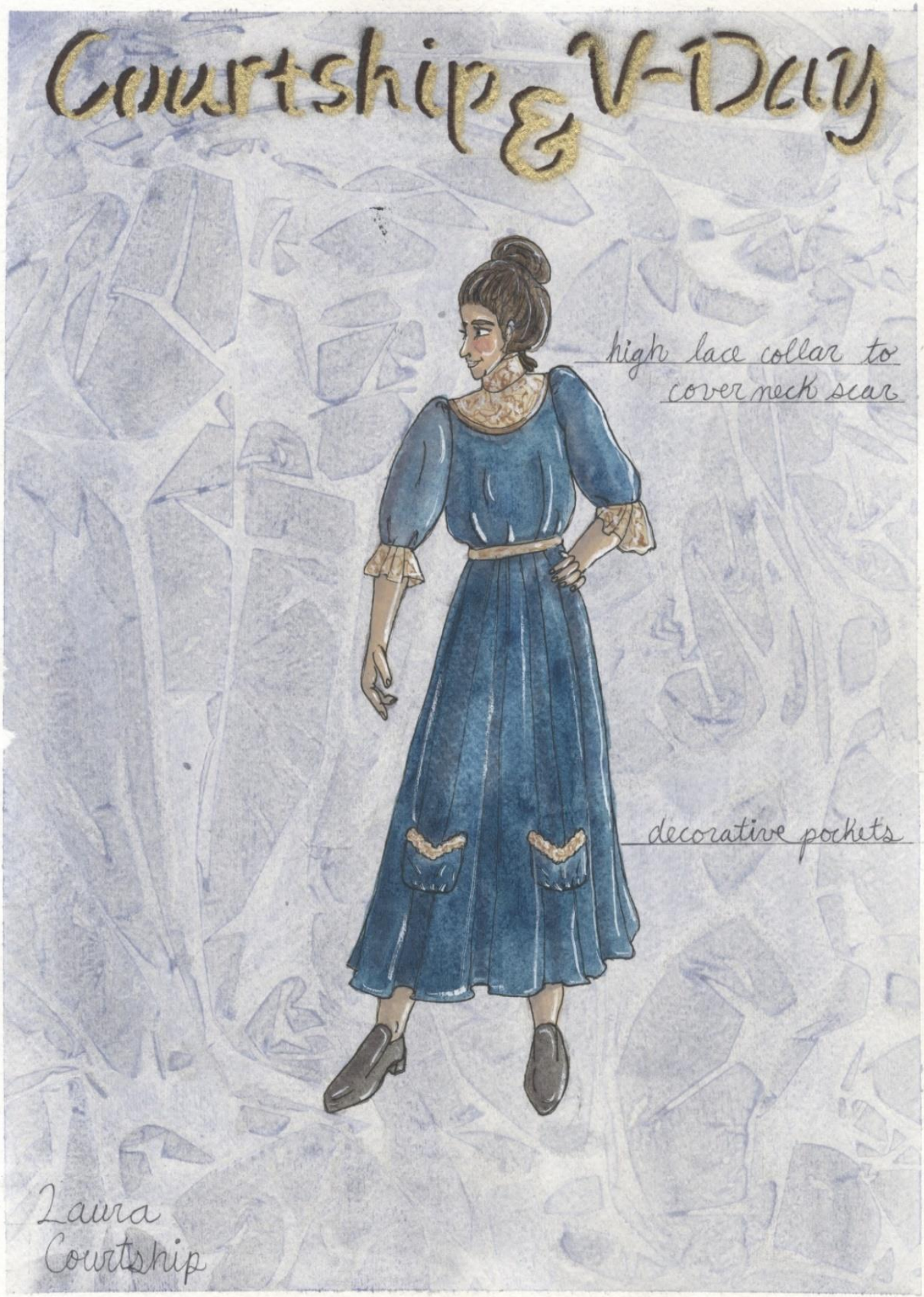

Laura Vaughn in Courtship, final rendering.

Brennan, Lauren E. Laura Vaughn in Courtship. 2015. Watercolor \& Marker. West Virginia University School of Theatre and Dance, Morgantown, WV. Digital Image. 


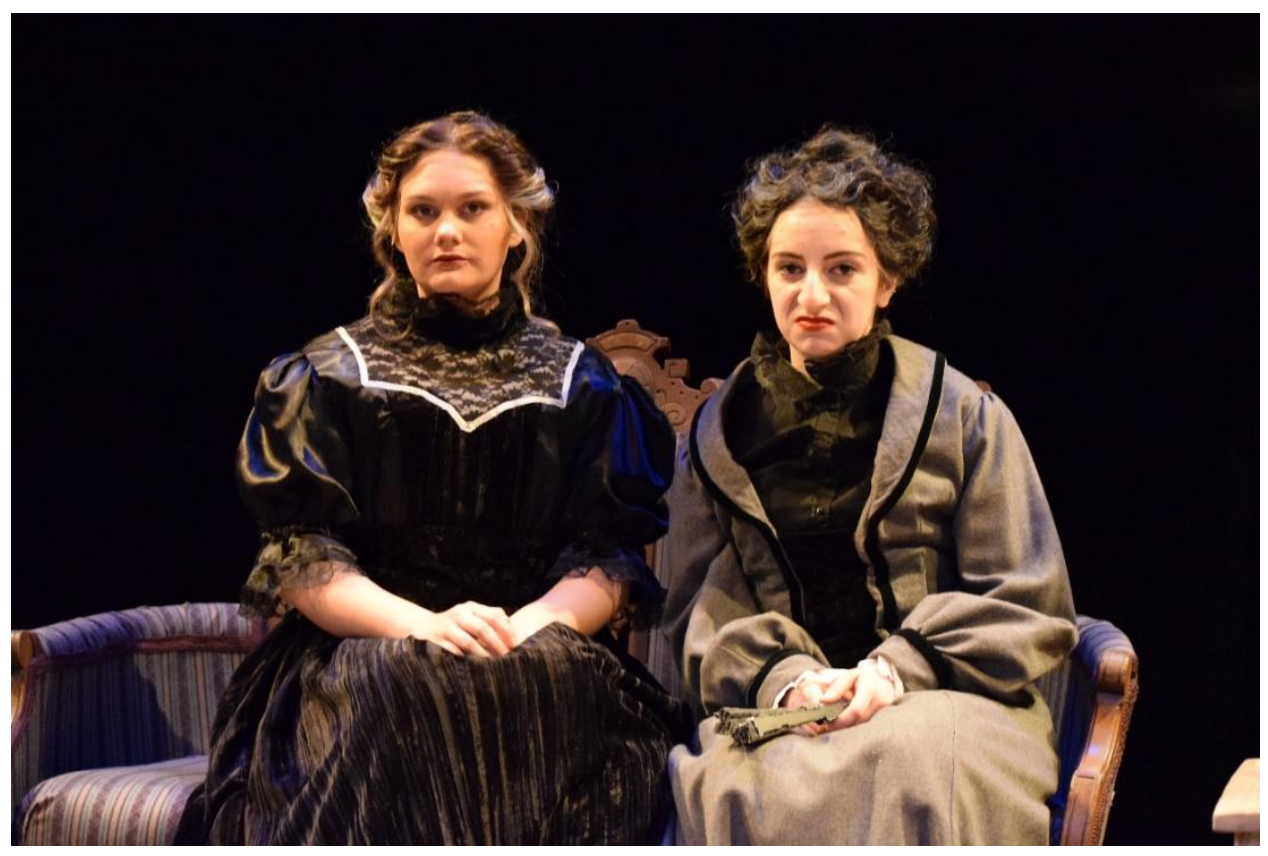

Aunt Lucy (Brianna Bowers) and Aunt Sarah (Katie Boothby) on the music room couch in Courtship.

Brennan, Lauren E. Aunts Lucy and Sarah Scowl on the Music Room Couch in Courtship. 2015. Photograph. West Virginia University School of Theatre \& Dance, Morgantown, WV.

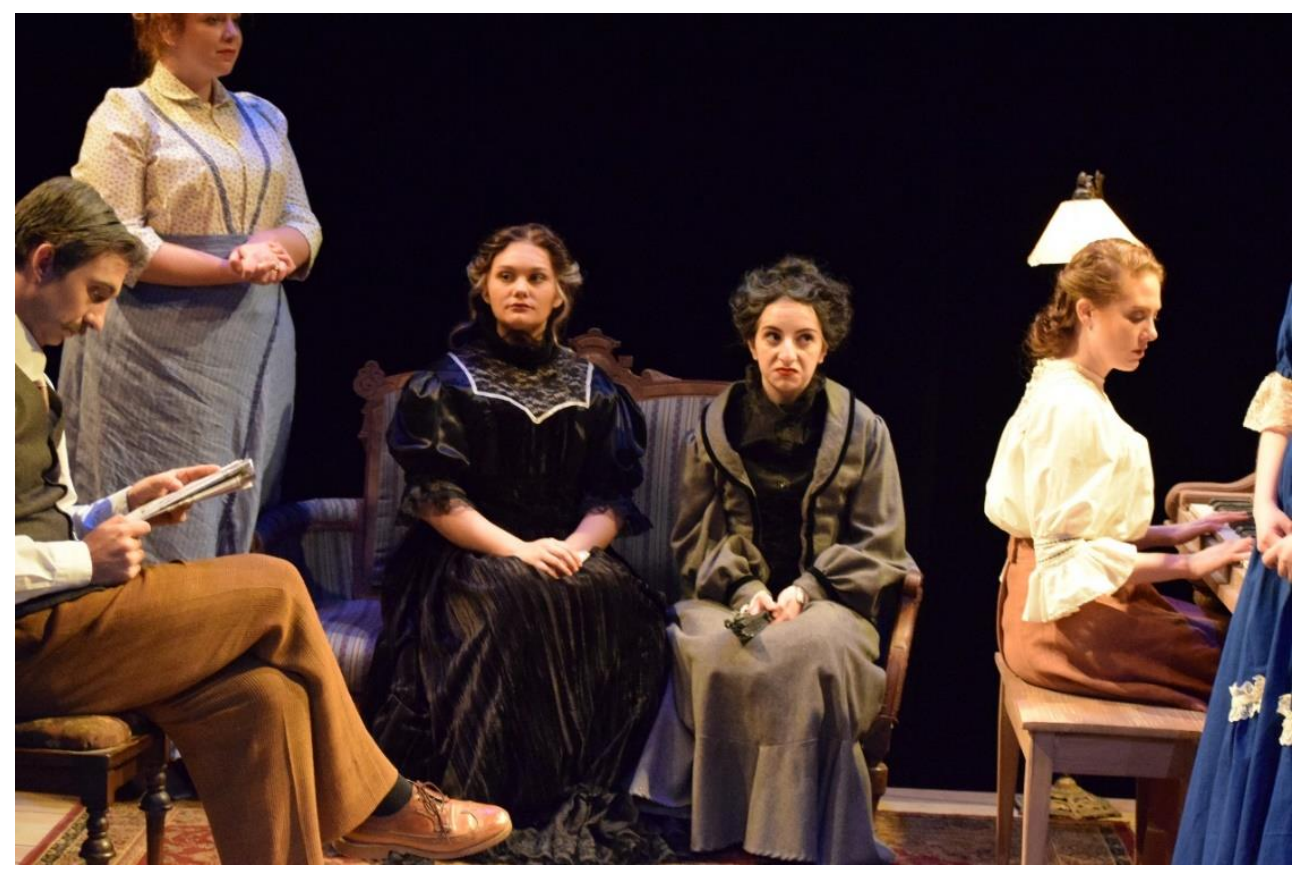

Aunt Lucy (Brianna Bowers) and Aunt Sarah (Katie Boothby) in Courtship.

Brennan, Lauren E. Aunts Lucy and Sarah in the Music Room in Courtship. 2015. Photograph. West Virginia University School of Theatre \& Dance, Morgantown, WV. 


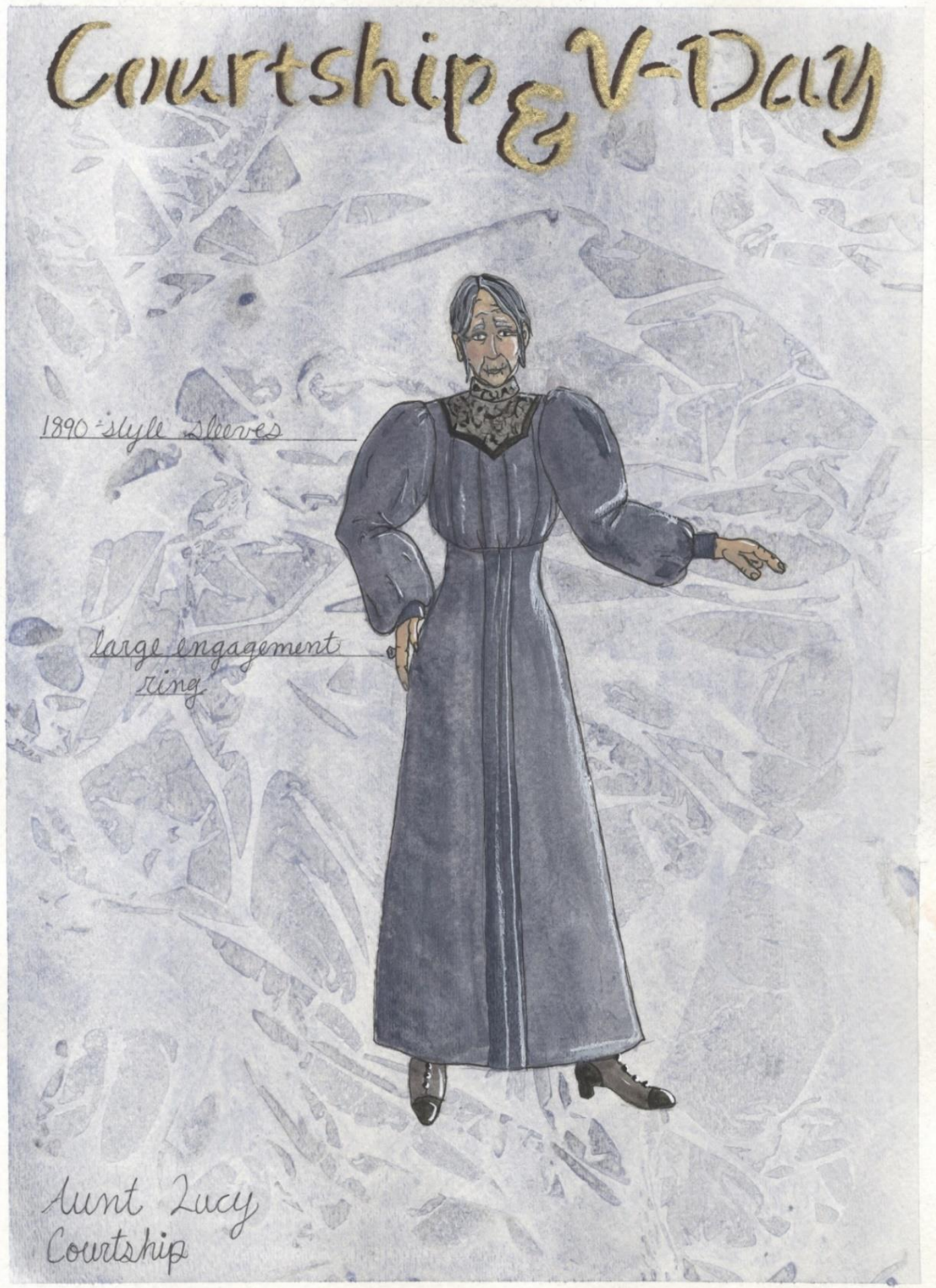

Aunt Lucy in Courtship, final rendering.

Brennan, Lauren E. Aunt Lucy in Courtship. 2015. Watercolor \& Marker. West Virginia University School of Theatre and Dance, Morgantown, WV. Digital Image. 


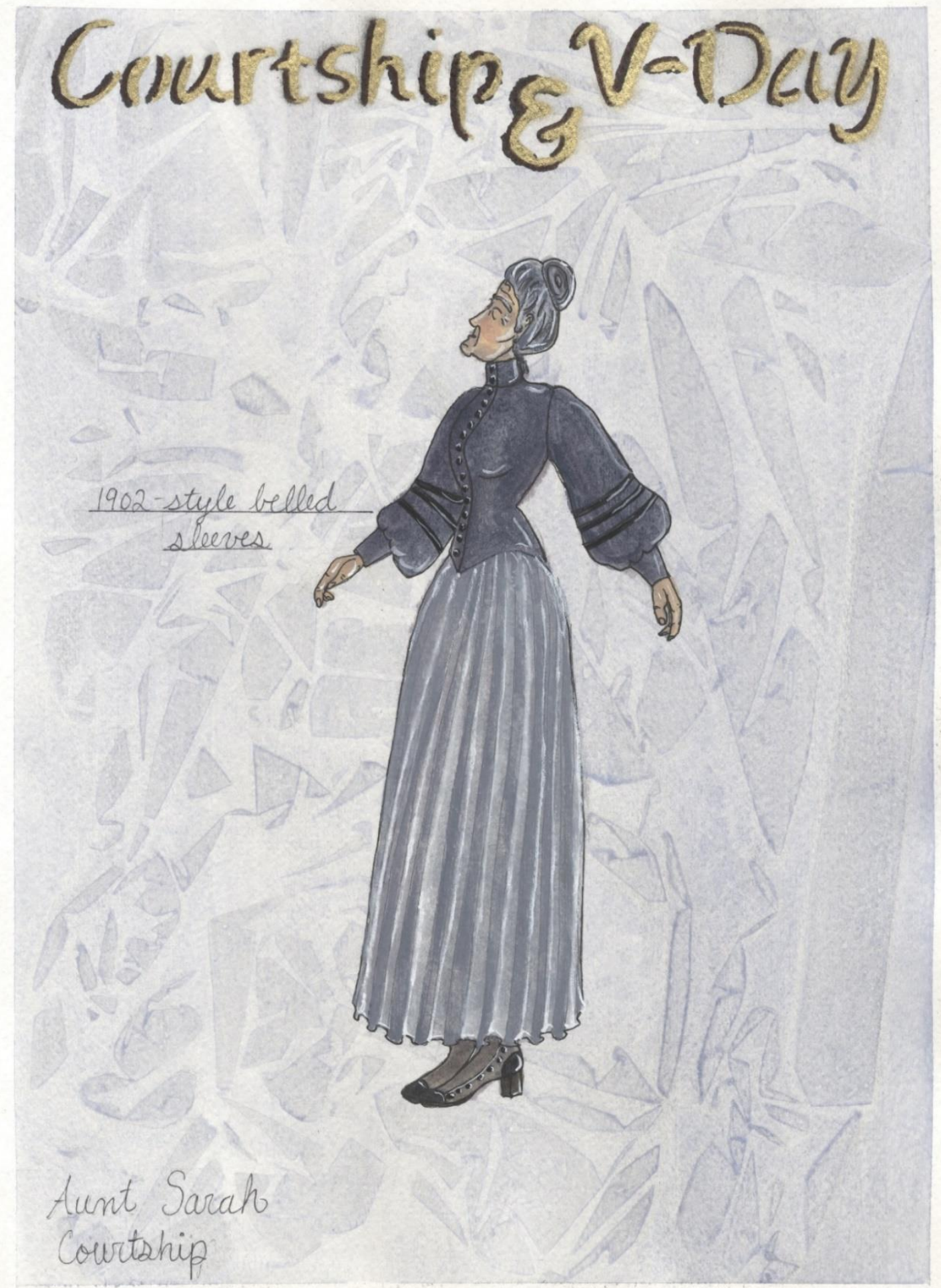

Aunt Sarah in Courtship, final rendering.

Brennan, Lauren E. Aunt Sarah in Courtship. 2015. Watercolor \& Marker. West Virginia University School of Theatre and Dance, Morgantown, WV. Digital Image. 


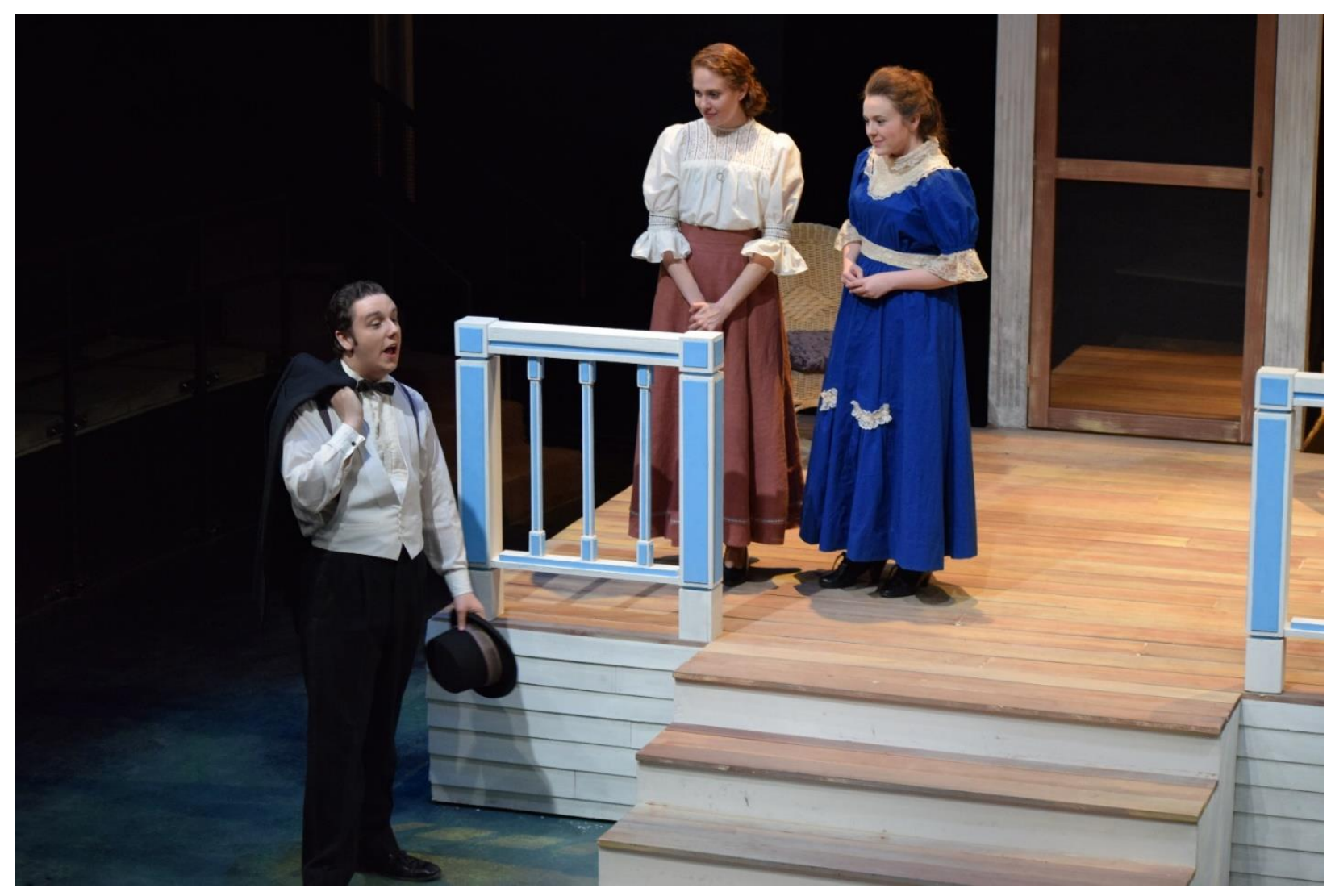

Steve Tyler (Joshua Clevenger), Elizabeth (Margaret Dransfield), and Laura (Mallory Robson) chat with Steve Tyler on the porch in Courtship.

Brennan, Lauren E. Elizabeth and Laura Chat with Steve Tyler on the Porch in Courtship. 2015. Photograph. West Virginia University School of Theatre \& Dance, Morgantown, WV. 


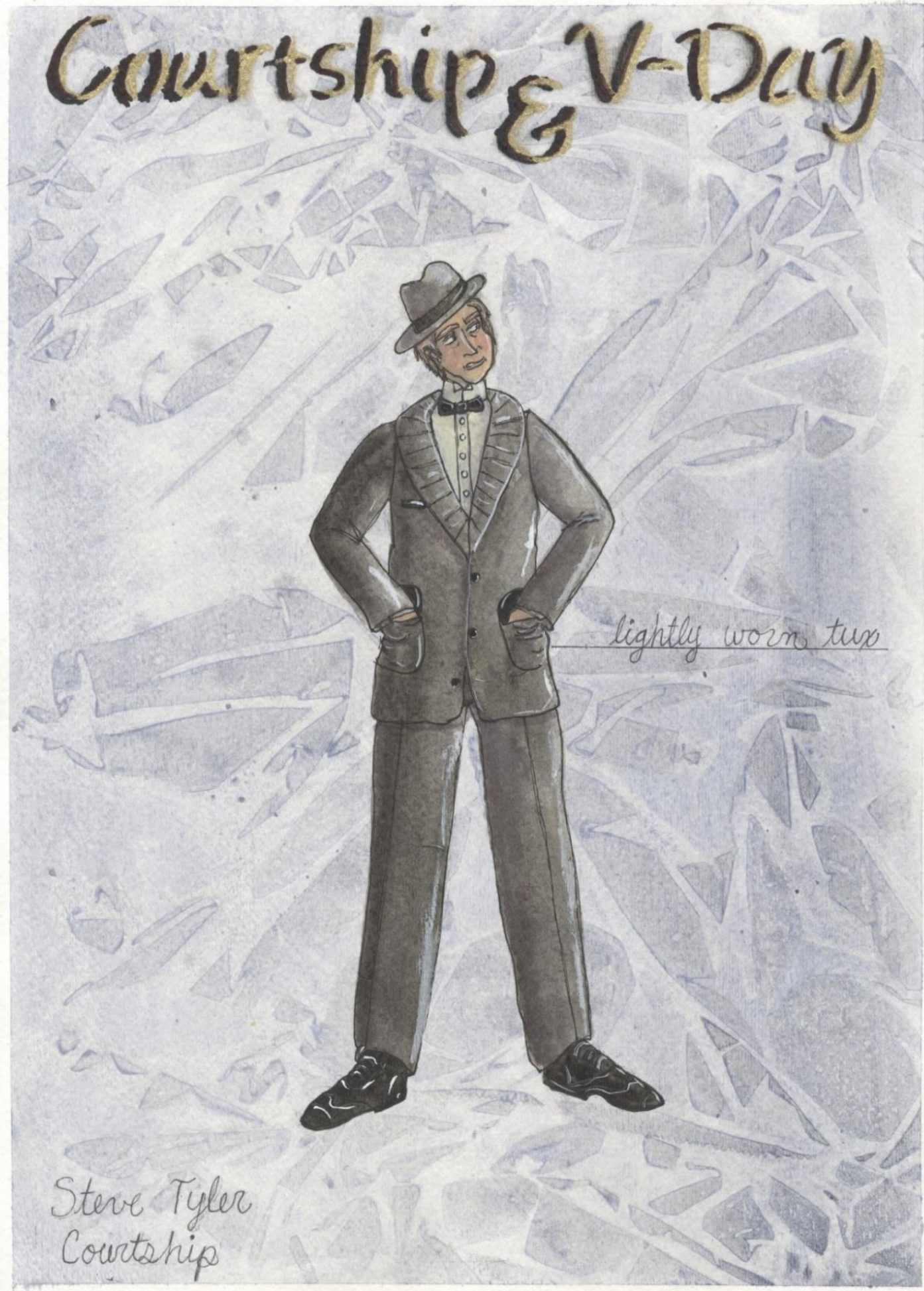

Steve Tyler in Courtship, final rendering.

Brennan, Lauren E. Steve Tyler in Courtship. 2015. Watercolor \& Marker. West Virginia University School of Theatre and Dance, Morgantown, WV. Digital Image. 


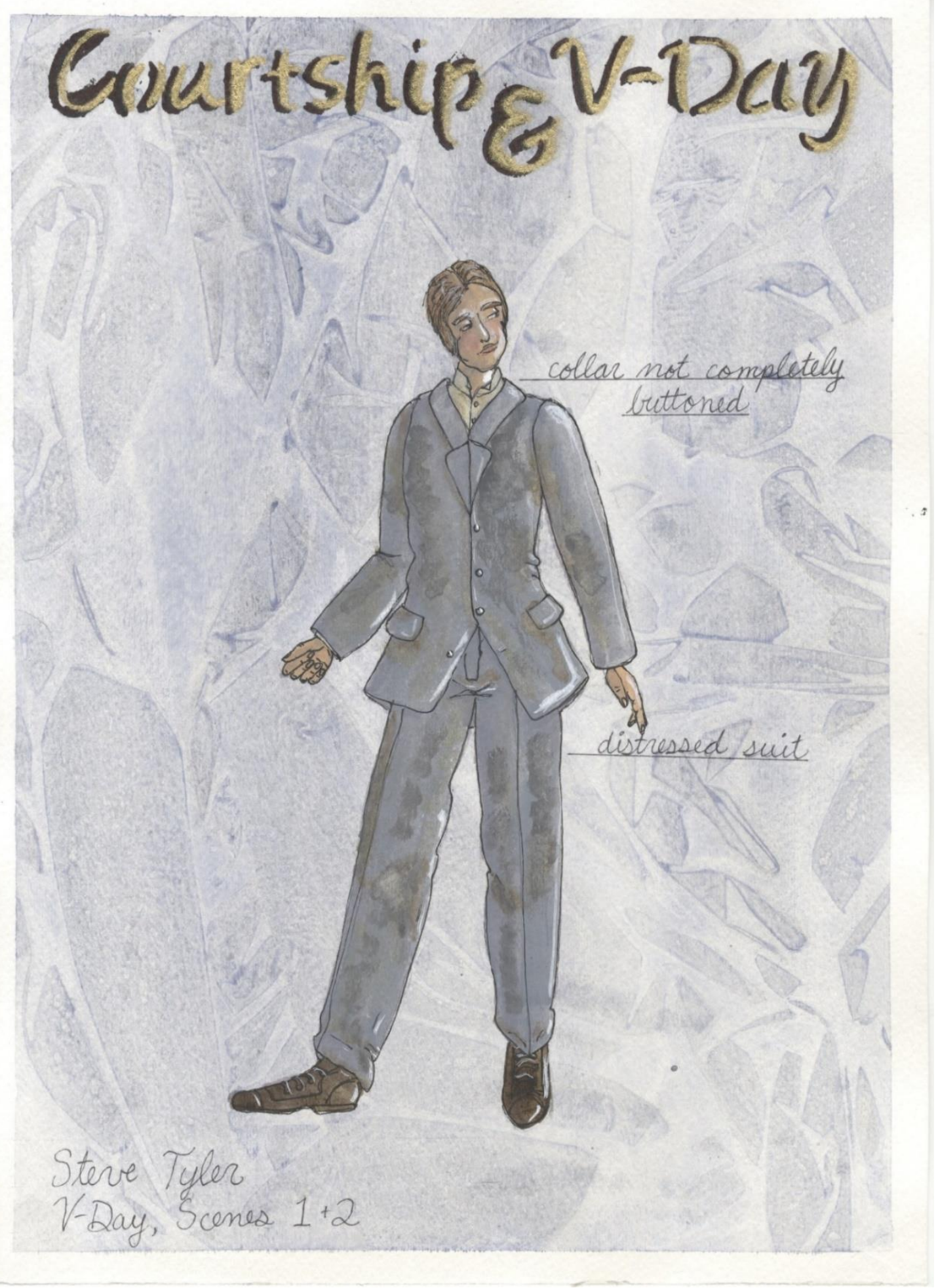

Steve Tyler in Valentine's Day, scenes 1 \& 2, final rendering.

Brennan, Lauren E. Steve Tyler in Valentine's Day. 2015. Watercolor \& Marker. West Virginia University School of Theatre and Dance, Morgantown, WV. Digital Image. 


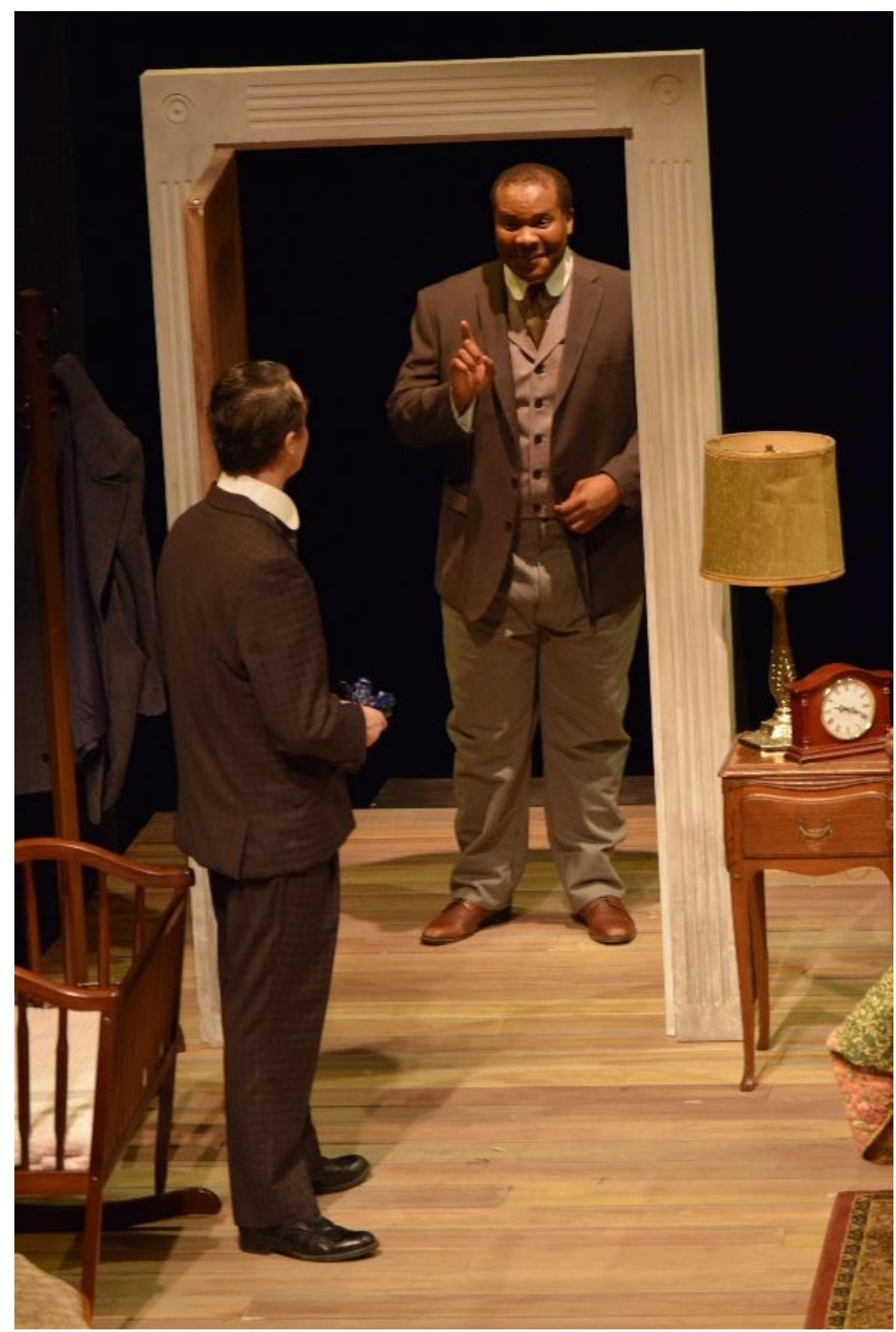

Horace (Isaac Snyder) and George Tyler (Lonnie Simmons) in Valentine's Day, scene 2.

Brennan, Lauren E. George Tyler visits in Valentine's Day Scene 2. 2015. Photograph. West Virginia University School of Theatre \& Dance, Morgantown, WV. 


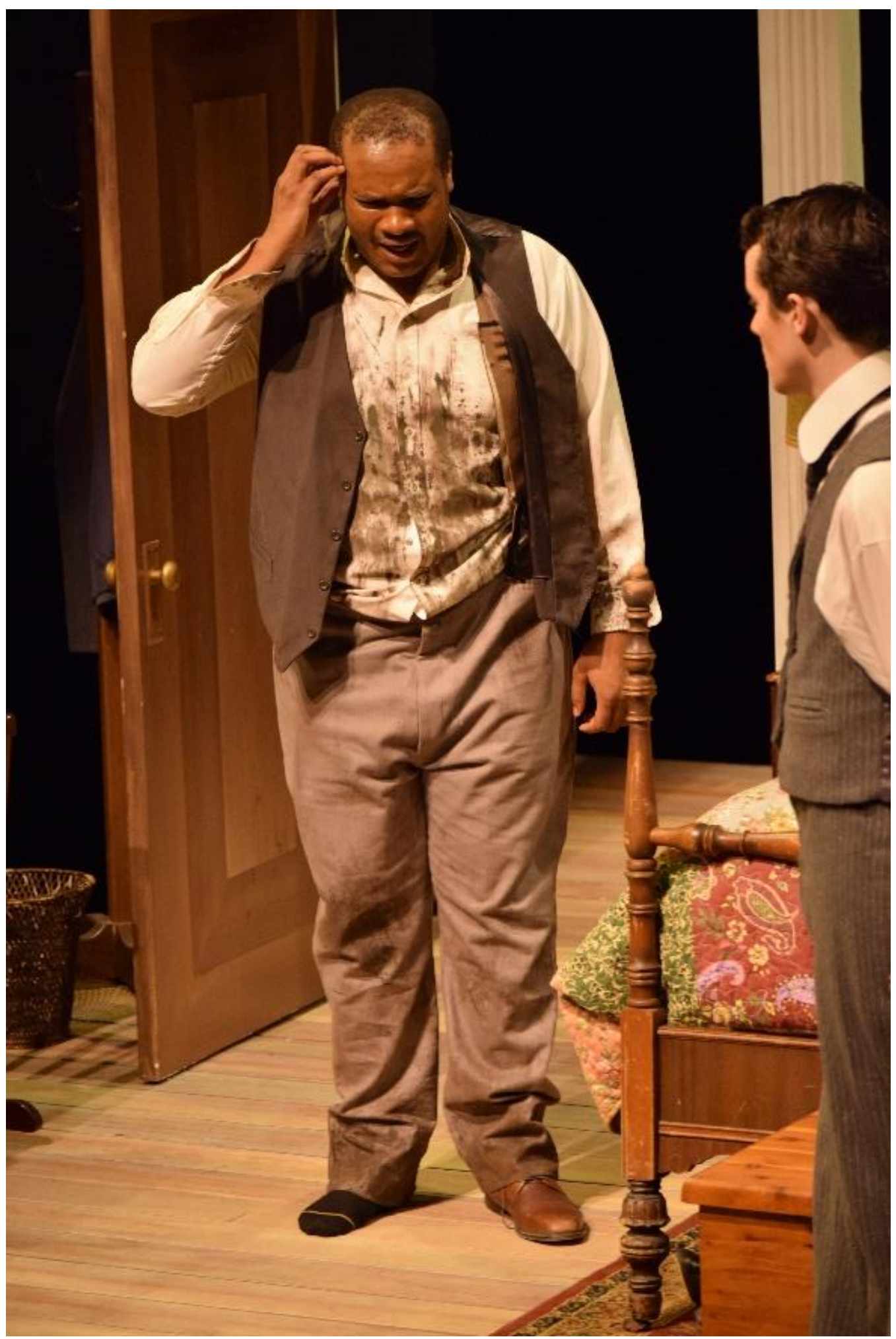

George Tyler (Lonnie Simmons) shows up disheveled in Valentine's Day, scene 3.

Brennan, Lauren E. George Tyler shows up disheveled in Valentine's Day Scene 3. 2015. Photograph. West Virginia University School of Theatre \& Dance, Morgantown, WV. 


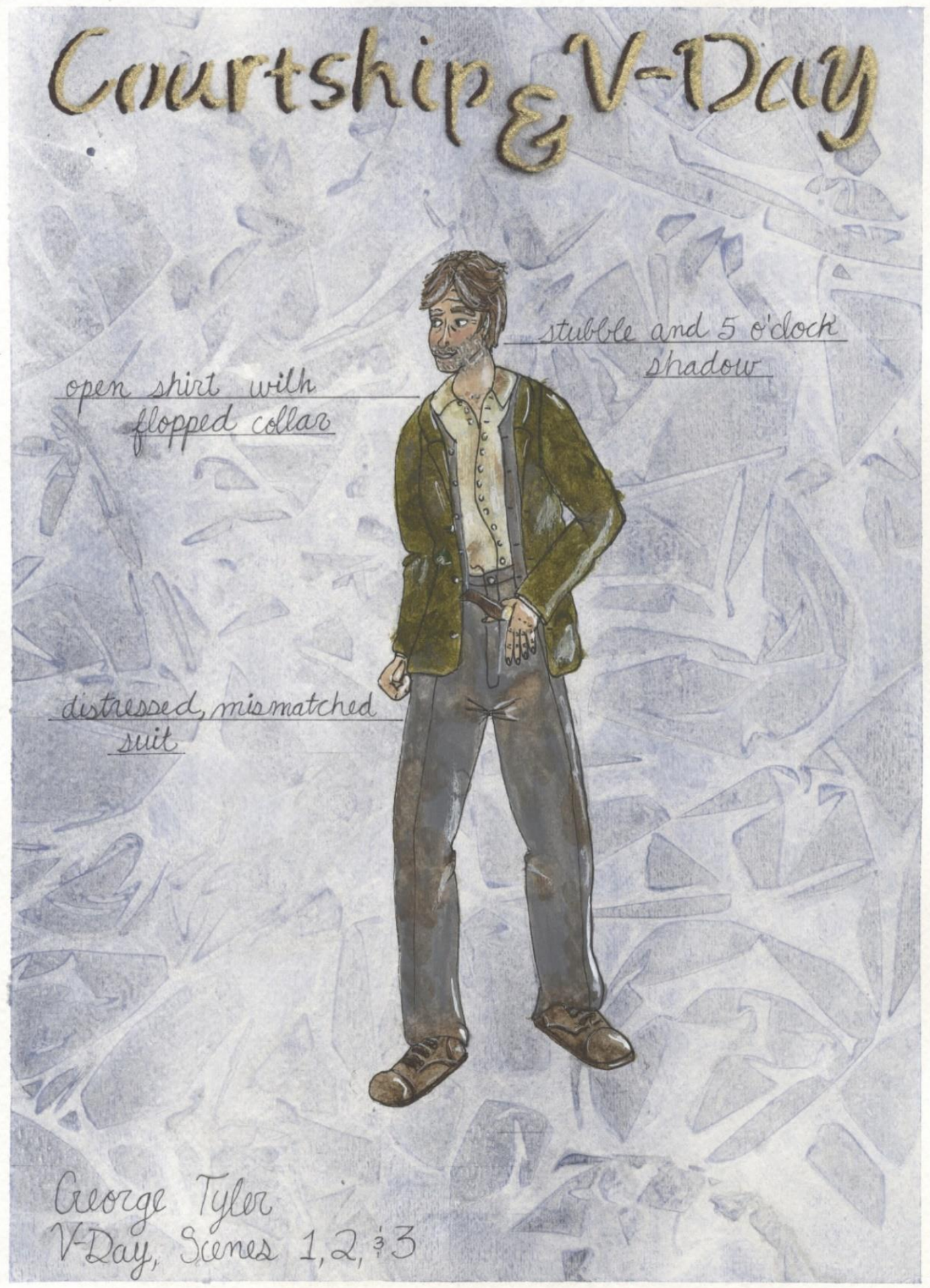

George Tyler in Valentine's Day, scenes 1-3, final rendering.

Brennan, Lauren E. George Tyler in Valentine's Day. 2015. Watercolor \& Marker. West Virginia University School of Theatre and Dance, Morgantown, WV. Digital Image. 


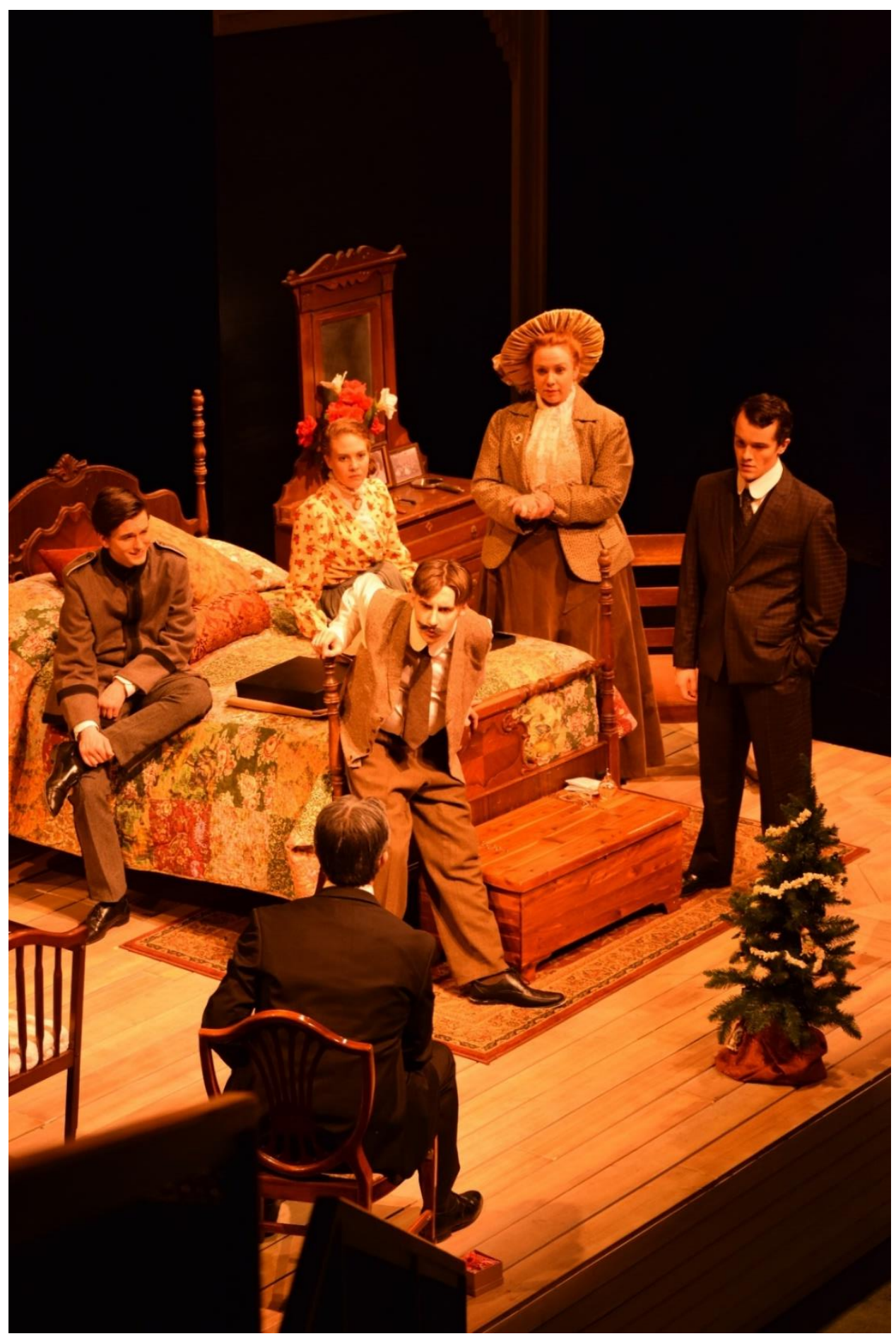

Mr. Vaughn (Joseph Bussey), Brother Vaughn (Woody Pond), Bobby Pate (Zachary Powers), Elizabeth (Margaret Dransfield), Mrs. Vaughn (Madeline Hintz), and Horace (Isaac Snyder) gather in the tiny one room home in Valentine's Day, scene 2.

Brennan, Lauren E. Bobby Drunkenly Interrupts the Vaughn's Christmas Day in Valentine's Day Scene 3. 2015. Photograph. West Virginia University School of Theatre \& Dance, Morgantown, WV. 


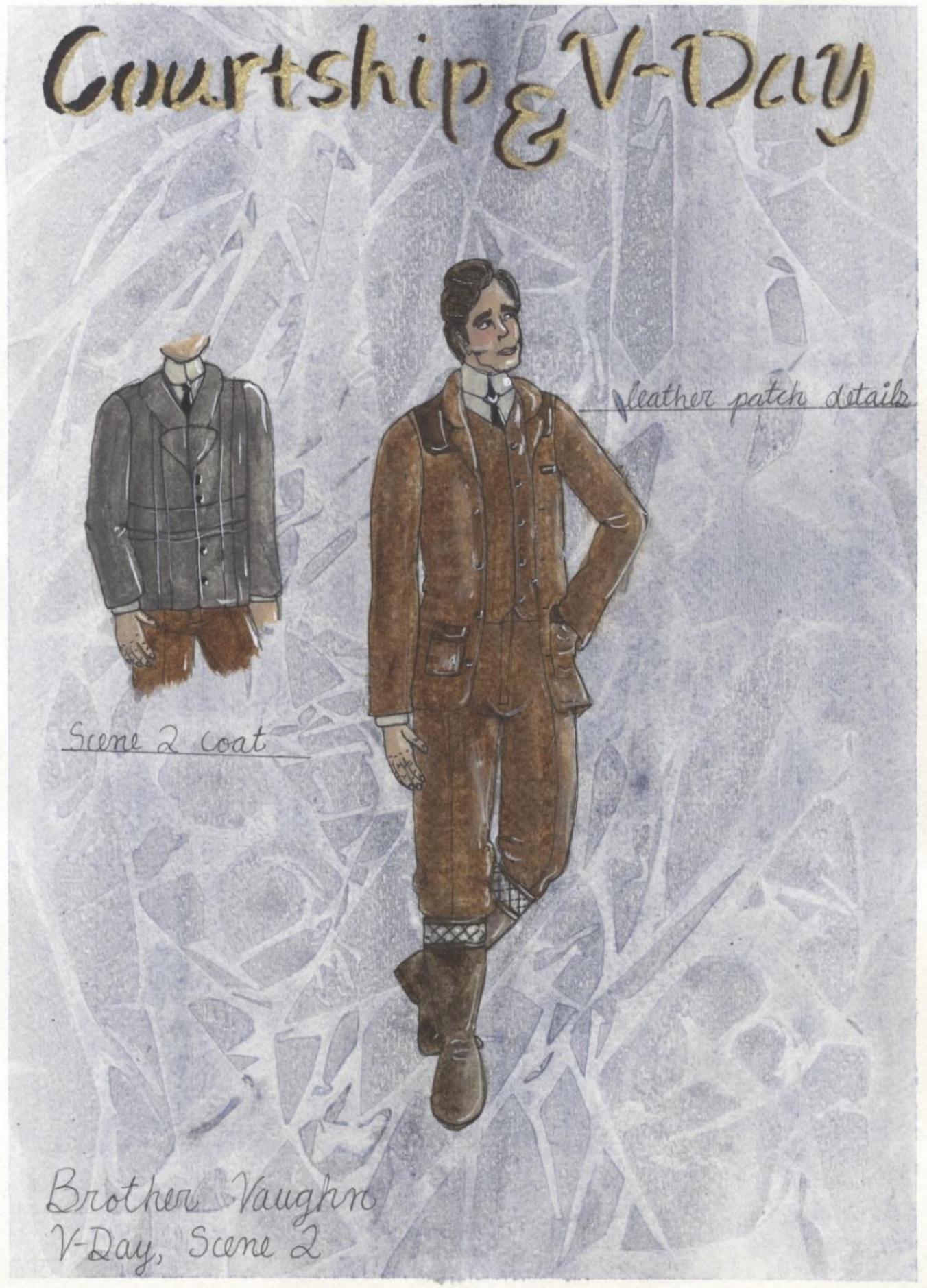

Brother Vaughn in Valentine's Day scene 2, **costume was adjusted following the final design presentation.

Brennan, Lauren E. Brother Vaughn in Valentine's Day. 2015. Watercolor \& Marker. West Virginia University School of Theatre and Dance, Morgantown, WV. Digital Image. 


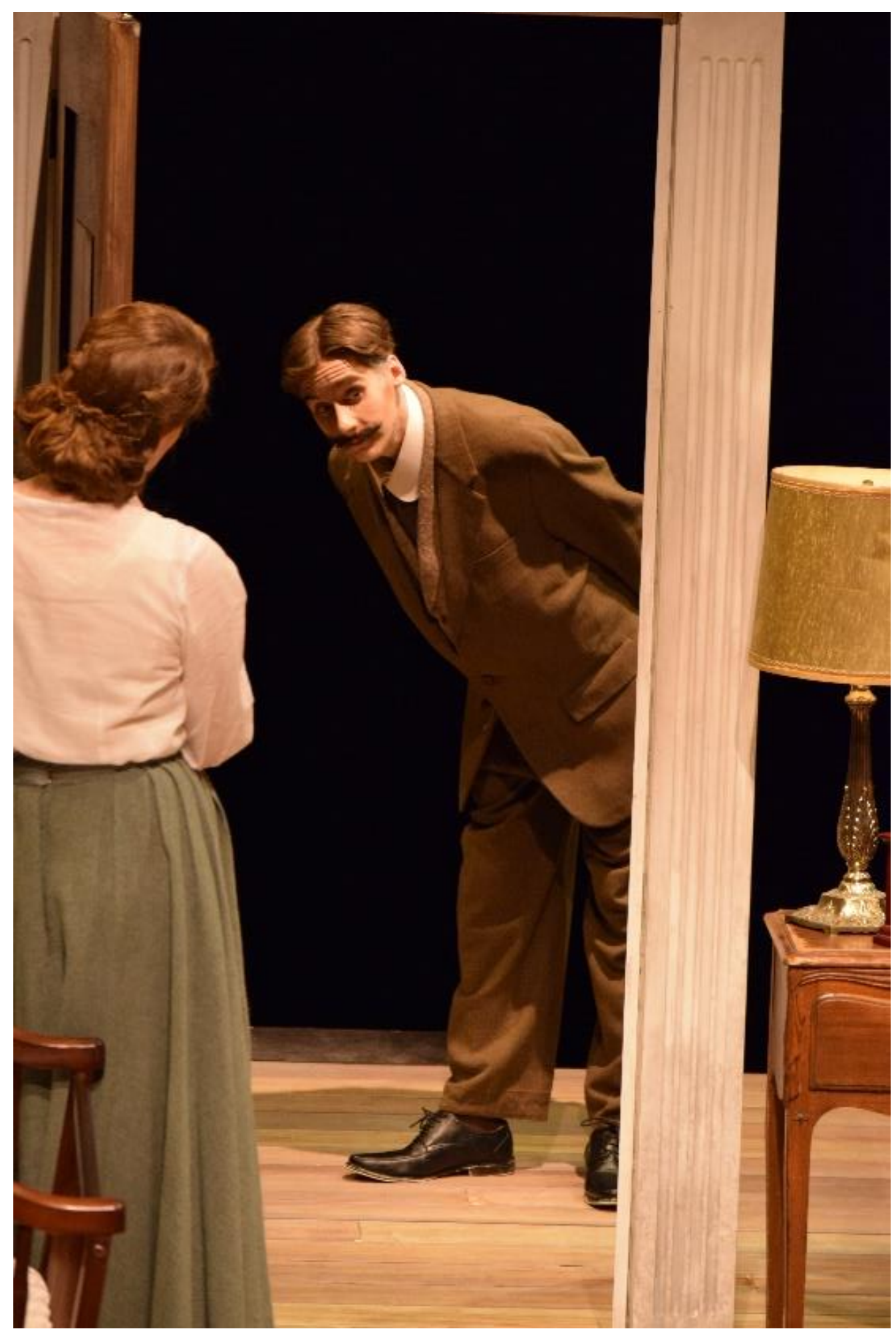

Bobby Pate (Zachary Powers) peeks in on Elizabeth and Horace's room in Valentine's Day, scene 1.

Brennan, Lauren E. Bobby Peeks in on Elizabeth and Horace's Room in Valentine's Day Scene 1. 2015. Photograph. West Virginia University School of Theatre \& Dance, Morgantown, WV. 


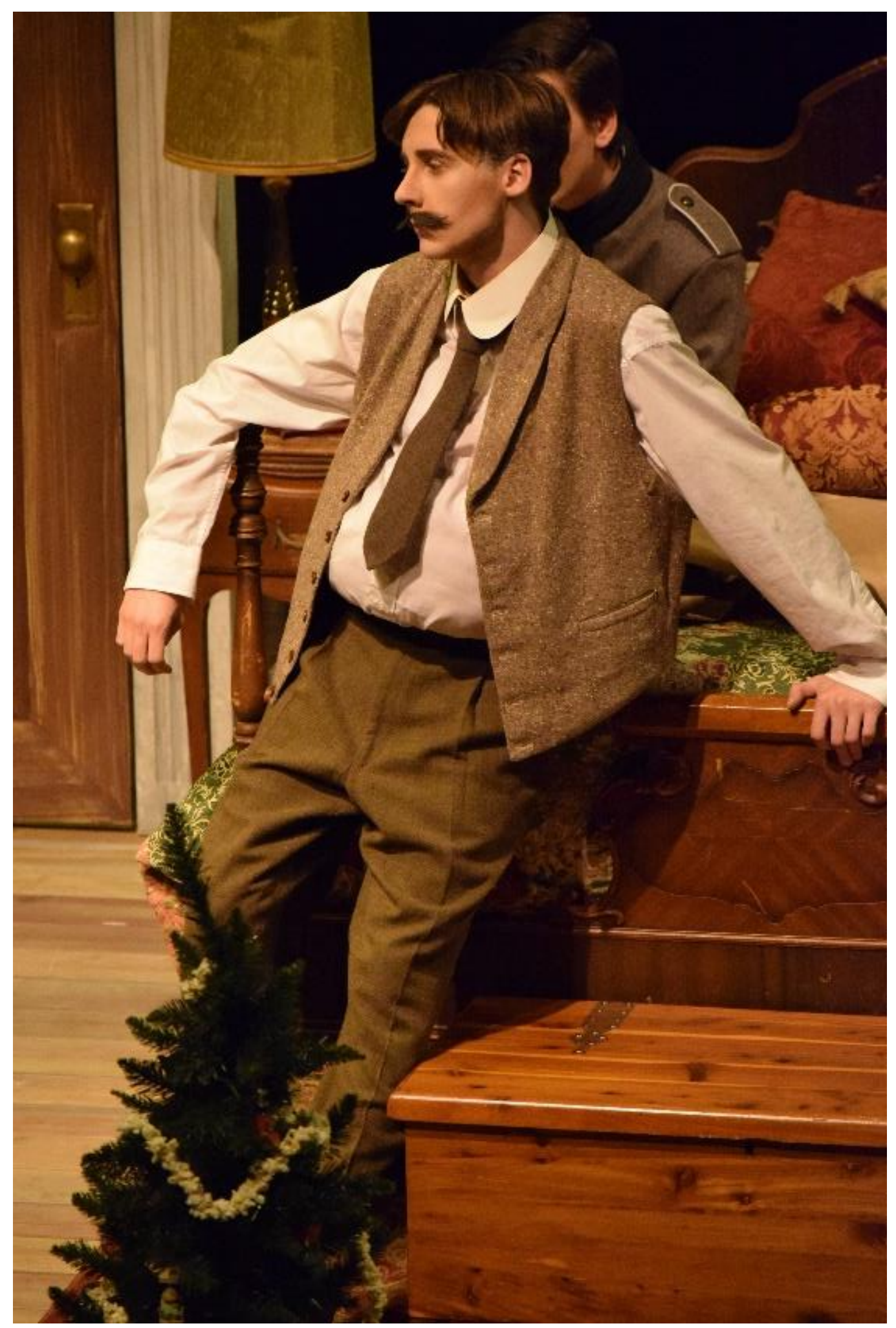

Bobby Pate (Zachary Powers) leans drunkenly against the bedpost in Valentine's Day, scene 2.

Brennan, Lauren E. Bobby Leans Drunkenly against the Bedpost in Valentine's Day Scene 2. 2015. Photograph. West Virginia University School of Theatre \& Dance, Morgantown, WV. 


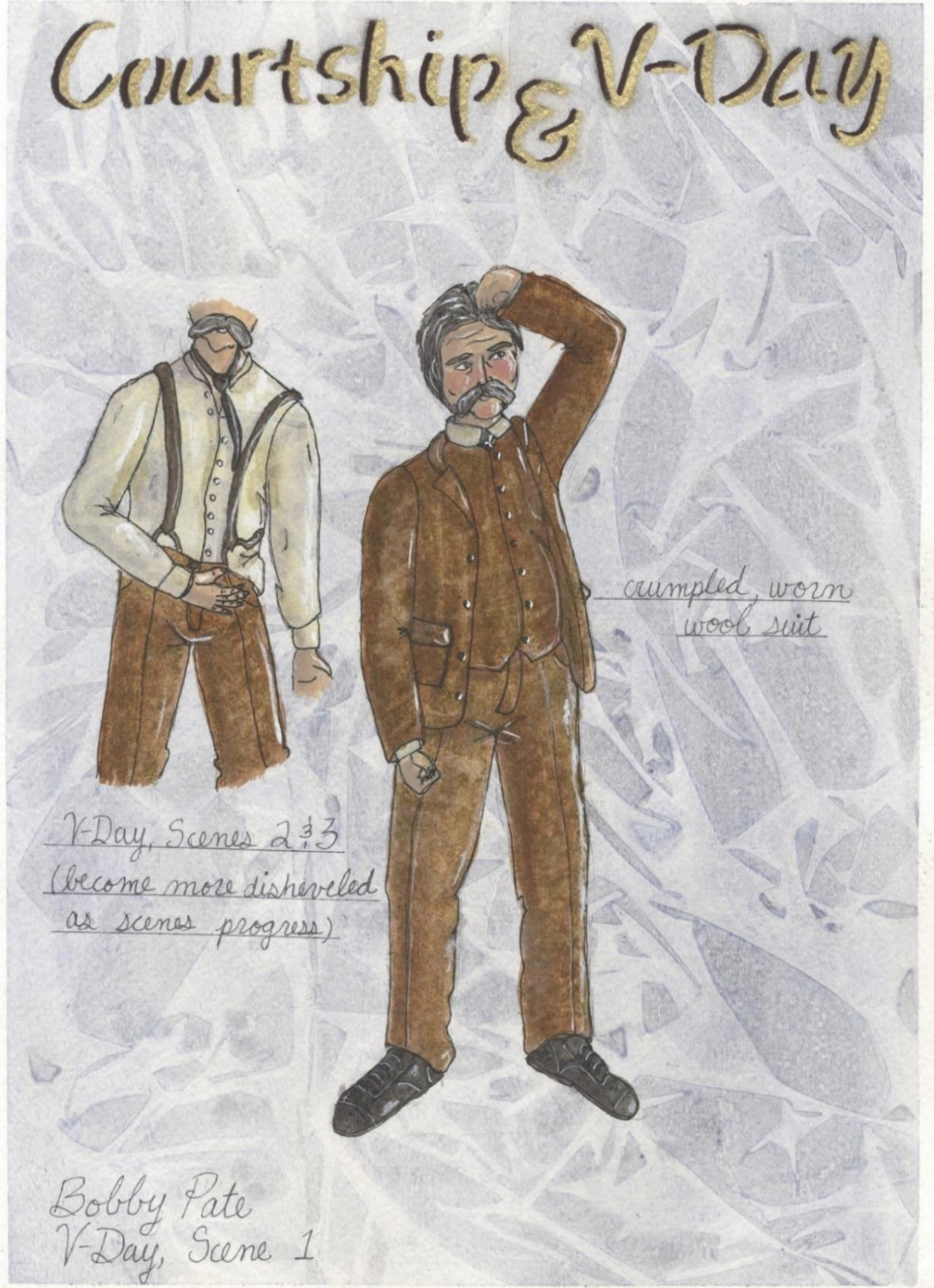

Bobby Pate in Valentine's Day scenes 1-3, final rendering.

Brennan, Lauren E. Bobby Pate in Valentine's Day. 2015. Watercolor \& Marker. West Virginia University School of Theatre and Dance, Morgantown, WV. Digital Image. 


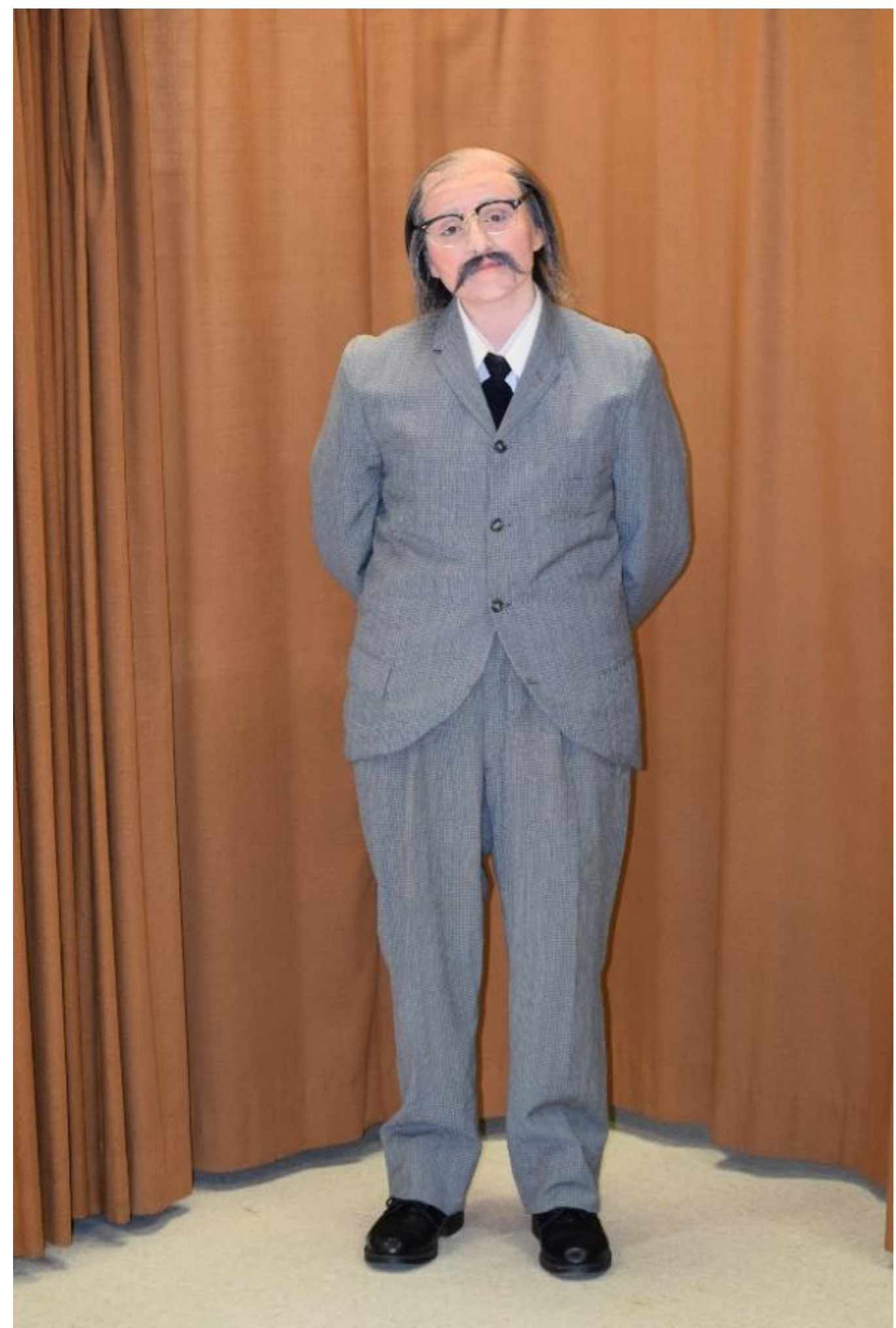

A backstage look at Dr. Goodhue (Mallory Robson).

Brennan, Lauren E. Backstage Detail of Dr. Goodhue Costume. 2015. Photograph. West Virginia University, Morgantown, WV. 


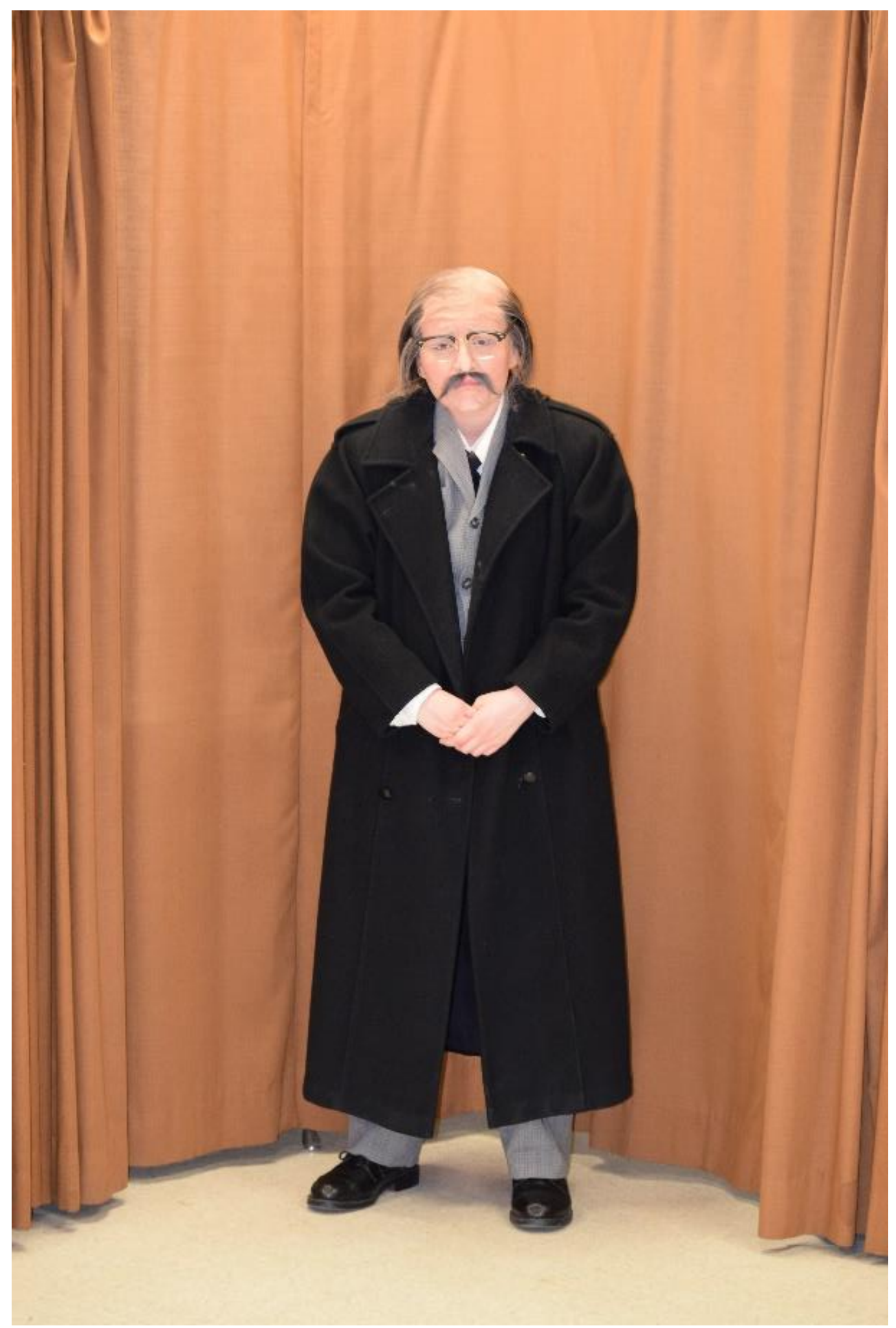

A backstage look at Dr. Goodhue (Mallory Robson) wearing his coat.

Brennan, Lauren E. Backstage Detail of Dr. Goodhue in Coat. 2015. Photograph. West Virginia University, Morgantown, WV. 


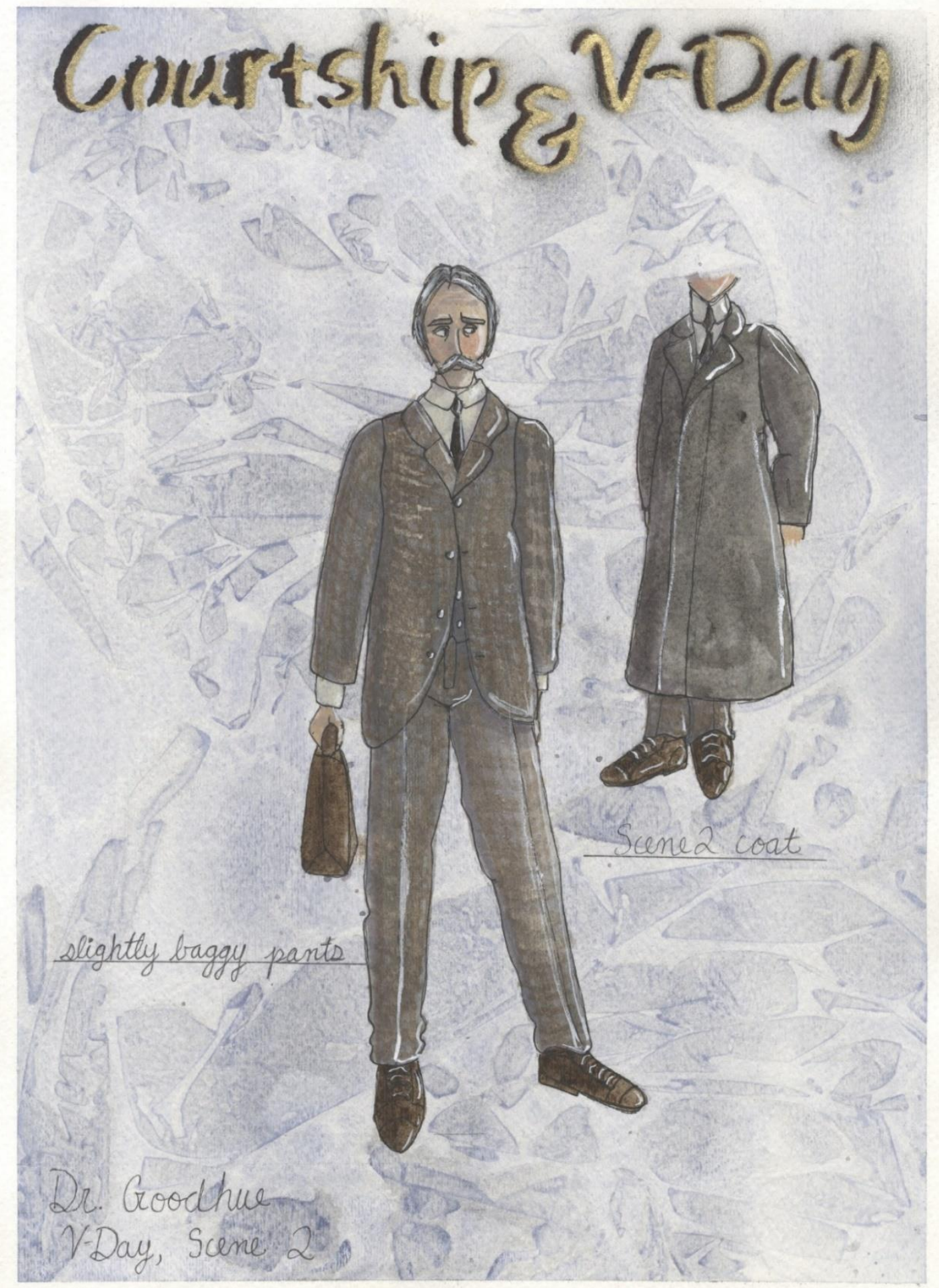

Dr. Goodhue in Valentine's Day scene 2, final rendering.

Brennan, Lauren E. Dr. Goodhue in Valentine's Day. 2015. Watercolor \& Marker. West Virginia University School of Theatre and Dance, Morgantown, WV. Digital Image. 


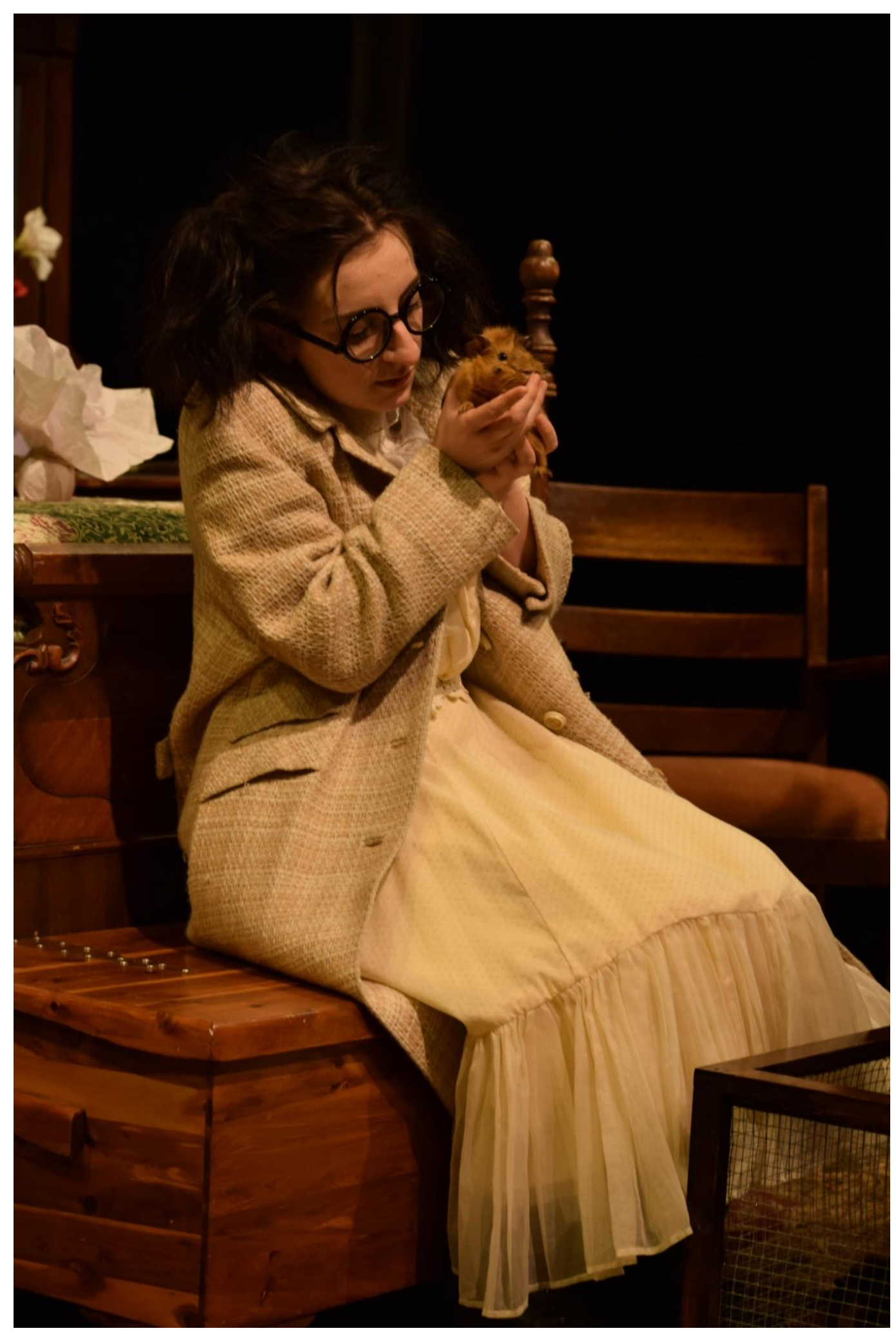

Bessie (Katie Boothby) plays with her guinea pig in Valentine's Day, scene 2.

Brennan, Lauren E. Bessie with Her Guinea Pigs in Valentine's Day Scene 2. 2015. Photograph. West Virginia University, Morgantown, WV. 


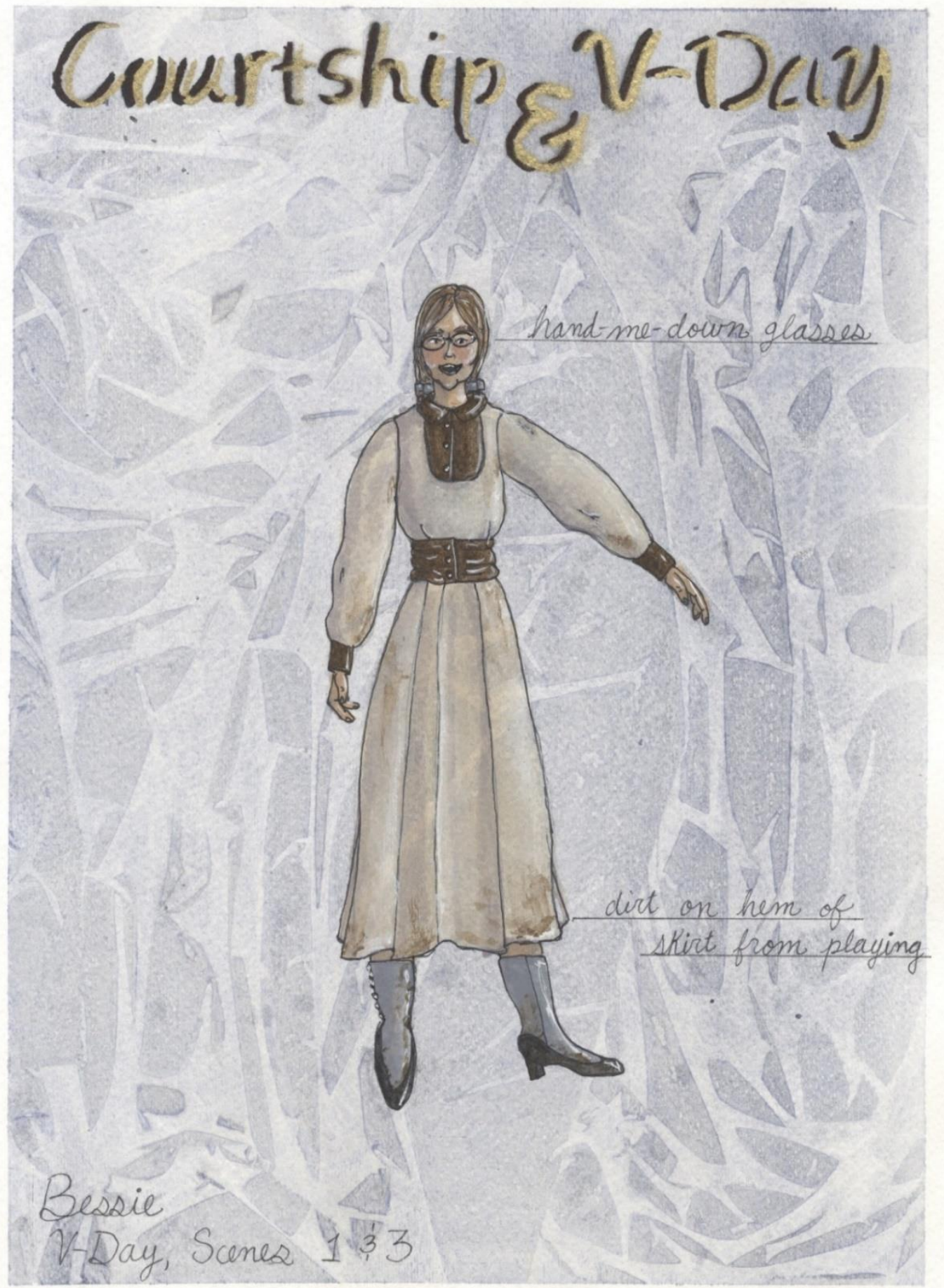

Bessie Stillman in Valentine's Day scene 2, final rendering. Though this plate originally designates this look for scenes $1 \& 3$, a switch with Bessie's original scene 2 look was made later in the process.

Brennan, Lauren E. Bessie in Valentine's Day Scene 2. 2015. Watercolor \& Marker. West Virginia University School of Theatre and Dance, Morgantown, WV. Digital Image. 


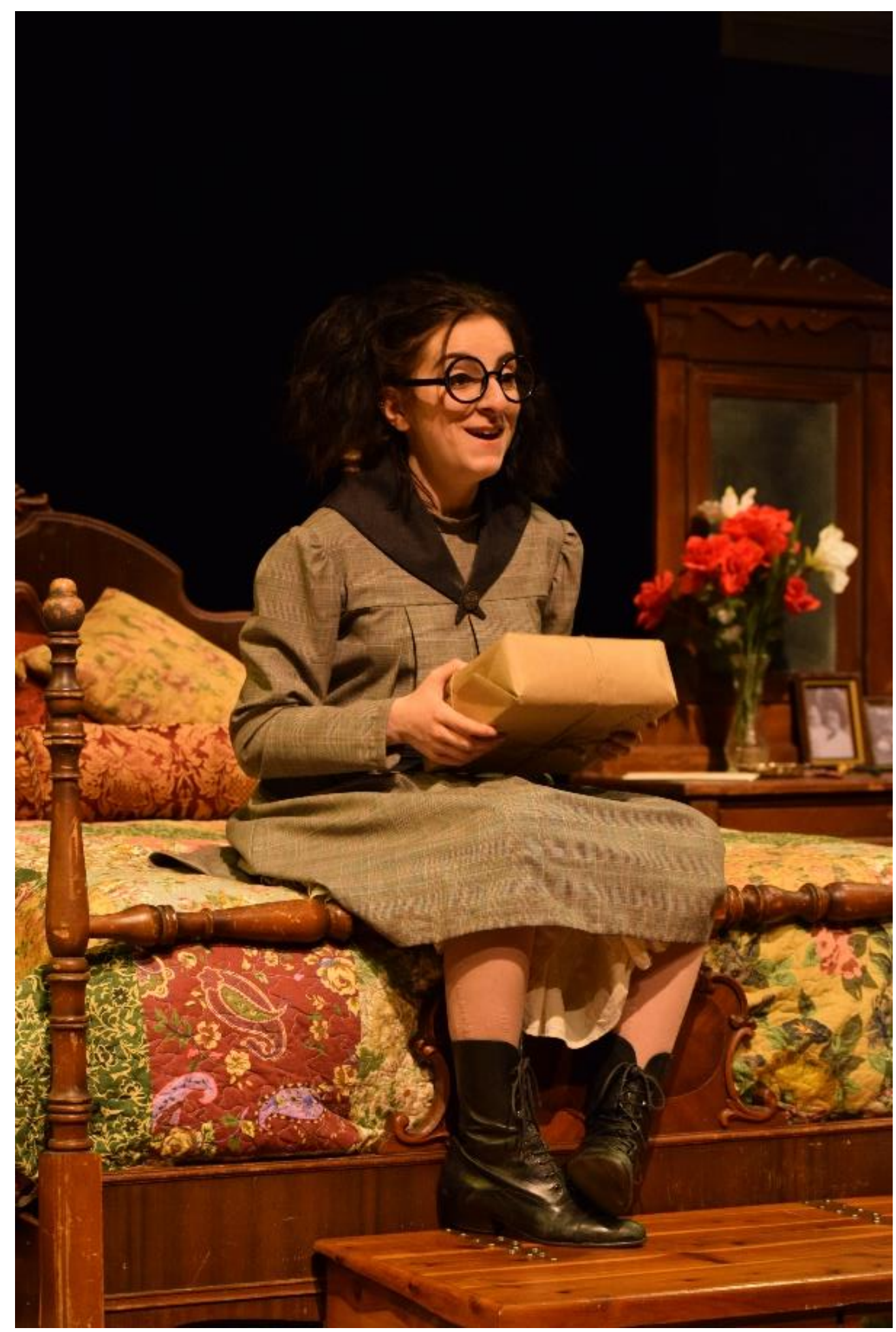

Bessie (Katie Boothby) holding a gift with excitement in Valentine's Day scene 1.

Brennan, Lauren E. Bessie Holding a Gift with Excitement in Valentine's Day Scene 1. 2015. Photograph. West Virginia University, Morgantown, WV. 


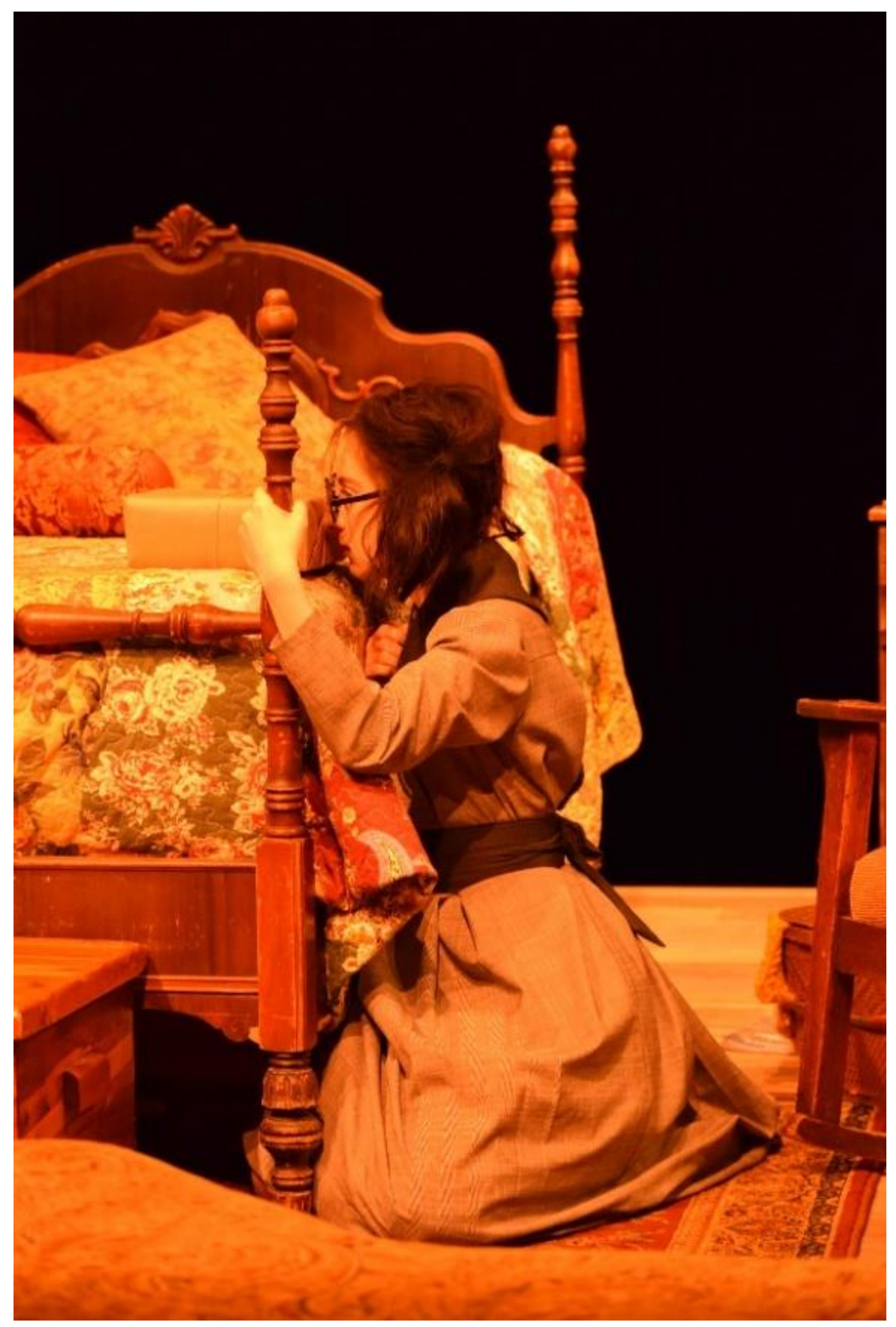

Bessie (Katie Boothby) huddled behind the bed in Valentine's Day, scene 3.

Brennan, Lauren E. Bessie Huddled behind the Bed in Valentine's Day Scene 3. 2015. Photograph. West Virginia University, Morgantown, WV. 


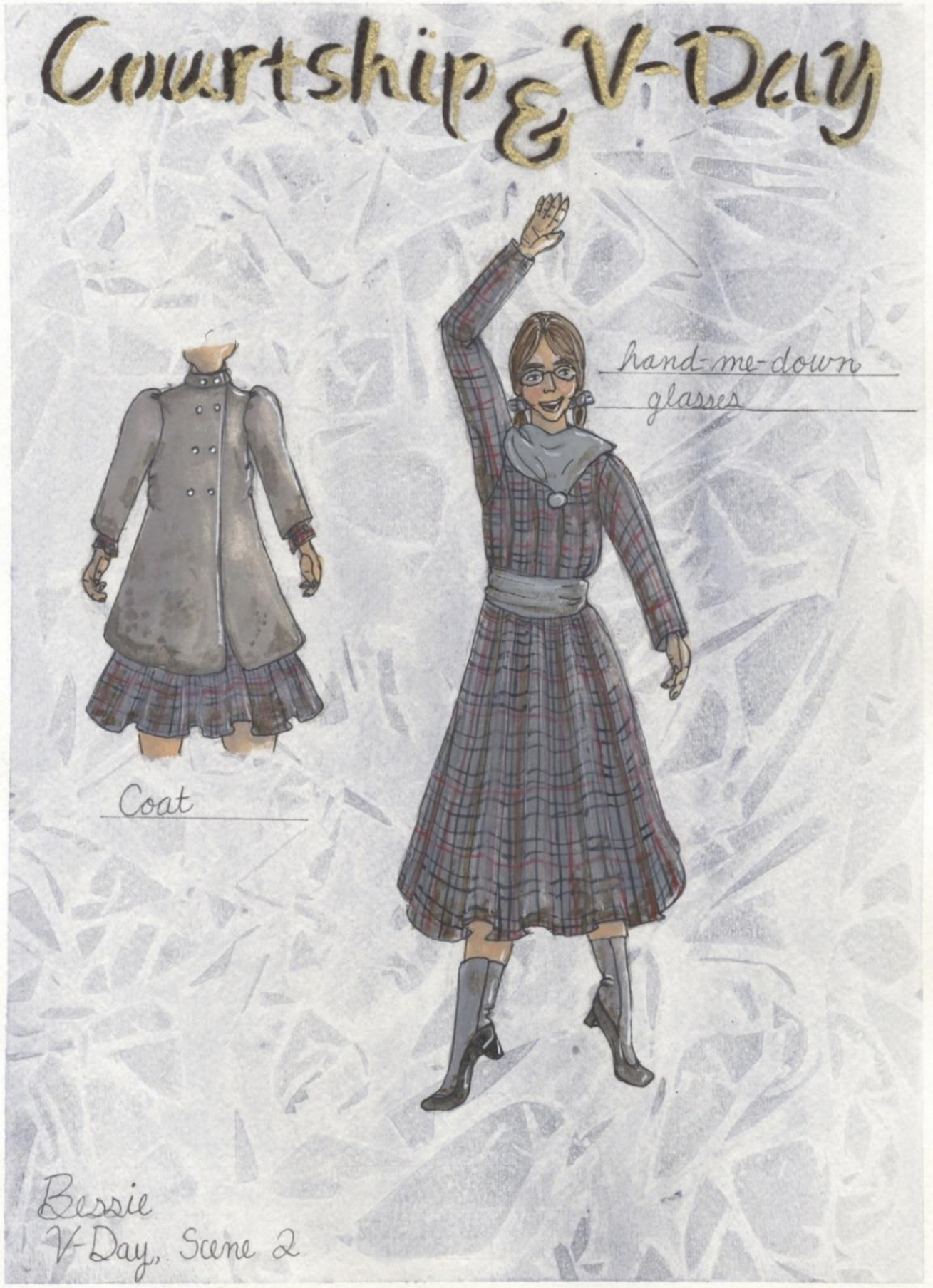

Bessie Stillman in Valentine's Day scenes 1 \& 3, final rendering. Though this plate originally designates this look for scene 2, a switch with Bessie's original scene 1 \& 3 looks was made later in the process.

Brennan, Lauren E. Bessie in Valentine's Day Scenes 1 \& 3. 2015. Watercolor \& Marker. West Virginia University School of Theatre and Dance, Morgantown, WV. Digital Image. 


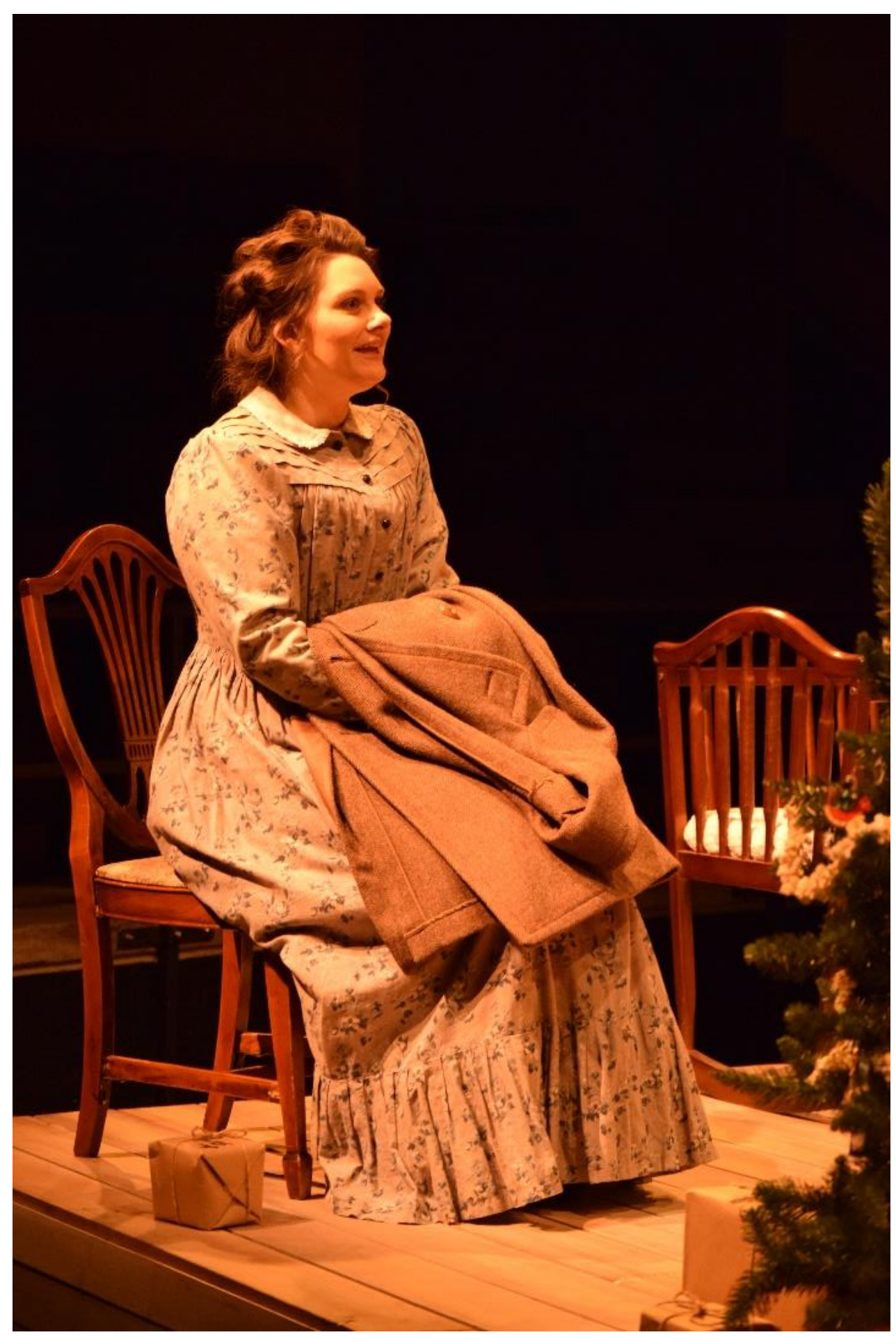

Miss Ruth Amos (Brianna Bowers) in Valentine's Day, scene 3.

Brennan, Lauren E. Ruth Amos in Valentine's Day Scene 3. 2015. Photograph. West Virginia University, Morgantown, WV. 


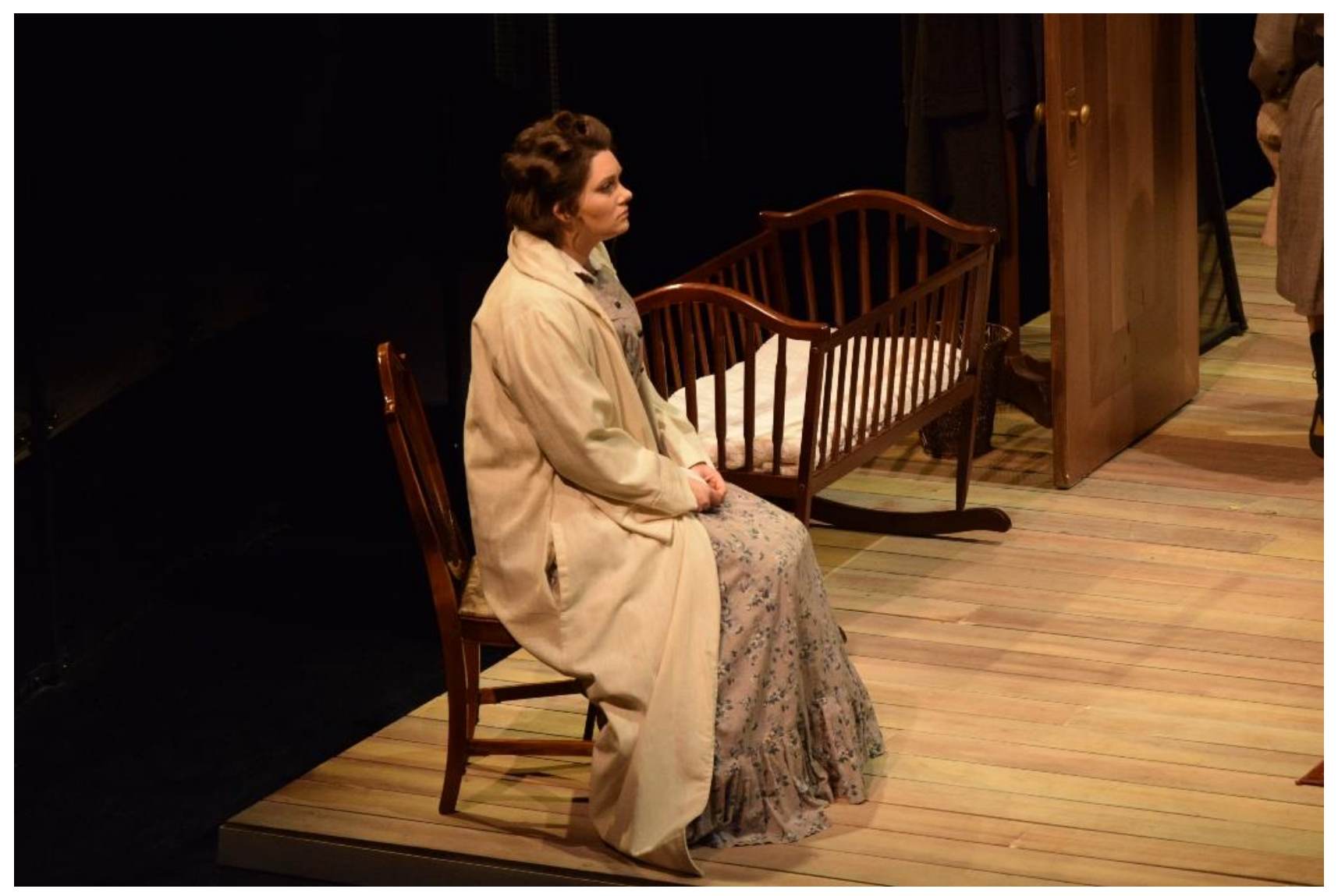

Miss Ruth Amos (Brianna Bowers) in Valentine's Day, scene 1.

Brennan, Lauren E. Ruth Amos in Valentine's Day Scene 1. 2015. Photograph. West Virginia University, Morgantown, WV. 


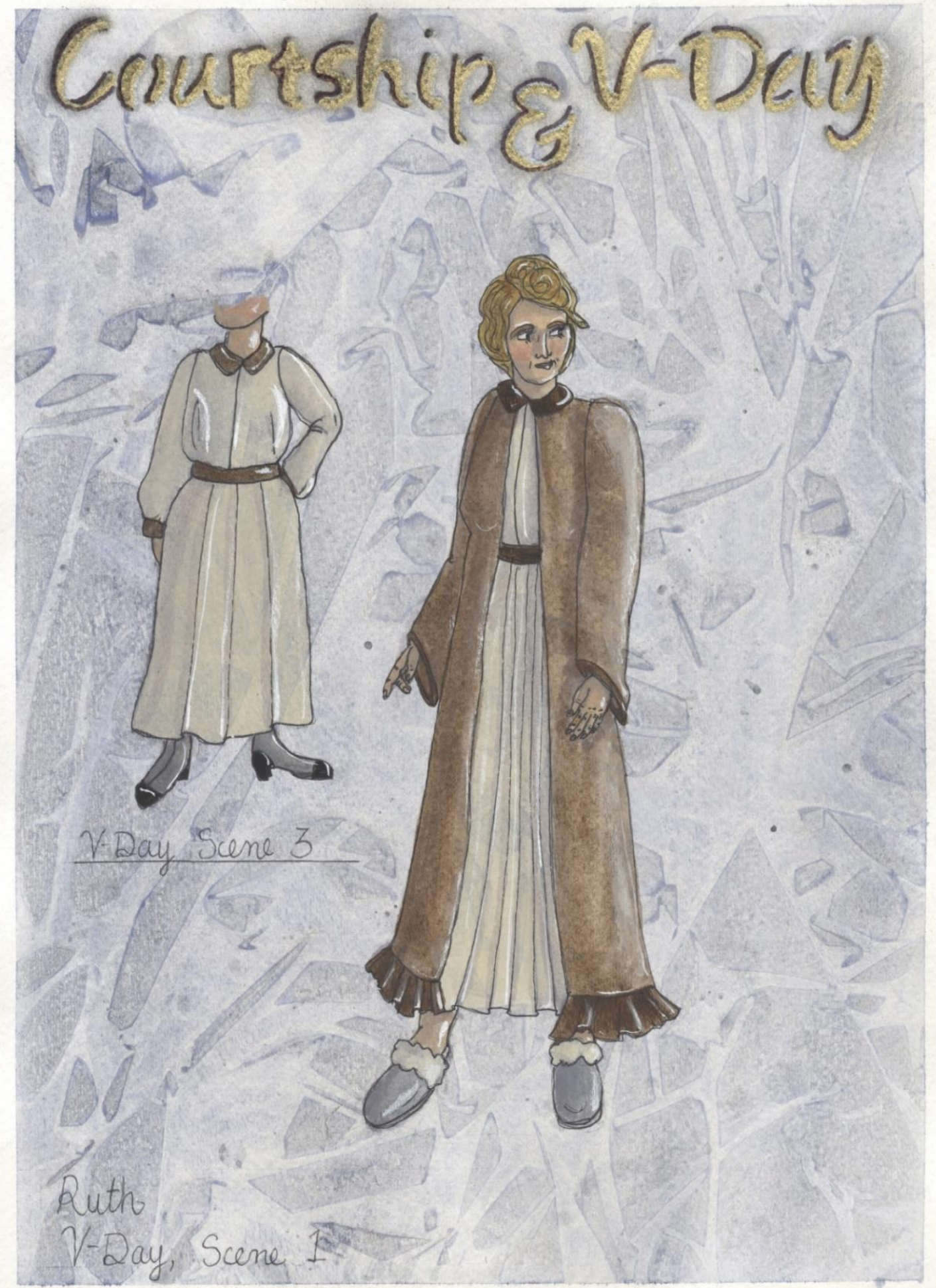

Ruth Amos in Valentine's Day scenes 1 \& 3, final rendering.

Brennan, Lauren E. Ruth Amos in Valentine's Day Scenes 1 \& 3. 2015. Watercolor \& Marker. West Virginia University School of Theatre and Dance, Morgantown, WV. Digital Image. 


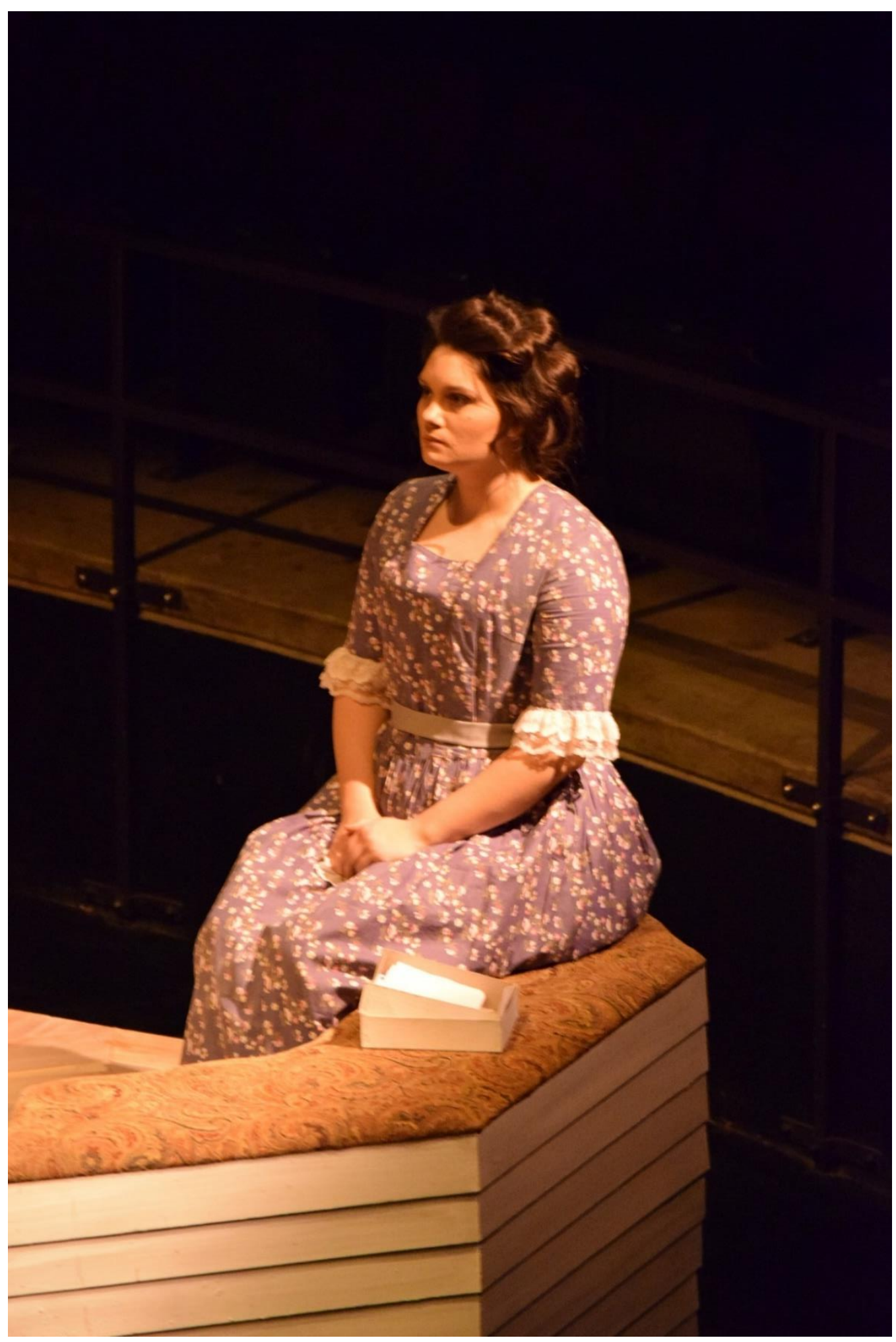

Miss Ruth Amos (Brianna Bowers) in Valentine's Day, scene 2.

Brennan, Lauren E. Ruth Amos in Valentine's Day Scene 2. 2015. Photograph. West Virginia University., Morgantown, WV. 


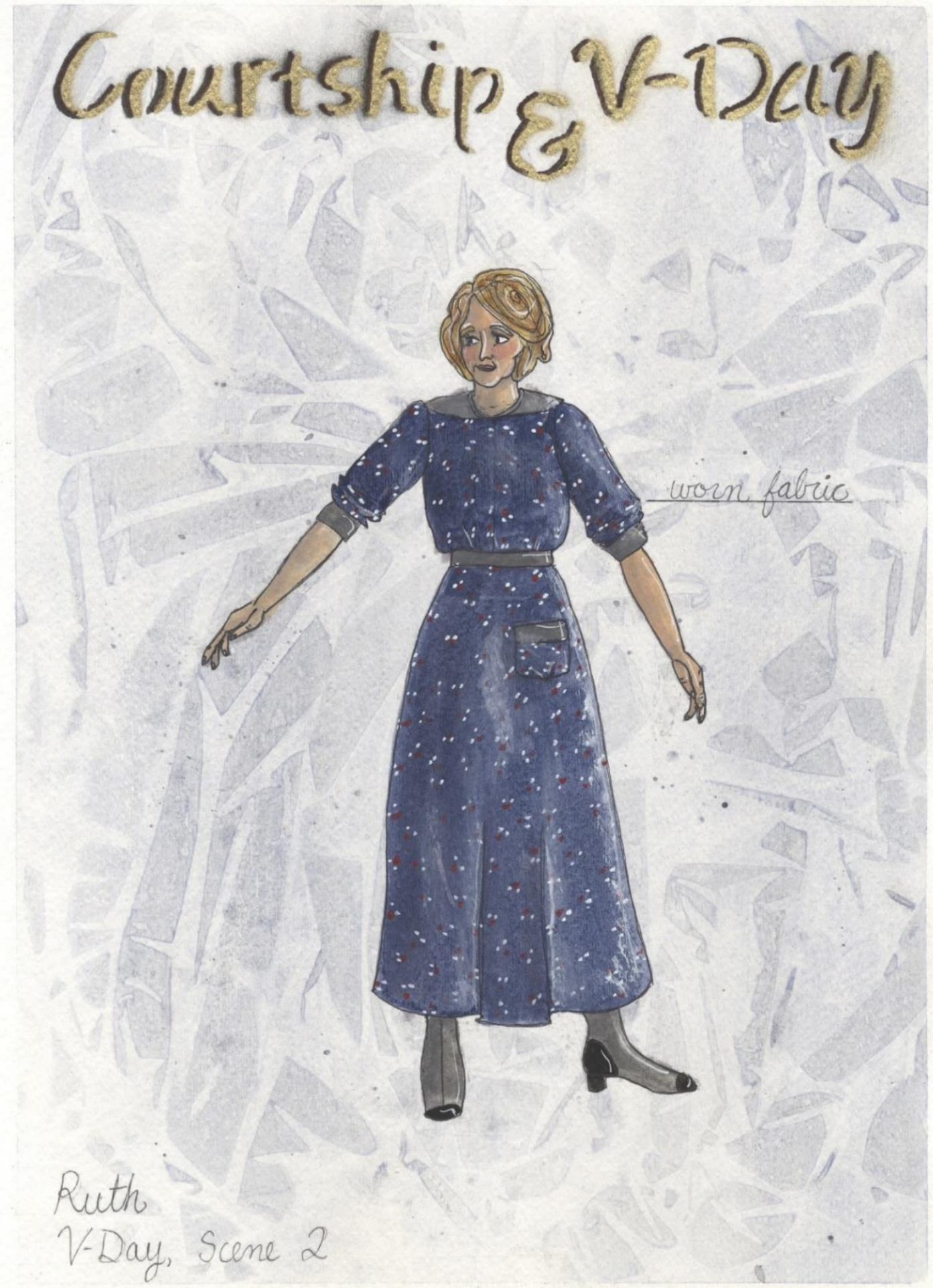

Ruth Amos in Valentine's Day scene 2, final rendering.

Brennan, Lauren E. Ruth Amos in Valentine's Day Scene 2. 2015. Watercolor \& Marker. West Virginia University School of Theatre and Dance, Morgantown, WV. Digital Image. 


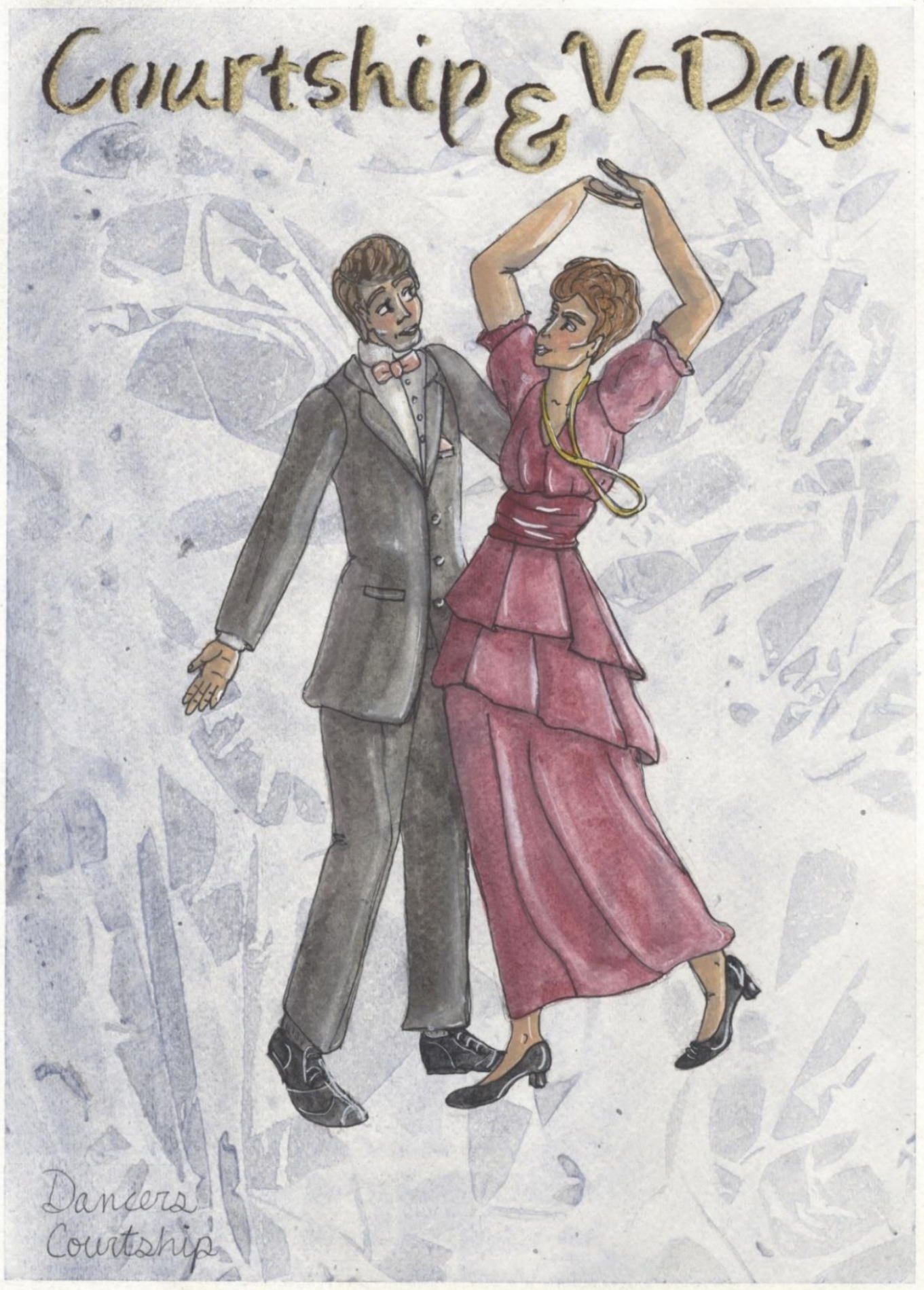

First plate of Dancers in Courtship, final rendering (characters/costumes eventually cut from the show).

Brennan, Lauren E. Dancers with Red Dress in Courtship. 2015. Watercolor \& Marker. West Virginia University School of Theatre and Dance, Morgantown, WV. Digital Image. 


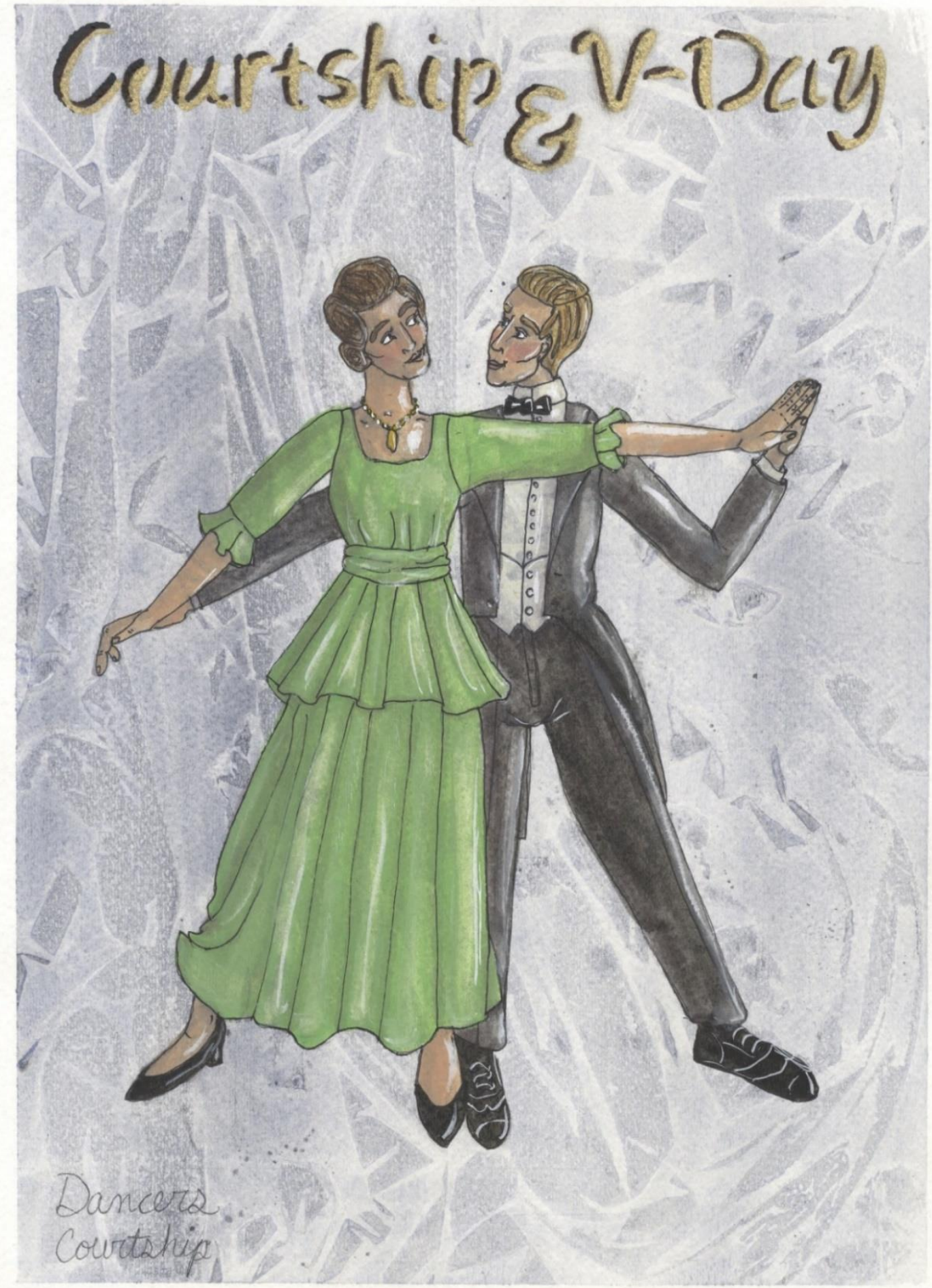

Second plate of Dancers in Courtship, final rendering (characters/costumes eventually cut from the show).

Brennan, Lauren E. Dancers with Green Dress in Courtship. 2015. Watercolor \& Marker. West Virginia University School of Theatre and Dance, Morgantown, WV. Digital Image. 


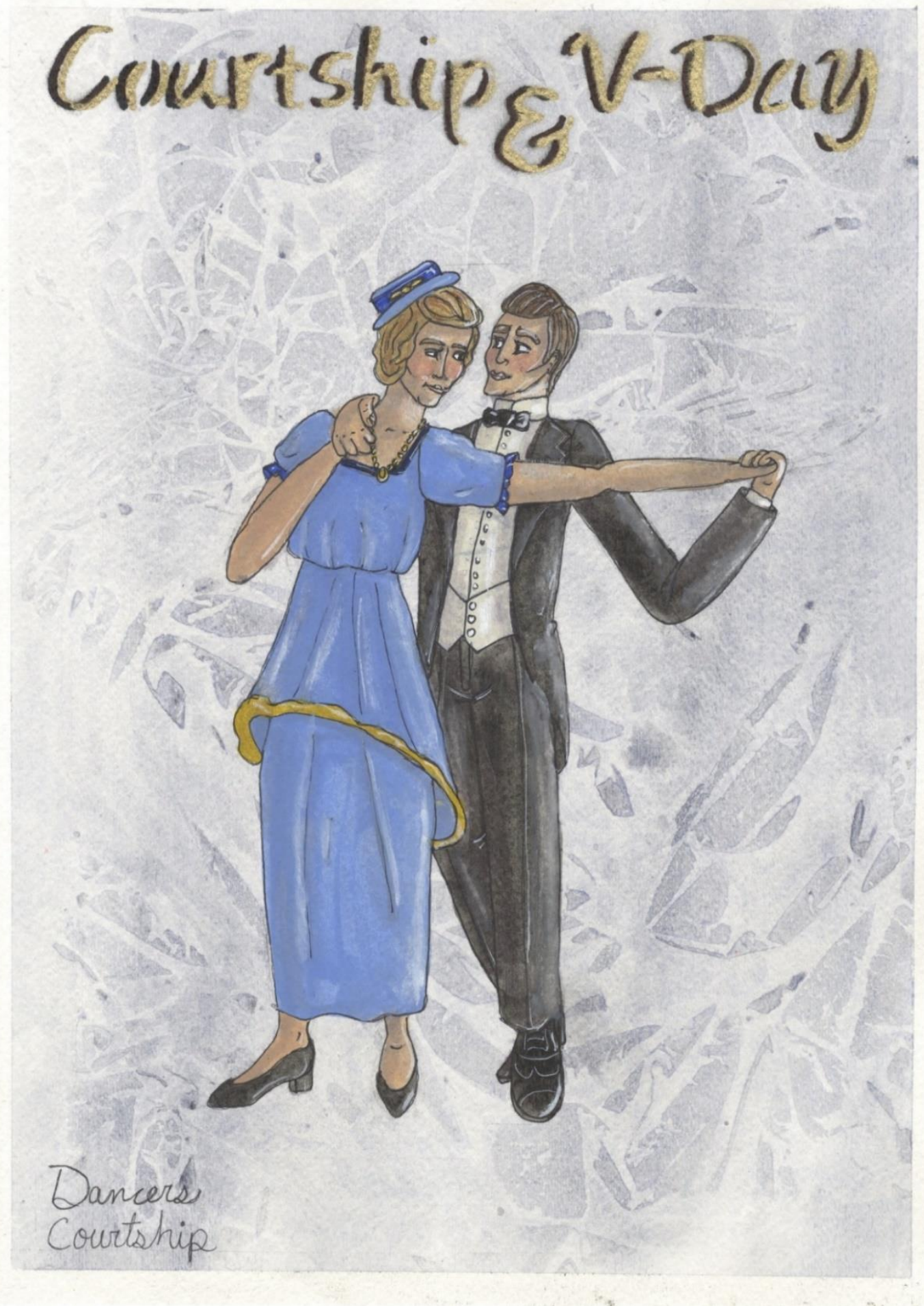

Third plate of Dancers in Courtship, final rendering (characters/costumes eventually cut from the show).

Brennan, Lauren E. Dancers with Blue Dress in Courtship. 2015. Watercolor \& Marker. West Virginia University School of Theatre and Dance, Morgantown, WV. Digital Image. 


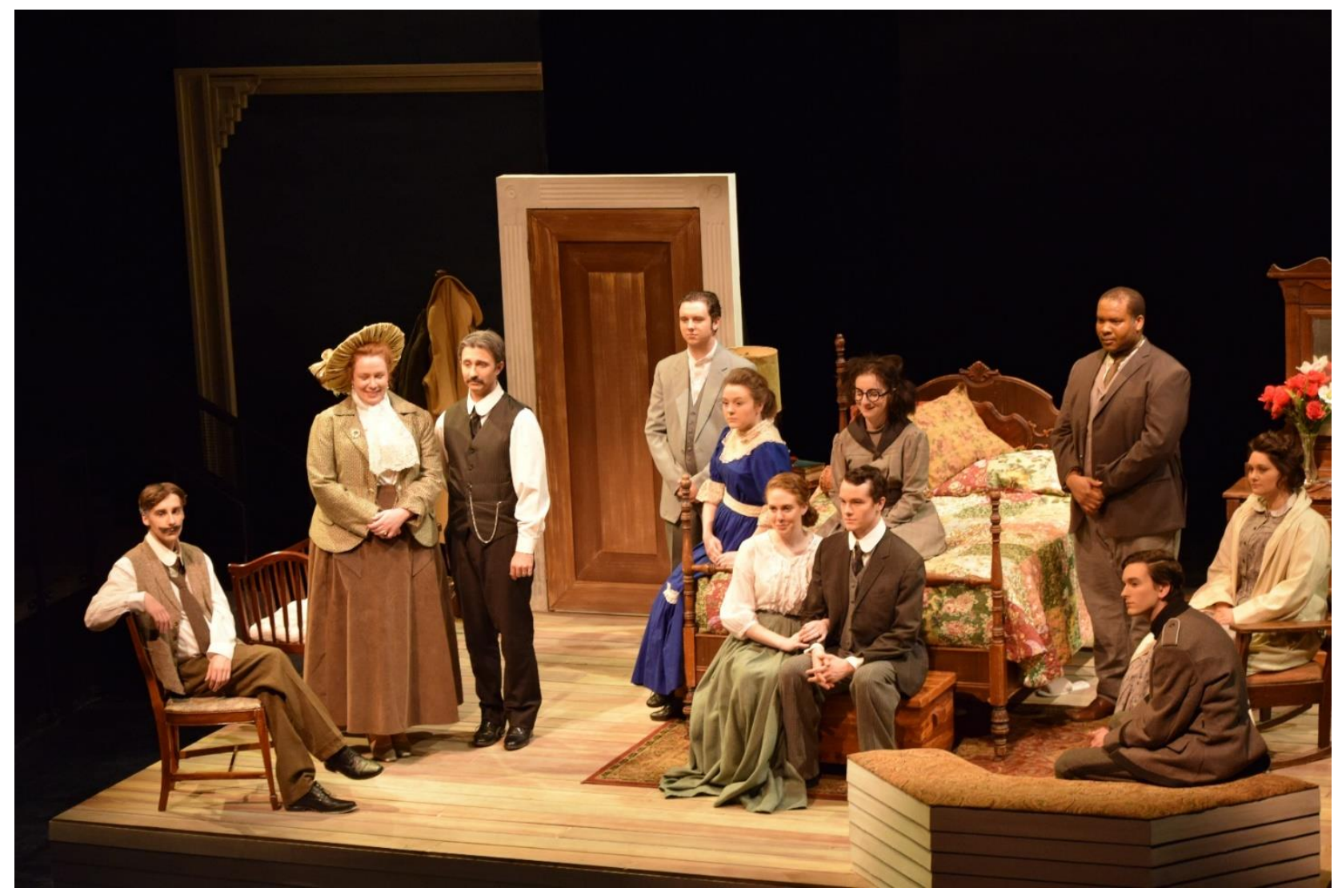

Full cast, left to right -- Zachary Powers, Madeline Hintz, Joseph Bussey, Joshua Clevenger (back), Mallory Robson (back), Margaret Dransfield, Katie Boothby (back), Isaac Snyder, Lonnie Simmons, Woody Pond, Brianna Bowers (back).

Brennan, Lauren E. Full cast on Stage for Photo Call on the Set of Valentine's Day. 2015. Photograph. West Virginia University. 


\section{APPENDIX IV: WORKING DRAWINGS FOR BUILD ITEMS}

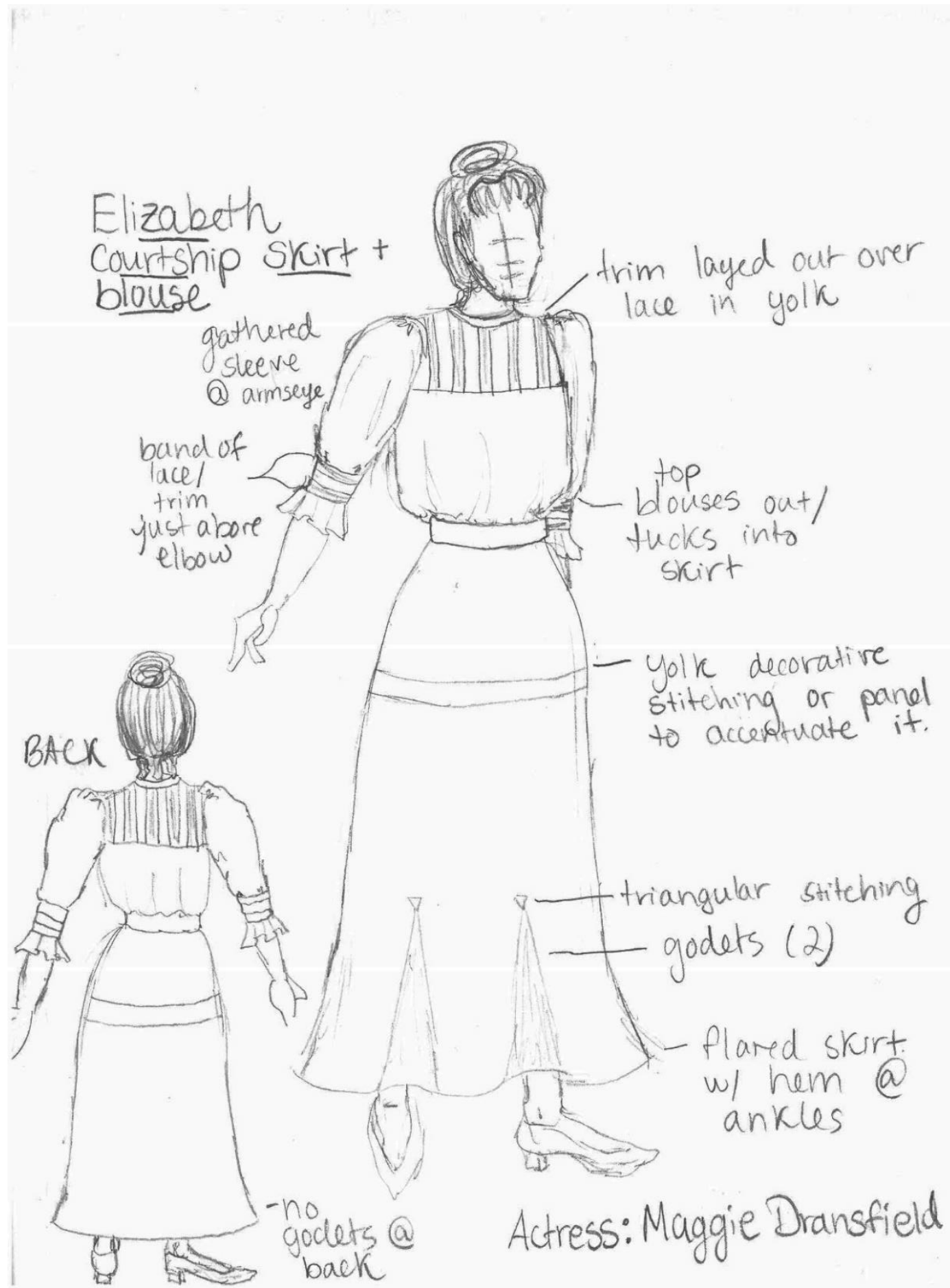

Working Drawing for Elizabeth's blouse and skirt in Courtship.

Brennan, Lauren E. Elizabeth Courtship Working Drawing. 2015. Pencil. West Virginia University School of Theatre and Dance, Morgantown, WV. Digital Image. 


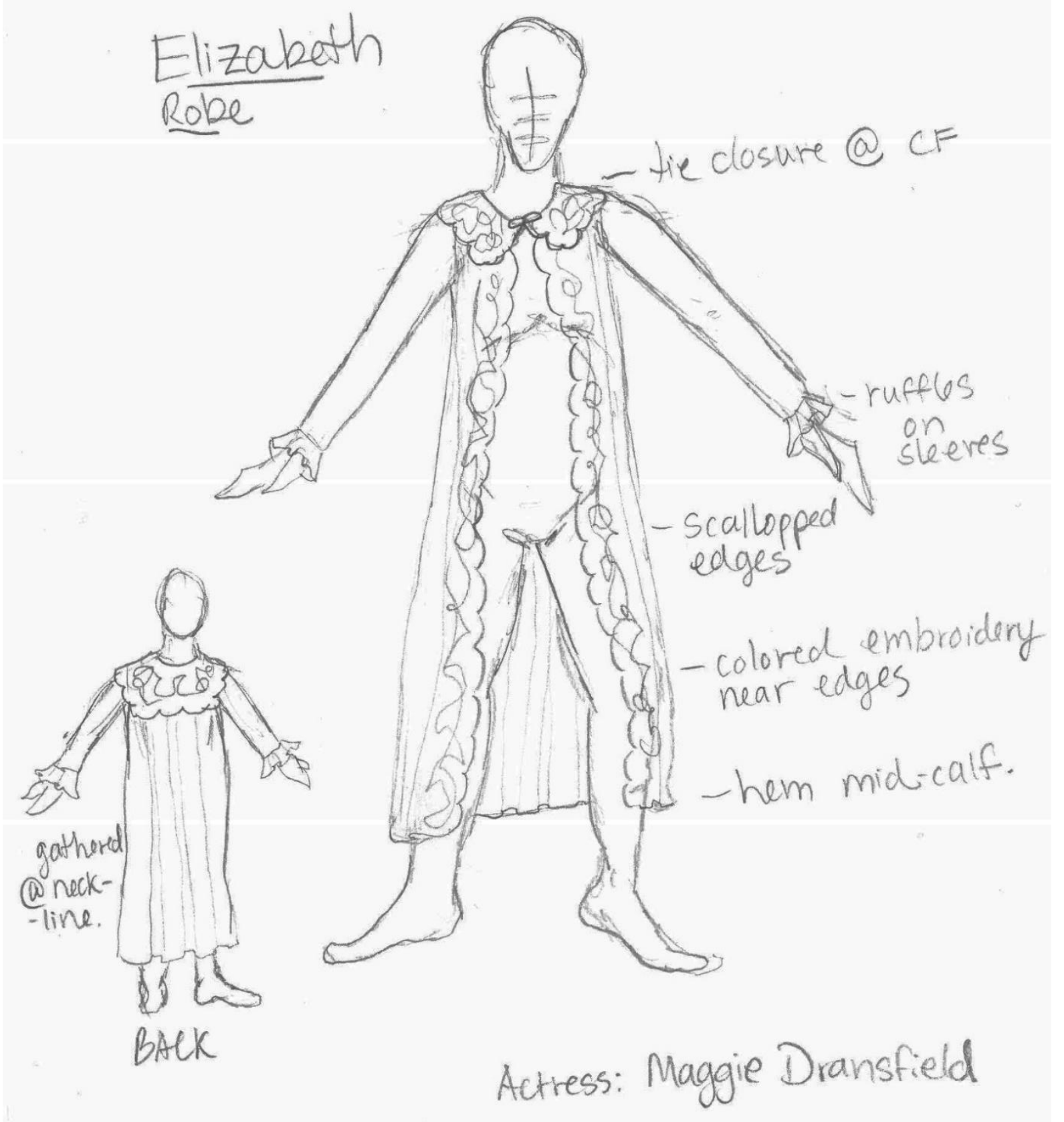

Working drawing for Elizabeth's robe in Valentine's Day, scene 2.

Brennan, Lauren E. Elizabeth Valentine's Day, Scene 2 Robe Working Drawing. 2015. Pencil. West Virginia University School of Theatre and Dance, Morgantown, WV. Digital Image. 


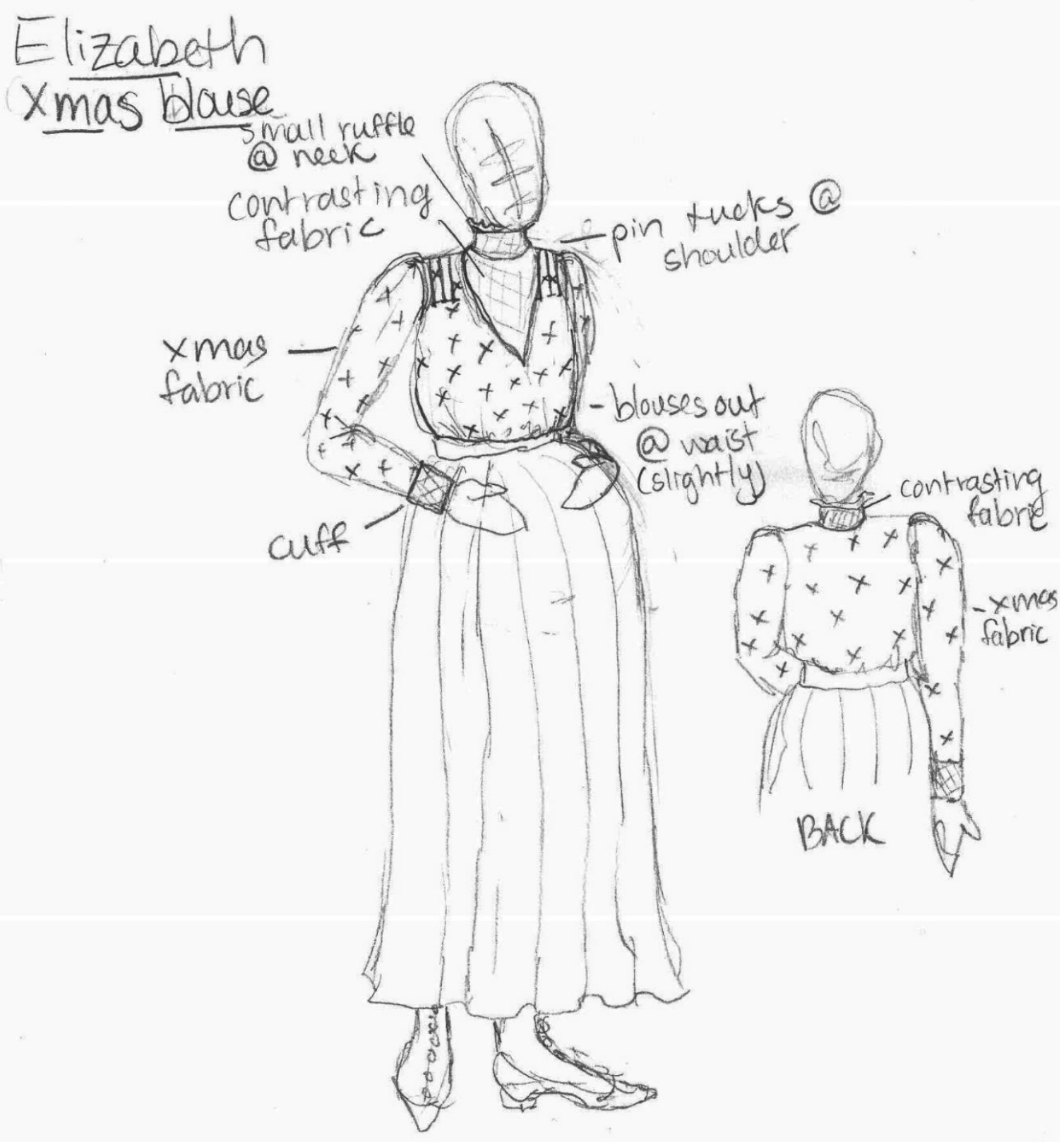

Working drawing for Elizabeth's blouse in Valentine's Day, scene 2.

Brennan, Lauren E. Elizabeth Valentine's Day, Scene 2 Blouse Working Drawing. 2015. Pencil. West Virginia University School of Theatre and Dance, Morgantown, WV. Digital Image. 


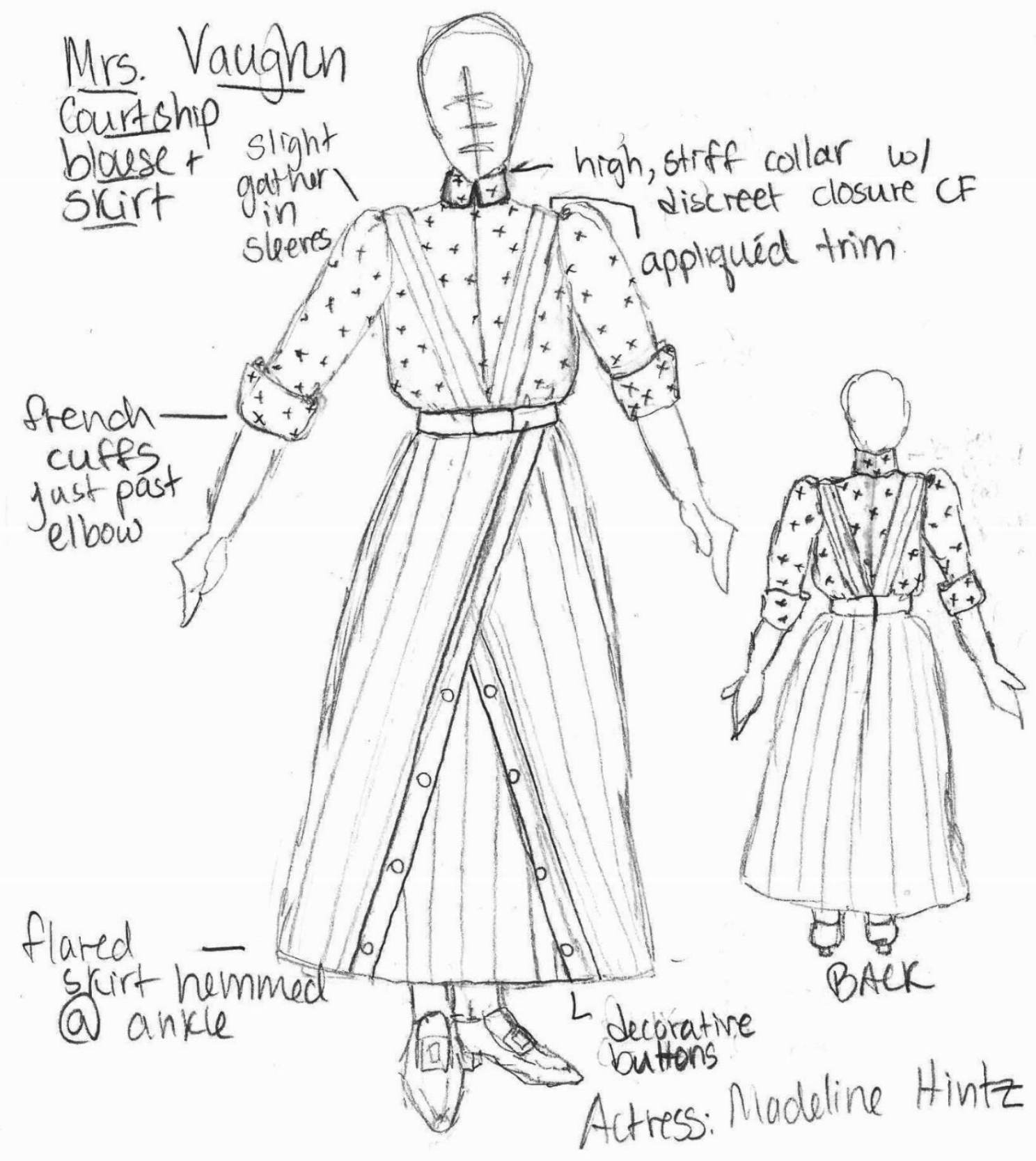

Working drawing for Mrs. Vaughn's blouse and skirt in Courtship.

Brennan, Lauren E. Mrs. Vaughn Courtship Working Drawing. 2015. Pencil. West Virginia University School of Theatre and Dance, Morgantown, WV. Digital Image. 


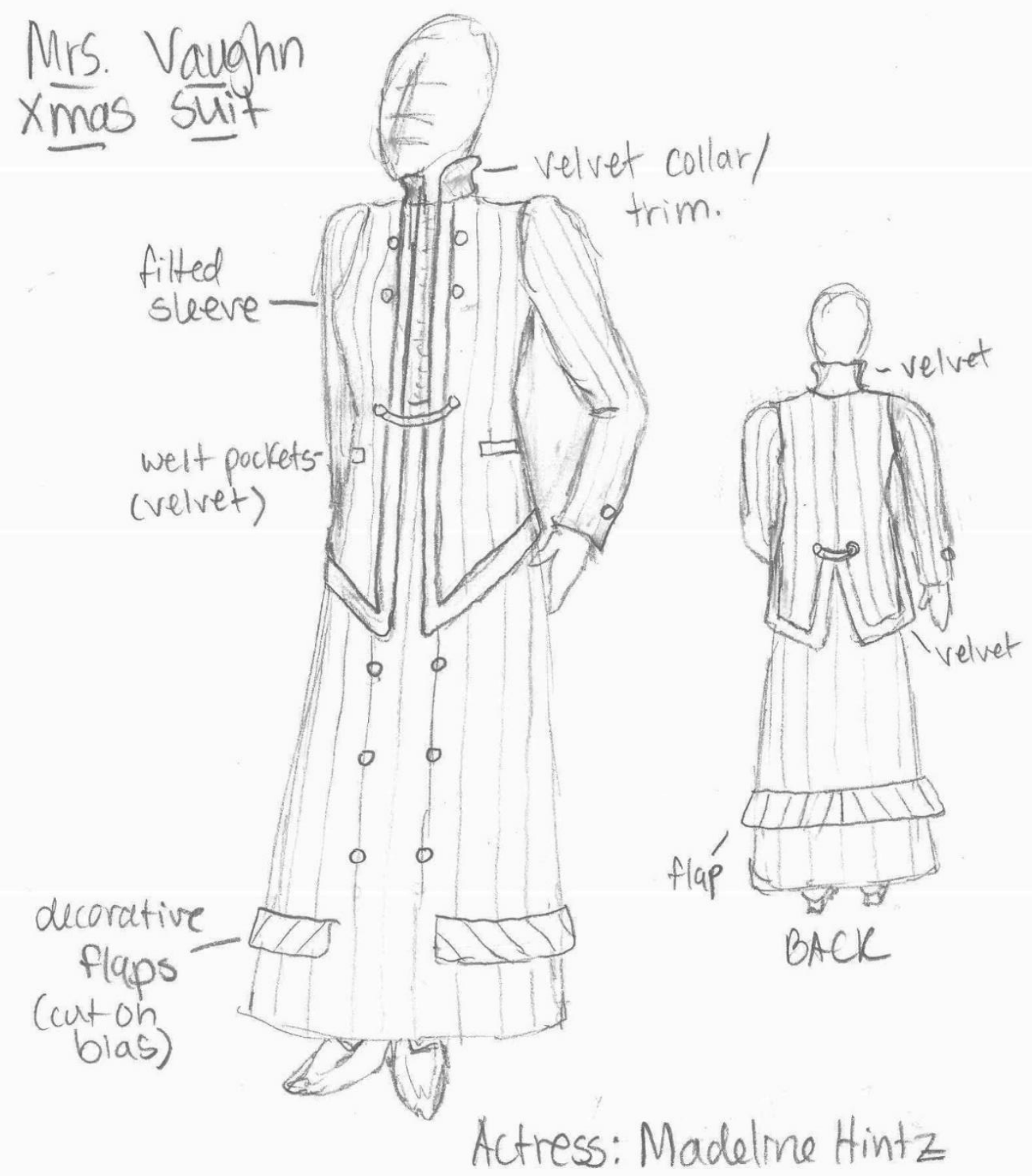

Working drawing for Mrs. Vaughn's suit in Valentine's Day, scene 2.

Brennan, Lauren E. Mrs. Vaughn Valentine's Day, Scene 2 Working Drawing. 2015. Pencil. West Virginia University School of Theatre and Dance, Morgantown, WV. Digital Image. 


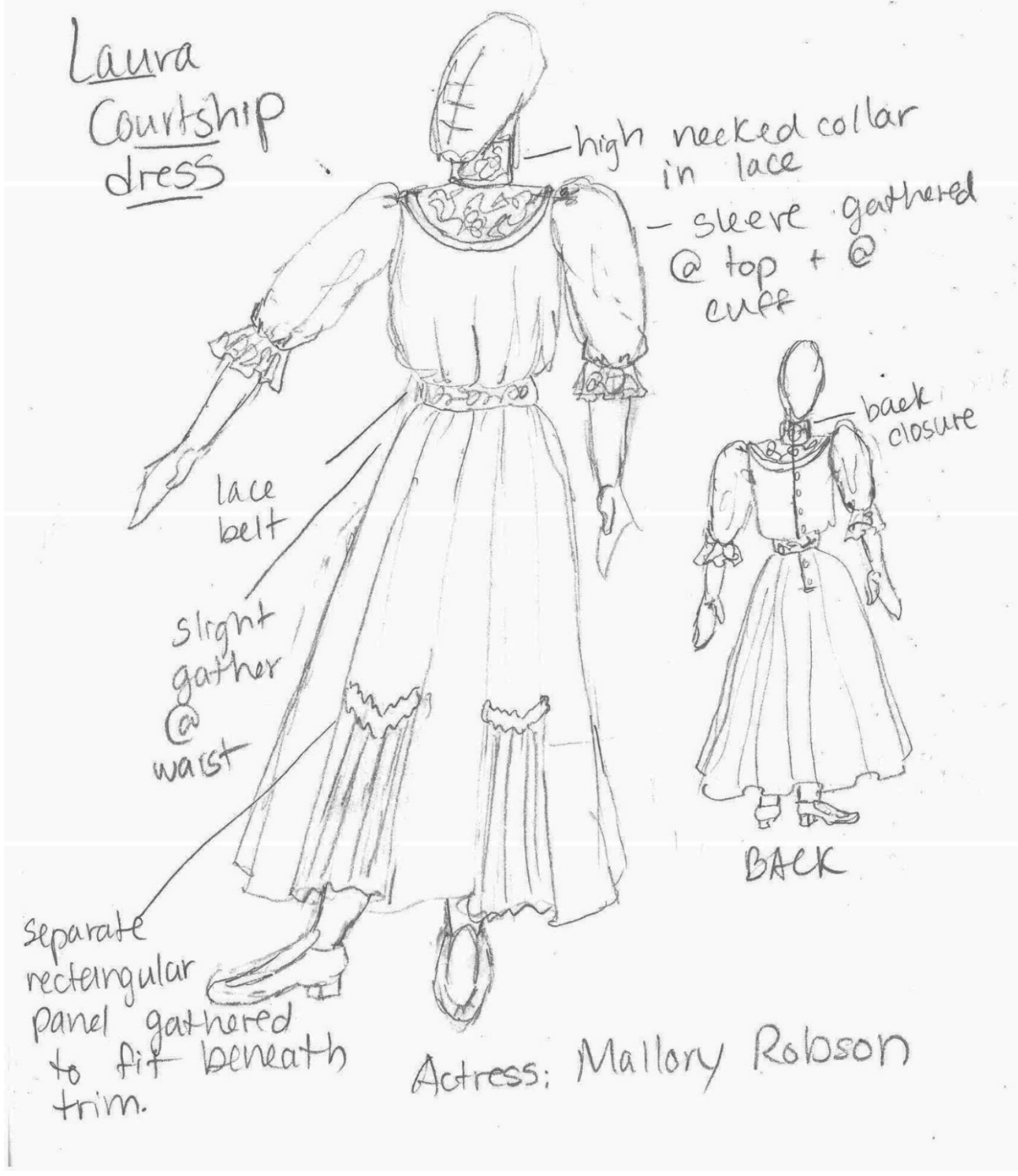

Working drawing for Laura Vaughn's dress in Courtship.

Brennan, Lauren E. Laura. Vaughn Courtship Working Drawing. 2015. Pencil. West Virginia University School of Theatre and Dance, Morgantown, WV. Digital Image.

174 


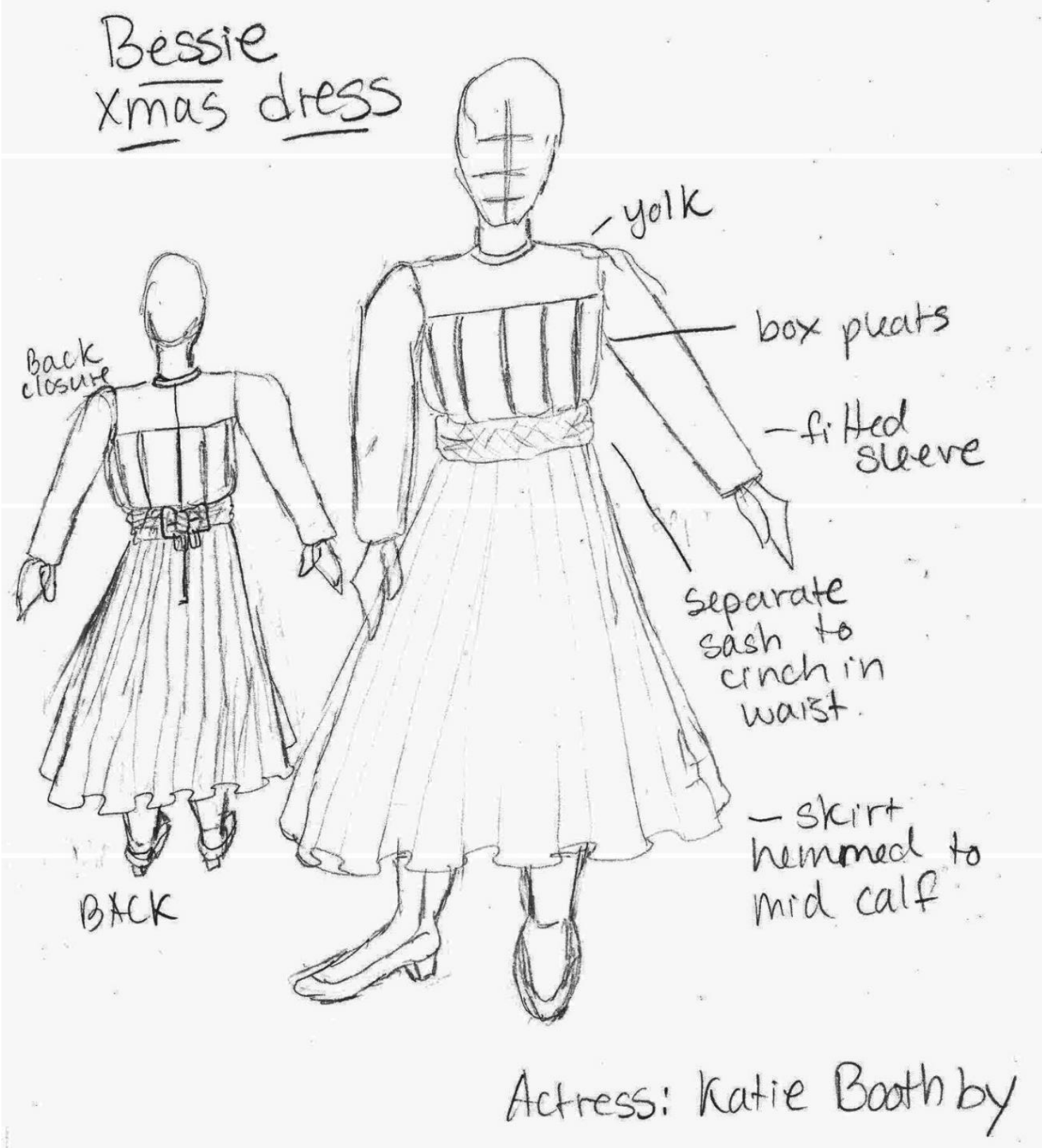

Working drawing for Bessie Stillman's dress in Valentine's Day, scenes 1 \& 3.

Brennan, Lauren E. Bessie Stillman Valentine's Day, Scenes 1 \& 3 Working Drawing. 2015. Pencil. West Virginia University School of Theatre and Dance, Morgantown, WV. Digital Image. 


\section{APPENDIX V: WIG AND PROSTHETIC MAKEUP DESIGN}

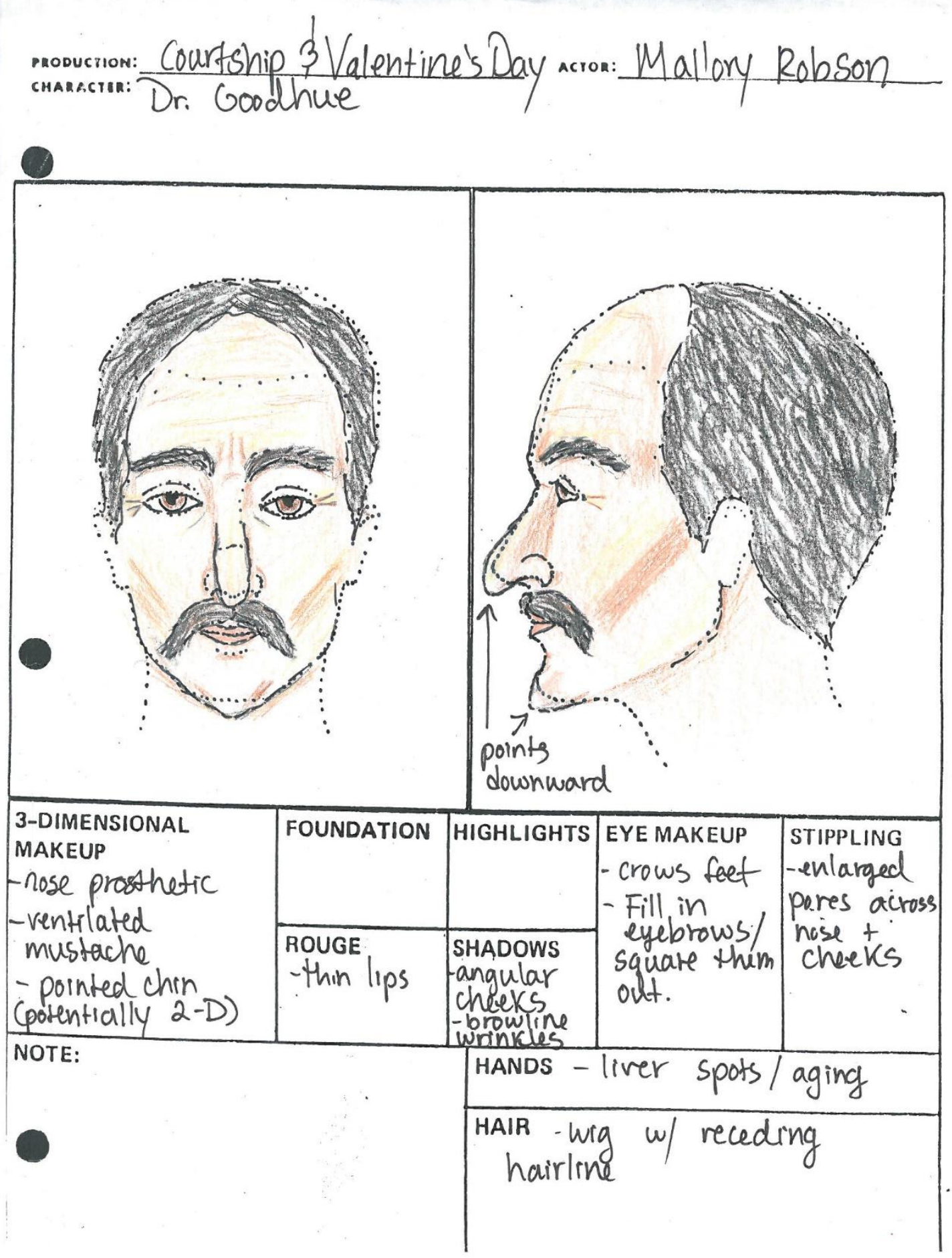

Dr. Goodhue Makeup Design.

Brennan, Lauren E. Dr. Goodhue Wig \& Prosthetic Makeup Design. 2015. Colored Pencil. West Virginia University School of Theatre and Dance, Morgantown, WV. Digital Image. 


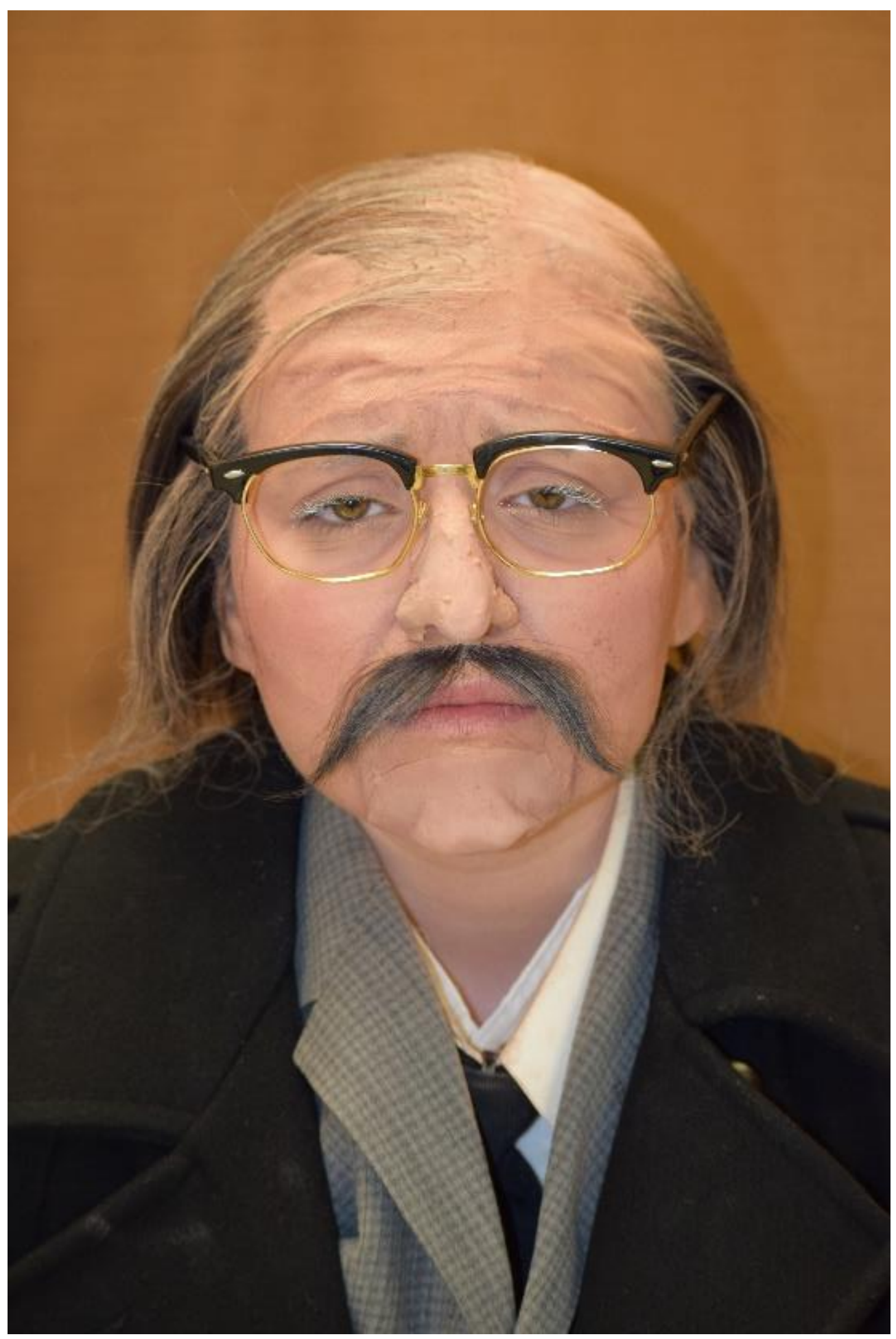

Mallory Robson as Dr. Goodhue with balding wig, mustache, latex prosthetic nose, latex prosthetic chin, and age makeup. Makeup and wig application by Kathleen Meighan. Front view.

Brennan, Lauren E. Dr. Goodhue Wig and Prosthetic Makeup Detail Front view. 2015. Photograph. West Virginia University, Morgantown, WV. 


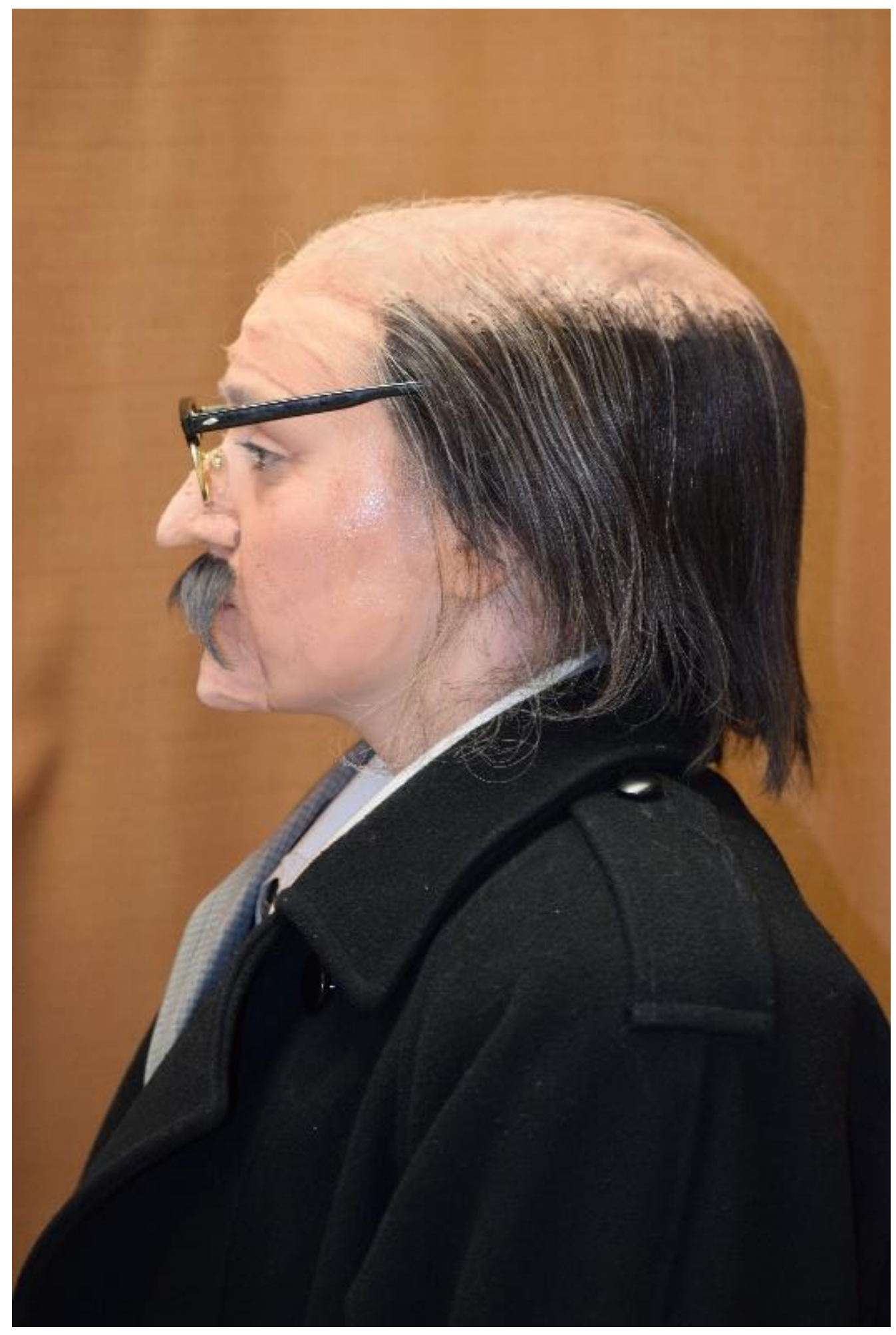

Mallory Robson as Dr. Goodhue with balding wig, mustache, latex prosthetic nose, latex prosthetic chin, and age makeup. Makeup and wig application by Kathleen Meighan. Side view.

Brennan, Lauren E. Dr. Goodhue Wig and Prosthetic Makeup Detail Side view. 2015. Photograph. West Virginia University, Morgantown, WV. 
APPENDIX VI: PRODUCTION CALENDAR

\begin{tabular}{|c|c|c|c|c|c|c|}
\hline SUNDAY & MONDAY & TUESDAY & WEDNESDAY & THURSDAY & FRIDAY & SATURDAY \\
\hline 27 & 28 & 29 & 30 & 31 & 01 & 02 \\
\hline 03 & 04 & 05 & 06 & 07 & 08 & 09 \\
\hline 10 & $\begin{array}{l}11 \\
\text { Piece list due; } \\
\text { Crafts list due }\end{array}$ & $\begin{array}{l}12 \\
\text { Build list decided }\end{array}$ & 13 & 14 & $\begin{array}{l}15 \\
\text { Have all fabric } \\
\text { sourced }\end{array}$ & 16 \\
\hline 17 & $\begin{array}{l}18 \\
\text { Auditions/Casting } \\
\text {; Measurements; } \\
\text { Assemble show } \\
\text { bible }\end{array}$ & 19 & 20 & 21 & 22 & 23 \\
\hline 24 & $\begin{array}{l}25 \\
\text { Begin } \\
\text { pulling/borrowing/ } \\
\text { ordering }\end{array}$ & 26 & 27 & 28 & $\begin{array}{l}29 \\
\text { Working } \\
\text { drawings to } \\
\text { cutter/draper; } \\
\text { Measurements \& } \\
\text { Headwraps }\end{array}$ & 30 \\
\hline 31 & 01 & \multicolumn{5}{|c|}{$\begin{array}{l}\text { Notes: } \\
\text { Designer ; Shop ; Crafts ; Crew }\end{array}$} \\
\hline 201 & $E$ & & & & & \\
\hline SUNDAY & MONDAY & TUESDAY & WEDNESDAY & THURSDAY & FRIDAY & SATURDAY \\
\hline 31 & $\begin{array}{l}01 \\
\text { Begin patterning } \\
\text { \& mockups; } \\
\text { Begin fittings; } \\
\text { Last day for }\end{array}$ & $\begin{array}{l}02 \\
\text { Fittings }\end{array}$ & $\begin{array}{l}03 \\
\text { Fittings; Begin } \\
\text { dyeing/painting }\end{array}$ & $\begin{array}{l}04 \\
\text { Fittings }\end{array}$ & $\begin{array}{l}05 \\
\text { Fittings; All fabric } \\
\text { in shop }\end{array}$ & 06 \\
\hline 07 & $\begin{array}{l}08 \\
\text { Fittings; Begin } \\
\text { final fabric }\end{array}$ & $\begin{array}{l}09 \\
\text { Fittings }\end{array}$ & $\begin{array}{l}10 \\
\text { Fittings }\end{array}$ & $\begin{array}{l}11 \\
\text { Fittings }\end{array}$ & $\begin{array}{l}12 \\
\text { Fittings; Local } \\
\text { Shopping } \\
\text { Complete }\end{array}$ & 13 \\
\hline 14 & $\begin{array}{l}15 \\
\text { Fittings }\end{array}$ & $\begin{array}{l}16 \\
\text { Fittings }\end{array}$ & $\begin{array}{l}17 \\
\text { Fittings }\end{array}$ & $\begin{array}{l}18 \\
\text { Fittings }\end{array}$ & $\begin{array}{l}19 \\
\text { Fittings complete; } \\
\text { Wig ventilation } \\
\text { complete }\end{array}$ & 20 \\
\hline 21 & $\begin{array}{l}22 \\
\text { Laundry list, final } \\
\text { piece list, } \\
\text { costume plot due }\end{array}$ & 23 & $\begin{array}{l}24 \\
\text { Stitching and } \\
\text { alterations } \\
\text { complete }\end{array}$ & $\begin{array}{l}25 \\
\text { Crew view }\end{array}$ & $\begin{array}{l}26 \\
\text { Racking; Wig } \\
\text { styling complete }\end{array}$ & 27 Wig training \\
\hline $\begin{array}{l}28 \\
\text { First Dress }\end{array}$ & $\begin{array}{l}29 \\
\text { Dark/Show notes }\end{array}$ & 01 & 02 & 03 & 04 & 05 \\
\hline 06 & 07 & $\begin{array}{l}\text { Notes: } \\
\text { Designer ; Shop ; }\end{array}$ & rafts ; Wigs ; Crew & & & \\
\hline
\end{tabular}




\begin{tabular}{|c|c|c|c|c|c|c|}
\hline SUNDAY & MONDAY & TUESDAY & WEDNESDAY & THURSDAY & FRIDAY & SATURDAY \\
\hline 28 & 29 & $\begin{array}{l}01 \\
\text { Second Dress }\end{array}$ & $\begin{array}{l}02 \\
\text { Third Dress }\end{array}$ & $\begin{array}{l}03 \\
\text { Preview }\end{array}$ & $\begin{array}{l}04 \\
\text { Opening night }\end{array}$ & $\begin{array}{l}05 \\
\text { Performance }\end{array}$ \\
\hline $\begin{array}{l}06 \\
\text { Matinee } \\
\text { Performance }\end{array}$ & 07 & 08 & 09 & 10 & $\begin{array}{l}11 \\
\text { Performance }\end{array}$ & $\begin{array}{l}12 \\
\text { Performance }\end{array}$ \\
\hline $\begin{array}{l}13 \\
\text { Matinee } \\
\text { Performance; } \\
\text { Strike }\end{array}$ & 14 & 15 & 16 & 17 & 18 & 19 \\
\hline 20 & 21 & 22 & 23 & 24 & 25 & 26 \\
\hline 27 & 28 & 29 & 30 & 31 & 01 & 02 \\
\hline 03 & 04 & $\begin{array}{l}\text { Notes: } \\
\text { Designer ; Shop }\end{array}$ & rafts ; Crew & & & \\
\hline
\end{tabular}




\section{APPENDIX VII: BUILD LISTS}

$\begin{array}{ll}\text { Costume Build List } & \\ \text { Character/Item } & \text { Actor } \\ 1 \text { Elizabeth Courship Blouse } & \text { Maggie } \\ 2 \text { Elizabeth Courship Skirt } & \text { Maggie } \\ 3 \text { Elizabeth Embroidered Robe } & \text { Maggie } \\ 4 \text { Elizabeth Christmas Day Blous } & \text { Maggie } \\ 5 \text { Mrs. Vaughn Courtship Blouse } & \text { Maddie } \\ 6 \text { Mrs. Vaughn Courtship Skirt } & \text { Maddie } \\ 7 \text { Mrs. Vaughn Christmas Day Suit } & \text { Maddie } \\ 8 \text { Horace Grey Pinstripe Vest } & \text { Isaac } \\ 9 \text { Horace Grey Pinstripe Pants } & \text { Isaac } \\ 10 \text { Bessie Plaid Christmas Day Dress } & \text { Katie } \\ 11 \text { Laura Courtship Dress } & \text { Mallory }\end{array}$

$\begin{array}{ll}\text { Hat List } & \\ \text { Character/Hat } & \text { Actor } \\ 1 \text { Mrs. Vaughn Christmas Day hat (build) } & \text { Maddie } \\ 2 \text { Horace Courtship top hat (pull) } & \text { Isaac } \\ 3 \text { Mr. Vaughn Christmas Day hat (pull) } & \text { Joe B. } \\ 5 \text { Steve Tyler Courtship hat (pull) } & \text { Josh }\end{array}$

Wig List

$\begin{array}{cl}\text { Character } & \text { Actor } \\ 1 \text { Dr. Goodhue } & \text { Mallory } \\ 3 \text { Aunt Lucy } & \text { Brianna } \\ 4 \text { Aunt Sarah } & \text { Katie }\end{array}$

Facial Hair List

$\begin{array}{ll}\text { Character } & \text { Actor } \\ 1 \text { Dr. Goodhue mustache } & \text { Mallory } \\ 2 \text { Bobby mustache } & \text { Zach }\end{array}$

Makeup List

$\begin{array}{ll}\text { Character } & \text { Actor } \\ 1 \text { Dr. Goodhue prosthetic nose } & \text { Mallory } \\ 2 \text { Dr. Goodhue prosthetic chin } & \text { Mallory }\end{array}$




\section{Distressing List}

\begin{tabular}{|c|c|c|c|}
\hline Actor & Character & Item & Type of Distressing \\
\hline 1 Josh Clevenger & Steve Tyler & Tux pants & Dust w/ baby powder \\
\hline 2 Josh Clevenger & Steve Tyler & Tux Jacket & Dust w/ baby powder \\
\hline 3 Josh Clevenger & Steve Tyler & Grey jacket & Make it looked worn/well-loved \\
\hline 4 Josh Clevenger & Steve Tyler & Grey pants & Make it looked worn/well-loved \\
\hline 5 Lonnie Simmons & George Tyler & Button up shirt & Worn, pit stains, a little dirt \\
\hline 6 Lonnie Simmons & George Tyler & Grey pants & worn, a dirty hem, dirt wiped on sides \\
\hline 8 Brianna Bowers & Ruth Amos & Blue floral dress & $\begin{array}{l}\text { Make it looked worn/well-loved-- } \\
\text { sunbleached }\end{array}$ \\
\hline 9 Katie Boothby & Bessie Stillman & Plaid dress & $\begin{array}{l}\text { Dirt around hem, make it look worn } \\
\text { and well-loved }\end{array}$ \\
\hline 10 Zach Powers & Bobby Pate & Button up shirt & Worn and well-loved, pit stains \\
\hline 11 Maggie Dransfield & $\begin{array}{l}\text { Elizabeth } \\
\text { Vaughn }\end{array}$ & White shoes & Spray down \\
\hline 12 Joe Bussey & Mr. Vaughn & Pink tie & Spray down \\
\hline 13 Brianna Bowers & Ruth Amos & Slippers & worn and well loved \\
\hline 14 Isaac Snyder & $\begin{array}{l}\text { Horace } \\
\text { Robedaux }\end{array}$ & Slippers & worn and well loved \\
\hline 15 Maggie Dransfield & $\begin{array}{l}\text { Elizabeth } \\
\text { Vaughn }\end{array}$ & Slippers & spray down \\
\hline
\end{tabular}




\section{APPENDIX VIII: SAMPLE OF COSTUME PLOT}

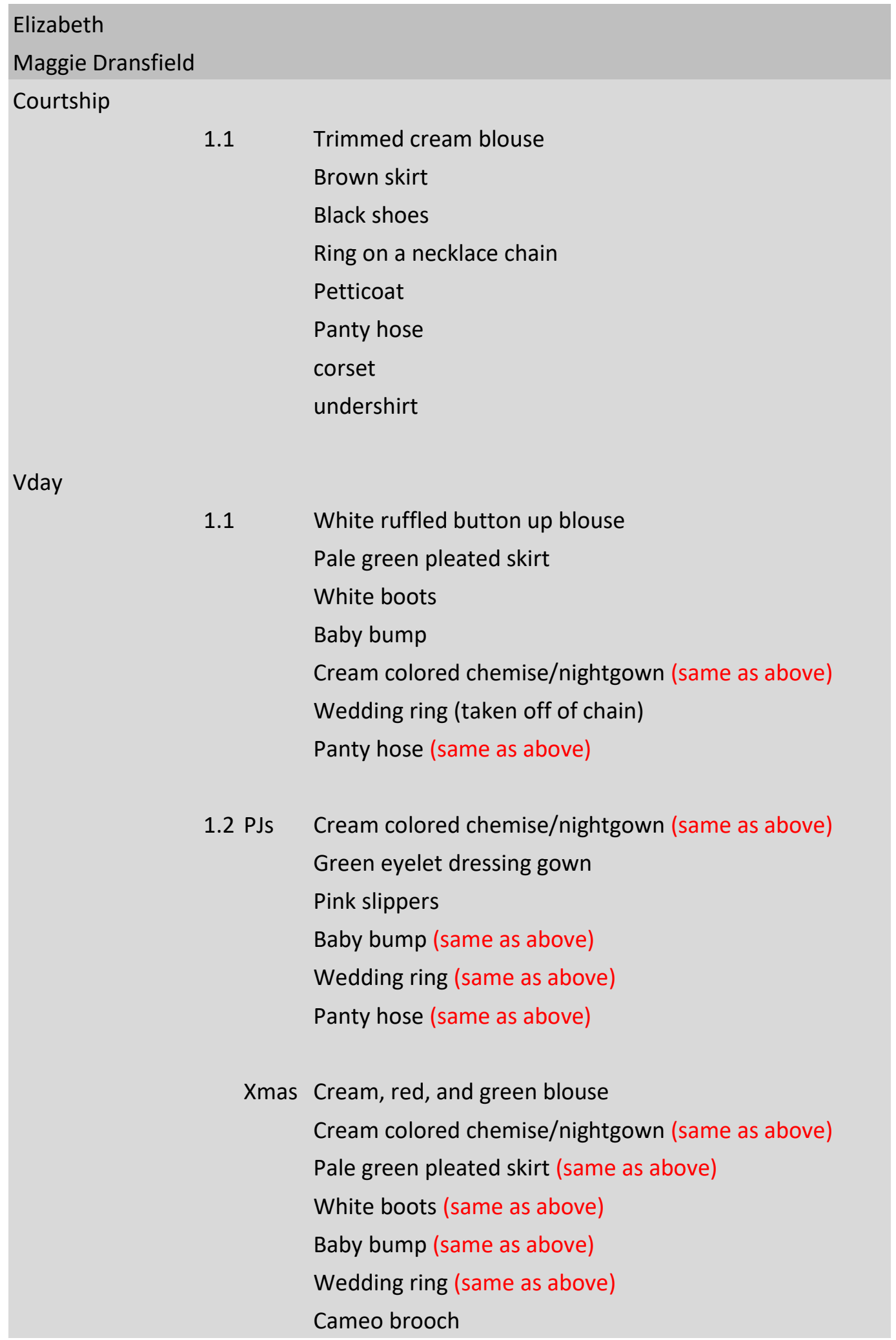




\begin{tabular}{|c|c|}
\hline \multirow{9}{*}{1.3} & Panty hose (same as above) \\
\hline & White ruffled button up blouse (same as above) \\
\hline & Pale green pleated skirt (same as above) \\
\hline & White boots (same as above) \\
\hline & Baby bump (same as above) \\
\hline & Wedding ring (same as above) \\
\hline & Fringed shawl \\
\hline & Cream colored chemise/nightgown (same as above) \\
\hline & Panty hose (same as above) \\
\hline
\end{tabular}

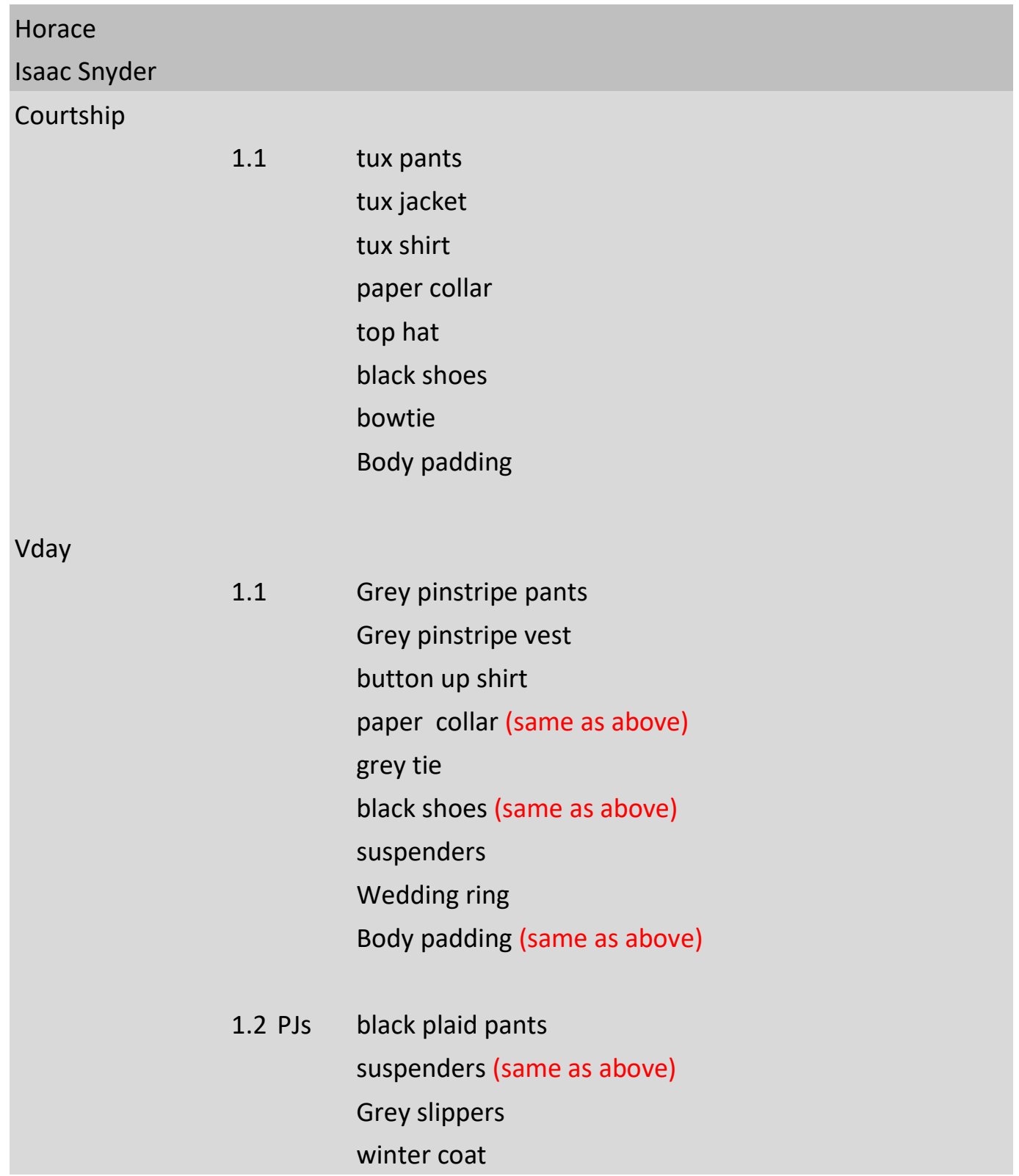


Wedding ring (same as above)

Body padding (same as above)

button up shirt (same as above)

detachable collar

1.2 Xmas Black plaid pants

Black plaid vest

Black plaid jacket

suspenders

button up shirt (same as above)

detachable collar (same as above)

pocket watch

black tie

black shoes (same as above)

Wedding ring (same as above)

Body padding (same as above)

1.3 Grey pinstripe pants (same as above)

Grey pinstripe vest (same as above)

Coordingating jacket

button up shirt (same as above)

grey tie (same as 1.1)

black shoes (same as above)

suspenders (same as above)

socks (same as above)

Wedding ring (same as above)

Body padding (same as above) 


\section{APPENDIX XIX: SAMPLE OF COSTUME PIECE LIST WITH CHECK BOXES FOR}

ORGANIZATIONAL USE

\begin{tabular}{|l|r|l|l|l|l|l|}
\hline Mr. Vaughn & & & Pulled/Purch. & Fit & Prepped & DONE \\
\hline Joe Bussey & & & & & & \\
\hline & 1 & Brown wool pants & & & \\
\hline & 2 & Grey wool vest & & & & \\
\hline & 3 & button up shirt & & & & \\
\hline & 4 & removable collar & & & & \\
\hline & 5 & Brown shoes & & & & \\
\hline & 6 & brown suspenders & & & & \\
\hline & 7 & peach tie & & & & \\
\hline & 8 & Wedding ring & & & \\
\hline & 9 & brown socks & & & \\
\hline & 10 & Black pants & & & \\
\hline & 11 & Black vest & & & & \\
\hline & 12 & Black jacket & & & & \\
\hline & 13 & Black tie & & & & \\
\hline & 14 & Black shoes & & & & \\
\hline & 15 & black suspenders & & & & \\
\hline 16 & Pocket watch & & & & \\
\hline & 17 & top hat & & & & \\
\hline 18 & black socks & & & & \\
\hline & 19 & Undershirt & handkerchief & & & \\
\hline
\end{tabular}

\begin{tabular}{|l|r|l|l|l|l|l|}
\hline Mrs. Vaughn & & & Pulled/Purch. & Fit & Prepped & DONE \\
\hline Maddie Hintz & & & & & & \\
\hline & 1 & Cream blouse w blue pattern & & & & \\
\hline & 2 & Black lace neck cloth & & & & \\
\hline & 4 & Blue pinstripe skirt & & & & \\
\hline & 5 & Shawl & & & & \\
\hline & 6 & Corset & & & & \\
\hline & 7 & Brown shoes & & & & \\
\hline & 8 & Wedding ring & & & & \\
\hline
\end{tabular}




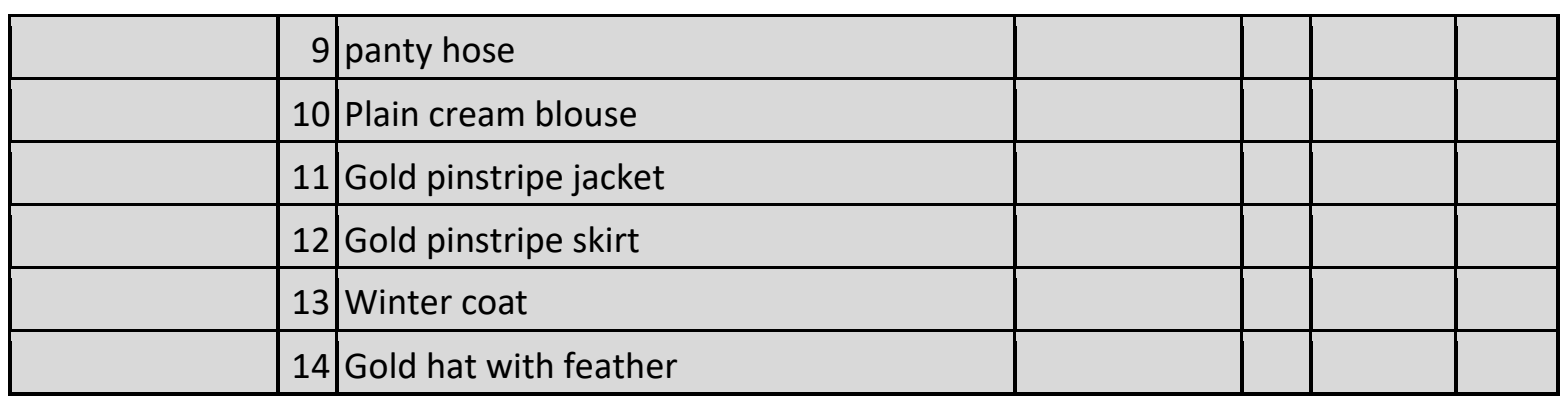

\begin{tabular}{|l|r|l|l|l|l|l|}
\hline Laura & & & Pulled/Purch. & Fit & Prepped & DONE \\
\hline Mallory Robson & & & & & & \\
\hline & 1 & Blue high necked dress & & & & \\
\hline & 2 & Corset & & & & \\
\hline & 3 & Black shoes & & & & \\
\hline & 4 & Panty hose & & & & \\
\hline
\end{tabular}


APPENDIX X: CHARACTER PLOT

\begin{tabular}{|c|c|c|c|c|}
\hline & Courtship & Vday, Scene 1 & Vday, Scene 2 & Vday, Scene 3 \\
\hline & 1915 & 1917 & 1917 & 1918 \\
\hline & Summer evening & $\begin{array}{l}\text { Xmas eve, late } \\
\text { afternoon }\end{array}$ & Xmas morning & $\begin{array}{l}\text { Early January } \\
\text { afternoon }\end{array}$ \\
\hline Elizabeth & $x$ & $x$ & $x$ & $x$ \\
\hline Horace & $x$ & $x$ & $x$ & $x$ \\
\hline Mr. Vaughn & $x$ & & $x$ & $x$ \\
\hline Mrs. Vaughn & $x$ & & $x$ & \\
\hline Laura & $x$ & & & \\
\hline Aunt Sarah & $x$ & & & \\
\hline Aunt Lucy & $x$ & & & \\
\hline Steve & $x$ & $x$ & $x$ & \\
\hline Bessie & & $x$ & $x$ & $x$ \\
\hline George & & $x$ & $x$ & $x$ \\
\hline Bobby & & $x$ & $x$ & $x$ \\
\hline Ruth & & $x$ & $x$ & $x$ \\
\hline Brother & & & $x$ & \\
\hline Dr. Goodhue & & & $x$ & \\
\hline
\end{tabular}




\section{APPENDIX XI: BUDGET SPREADSHEET}

\begin{tabular}{|c|c|c|c|c|c|c|}
\hline \multirow{2}{*}{\multicolumn{2}{|c|}{\begin{tabular}{|l} 
Character \\
Flizaheth
\end{tabular}}} & $\begin{array}{l}\text { Costume } \\
\text { Pieces } \\
\end{array}$ & Pull/Buy/Build/Rent & Source & Price & Notes \\
\hline & & & & & & \\
\hline & 1 & $\begin{array}{l}\text { Trimmed } \\
\text { cream blouse }\end{array}$ & Build & Fabric.com & $\$ 26.00$ & $\begin{array}{l}1.5 \text { yds kona @ } \\
6.27 / y d ; 1.5 \text { yds } \\
\text { mesh @ 10.98/yd }\end{array}$ \\
\hline & 2 & Brown skirt & Build & Fabric.com & $\$ 40$ & $\begin{array}{l}5 \text { yds linen @ } \\
7.98 / y d\end{array}$ \\
\hline & 3 & Brown shoes & Pull & & $\$ 0$ & \\
\hline & 4 & $\begin{array}{l}\text { Ring on a } \\
\text { necklace chain }\end{array}$ & Pull/Buy & Gabe's & $\$ 10$ & \\
\hline & 5 & Panty hose & Pull & & $\$ 0$ & \\
\hline & 6 & Corset & Pull & & $\$ 0$ & \\
\hline & 7 & $\begin{array}{l}\text { Button up } \\
\text { blouse }\end{array}$ & Pull & & $\$ 0$ & \\
\hline & 8 & $\begin{array}{l}\text { Blue pleated } \\
\text { skirt }\end{array}$ & Pull/Build & Fabric.com & $\$ 32$ & $\begin{array}{l}7 \text { yds wool @ } \\
4.44 / y d\end{array}$ \\
\hline & 9 & $\begin{array}{l}\text { Black and } \\
\text { cream boots }\end{array}$ & Buy/Pull & $\begin{array}{l}\text { Histor. } \\
\text { Emp }\end{array}$ & $\$ 45$ & \\
\hline & 10 & Baby bump & Pull/Build & & $\$ 0$ & shop materials \\
\hline & 11 & $\begin{array}{l}\text { Wedding ring } \\
\text { (double of ring } \\
\text { from necklace } \\
\text { chain) }\end{array}$ & Pull/Buy & Gabe's & $\$ 10$ & \\
\hline & 12 & $\begin{array}{l}\text { Light blue } \\
\text { nightgown }\end{array}$ & Buy & Gabe's & $\$ 15$ & \\
\hline & 13 & $\begin{array}{l}\text { Cream and } \\
\text { blue } \\
\text { embroidered } \\
\text { dressing gown }\end{array}$ & Build & & $\$ 25$ & $\begin{array}{l}5 \text { yds scalloped } \\
\text { eyelet, } 4.98 / y d\end{array}$ \\
\hline & 14 & Blue slippers & Buy & & $\$ 15$ & \\
\hline & 15 & $\begin{array}{l}\text { Cream, red, } \\
\text { and green } \\
\text { blouse }\end{array}$ & Build/Pull & & $\$ 15$ & \\
\hline & 16 & $\begin{array}{l}\text { Pendant } \\
\text { necklace }\end{array}$ & Pull & & $\$ 0$ & \\
\hline & 17 & Fringed shawl & Pull/Buy & & $\$ 12$ & \\
\hline & & & Total Allotted: & & $\$ 245.00$ & \\
\hline
\end{tabular}




\begin{tabular}{|c|c|c|c|c|c|c|}
\hline Character & & $\begin{array}{l}\text { Costume } \\
\text { Pieces }\end{array}$ & Pull/Buy/Build/Rent & Source & Price & Notes \\
\hline \multicolumn{7}{|l|}{ Horace } \\
\hline & 1 & tux pants & Rent & & $\$ 30$ & \\
\hline & 2 & tux vest & Rent & & $\$ 30$ & \\
\hline & 3 & tux jacket & Rent & & $\$ 55$ & \\
\hline & 4 & tux shirt & Pull/Buy & Amazon & $\$ 20$ & \\
\hline & 5 & top hat & Pull & & $\$ 0$ & \\
\hline & 6 & black shoes & Pull & & $\$ 0$ & \\
\hline & 7 & bowtie & Pull & & $\$ 0$ & \\
\hline & 8 & $\begin{array}{l}\text { Grey pinstripe } \\
\text { pants }\end{array}$ & Pull & & $\$ 0$ & \\
\hline & 9 & $\begin{array}{l}\text { Grey pinstripe } \\
\text { vest }\end{array}$ & Pull & & $\$ 0$ & \\
\hline & 10 & button up shirt & Pull & & $\$ 0$ & \\
\hline & 11 & grey tie & Pull & & $\$ 0$ & \\
\hline & 12 & suspenders & Pull & & $\$ 0$ & \\
\hline & 13 & Wedding ring & Pull & & $\$ 0$ & \\
\hline & 14 & Union suit top & Pull & & $\$ 0$ & \\
\hline & 16 & brown slippers & Pull/Buy & & $\$ 15$ & \\
\hline & 17 & winter coat & Pull/Buy & & $\$ 50$ & \\
\hline & 18 & $\begin{array}{l}\text { Grey/Black } \\
\text { houndstooth } \\
\text { pants }\end{array}$ & Pull/Buy & & $\$ 30$ & \\
\hline & 19 & $\begin{array}{l}\text { Grey/Black } \\
\text { houndstooth } \\
\text { vest }\end{array}$ & Pull/Buy & & $\$ 30$ & \\
\hline & 20 & $\begin{array}{l}\text { Grey/Black } \\
\text { houndstooth } \\
\text { jacket }\end{array}$ & Pull/Buy & & $\$ 55$ & \\
\hline & 21 & pocket watch & Pull & & $\$ 0$ & \\
\hline & 22 & black tie & Pull & & $\$ 0$ & \\
\hline & 23 & $\begin{array}{l}\text { Grey pinstripe } \\
\text { jacket }\end{array}$ & Pull/Buy & & $\$ 0$ & \\
\hline & & & Total Allotted: & & $\$ 315$ & \\
\hline
\end{tabular}

\begin{tabular}{|c|c|c|c|c|c|c|}
\hline Character & & $\begin{array}{l}\text { Costume } \\
\text { Pieces }\end{array}$ & Pull/Buy/Build/Rent & Source & Price & Notes \\
\hline \multicolumn{7}{|l|}{ Mr. Vaughn } \\
\hline & 1 & $\begin{array}{l}\text { Brown wool } \\
\text { pants }\end{array}$ & Pull/Buy & & $\$ 25$ & \\
\hline & 2 & Grey wool vest & Pull/Buy & & $\$ 25$ & \\
\hline & 3 & $\begin{array}{l}\text { Grey wool } \\
\text { jacket }\end{array}$ & Pull/Buy & & $\$ 55$ & \\
\hline
\end{tabular}




\begin{tabular}{|r|r|l|l|r|r|r|}
\hline & 4 & button up shirt & Pull & & $\$ 0$ & \\
\hline & 5 & Brown shoes & Pull & & $\$ 0$ & \\
\hline & 6 & suspenders & Pull & & $\$ 0$ & \\
\hline & 7 & peach tie & Pull & & $\$ 0$ & \\
\hline & 8 & Wedding ring & Pull & $\$ 0$ & \\
\hline & 9 & brown socks & Pull & & $\$ 0$ & \\
\hline & 10 & Black pants & Pull/Buy & & $\$ 30$ & \\
\hline & 11 & Black vest & Pull/Buy & & $\$ 30$ & \\
\hline & 12 & Black jacket & Pull/Buy & & $\$ 55$ & \\
\hline & 13 & Black tie & Pull & & $\$ 0$ & \\
\hline & 14 & Black shoes & Pull & & $\$ 0$ & \\
\hline & 15 & Pocket watch & Pull & & $\$ 0$ & \\
\hline & 16 & top hat & Pull & & $\$ 0$ & \\
\hline & 17 & black socks & Pull & & $\$ 0$ & \\
\hline & 18 & button up with & & & $\$ 0$ & \\
\hline & collar taken off & Pull & & & $\$ 220$ & \\
\hline
\end{tabular}

\begin{tabular}{|c|c|c|c|c|c|c|}
\hline Character & & $\begin{array}{l}\text { Costume } \\
\text { Pieces }\end{array}$ & Pull/Buy/Build/Rent & Source & Price & Notes \\
\hline \multicolumn{7}{|l|}{$\begin{array}{l}\text { Mrs. } \\
\text { Vaughn }\end{array}$} \\
\hline & 1 & Eyelet blouse & Buy & & $\$ 15$ & \\
\hline & 2 & Lace neck cloth & Pull/Build & & $\$ 0$ & shop supplies \\
\hline & 3 & Belt & Pull & & $\$ 0$ & \\
\hline & 4 & $\begin{array}{l}\text { Blue pinstripe } \\
\text { skirt }\end{array}$ & Build & & $\$ 32$ & \\
\hline & 5 & Corset & Pull & & $\$ 0$ & \\
\hline & 6 & Brown shoes & Pull & & $\$ 0$ & \\
\hline & 7 & Wedding ring & Pull & & $\$ 0$ & \\
\hline & 8 & panty hose & Pull & & $\$ 0$ & \\
\hline & 9 & Blouse & Pull & & $\$ 0$ & \\
\hline & 10 & $\begin{array}{l}\text { Gold pinstripe } \\
\text { jacket }\end{array}$ & Build & & $\$ 40$ & $\begin{array}{l}\text { 4yds pinstripe @ } \\
\$ 9.09 / y d\end{array}$ \\
\hline & 11 & $\begin{array}{l}\text { Gold pinstripe } \\
\text { skirt }\end{array}$ & Build & & $\$ 40$ & $\begin{array}{l}\text { 4yds pinstripe @ } \\
\$ 9.09 / y d\end{array}$ \\
\hline & 12 & Winter coat & Pull/Buy & & $\$ 40$ & \\
\hline & 13 & $\begin{array}{l}\text { Gold hat with } \\
\text { feather }\end{array}$ & Pull/cover & & $\$ 10$ & $\begin{array}{l}\text { 1yd pinstripe @ } \\
9.09 / y d \text {; feather } \\
\text { from stock }\end{array}$ \\
\hline & & & Total Allotted: & & $\$ 177$ & \\
\hline
\end{tabular}




\begin{tabular}{|l|l|l|l|l|r|l|}
\hline Character & & $\begin{array}{l}\text { Costume } \\
\text { Pieces }\end{array}$ & Pull/Buy/Build/Rent & Source & Price & Notes \\
\hline Laura & & & & & & \\
\hline & 1 & $\begin{array}{l}\text { Blue high } \\
\text { necked dress }\end{array}$ & Buy/Rent & & $\$ 86$ & \\
\hline & 2 & Corset & Pull & & $\$ 0$ & \\
\hline & 3 & Black shoes & Pull & & $\$ 0$ & \\
\hline & 4 & Panty hose & Pull & & $\$ 0$ & \\
\hline & & & Total Allotted: & & $\$ 86$ & \\
\hline
\end{tabular}

\begin{tabular}{|l|l|l|l|l|r|l|}
\hline Character & & $\begin{array}{l}\text { Costume } \\
\text { Pieces }\end{array}$ & Pull/Buy/Build/Rent & Source & Price & Notes \\
\hline Aunt Sarah & & & & & & \\
\hline & 1 & $\begin{array}{l}\text { Grey high } \\
\text { necked dress }\end{array}$ & Pull/Buy/Rent & & $\$ 86$ & \\
\hline & 2 & Corset & Pull & & $\$ 0$ & \\
\hline & 3 & black boots & Pull & & $\$ 0$ & \\
\hline & 4 & Panty hose & Pull & & $\$ 0$ & \\
\hline & & & Total Allotted: & & $\$ 86$ & \\
\hline
\end{tabular}

\begin{tabular}{|l|l|l|l|l|r|r|}
\hline Character & & $\begin{array}{l}\text { Costume } \\
\text { Pieces }\end{array}$ & Pull/Buy/Build/Rent & Source & Price & Notes \\
\hline Aunt Lucy & & $\begin{array}{l}\text { Dark grey } \\
\text { bodice }\end{array}$ & Pull/Buy/Rent & & $\$ 86$ & \\
\hline & & $\begin{array}{l}\text { Light grey } \\
\text { pleated skirt }\end{array}$ & Pull & & $\$ 0$ & \\
\hline & 3 & Corset & Pull & & $\$ 0$ & \\
\hline & 4 & Black boots & Pull/Buy & & $\$ 30$ & \\
\hline & 5 & Panty hose & Pull & & $\$ 0$ & \\
\hline & & & Total Allotted: & & $\$ 116$ & \\
\hline
\end{tabular}

\begin{tabular}{|l|l|l|l|l|r|l|}
\hline Character & & $\begin{array}{l}\text { Costume } \\
\text { Pieces }\end{array}$ & Pull/Buy/Build/Rent & Source & Price & Notes \\
\hline Bessie & & & & & & \\
\hline & 1 & Plaid dress & Build & $\begin{array}{l}\text { fabric from stock, } \\
\text { need buttons }\end{array}$ \\
\hline & 2 & $\begin{array}{l}\text { Cream and } \\
\text { black boots }\end{array}$ & Buy & Hist. Emp. & $\$ 45$ & \\
\hline & 3 & Glasses & Pull & & $\$ 0$ & \\
\hline & 4 & Panty hose & Pull & & $\$ 0$ & \\
\hline & 5 & Winter coat & Pull/Buy & Gabe's & $\$ 30$ & \\
\hline
\end{tabular}




\begin{tabular}{|r|r|l|l|r|r|l|}
\hline & 6 & Grey sash & Pull/Build & & \$0 & shop fabric \\
\hline & & $\begin{array}{l}\text { Cream and } \\
\text { brown dress }\end{array}$ & Pull/Buy/Rent & & & \\
\hline & 8 & Brown sash & Pull/Build & & $\$ 86$ & \\
\hline & & Total Allotted: & & $\$ 171$ & \\
\hline
\end{tabular}

\begin{tabular}{|l|l|l|l|l|r|l|}
\hline Character & & $\begin{array}{l}\text { Costume } \\
\text { Pieces }\end{array}$ & Pull/Buy/Build/Rent & Source & Price & Notes \\
\hline Miss Ruth & & & & & & \\
\hline & 1 & Cream dress & Pull/Rent & & $\$ 86$ & \\
\hline & 2 & brown sash & Pull/Build & & $\$ 0$ & shop materials \\
\hline & 3 & $\begin{array}{l}\text { Brown } \\
\text { housecoat }\end{array}$ & Pull/Buy & Gabe's & $\$ 15$ & \\
\hline & 4 & Corset & Pull & & $\$ 0$ & \\
\hline & 5 & grey slippers & Pull/Buy & & $\$ 15$ & \\
\hline & 6 & panty hose & Pull & & $\$ 0$ & \\
\hline & 7 & $\begin{array}{l}\text { blue polka dot } \\
\text { dress }\end{array}$ & Build/Rent & & $\$ 45$ & Fabric \\
\hline & 8 & grey sash & Pull/Build & & $\$ 0$ & shop fabric \\
\hline & 9 & Grey boots & Pull & & $\$ 0$ & \\
\hline & & & Total Allotted: & & $\$ 161$ & \\
\hline
\end{tabular}

\begin{tabular}{|c|c|c|c|c|c|c|}
\hline Character & & $\begin{array}{l}\text { Costume } \\
\text { Pieces }\end{array}$ & Pull/Buy/Build/Rent & Source & Price & Notes \\
\hline \multicolumn{7}{|l|}{$\begin{array}{l}\text { Brother } \\
\text { Vaughn }\end{array}$} \\
\hline & 1 & $\begin{array}{l}\text { Brown wool } \\
\text { pants }\end{array}$ & Pull/Buy & & $\$ 30$ & \\
\hline & 2 & $\begin{array}{l}\text { Brown wool } \\
\text { vest }\end{array}$ & Pull/Buy & & $\$ 30$ & \\
\hline & 3 & $\begin{array}{l}\text { Brown wool } \\
\text { jacket with } \\
\text { leather details }\end{array}$ & Pull/Buy & & $\$ 55$ & \\
\hline & 4 & Button up shirt & Pull & & $\$ 0$ & \\
\hline & 5 & Brown tie & Pull & & $\$ 0$ & \\
\hline & 6 & Brown boots & Pull/Buy & & $\$ 40$ & \\
\hline & 7 & Winter coat & Pull & & $\$ 0$ & \\
\hline & 8 & socks & Pull & & $\$ 0$ & \\
\hline & & & Total Allotted: & & $\$ 155$ & \\
\hline
\end{tabular}




\begin{tabular}{|c|c|c|c|c|c|c|}
\hline Character & & $\begin{array}{l}\text { Costume } \\
\text { Pieces }\end{array}$ & Pull/Buy/Build/Rent & Source & Price & Notes \\
\hline \multicolumn{7}{|l|}{$\begin{array}{l}\text { Dr. } \\
\text { Goodhue }\end{array}$} \\
\hline & 1 & $\begin{array}{l}\text { Grey/brown } \\
\text { tween pants }\end{array}$ & Pull/Buy & & $\$ 25$ & \\
\hline & 2 & $\begin{array}{l}\text { Grey/brown } \\
\text { tweed vest }\end{array}$ & Pull/Buy & & $\$ 25$ & \\
\hline & 3 & $\begin{array}{l}\text { Grey/brown } \\
\text { tweed jacket }\end{array}$ & Pull/Buy & & $\$ 50$ & \\
\hline & 4 & $\begin{array}{l}\text { Button down } \\
\text { shirt }\end{array}$ & Pull & & $\$ 0$ & \\
\hline & 5 & Tie & Pull & & $\$ 0$ & \\
\hline & 6 & Brown shoes & Pull & & $\$ 0$ & \\
\hline & 7 & Briefcase & Pull & & $\$ 0$ & \\
\hline & 8 & Winter coat & Pull & & $\$ 0$ & \\
\hline & 9 & socks & Pull & & $\$ 0$ & \\
\hline & & & Total Allotted: & & $\$ 100$ & \\
\hline
\end{tabular}

\begin{tabular}{|l|l|l|l|r|r|r|}
\hline Character & & $\begin{array}{l}\text { Costume } \\
\text { Pieces }\end{array}$ & Pull/Buy/Build/Rent & Source & Price & Notes \\
\hline Bobby & & & & & & \\
\hline & 1 & $\begin{array}{l}\text { Brown wool } \\
\text { pants }\end{array}$ & Pull/Buy & & \\
& 2 & $\begin{array}{l}\text { Brown wool } \\
\text { vest }\end{array}$ & Pull/Buy & & $\$ 0$ & \\
\hline & & $\begin{array}{l}\text { Brown wool } \\
\text { jacket }\end{array}$ & Pull/Buy & & $\$ 0$ & \\
\hline & 4 & Button up shirt & Pull & & $\$ 0$ & \\
\hline & 5 & Black tie & Pull & & $\$ 0$ & \\
\hline & 6 & Black shoes & Pull & & $\$ 0$ & \\
\hline & 7 & Socks & Pull & & $\$ 0$ & \\
\hline & & & Total Allotted: & & $\$ 0$ & \\
\hline
\end{tabular}

\begin{tabular}{|l|l|l|l|r|r|l|}
\hline Character & & $\begin{array}{l}\text { Costume } \\
\text { Pieces }\end{array}$ & Pull/Buy/Build/Rent & Source & Price & Notes \\
\hline Steve Tyler & & & & & & \\
\hline & 1 & tux pants & Pull & & $\$ 0$ & \\
\hline & 2 & tux vest & Pull & & $\$ 0$ & \\
\hline & 3 & tux jacket & Pull & & $\$ 0$ & \\
\hline & 4 & tux shirt & Pull & & $\$ 0$ & \\
\hline & 5 & black shoes & Pull & & $\$ 0$ & \\
\hline
\end{tabular}




\begin{tabular}{|r|r|l|l|r|r|r|}
\hline & 6 & grey bowtie & Pull/Build & & $\$ 5$ & \\
\hline & 7 & hat & Pull & & $\$ 0$ & \\
\hline & 8 & socks & Pull & & $\$ 0$ & \\
\hline & 9 & Grey pants & Pull/Buy & & $\$ 30$ & \\
\hline & 10 & Grey vest & Pull/Buy & & $\$ 30$ & \\
\hline & 11 & Grey jacket & Pull/Buy & & $\$ 55$ & \\
\hline & 12 & Button up shirt & Pull & & $\$ 0$ & \\
\hline & 13 & Brown shoes & Pull & & $\$ 0$ & \\
\hline & & Total Allotted: & & $\$ 120$ & \\
\hline
\end{tabular}

\begin{tabular}{|l|l|l|l|l|r|l|}
\hline Character & & $\begin{array}{l}\text { Costume } \\
\text { Pieces }\end{array}$ & Pull/Buy/Build/Rent & Source & Price & Notes \\
\hline $\begin{array}{l}\text { George } \\
\text { Tyler }\end{array}$ & & & & & \\
\hline & 1 & $\begin{array}{l}\text { Grey wool } \\
\text { pants }\end{array}$ & Pull/Buy & & $\$ 0$ & \\
\hline & 2 & Grey vest & Pull & & $\$ 0$ & \\
\hline & 3 & $\begin{array}{l}\text { Olive green } \\
\text { jacket }\end{array}$ & Pull/Buy & & $\$ 50$ & \\
\hline & 4 & Button up shirt & Pull & & $\$ 0$ & \\
\hline & 5 & Brown shoes & Pull & & $\$ 0$ & \\
\hline & 6 & socks & Pull & & $\$ 0$ & \\
\hline & 7 & brown belt & Pull & & $\$ 0$ & \\
\hline & & Total Allotted: & & $\$ 50$ & \\
\hline
\end{tabular}

\begin{tabular}{|c|c|c|c|c|c|c|}
\hline Character & & $\begin{array}{l}\text { Costume } \\
\text { Pieces }\end{array}$ & Pull/Buy/Build/Rent & Source & Price & Notes \\
\hline \multicolumn{7}{|l|}{$\begin{array}{l}\text { Male } \\
\text { Dancer } 1\end{array}$} \\
\hline & 1 & tux pants & Rent & & $\$ 30$ & \\
\hline & 2 & tux vest & Rent & & $\$ 30$ & \\
\hline & 3 & tux jacket & Rent & & $\$ 55$ & \\
\hline & 4 & tux shirt & Pull & & $\$ 0$ & \\
\hline & 5 & bowtie & Pull/Build & & $\$ 5$ & \\
\hline & 6 & black shoes & Pull & & $\$ 0$ & \\
\hline & 7 & socks & Pull & & $\$ 0$ & \\
\hline & & & Total Allotted: & & $\$ 120$ & \\
\hline
\end{tabular}

\begin{tabular}{|l|l|l|l|l|l|}
\hline Character & $\begin{array}{l}\text { Costume } \\
\text { Pieces }\end{array}$ & Pull/Buy/Build/Rent & Source & Price & Notes \\
\hline $\begin{array}{l}\text { Female } \\
\text { Dancer } 1\end{array}$ & & & & & \\
\hline
\end{tabular}




\begin{tabular}{|r|r|l|l|r|r|r|}
\hline & & $\begin{array}{l}\text { Green chiffon } \\
\text { dress }\end{array}$ & Rent & & $\$ 86$ & \\
\hline & 2 & Corset & Pull & & $\$ 0$ & \\
\hline & 3 & Necklace & Pull & & $\$ 0$ & \\
\hline & 4 & Panty hose & Pull & & $\$ 0$ & \\
\hline & 5 & Black shoes & Pull & & $\$ 0$ & \\
\hline & & Total Allotted: & & $\$ 86$ & \\
\hline
\end{tabular}

\begin{tabular}{|c|c|c|c|c|c|c|}
\hline \multicolumn{2}{|l|}{ Character } & $\begin{array}{l}\text { Costume } \\
\text { Pieces }\end{array}$ & Pull/Buy/Build/Rent & Source & Price & Notes \\
\hline \multicolumn{7}{|l|}{$\begin{array}{l}\text { Male } \\
\text { Dancer } 2\end{array}$} \\
\hline & 1 & tux pants & Rent & & $\$ 30$ & \\
\hline & 2 & tux vest & Rent & & $\$ 30$ & \\
\hline & 3 & tux jacket & Rent & & $\$ 55$ & \\
\hline & 4 & tux shirt & Pull & & $\$ 0$ & \\
\hline & 5 & pink bowtie & Pull/Build & & $\$ 5$ & \\
\hline & 6 & black shoes & Pull & & $\$ 0$ & \\
\hline & 7 & socks & Pull & & $\$ 0$ & \\
\hline & & & Total Allotted: & & $\$ 120$ & \\
\hline
\end{tabular}

\begin{tabular}{|l|r|l|l|l|r|l|}
\hline Character & & $\begin{array}{l}\text { Costume } \\
\text { Pieces }\end{array}$ & Pull/Buy/Build/Rent & Source & Price & Notes \\
\hline $\begin{array}{l}\text { Female } \\
\text { Dancer 2 }\end{array}$ & & & & & & \\
\hline & 1 & Deep red dress & Rent & & $\$ 86$ & \\
\hline & 2 & Corset & Pull & & $\$ 0$ & \\
\hline & 3 & Gold necklace & Pull & & $\$ 0$ & \\
\hline & 4 & Black shoes & Pull & & $\$ 0$ & \\
\hline & 5 & Panty hose & Pull & & $\$ 0$ & \\
\hline & & & Total Allotted: & & $\$ 86$ & \\
\hline
\end{tabular}

\begin{tabular}{|l|r|l|l|r|r|l|}
\hline Character & & $\begin{array}{l}\text { Costume } \\
\text { Pieces }\end{array}$ & Pull/Buy/Build/Rent & Source & Price & Notes \\
\hline $\begin{array}{l}\text { Male } \\
\text { Dancer 3 }\end{array}$ & & & & & \\
\hline & 1 & tux pants & Rent & & $\$ 30$ & \\
\hline & 2 & tux vest & Rent & & $\$ 30$ & \\
\hline & 3 & tux jacket & Rent & & $\$ 55$ & \\
\hline & 4 & tux shirt & Pull & & $\$ 0$ & \\
\hline & 5 & bowtie & Pull/Build & & $\$ 5$ & \\
\hline & 6 & black shoes & Pull & & $\$ 0$ & \\
\hline
\end{tabular}




\begin{tabular}{|l|l|l|l|r|r|r|}
\hline & 7 & socks & Pull & $\$ 0$ & \\
\hline & & & Total Allotted: & & $\$ 120$ & \\
\hline
\end{tabular}

\begin{tabular}{|l|l|l|l|r|r|l|}
\hline Character & & $\begin{array}{l}\text { Costume } \\
\text { Pieces }\end{array}$ & Pull/Buy/Build/Rent & Source & Price & Notes \\
\hline Dancer 3 & & & & & & \\
\hline & & & & & & \\
\hline & 1 & Blue dress & Rent & & $\$ 86$ & \\
\hline & 2 & Corset & Pull & & $\$ 0$ & \\
\hline & 3 & Gold necklace & Pull & & $\$ 0$ & \\
& 4 & Black shoes & Pull & & $\$ 0$ & \\
\hline & 5 & Blue hat & Pull & & $\$ 0$ & \\
\hline & 6 & Panty hose & Pull & & $\$ 0$ & \\
\hline & & Total Allotted: & & $\$ 86$ & \\
\hline
\end{tabular}

\begin{tabular}{|lr|}
\hline $\begin{array}{l}\text { Total } \\
\text { Budget }\end{array}$ & $\$ 3,000$ \\
\hline $\begin{array}{l}\text { Dry } \\
\text { Cleaning }\end{array}$ & $\$ 400$ \\
\hline Emergency & \\
Fund & $\$ 100$ \\
\hline $\begin{array}{l}\text { Total Spent } \\
\text { before DC \& } \\
\text { EF }\end{array}$ & \\
\hline $\begin{array}{l}\text { Total Spent } \\
\text { after DC \& } \\
\text { EF }\end{array}$ & $\$ 2,620$ \\
\hline $\begin{array}{l}\text { Total } \\
\text { Remaining }\end{array}$ & \\
\hline
\end{tabular}




\section{WORKS CITED}

Barton, Lucy. "Chapter XIX: New Century." Historic Costume for the Stage. Boston: Walter H. Baker Company, 1963. 525-76. Print

Bigelow, Jacob, Alan McEwen, and Gerald McGonigle, "Initial Design Meeting.” Audio Recording. 2015.

Brown, Marianne. "The Birth of Maternity Wear Clothing for the Expectant Mother in America, 1910-1963." MA thesis. Fashion Institute of Technology, State University of New York, 2009, ProQuest Dissertations and Theses Database. Web. 30 Dec. 2015.

Cole, David. Survey of U.S. Army Uniforms, Weapons and Accoutrements. 2007. U.S. Army Center of Military History, Ft. McNair, DC. PDF file.

Foote, Horton. Courtship ; Valentine's Day ; 1918: Three Plays from "the Orphans' Home Cycle". New York: Grove Press, 1987. Print. 


\section{IMAGE SOURCES}

1. Unidentified Yearbook Page - Seniors. Historic Photograph. N. p., n. d. Web.

2. Brennan, Lauren. Steve Tyler in Valentine’s Day. 2015. Watercolor \& Marker. West Virginia

University School of Theatre and Dance, Morgantown, WV. Digital Image.

3. Muriel Goldsmith. 29 Oct. 1915. Photograph. Forensic Archives, Sydney Justice \& Police

Museum, Wagga Wagga. Digital Image.

4. Fisher, George Elmer. George Elmer Fisher Family Portrait. C. 1910. Photograph.

Frontierfamilies.net. Web.

5. Detachable Collar. Digital Image. The Tweed Pig. N. p., 29 Apr. 2013. Web.

6. College Quartette. 1917. The Bronco, Yearbook of Simmons College, Abilene. The Portal to

Texas History. Web.

7. William Ezekial Wells with His Second Wife Ida Wells. C. 1915. Photograph. Hatchetts.com. Web.

8. Watkins, Dorothy. 1915 Shirtwaist Blouse Pattern No. 6693-14492. Digital Image. Free Vintage Art. Web.

9. Tucked Shirt-Waist and Circular Skirt Pattern Nos. 9269 \& 9260. Digital Image. Vintage Victorian. Web.

10. Art and Picture Collection, the New York Public Library. "Mccall Patterns: Illustrating the New Coat Lines in a Suit of Tweed." The New York Public Library Digital Collections. 1915.

11. Late Edwardian Summer Dress with Fabulous Embroidered Trim. Digital Image. Extant Gowns. Isabella D’Angelo, 27 Oct. 2015. Web.

12. Brennan, Lauren. Elizabeth Vaughn in Courtship. 2015. Watercolor \& Marker. West Virginia University School of Theatre and Dance, Morgantown, WV. Digital Image.

13. Brennan, Lauren E. Front View of Margaret Dransfield as Elizabeth Vaughn in Courtship. 2015. Photograph. West Virginia University School of Theatre \& Dance, Morgantown, WV.

14. Brennan, Lauren E. Back View of Margaret Dransfield as Elizabeth Vaughn in Courtship. 2015. Photograph. West Virginia University School of Theatre \& Dance, Morgantown, WV.

15. H. W. Gossard Maternity Corset. 1913. Digital Image. N. p., Chicago. Web.

16. Mabel, Ben, and Fred Hoyle. 1915. Fred Hoyle: An Online Exhibition. St. John's College, University of Cambridge. Web.

17. Brennan, Lauren. Elizabeth Vaughn in Valentine's Day Scene 2. 2015. Watercolor \& Marker. West Virginia University School of Theatre and Dance, Morgantown, WV. Digital Image. 
18. Brennan, Lauren E. Mr. Vaughn Reconciles with Elizabeth and Horace in Valentine's Day Scene 3. 2015. Photograph. West Virginia University School of Theatre \& Dance, Morgantown, WV.

19. Brennan, Lauren E. Elizabeth and Mrs. Vaughn bond over baby in Valentine's Day Scene 2. 2015. Photograph. West Virginia University School of Theatre \& Dance, Morgantown, WV.

20. PA Duryea 1900s Klink Nasiatka Family Friends 1. Digital Image. Dureyea PA. N. p., n. d. Web. www.duryepa.com/1900to1909/1900to1909.htm.

21. Brennan, Lauren. Laura Vaughn. 2015. Watercolor \& Marker. West Virginia University School of Theatre and Dance, Morgantown, WV. Digital Image.

22. Brennan, Lauren E. Laura and Elizabeth on the Porch in Courtship. 2015. Photograph. West Virginia University School of Theatre \& Dance, Morgantown, WV.

23. Vroolijk Paaschfeest Greeting Card from 1915. Digital Image. Flickriver. Flickr, Feb. 2010. Web.

24. Brennan, Lauren. Mr. Vaughn in Courtship. 2015. Watercolor \& Marker. West Virginia University School of Theatre and Dance, Morgantown, WV. Digital Image.

25. Brennan, Lauren E. Mr. Vaughn in Courtship. 2015. Photograph. West Virginia University School of Theatre \& Dance, Morgantown, WV.

26. Brdlik Family Portrait. Digital Image. RootsWeb.Ancestry.com, n. d. Web. Freepages.geneaology.rootsweb.ancestry.com/ brdlik

27. Brennan, Lauren. Mr. Vaughn in Valentine's Day. 2015. Watercolor \& Marker. West Virginia University School of Theatre and Dance, Morgantown, WV. Digital Image.

28. Brennan, Lauren E. Mr. Vaughn Reconciles with Elizabeth and Horace in Valentine's Day Scene 3. 2015. Photograph. West Virginia University School of Theatre \& Dance, Morgantown, WV.

29. Early 1900s Women in Starched Collars. Digital Image. The American Way of Business. Wordpress, 18 Nov. 2013. Web.

30. \#400 Ladies' Shirt-Waist: Circa 1914. Digital Image. Saundra Ros Altman 's: Past Patterns. Past Patterns, 1979. Web.

31. Brennan, Lauren E. Mrs. Vaughn in Courtship. 2015. Photograph. West Virginia University School of Theatre \& Dance, Morgantown, WV.

32. 1912-1913 Couple. Digital Image. Forgotten Faces and Long Ago Places. Blogspot, 23 Dec.2012. Web. 
33. Brennan, Lauren. Mrs. Vaughn in Valentine's Day. 2015. Watercolor \& Marker. West Virginia University School of Theatre and Dance, Morgantown, WV. Digital Image.

34. Brennan, Lauren E. Cast of Valentine's Day. 2015. Photograph. West Virginia University School of Theatre \& Dance, Morgantown, WV.

35. Antique $19^{\text {th }}$ Century Victorian Bodice Blouse Embroidered Lace. Digital Image. Ebay. N. p., n. d. Web.

36. 1890s Sleeves of Doom Autumn Colored Dress. Digital Image. Extant Gowns. Isabella D’Angelo, 6 Jan. 2016. Web.

37. Allum: Maryland and Pennsylvania... Westward. Historic Photograph. N. p., n. d. Web.

38. Unidentified Family Portrait. Historic Photograph. N. p., n. d. Web.

39. Brennan, Lauren. Aunt Sarah. 2015. Watercolor \& Marker. West Virginia University School of Theatre and Dance, Morgantown, WV. Digital Image.

40. Brennan, Lauren. Aunt Lucy. 2015. Watercolor \& Marker. West Virginia University School of Theatre and Dance, Morgantown, WV. Digital Image.

41. Brennan, Lauren E. Aunts Lucy and Sarah in the Music Room in Courtship. 2015. Photograph. West Virginia University School of Theatre \& Dance, Morgantown, WV.

42. 1912 Tuxedos. Digital Image. Demode Couture. N. p., 2011. Web. Demodecouture.com/titantictrends

43. Brennan, Lauren. Horace Robedaux in Courtship. 2015. Watercolor \& Marker. West Virginia University School of Theatre and Dance, Morgantown, WV. Digital Image.

44. Brennan, Lauren E. Horace and Elizabeth Chat on the Front Porch in Courtship. 2015. Photograph. West Virginia University School of Theatre \& Dance, Morgantown, WV.

45. Men in Union Suits. Digital Image. Art of Manliness. N. p., 21 Dec. 2011. Web. Www.artofmanliness.com/2011/12/21/cold-weather-dressing.

46. Brennan, Lauren. Horace Robedaux in Valentine's Day Scene 1. 2015. Watercolor \& Marker. West Virginia University School of Theatre and Dance, Morgantown, WV. Digital Image. 47. Mabel, Ben, and Fred Hoyle. 1915. Fred Hoyle: An Online Exhibition. St. John's College, University of Cambridge. Web.

48. Brennan, Lauren. Horace Robedaux in Valentine's Day Scene 2. 2015. Watercolor \& Marker. West Virginia University School of Theatre and Dance, Morgantown, WV. Digital Image. 
49. Brennan, Lauren E. Horace on Christmas in Valentine's Day Scene 2. 2015. Photograph. West Virginia University School of Theatre \& Dance, Morgantown, WV.

50. Brennan, Lauren E. Horace and Elizabeth in Valentine's Day Scene 3. 2015. Photograph. West Virginia University School of Theatre \& Dance, Morgantown, WV.

51. Bishop, Katy. Men's Evening Dress for Ragtime Era. Digital Image. Vintage Victorian. N. p. 2011. Web.

52. Brennan, Lauren. Steve Tyler in Courtship. 2015. Watercolor \& Marker. West Virginia University School of Theatre and Dance, Morgantown, WV. Digital Image.

53. Brennan, Lauren E. Elizabeth and Laura Chat with Steve Tyler on the Porch in Courtship. 2015. Photograph. West Virginia University School of Theatre \& Dance, Morgantown, WV.

54. Kanalley, Craig. Kanalley Family Portrait. Digital Image. Journey into Genealogy. N. p., 25 Aug. 2012. Web.

55. Brennan, Lauren. Bessie Stillman in Valentine’s Day Scenes 1 \& 3. 2015. Watercolor \& Marker. West Virginia University School of Theatre and Dance, Morgantown, WV. Digital Image.

56. Brennan, Lauren E. Bessie with Her Guinea Pigs in Valentine's Day Scene 2. 2015. Photograph. West Virginia University, Morgantown, WV.

57. Brennan, Lauren E. Bessie Holding a Gift with Excitement in Valentine's Day Scene 1. 2015. Photograph. West Virginia University, Morgantown, WV.

58. Mugshot of Harry Chapman. June, 1924. Photograph. Forensic Archives, Sydney Justice \& Police Museum. Digital Image.

59. Brennan, Lauren. George Tyler. 2015. Watercolor \& Marker. West Virginia University School of Theatre and Dance, Morgantown, WV. Digital Image.

60. Brennan, Lauren E. George Tyler shows up disheveled in Valentine's Day Scene 3. 2015. Photograph. West Virginia University School of Theatre \& Dance, Morgantown, WV.

61. Reimers Family, (c. 1900s) Photograph. N. d. Dublin Heritage Park and Museums, Dublin. Online Archive of California. Web.

62. Brennan, Lauren. Bobby Pate. 2015. Watercolor \& Marker. West Virginia University School of Theatre and Dance, Morgantown, WV. Digital Image.

63. Brennan, Lauren E. Bobby Leans Drunkenly against the Bedpost in Valentine's Day Scene 2. 2015. Photograph. West Virginia University School of Theatre \& Dance, Morgantown, WV. 
64. Krause Family on the Farm - Calhoun Co, Illinois 1921. Digital Image. Origin Hunters. N. p., 21 Nov. 2011. Web.

65. Brennan, Lauren. Ruth Amos in Valentine's Day Scene 2. 2015. Watercolor \& Marker. West Virginia University School of Theatre and Dance, Morgantown, WV. Digital Image.

66. Brennan, Lauren E. Ruth Amos in Valentine's Day Scene 3. 2015. Photograph. West Virginia University, Morgantown, WV.

67. Queen Elizabeth as Elizabeth Bowes Lyon as a Young Child. 2001. Photograph. Popperfoto. Getty Images. Web.

68. Brennan, Lauren. Brother Vaughn in Valentine's Day Scene 2. 2015. Watercolor \& Marker. West Virginia University School of Theatre and Dance, Morgantown, WV. Digital Image.

69. Brennan, Lauren E. Full cast on Stage for Photo Call on the Set of Valentine's Day. 2015. Photograph. West Virginia University, Morgantown, WV.

70. Heim, Richard A. Sam F. Heim Family. 1915. The Pennsylvania Colony of Nebraska Historical Society. Web.

71. Szacinski, L. Andreas Hanson. 1913. Oslo Museum. Oslobuilder.no. Web.

72. Brennan, Lauren. Dr. Goodhue. 2015. Watercolor \& Marker. West Virginia University School of Theatre and Dance, Morgantown, WV. Digital Image.

73. Brennan, Lauren E. Backstage Detail of Dr. Goodhue Costume. 2015. Photograph. West Virginia University, Morgantown, WV.

74. Brennan, Lauren E. Backstage Detail of Dr. Goodhue in Coat. 2015. Photograph. West Virginia University, Morgantown, WV.

75. Powers, Ricard. Ragtime Era Dancers with Yellow Dress. Digital Image. Stanford, n. d. Web.

76. Powers, Ricard. Ragtime Era Dancers with Red Dress. Digital Image. Stanford, n. d. Web.

77. Powers, Ricard. Ragtime Era Dancers with Pink Dress. Digital Image. Stanford, n. d. Web.

78. Brennan, Lauren. Courtship Dancers with Blue Dress. 2015. Watercolor \& Marker. West Virginia University School of Theatre and Dance, Morgantown, WV. Digital Image.

79. Brennan, Lauren. Courtship Dancers with Red Dress. 2015. Watercolor \& Marker. West Virginia University School of Theatre and Dance, Morgantown, WV. Digital Image.

80. Brennan, Lauren. Courtship Dancers with Green Dress. 2015. Watercolor \& Marker. West Virginia University School of Theatre and Dance, Morgantown, WV. Digital Image. 
81. Dwight D. Eisenhower's West Point Graduation. 1915. Photograph. West Point. Panache Career Strategies. Web.

82. General William W. Eagle's West Point Uniform. N. d. Old Jail Museum of Noble County, Indiana, Albion. Rootsweb. Web.

83. Marching Band Coat P81BC12. Digital Image. Randman's Company. N. p. n. d. Web.

84. Marching Band Uniform Rental \#0110NORTH158. Digital Image. Marching Links. N. p. n. d. Web.

85. Hill Military Academy. C. 1905. Oregon Historical Society Research Library. The Oregon Encyclopedia. Web.

86. Downton Abbey Hair Tutorial_Lady Sybil. Dir. Maria Hansen Trooyen. Youtube. N. p., 10 Sept. 2012. Web.

87. Brennan, Lauren E. Margaret Dransfield as Elizabeth Vaughn in Valentine's Day. 2015. Photograph. West Virginia University School of Theatre \& Dance, Morgantown, WV.

88. Brennan, Lauren E. Side View of Aunt Lucy Wig in Curlers. 2015. Photograph. West Virginia University, Morgantown, WV.

89. Brennan, Lauren E. Side View of Aunt Sarah Wig in Curlers. 2015. Photograph. West Virginia University, Morgantown, WV.

90. Brennan, Lauren E. Front View of Aunt Lucy Wig. 2015. Photograph. West Virginia University, Morgantown, WV.

91. Brennan, Lauren E. Front View of Aunt Sarah Wig. 2015. Photograph. West Virginia University, Morgantown, WV. 